\title{
Genetic risk factors in prediction and treatment of chronic post-surgical pain
}

Citation for published version (APA):

van Reij, R. (2020). Genetic risk factors in prediction and treatment of chronic post-surgical pain. [Doctoral Thesis, Maastricht University]. Maastricht University. https://doi.org/10.26481/dis.20200917rr

Document status and date:

Published: 01/01/2020

DOI:

10.26481/dis.20200917rr

Document Version:

Publisher's PDF, also known as Version of record

\section{Please check the document version of this publication:}

- A submitted manuscript is the version of the article upon submission and before peer-review. There can be important differences between the submitted version and the official published version of record.

People interested in the research are advised to contact the author for the final version of the publication, or visit the DOI to the publisher's website.

- The final author version and the galley proof are versions of the publication after peer review.

- The final published version features the final layout of the paper including the volume, issue and page numbers.

Link to publication

\footnotetext{
General rights rights.

- You may freely distribute the URL identifying the publication in the public portal. please follow below link for the End User Agreement:

www.umlib.nl/taverne-license

Take down policy

If you believe that this document breaches copyright please contact us at:

repository@maastrichtuniversity.nl

providing details and we will investigate your claim.
}

Copyright and moral rights for the publications made accessible in the public portal are retained by the authors and/or other copyright owners and it is a condition of accessing publications that users recognise and abide by the legal requirements associated with these

- Users may download and print one copy of any publication from the public portal for the purpose of private study or research.

- You may not further distribute the material or use it for any profit-making activity or commercial gain

If the publication is distributed under the terms of Article $25 \mathrm{fa}$ of the Dutch Copyright Act, indicated by the "Taverne" license above, 
Genetic Risk Factors in prediction and treatment of Chronic Post-Surgical Pain

Roel Robert Ingeborg van Reij

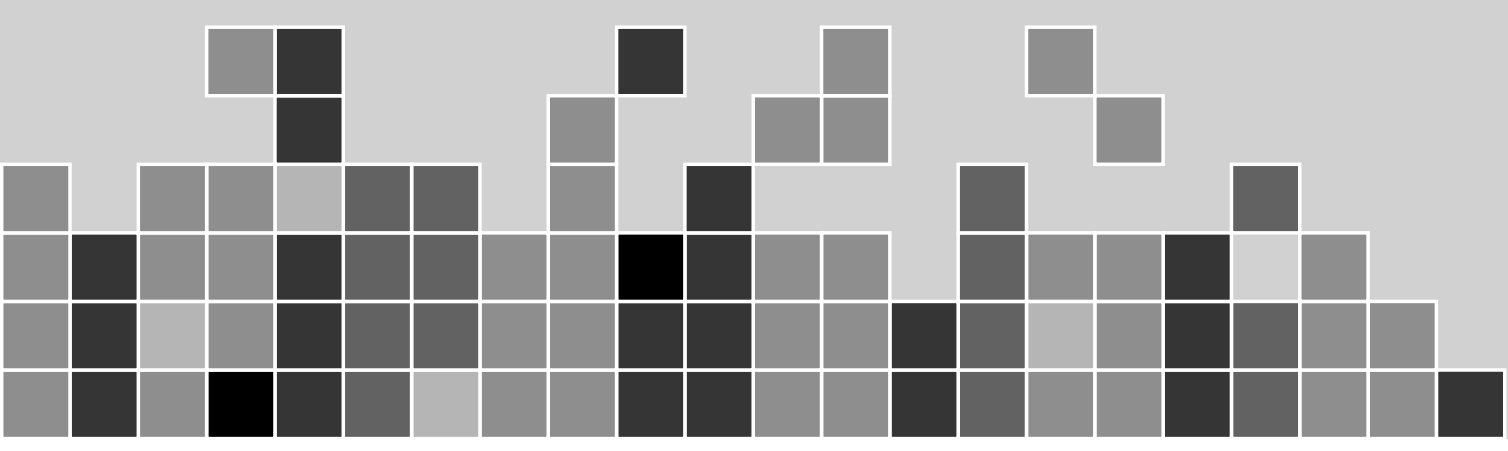


(C) copyright Roel van Reij, Maastricht, 2020

Cover design \& printing: Jurgen Bessems, Druk partners Zuid ISBN: 978-94-6380-859-0

All rights reserved. No part of this thesis may be reproduced, stored in a retrieval system of any nature, or transmitted in any form or by any means, electronic, mechanical, photocopying, recording, or otherwise, without permission of the author 


\section{Universiteit Maastricht}

Genetic Risk Factors in prediction and treatment of Chronic Post-Surgical Pain

\section{ACADEMISCH PROEFSCHRIFT}

ter verkrijging van de graad van doctor aan de Universiteit Maastricht,

op gezag van de Rector Magnificus, Prof.dr. Rianne M. Letschert

volgens het besluit van het College van Decanen,

in het openbaar te verdedigen

op donderdag 17 September 2020 om 14.00 uur

door

Roel Robert Ingeborg van Reij 


\section{Promotor}

Prof. Dr. EAJ Joosten

Copromotor

Dr. NJ van den Hoogen (University of Calgary, Canada)

\section{Beoordelingscommissie}

Prof. Dr. HJM Smeets (voorzitter)

Dr. RLM van Boekel (Radboud UMC)

Prof. Dr. CG Faber

Prof. Dr. AMJM van den Maagdenberg (Leiden UMC)

Prof. Dr. J van Zundert 


\section{Table of Contents}

\section{Chapter 1}

General Introduction

\section{Chapter 2}

Dopaminergic neurotransmission and genetic variations in chronification of Post-Surgical Pain

\section{Chapter 3}

The association between genome-wide polymorphisms and

chronic postoperative pain: a prospective observational study

\section{Chapter 4}

Risk loci associated with chronic post-surgical pain uncovered using

meta-analysis and transcriptome-wide Mendelian randomization

\section{Chapter 5}

Polygenic risk scores indicates genetic overlap between

peripheral pain syndromes and Chronic Postsurgical Pain

\section{Chapter 6}

Dopamine-neurotransmission and nociception in zebrafish:

an anti-nociceptive role of Dopamine Receptor drd2a

\section{Chapter 7}

General Discussion

\section{Chapter 8}

Summary

\section{Appendix}

Valorisation

Curriculum Vitae

List of publications 

CHAPTER 1

General Introduction

R. R. I. van Reij

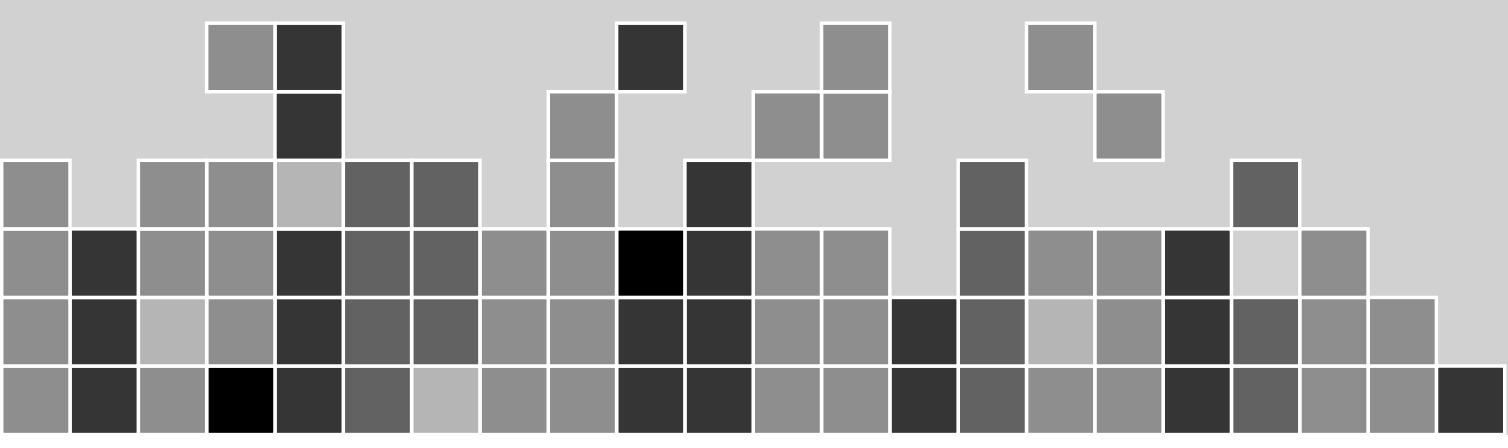


8 | C h a p ter 1 


\section{Chronic postsurgical pain}

CPSP occurs in $5-85 \%$ of the patients depending on the type of surgery [1-3]. Chronic postsurgical pain (CPSP) has recently been classified under the International Classification of Diseases-11 (ICD-11) [1]. With that, classification the international association for the study of pain (IASP) defined CPSP as follows 'pain that develops or increases in intensity after a surgical procedure or a tissue injury and that persists beyond the healing process, i.e. at least 3 months after the initiating event' [1]. Here it is important to note that with CPSP the pain persists beyond the healing process and thus lasts longer than might be expected. Furthermore, in the recent ICD-11 states that beside the general classification of CPSP there are subdiagnoses for specific surgeries that most commonly lead to CPSP e.g. hysterectomy, thoracotomy, breast surgery or amputation. The use of these subdiagnoses then optimally reflects the causes of the pain involved with specific surgeries [1]. Large surgeries like thoracotomy and breast surgery with a larger wound and in more nerve-innervated sites have a higher incidence of CPSP than eye surgery, which is characterized by its minimally invasive surgical procedures [1-3].

CPSP has a high impact on the social, economic, and quality aspects of life of patients affected and their relatives [4-6]. Patients with severe CPSP report higher incidence of depressive symptoms, sleep disturbances, anxiety and other comorbid disorders [4, 7]. Furthermore, CPSP patients report an increased work and activity impairment, which worsens as pain increased. In total, the economic costs (direct and indirect) associated with CPSP per patient has been estimated to be $\$ 41.463$,per year in the United States of America (USA) alone whereby costs increase related to the severity of the pain [4]. 
Acute pain after surgery is caused by tissue damage leading to stimulation of the peripheral nociceptors and nociception [8]. Peripheral nociceptors are located at the endings of the afferent nociceptive fibres. Tissue damage results in a local inflammatory process, which triggers the nociceptors and may result in peripheral sensitization. Peripheral sensitization is defined by IASP as 'Increased responsiveness and reduced threshold of nociceptive neurons in the periphery to the stimulation of their receptive fields' $[8,9]$. As a consequence more action potentials will be send, via the nociceptive afferents, to the spinal cord. Then the signal (action potentials) is transferred to the pain transmission neurons in the spinal cord. Upon continuous generation of action potentials, the communication between the nociceptive afferents and the pain transmission neurons in the spinal cord becomes sensitized. This sensitization is referred to as central sensitization, defined by the IASP as Increased responsiveness of nociceptive neurons in the central nervous system to their normal or subthreshold afferent input'. Central sensitization leads to an increase of action potential transmission from the spinal gate to supraspinal nociception related areas, where the perception and affective components will be combined into pain. The process of central sensitization and deregulated communication between nociceptive afferents and pain transmission neurons in the spinal cord, is considered to be fundamental in the chronification of pain. $[8,9]$. The pain gate in the spinal cord plays an important role in this process of central sensitization. At the spinal pain gate, the nociceptive signal of the nociceptive afferent ( $\mathrm{C}$ fibers) is transmitted to the projection neuron which transmits the signal to the brain [10-12]. At this level the nociceptive signal can be modulated by either innocuous stimulation (i.e. touch stimuli) or by descending inhibitory control modulated by three different neurotransmitters: serotonin, noradrenaline and dopamine [1013].

While serotonin and noradrenaline are widely studied in the context of pain, dopamine is often overlooked in analgesic strategies [14]. Dopamine can inhibit the transmission of the nociceptive signal in the spinal cord by activation of the 
D2 receptors and can facilitate central sensitization via the D1 receptors [14-16]. Dopaminergic neurotransmission, is most known for its involvement in reward, mood and locomotion [17-19]. DA provides the communication within the basal ganglia and connection to the locomotor networks in the brainstem as well as influences the central pattern generators in the ventral horn of the spinal cord [20, 21]. Furthermore, DA is released in the VTA response to a drug or natural reward $[22,23]$. As pain management strategies focussed on dopamine can affect these systems as well, targeting dopamine remains a challenge.

The current perioperative pain management strategy is mainly focussed at the prevention or treatment of acute postoperative pain and remains suboptimal for prevention and treatment of CPSP [24, 25]. Multimodal analgesia is key in the acute postoperative pain management strategy where the first step consists of regional or local analgesia specific for the invasiveness of the surgery followed by non-opioidergic systemic analgesia and opioid medication, where the latter is used as a rescue medication $[25,26]$. Nevertheless, the treatment remains suboptimal to prevent or treat CPSP leading to a high incidence of CPSP. Improving pharmacological interventions remains a challenge and the identification of new targets can aid in optimizing the treatment strategy [27]. Besides optimizing treatment strategies, it is important to identify the patients at risk of developing CPSP in order to prevent CPSP from occurring. Lack of knowledge on genetic risk factors and mechanism(s) underlying the development of CPSP inhibits accurate identification of patients at risk and development of new targets for pharmacological interventions and treatment.

The aim of this thesis is to the study the genetic risk factors of CPSP and to identify the functional effects of genetic variation on nociception and chronic pain in both clinical and preclinical studies. 


\subsection{Prediction of CPSP}

Clinical, demographical, psychological and genetic risk factors of CPSP have been identified over the last years [2, 28-32]. Here, I will discuss current evidence on these risk factors.

\subsubsection{Clinical risk factors of CPSP}

Clinical risk factors associated with CPSP include the type of surgery (more invasive surgery, higher incidence), the duration of surgery as well as the level of intraoperative nerve damage $[28,30]$. All these clinical risk factors indicate that the risk of developing CPSP is increased with major surgeries, as this is likely to be related to a higher degree of tissue damage [30].

\subsubsection{Demographical risk factors of CPSP}

Patient related demographical risk factors for CPSP include age, biological sex and pre-operative pain. The most prominent demographical risk factor for CPSP is perioperative pain [28]. Both pre-operative pain and acute postoperative pain are important predictors for development of CPSP [2, 29-31]. It is possible that the pre-operative pain primes the nociceptive system leading to higher susceptibility to the development of chronic pain [30]. The severity of acute postsurgical pain (APSP) seems to be related to the clinical risk factors, as more invasive surgery is usually accompanied by more severe APSP [28]. Younger age and female biological sex have consistently been associated with a higher prevalence of CPSP [28-30]. The mechanism underlying pain has been shown to be different between the biological sexes due to both hormonal effects and differential immune response [33-36]. Interestingly, most of the research on pain intervention was conducted on males possibly explaining the higher prevalence in women [37-39]. Younger age is associated with a more severe pathology, which requires a more invasive approach and therefore leads to a higher prevalence of CPSP [31]. 


\subsubsection{Psychological risk factors of CPSP}

Psychological risk factors associated with CPSP include pre-operative anxiety and pain catastrophizing $[28,32]$. Pain catastrophizing is the tendency to describe a pain experience in more exaggerated terms than the average person, to ruminate on it more, and/or to feel more helpless about the experience [40]. Anxiety can be separated into state- and trait anxiety where state anxiety is a temporary condition experienced in a specific situation and trait-anxiety is a general tendency to perceive situation [32]. The central idea is that patients with psychological flexibility (more optimistic outlook on pain after surgery, and more confidence in the outcome of the procedure) will have a better outcome of the surgery compared to those who are inflexible [41]. This is summarized in the fear-avoidance model of pain whereby negative coping with the pain leads to a vicious cycle of pain while positive coping leads to recovery $[42,43]$. Anxiety, both trait and state, leads to preventative strategies and avoidance behaviour which leads to disuse of the affected body parts and negatively influences the resolution of pain [44]. The fearavoidance model incorporates both pain catastrophizing and anxiety in a single model indicating that these are simultaneously affecting the outcome after surgery [42-44].

\subsubsection{Genetic risk factors of CPSP}

Genetic risk factors of CPSP have been studied in a limited number of studies and only a restricted and selected number of genes and/or subset of genes have been studied up until now [45]. Despite the limited number of studies, an association was shown between several genes such as COMT, OPRM1, DRD2 and CACNG2 and the development of CPSP [45]. However, a good understanding of the genetic risk factors and its putative role in CPSP is still lacking to date [2, 28]. Identifying the genetic risk factors of CPSP will aid in the prediction of CPSP as well as provide insight into the biological mechanisms [46, 47]. Most of the genes associated with CPSP can be classified as related to either inflammatory cytokines, 
catecholamine signalling (e.g. dopamine and noradrenaline) or ion channels (calcium or potassium). Catecholamine signalling and especially dopaminergic neurotransmission are of interest as several components of the signalling pathway (GCH1 in dopamine-synthesis, DRD2 as a dopamine-receptor and COMT in dopamine-degradation) have been associated with CPSP. It is therefore important to focus on the genetic mutations related to dopaminergic neurotransmission in a context of CPSP and a good understanding of the relation and/or association is needed.

Genetic studies employ either a gene-based approach where there is a focus on a subset of genes or a genome-wide approach where risk factors across the genome are associated with the phenotype [48]. In a GWAS study not all SNPs in the genome are genotyped but a fraction of them and most of the other SNPs are in high linkage disequilibrium with these SNPs so it can be assumed that if the genotyped SNP is present these other SNPs are as well [49]. Genome-wide association studies (GWAS) are able to validate the genes found by gene-targeted studies but also lead to new findings and thereby could elucidate new mechanisms underlying a disease [50]. A beautiful example of the use and implementation of GWAS analysis and the discovery of genetic risk factors has been shown in the field of migraine, which resulted in the identification of biological pathways involved [51]. In order to implement genetic risk factors in prediction of CPSP, large-scale GWAS studies in well-studied and diagnosed CPSP cohorts are needed to elucidate the genetic risk factors of CPSP and understand the underlying biology. In this thesis, the main cohort studied in relation to CPSP is a hysterectomy cohort, which has been extensively described, however, mainly related and restricted to clinical, psychological and demographical risk factors [29, 52]. This hysterectomy cohort is exclusively female, and about $10 \%$ of the cohort develops CPSP [14]. Furthermore, a significant association between employment status, preoperative pain, postoperative pain, inflammation status and CPSP was reported and the implementation of these factors in a prediction explained of $78 \%$ 
of the variation [52]. As peripheral blood samples were collected from the hysterectomy cohort (= discovery cohort) before the surgery this enabled further genetic analyses in conjunction to the already studied demographical, clinical and psychological risk factors [29]. It needs further emphasis that possible genetic associations found in the discovery cohort need to be replicated in other CPSP patient populations (or replication cohorts). Both replication and external validation are necessary to confirm that the findings are reproducible and to provide more conclusive statements on genetic risk factors and CPSP.

\subsection{The effect of genetic variations on biological functioning}

The link between genetic variation and CPSP is not direct, but rather through a complex mechanism whereby several steps have to take place before a genotype affects the phenotype $[48,53]$. The following section will briefly introduce how genetic variation affects proteins and how this could affect the development of chronic pain.

\subsubsection{Mutations in the genome affect protein functioning}

On estimate there are about 19,000 genes coding for proteins in the human genome covering 1-2\% of the DNA [54]. A protein-coding gene consists of an open reading frame which contains protein coding sequences (exons) and non-protein coding sequence (introns) which dictate splicing sites and this open reading frame is flanked by regulatory sites [55-57]. The regulatory sites can control the rate of transcription and determine the start site of transcription [58]. The DNA is converted into to protein in two steps. First, it is transcribed into mRNA (messenger RNA) by RNA polymerases and then translated into proteins by ribosome complexes $[58,59]$. 
Genetic association studies such as genome-wide association studies (GWAS) and gene-targeted studies are intended to analyse variations in the DNA in relation to a phenotype. A mutation is defined as any alteration to the DNA sequence [60]. When mutations persist in the genome, they become single nucleotide polymorphisms (SNP). SNPs are single base-pair alterations, which are common in the population, meaning present in more than $1 \%$ of the population[60].

SNPs located in coding regions can either lead to the same amino acid in the protein (synonymous) or result in transition and inclusion of a different amino acid in the protein (non-synonymous) which then most likely affects protein functioning (Figure 1) [61, 62]. Non-synonymous SNPs can be divided into missense and nonsense SNPs whereby missense SNPs can affect protein functioning (e.g. altered ligand binding, altered protein stability) and nonsense SNPs lead to a premature stop codon $[62,63]$. One of the most well-known diseases associated with non-synonymous missense SNPs is sickle cell disease whereby the GAG codon is changed into a GTG codon causing a valine to be built into the protein instead of glutamic acid leading to a dysfunctional protein and eventually a dysfunctional red blood cell [60]. Synonymous SNPs lead to the same amino acid being translated from the mRNA and often the effect is considered neutral. However, there is a bias in codon usage and efficiency in the human cells which means that some codons used are translated more efficiently leading to a faster production of proteins thereby affecting the protein functioning [64, 65]. 


\section{No mutation Point Mutations}
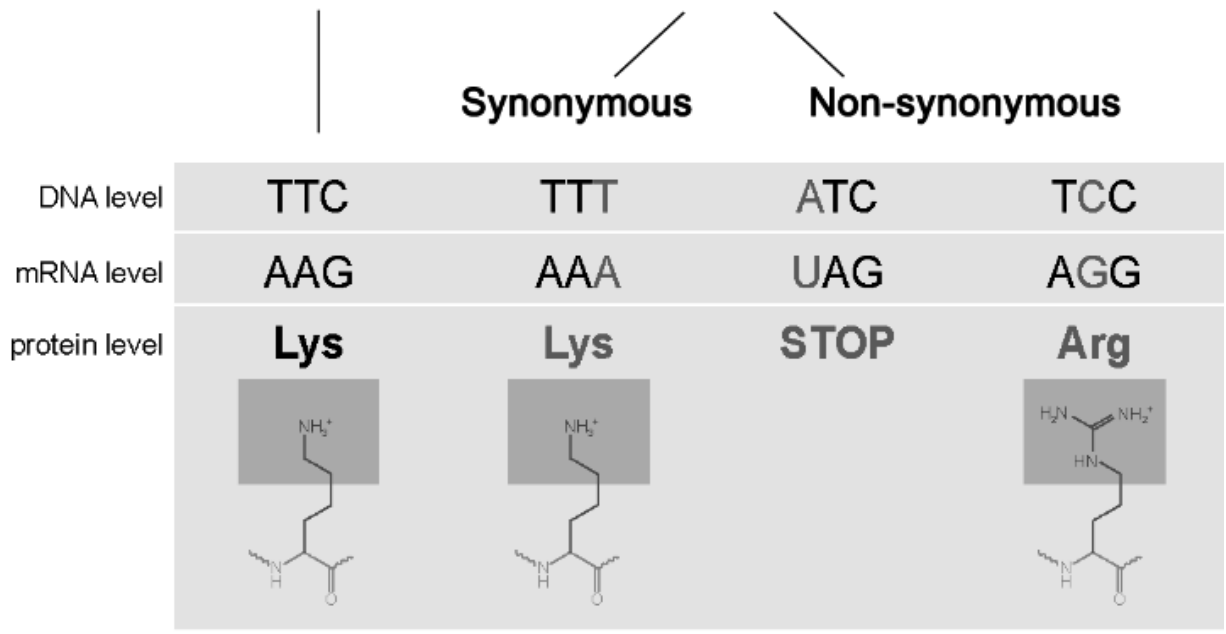

Figure 1: Illustration of the effects of different types of mutations. The codon sequence without mutation is displayed on the far left side under the header no mutation. The introduction of a synonymous mutation (middle left) in the codon leads to alterations on the level of the DNA and the mRNA but leads to the incorporation of the same amino acid in the protein. The introduction of a non-synonymous mutation in the codon leads to either a premature stop codon (middle right) also known as a nonsense mutation or to a missense mutation (far right) which introduces a different amino acid in the protein sequence. Adapted from Wikimedia commons Different Types of Mutations.png under a creative commons license

A synonymous SNP within multi-drug resistance $1(M D R-1))$ has been associated with altered drug responsiveness in humans. The SNP causes a rare codon to be necessary for the translation into mRNA, which alters the post processing of the protein and thereby alters the substrate specificity [66]. Furthermore, different codons can affect the mRNA folding stability and thereby affect the folding of the protein, which could alter the accessibility of the ligand binding site of a protein [65]. SNPs located in intronic regions or the untranslated regions on both sides of the open reading frame do not affect protein functioning directly but can lead to major effects. Intronic SNPs can induce alternate splicing by adding, removing or altering splice sites and can affect the expression of a gene [67]. Two intronic SNPs within dopamine receptor DRD2 (rs2283265 and rs1076560) have been identified 
which shifted the alternative splicing of this dopamine receptor from the short variant (expressed pre-synaptically) to the long variant (expressed mainly postsynaptically). Hence, the effects of the DRD2 activation vary substantially between pre- and post-synapse and these SNPs have been associated with an altered cognitive performance [68].

Although GWAS analysis provides insights into association between SNPs and CPSP, it does not provide evidence on causality [69]. SNPs associated with disease phenotypes often exert their effect through altering target gene expression [69]. Gene expression is a quantitative trait, which is influenced by many factors among which SNPs contained in expression quantitative trait loci (eQTLs) [70]. eQTLs are regions of the genome containing SNPs which affect the expression of one or more genes [70]. eQTLs can be divided into cis- and trans-eQTLs whereby ciseQTLs affect nearby genes (within a few hundred kilo base-pairs of a gene) and trans-eQTLs affect distant genes often through diffusible factors such as transcription factors[70] (Figure 2). Most investigations study the variations surrounding the gene of interest and focus thereby on the cis-eQTLs [70, 71]. Most genes have multiple eQTLs and the interaction between the eQTLs affects the gene expression [71]. These interactions between eQTLs and gene expression are often tissue specific [69].

All these different mechanisms contribute to development of disorders and CPSP. Each individual has a specific combination of SNPs and this could be used in clinical prediction modelling $[47,73,74]$. 


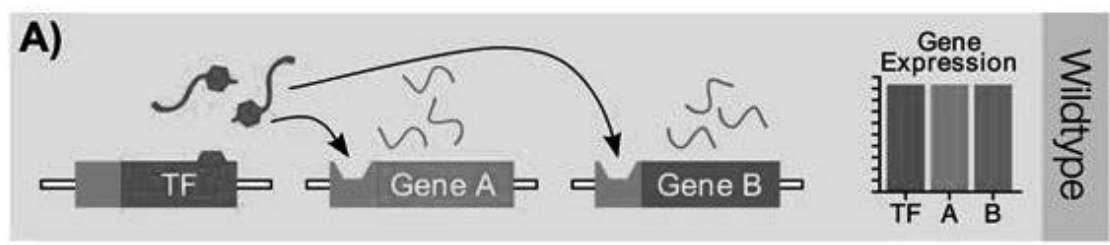

B)
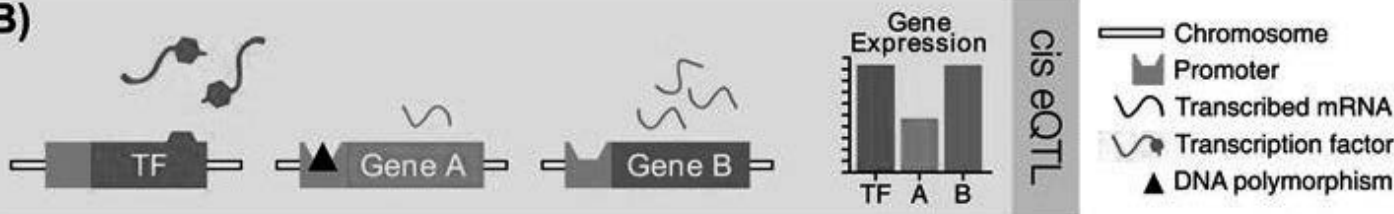

C)

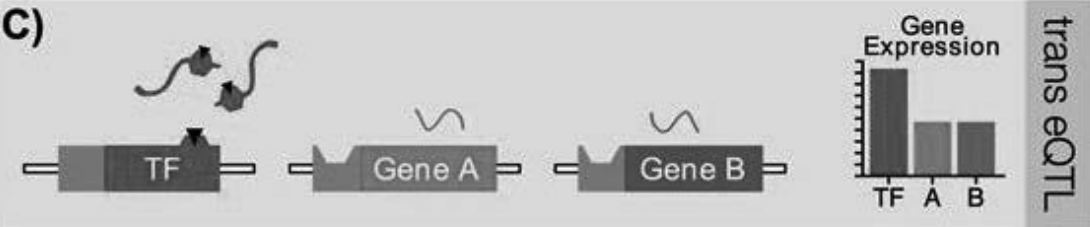

Figure 2: illustration of cis and trans expression quantitative trait loci. A) The transcription factor (TF) binds to the transcription site of gene $A$ and gene B leading to their transcription and subsequent gene expression. $B$ ) Due to a mutation in the transcription site of gene A, the transcription factor cannot bind properly anymore leading to a decreased expression of gene A. this is a cis eQTL as the mutation altering the gene expression is located closely to the gene. C) There is a mutation in the gene encoding for the TF leading to a decreased binding at the transcription site of both gene $A$ and $B$ decreasing their expression. This is a trans$e Q T L$ as the mutation is located further away of the gene which expression is influenced. Reproduced with permission from Wolen et al., [72].

\subsubsection{Common genetic risk factors for chronic pain syndromes}

As chronic pain conditions are known to follow a basic pattern in which an environmental factor (e.g. surgical trauma, infection, and injury) leads to an acute pain state which, if not resolved, can lead to a chronic pain syndrome [46, 75-77]. It is suggested that common biological pathways (e.g. inflammation or extracellular composition) underlie the different chronic pain syndromes [78, 79]. Common biological pathways underlying different disorders often entail common genetic risk factors. One genetic locus underlying two or more different phenotypic traits is called pleiotropy [80]. This means that a SNP can be involved in more than one distinct phenotype and could possibly underlie common factors 
between the phenotypes $[80,81]$. In order to study and explore the genetic pleiotropy between different chronic pain disorders analysis of polygenic risk scores (PRS) is possible and allows the detection and insights into possible common biological mechanisms across the disorders. PRS scores are the aggregated relative risk of developing a disorder based on summing SNPs associated with the disorder [82]. These mechanism-based insights might then result in targeting and development of new drugs for better treatment of CPSP.

\subsection{Genetics and new venues to pharmacological treatment of CPSP}

Genetic association studies have associated inflammatory cytokines, ion channels and catecholamines with the development of CPSP and this makes inflammatory cytokines as well as ion-channels or catecholamines excellent targets for pharmacological treatment of CPSP [45]. Inflammation is a risk factor for the development of CPSP and several preventive pharmacological strategies (such as corticosteroids and NSAIDs) are already employed peri-operatively and are part of the current multi-modal analgesic protocol [83]. Mutations in ion channels signalling (calcium and potassium) alter the conductivity of the nerves and thereby may affect the chronification process and thus the development of CPSP. Medication focussed on voltage-gated calcium signalling (for example gabapentinoids) are widely used in neuropathic pain and are increasingly used in treatment of acute postsurgical pain as well as CPSP management [83]. However, pharmacological treatments modulating very general process as for instance the role of calcium channels in neurotransmission may have large side-effects thereby making it difficult to find a balance between clinical benefits and aversive effects [83]. Catecholamine signalling includes various neurotransmitters like adrenaline, noradrenaline and dopamine, which are all synthetized and degraded via a common mechanism [84]. Drugs acting via the receptors involved in adrenaline neurotransmission (e.g. Clonidine as a $\alpha 2$-adrenergic receptor agonist) were proposed as treatment in both acute and chronic pain [83]. Clonidine has, 
however, also been associated with hemodynamic side effects due to it prominent role in the sympathetic nervous system and regulation of blood vessels dilatation and constriction [83]. Evidence of its efficacy in CPSP is currently not complete [83]. The recurrent associations with genes within the dopaminergic neurotransmission suggest catecholamines and more specific dopamine (see 3.2.1) as a likely target for developing pharmacological treatment of CPSP $[45,83,85$ 87].

In order to focus and boost the research on development of CPSP treatment related to dopaminergic neurotransmission, preclinical studies are needed and we aimed to develop a zebrafish model for a clinical genetic phenotype and test the effects on nociception in a validated assay [88]. This makes fast and reliable screening of functional effects of SNPs associated with pain phenotypes and new drugs possible which may modulate the various proteins involved like DRD2 receptor.

\section{Research questions of the Thesis}

1. What is the role and impact of genetic variations related to dopaminergic neurotransmission in CPSP?

2. What are the genome-wide risk factors of CPSP and the related functional mechanisms?

3. What is the shared genetic aetiology between different chronic pain disorders including CPSP and does this provide insights into the common biological mechanisms underlying chronic pain?

\section{Outline of the Thesis}

Research question 1 is addressed in Chapter 2 and Chapter 6. Chapter 2 summarizes the current literature regarding clinical and preclinical evidence on the genetic variations related to dopaminergic neurotransmission and its role in 
chronic postsurgical pain. The genes most studied in association with CPSP are COMT, GCH1 and DRD2, which are all related to dopaminergic signalling. Therefore, a clinical phenotype of a decreased availability of the DRD2 receptor is modelled in an experimental zebrafish animal model and possible pharmacological treatment options were implemented in Chapter 6. In order to study the genetic risk factors of CPSP in an unbiased approach we formulated research question 2. A first genome-wide association study on CPSP is performed in a discovery cohort (hysterectomy patients and CPSP, Number NTR2702, Dutch Trial Register (http://www.trialregister.nl/trialreg/index.asp) and subsequently in a replication cohort (registry number NCT02002663 and NCT01989351, https://clinicaltrials.gov/ct2/home) (see Chapter 3). To gain further insight on the biological aspects of genetic risk factors and the functional mechanisms in the context of CPSP, Chapter 4 discusses the downstream biological effects of the identified SNPs on the transcriptome and protein expression in detail. Research question 3, is studied in Chapter 5 and analyses possible shared genetic aetiology between different chronic pain disorders (Rheumatoid Arthritis, Sciatica, Chronic widespread pain, Osteoarthritis). Finally, Chapter 7 will conclude, summarize and discuss the main findings of this thesis and its possible impact for prediction and/or treatment of CPSP. 


\section{References}

1. Schug SA, Lavand'homme P, Barke A, Korwisi B, Rief W, Treede R-D, Pain TITftCoC: The IASP classification of chronic pain for ICD-11: chronic postsurgical or posttraumatic pain. PAIN 2019, 160(1):45-52.

2. Kehlet H, Jensen TS, Woolf CJ: Persistent postsurgical pain: risk factors and prevention. The Lancet 2006, 367(9522):1618-1625.

3. Werner M, Kongsgaard U: I. Defining persistent post-surgical pain: is an update required? British journal of anaesthesia 2014, 113(1):1-4.

4. Parsons B, Schaefer C, Mann R, Sadosky A, Daniel S, Nalamachu S, Stacey BR, Nieshoff EC, Tuchman M, Anschel A: Economic and humanistic burden of post-trauma and postsurgical neuropathic pain among adults in the United States. Journal of pain research 2013, 6:459.

5. Aasvang E, Kehlet $\mathrm{H}$ : Chronic postoperative pain: the case of inguinal herniorrhaphy. British journal of anaesthesia 2005, 95(1):69-76.

6. No FS: Chronic Postsurgical Pain: Definition, Impact, and Prevention. 2017.

7. Peng Z, Li H, Zhang C, Qian X, Feng Z, Zhu S: A retrospective study of chronic postsurgical pain following thoracic surgery: prevalence, risk factors, incidence of neuropathic component, and impact on qualify of life. PloS one 2014, 9(2):e90014.

8. Pak DJ, Yong RJ, Kaye AD, Urman RD: Chronification of Pain: Mechanisms, Current Understanding, and Clinical Implications. Current Pain and Headache Reports 2018, 22(2):9.

9. Merskey H: Part III pain terms, a current list with definitions and notes on usage. Classification of chronic pain-descriptions of chronic pain syndromes and definitions of pain terms 1994:207-214.

10. Melzack R, Wall PD: Pain mechanisms: a new theory. Science 1965, 150(3699):971-979.

11. Heinricher M, Tavares I, Leith J, Lumb B: Descending control of nociception: specificity, recruitment and plasticity. Brain research reviews 2009, 60(1):214-225.

12. Hunt SP, Mantyh PW: The molecular dynamics of pain control. Nat Rev Neurosci 2001, 2(2):83-91.

13. Millan MJ: Descending control of pain. Progress in Neurobiology 2002, 66(6):355-474.

14. Wood PB: Role of central dopamine in pain and analgesia. Expert Review of Neurotherapeutics 2008, 8(5):781-797.

15. Aira Z, Barrenetxea T, Buesa I, Martinez E, Azkue JJ: Spinal D1-like dopamine receptors modulate NMDA receptor-induced hyperexcitability and NR1 subunit phosphorylation at serine 889. Neurosci Lett 2016, 618:152-158.

16. Cobacho N, de la Calle JL, Paino CL: Dopaminergic modulation of neuropathic pain: analgesia in rats by a D2-type receptor agonist. Brain Res Bull 2014, 106:62-71.

17. Antypa N, Drago A, Serretti A: The role of COMT gene variants in depression: Bridging neuropsychological, behavioral and clinical phenotypes. Neurosci Biobehav Rev 2013, 37(8):1597-1610. 
18. Ryczko D, Dubuc R: Dopamine and the Brainstem Locomotor Networks: From Lamprey to Human. Frontiers in neuroscience 2017, 11:295.

19. Scott DJ, Stohler CS, Egnatuk CM, Wang H, Koeppe RA, Zubieta JK: Individual differences in reward responding explain placebo-induced expectations and effects. Neuron 2007, 55(2):325-336.

20. Ryczko D, Cone JJ, Alpert MH, Goetz L, Auclair F, Dubé C, Parent M, Roitman MF, Alford S, Dubuc R: A descending dopamine pathway conserved from basal vertebrates to mammals. Proceedings of the National Academy of Sciences 2016, 113(17):E2440-E2449.

21. Sharples SA, Koblinger K, Humphreys JM, Whelan PJ: Dopamine: a parallel pathway for the modulation of spinal locomotor networks. Frontiers in neural circuits 2014, 8:55-55.

22. Nestler EJ, Carlezon WA: The Mesolimbic Dopamine Reward Circuit in Depression. Biological psychiatry 2006, 59(12):1151-1159.

23. Radwan B, Liu H, Chaudhury D: The role of dopamine in mood disorders and the associated changes in circadian rhythms and sleep-wake cycle. Brain Research 2019, 1713:4251.

24. Rawal N: Current issues in postoperative pain management. European journal of anaesthesiology 2016, 33(3):160-171.

25. Wick EC, Grant MC, Wu CL: Postoperative Multimodal Analgesia Pain Management With Nonopioid Analgesics and Techniques: A Review. JAMA surgery 2017, 152(7):691697.

26. Dunkman WJ, Manning MW: Enhanced Recovery After Surgery and Multimodal Strategies for Analgesia. The Surgical clinics of North America 2018, 98(6):1171-1184.

27. Thapa P, Euasobhon P: Chronic postsurgical pain: current evidence for prevention and management. The Korean journal of pain 2018, 31(3):155-173.

28. Katz J, Seltzer Ze: Transition from acute to chronic postsurgical pain: risk factors and protective factors. Expert Rev Neurother 2009, 9(5):723-744.

29. Theunissen M, Peters ML, Schepers J, Maas JW, Tournois F, van Suijlekom HA, Gramke H-F, Marcus MA: Recovery 3 and 12 months after hysterectomy: epidemiology and predictors of chronic pain, physical functioning, and global surgical recovery. Medicine 2016, 95(26):e3980.

30. Cregg R, Anwar S, Farquhar-Smith P: Persistent postsurgical pain. Current opinion in supportive and palliative care 2013, 7(2):144-152.

31. Macrae W: Chronic post-surgical pain: 10 years on. British journal of anaesthesia 2008, 101(1):77-86.

32. Theunissen M, Peters ML, Bruce J, Gramke H-F, Marcus MA: Preoperative anxiety and catastrophizing: a systematic review and meta-analysis of the association with chronic postsurgical pain. The Clinical journal of pain 2012, 28(9):819-841.

33. Craft RM: Modulation of pain by estrogens. Pain 2007, 132 Suppl 1:S3-12.

34. van Hecke O, Torrance N, Smith BH: Chronic pain epidemiology and its clinical relevance. Br J Anaesth 2013, 111(1):13-18. 
35. Mapplebeck JC, Beggs S, Salter MW: Sex differences in pain: a tale of two immune cells. Pain 2016, 157 Suppl 1:S2-6.

36. Rosen S, Ham B, Mogil JS: Sex differences in neuroimmunity and pain. Journal of neuroscience research 2017, 95(1-2):500-508.

37. Mogil JS, Chanda ML: The case for the inclusion of female subjects in basic science studies of pain. PAIN 2005, 117(1):1-5.

38. Legato MJ: Rethinking Gender-Specific Medicine. Women's Health 2006, 2(5):699-703.

39. North RY, Li Y, Ray P, Rhines LD, Tatsui CE, Rao G, Johansson CA, Zhang H, Kim YH, Zhang $\mathrm{B}$ et al: Electrophysiological and transcriptomic correlates of neuropathic pain in human dorsal root ganglion neurons. Brain : a journal of neurology 2019, 142(5):1215-1226.

40. Van Damme S, Crombez G, Bijttebier P, Goubert L, Van Houdenhove B: A confirmatory factor analysis of the Pain Catastrophizing Scale: invariant factor structure across clinical and non-clinical populations. Pain 2002, 96(3):319-324.

41. Weinrib AZ, Azam MA, Birnie KA, Burns LC, Clarke H, Katz J: The psychology of chronic post-surgical pain: new frontiers in risk factor identification, prevention and management. British journal of pain 2017, 11(4):169-177.

42. Alodaibi FA, Minick KI, Fritz JM: Do preoperative fear avoidance model factors predict outcomes after lumbar disc herniation surgery? A systematic review. Chiropr Man Therap 2013, 21(1):40-40.

43. Kroska EB: A meta-analysis of fear-avoidance and pain intensity: The paradox of chronic pain. Scandinavian journal of pain 2016, 13:43-58.

44. Leeuw M, Goossens MEJB, Linton SJ, Crombez G, Boersma K, Vlaeyen JWS: The FearAvoidance Model of Musculoskeletal Pain: Current State of Scientific Evidence. Journal of Behavioral Medicine 2007, 30(1):77-94.

45. Hoofwijk DMN, van Reij RRI, Rutten BP, Kenis G, Buhre WF, Joosten EA: Genetic polymorphisms and their association with the prevalence and severity of chronic postsurgical pain: a systematic review. British Journal of Anaesthesia 2016, 117(6):708-719.

46. Diatchenko L, Fillingim RB, Smith SB, Maixner W: The phenotypic and genetic signatures of common musculoskeletal pain conditions. Nature Reviews Rheumatology 2013, 9(6):340.

47. Abraham G, Inouye M: Genomic risk prediction of complex human disease and its clinical application. Current Opinion in Genetics \& Development 2015, 33:10-16.

48. Manolio TA, Collins FS, Cox NJ, Goldstein DB, Hindorff LA, Hunter DJ, McCarthy MI, Ramos EM, Cardon LR, Chakravarti A: Finding the missing heritability of complex diseases. Nature 2009, 461(7265):747-753.

49. Kruglyak L: The road to genome-wide association studies. Nature Reviews Genetics 2008, 9(4):314-318.

50. Yengo L, Sidorenko J, Kemper KE, Zheng Z, Wood AR, Weedon MN, Frayling TM, Hirschhorn J, Yang J, Visscher PM: Meta-analysis of genome-wide association studies for height and body mass index in approximately 700000 individuals of European ancestry. Hum Mol Genet 2018, 27(20):3641-3649. 
51. Gormley P, Anttila V, Winsvold BS, Palta P, Esko T, Pers TH, Farh K-H, Cuenca-Leon E, Muona M, Furlotte NA et al: Meta-analysis of 375,000 individuals identifies 38 susceptibility loci for migraine. Nature genetics 2016, 48(8):856-866.

52. Hoofwijk DMN, van Reij RRI, Rutten BPF, Kenis G, Theunissen M, Joosten EA, Buhre WF, van den Hoogen NJ: Genetic polymorphisms and prediction of chronic post-surgical pain after hysterectomy-a subgroup analysis of a multicenter cohort study. Acta Anaesthesiol Scand 2019, 63(8):1063-1073.

53. Tak YG, Farnham PJ: Making sense of GWAS: using epigenomics and genome engineering to understand the functional relevance of SNPs in non-coding regions of the human genome. Epigenetics \& Chromatin 2015, 8(1):57.

54. Claverie J-M: Fewer Genes, More Noncoding RNA. Science 2005, 309(5740):1529-1530.

55. Bicknell AA, Cenik C, Chua HN, Roth FP, Moore MJ: Introns in UTRs: Why we should stop ignoring them. BioEssays 2012, 34(12):1025-1034.

56. Pennacchio LA, Bickmore W, Dean A, Nobrega MA, Bejerano G: Enhancers: five essential questions. Nat Rev Genet 2013, 14(4):288-295.

57. Mortazavi A, Williams BA, McCue K, Schaeffer L, Wold B: Mapping and quantifying mammalian transcriptomes by RNA-Seq. Nat Methods 2008, 5(7):621-628.

58. Clancy S: DNA transcription. Nature education 2008, 1(1):41.

59. Clancy S, Brown W: Translation: DNA to mRNA to protein. Nature Education 2008, 1(1):101.

60. Clancy S: Genetic mutation. Nature Education 2008, 1(1):187.

61. Yates CM, Sternberg MJE: The Effects of Non-Synonymous Single Nucleotide Polymorphisms (nsSNPs) on Protein-Protein Interactions. Journal of Molecular Biology 2013, 425(21):3949-3963.

62. Wang Z, Moult J: SNPs, protein structure, and disease. Human mutation 2001, 17(4):263270.

63. Balasubramanian S, Fu Y, Pawashe M, McGillivray P, Jin M, Liu J, Karczewski KJ, MacArthur DG, Gerstein M: Using ALoFT to determine the impact of putative loss-offunction variants in protein-coding genes. Nature communications 2017, 8(1):382-382.

64. Carlini DB, Stephan W: In vivo introduction of unpreferred synonymous codons into the Drosophila Adh gene results in reduced levels of ADH protein. Genetics 2003, 163(1):239243.

65. Kahali B, Basak S, Ghosh TC: Reinvestigating the codon and amino acid usage of S. cerevisiae genome: A new insight from protein secondary structure analysis. Biochemical and biophysical research communications 2007, 354(3):693-699.

66. Kimchi-Sarfaty C, Oh JM, Kim IW, Sauna ZE, Calcagno AM, Ambudkar SV, Gottesman MM: A "silent" polymorphism in the MDR1 gene changes substrate specificity. Science 2007, 315(5811):525-528.

67. Cooper DN: Functional intronic polymorphisms: Buried treasure awaiting discovery within our genes. Hum Genomics 2010, 4(5):284-288. 
68. Zhang Y, Bertolino A, Fazio L, Blasi G, Rampino A, Romano R, Lee ML, Xiao T, Papp A, Wang D et al: Polymorphisms in human dopamine D2 receptor gene affect gene expression, splicing, and neuronal activity during working memory. Proceedings of the National Academy of Sciences of the United States of America 2007, 104(51):20552-20557.

69. Gallagher MD, Chen-Plotkin AS: The Post-GWAS Era: From Association to Function. American journal of human genetics 2018, 102(5):717-730.

70. Albert FW, Kruglyak L: The role of regulatory variation in complex traits and disease. Nat Rev Genet 2015, 16(4):197-212.

71. Rockman MV, Kruglyak L: Genetics of global gene expression. Nature Reviews Genetics 2006, 7:862.

72. Wolen A, Miles M: Identifying Gene Networks Underlying the Neurobiology of Ethanol and Alcoholism. Alcohol research : current reviews 2012, 34:306-317.

73. Müller B, Wilcke A, Boulesteix A-L, Brauer J, Passarge E, Boltze J, Kirsten H: Improved prediction of complex diseases by common genetic markers: state of the art and further perspectives. Human Genetics 2016, 135(3):259-272.

74. Hoehe MR, Morris-Rosendahl DJ: The role of genetics and genomics in clinical psychiatry. Dialogues Clin Neurosci 2018, 20(3):169-177.

75. Chapman CR, Vierck CJ: The Transition of Acute Postoperative Pain to Chronic Pain: An Integrative Overview of Research on Mechanisms. The Journal of Pain 2017, 18(4):359.e351359.e338.

76. Bérubé M, Choinière M, Laflamme YG, Gélinas C: Acute to chronic pain transition in extremity trauma: A narrative review for future preventive interventions (part 2). International Journal of Orthopaedic and Trauma Nursing 2017, 24:59-67.

77. Pogatzki-Zahn E, Segelcke D, Zahn P: Mechanisms of acute and chronic pain after surgery: update from findings in experimental animal models. Current Opinion in Anesthesiology 2018, 31(5):575-585.

78. Parisien M, Khoury S, Chabot-Doré A-J, Sotocinal SG, Slade GD, Smith SB, Fillingim RB, Ohrbach R, Greenspan JD, Maixner W et al: Effect of Human Genetic Variability on Gene Expression in Dorsal Root Ganglia and Association with Pain Phenotypes. Cell Reports 2017, 19(9):1940-1952.

79. Parisien M, Samoshkin A, Tansley SN, Piltonen MH, Martin LJ, El-Hachem N, Dagostino C, Allegri M, Mogil JS, Khoutorsky A et al: Genetic pathway analysis reveals a major role for extracellular matrix organization in inflammatory and neuropathic pain. Pain 2019.

80. Stearns FW: One hundred years of pleiotropy: a retrospective. Genetics 2010, 186(3):767773.

81. Pickrell JK, Berisa T, Liu JZ, Segurel L, Tung JY, Hinds DA: Detection and interpretation of shared genetic influences on 42 human traits. Nat Genet 2016, 48(7):709-717.

82. Levine ME, Crimmins EM, Prescott CA, Phillips D, Arpawong TE, Lee J: A Polygenic Risk Score Associated with Measures of Depressive Symptoms Among Older Adults. Biodemography and Social Biology 2014, 60(2):199-211. 
83. Richebé P, Capdevila X, Rivat C: Persistent Postsurgical Pain: Pathophysiology and Preventative Pharmacologic Considerations. Anesthesiology: The Journal of the American Society of Anesthesiologists 2018, 129(3):590-607.

84. Eisenhofer G, Kopin IJ, Goldstein DS: Catecholamine metabolism: a contemporary view with implications for physiology and medicine. Pharmacol Rev 2004, 56(3):331-349.

85. Rut M, Machoy-Mokrzynska A, Reclawowicz D, Sloniewski P, Kurzawski M, Drozdzik M, Safranow K, Morawska M, Bialecka M: Influence of variation in the catechol-Omethyltransferase gene on the clinical outcome after lumbar spine surgery for one-level symptomatic disc disease: a report on 176 cases. Acta Neurochir (Wien) 2014, 156(2):245252.

86. Belfer I, Dai F, Kehlet H, Finelli P, Qin L, Bittner R, Aasvang EK: Association of functional variations in COMT and GCH1 genes with postherniotomy pain and related impairment. Pain 2015, 156(2):273-279.

87. Montes A, Roca G, Sabate S, Lao JI, Navarro A, Cantillo J, Canet J, Group GS: Genetic and Clinical Factors Associated with Chronic Postsurgical Pain after Hernia Repair, Hysterectomy, and Thoracotomy: A Two-year Multicenter Cohort Study. Anesthesiology 2015, 122(5):1123-1141.

88. Eijkenboom I, Sopacua M, Otten ABC, Gerrits MM, Hoeijmakers JGJ, Waxman SG, Lombardi R, Lauria G, Merkies ISJ, Smeets HJM et al: Expression of pathogenic SCN9A mutations in the zebrafish: A model to study small fiber neuropathy. Experimental Neurology 2018, 311:257-264. 
CHAPTER 2

\section{Dopaminergic neurotransmission and genetic variations in chronification of Post-Surgical Pain}

R.R.I. van Reij, E.A.J. Joosten, N.J. van den Hoogen

British Journal of Anaesthesia 2019, 123(6):853-864.

PMID 31558312, DOI: 10.1016/j.bja.2019.07.028

R. R. I. van Reij

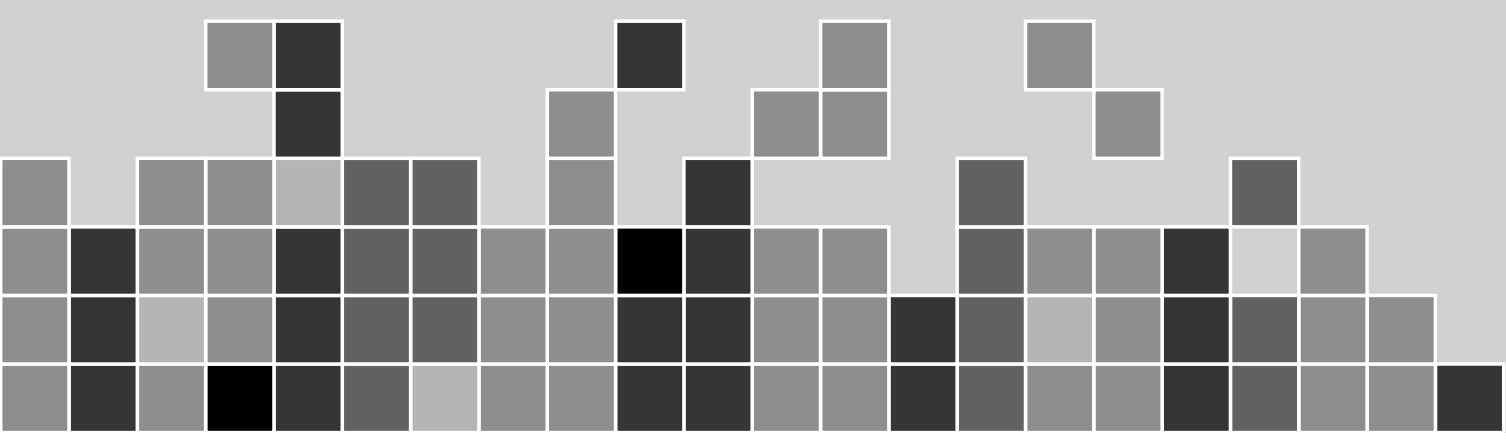


$30 \mid$ Chapter 2 


\section{Unstructured Summary}

Chronic postsurgical pain (CPSP) is a debilitating condition affecting $10-50 \%$ of surgical patients. The current treatment strategy for CPSP is not optimal and the identification of genetic variations in surgical patients might help to improve prediction as well as the treatment of CPSP. The neurotransmitter Dopamine (DA) is interesting in this aspect, as it has been associated with several chronic pain disorders. This review focusses at DA neurotransmission as a potential target in the treatment of CPSP. The current knowledge on genetic variations within DA neurotransmission and its role in CPSP susceptibility is reviewed. Three genes within DA neurotransmission (COMT, GCH1 and DRD2) have been associated with a variability in pain sensitivity, development of CPSP and analgesic requirement. The direction of the effect of the association is sometimes inconclusive due to contradictory results, but ample evidence suggests a modulatory role of DA. Due to this modulatory role, DA is an excellent pharmacological target in treatment of pain. Pharmacotherapy focussed at DAneurotransmission has a high potential in both the prevention (via D1LRs) and treatment (via D2LRs and DA reuptake inhibitors) of CPSP. The development of prediction models including genetic risk factors is needed to better identify the patients at risk.

Key words: Chronic Post-Surgical Pain, Dopamine, Pain sensitivity, Pharmacology, Single Nucleotide Polymorphisms 


\section{Introduction}

Chronic postsurgical pain (CPSP) affects $10-50 \%$ of surgical patients, severely decreasing quality of life and socioeconomic status [1-3]. The risk factors for developing CPSP can be divided into psychological, demographical, clinical and genetic risk factors. The psychological risk factors consist of pre-surgical catastrophizing and anxiety amongst others, providing a clear link with the biopsychosocial model of pain. The demographical risk factors consist of young age, female sex and most importantly pre-surgical pain [4, 5]. Clinical risk factors consist of type and duration of surgery and intraoperative nerve damage. All of these factors affect the development of chronic pain phenotypes after surgery [4, 5].

The current perioperative pain management strategy is focussed on prevention or treatment of acute postoperative pain [6,7]. Treatment of acute postoperative pain is provided using both opioid and non-opioid treatments, tailored to the specific surgery type and specific patient needs. Multimodal analgesia is the cornerstone of postsurgical pain management in order to reduce opioid requirements and minimize serious side effects of opioids, thereby facilitating early patient recovery $[7,8]$. The first step consists of regional or local anaesthesia specific for the invasiveness of the surgery $[7,8]$. The second step is non-opioid systemic analgesics, which provide initial analgesia and modulate stress $[7,8]$. Opioids are then used as rescue medication or to cover regions of inadequate regional anaesthesia coverage $[7,8]$. Multimodal techniques minimize opioid use as opioids have many and potentially dangerous side effects (including nausea, respiratory depression, tolerance, opioid induced hyperalgesia, and opioid withdrawal symptoms) and long-term use of opioids should be avoided when possible[6-8]. Nevertheless the current treatment strategy for CPSP remains suboptimal, which is possibly due to lack of new/optimal treatment targets [9]. 
Dopaminergic neurotransmission (DA-neurotransmission), most known for its involvement in psychological disorders, has been associated with chronic pain syndromes including CPSP and is often overlooked when it comes to analgesic treatment strategies [10-13]. This review will focus on the role of DA in chronification of pain, and its potential for optimizing treatment protocols of CPSP.A recent review showed that a number of genes involved in DAneurotransmission were reported to be associated with the prevalence and severity of chronic postsurgical [14]. This is in line with other studies that suggest an important role for DA-neurotransmission in chronification of pain [15, 16]. Hence, the understanding of DA-modulation in nociception and the role of genetics related to DA-neurotransmission is important and may result in better prediction models and in new treatment options for CPSP.

The objective of this review is to discuss: (1) The effect of genetic variation within DA- neurotransmission on susceptibility to CPSP; and (2) The potential of DAneurotransmission modulation in prevention of chronification of postsurgical pain and treatment of CPSP. Since the evidence in certain areas concerning dopamine and CPSP is limited, we will review and extrapolate the evidence collected from other research fields in which pain is involved and where dopamine plays a critical role (e.g. pain in Parkinson's disease).

\section{Dopaminergic Neurotransmission}

Dopamine (DA) is involved in locomotion, psychological processing and the reward system on supraspinal levels $[17,18]$. Moreover, DA is involved in the modulation of nociception at the spinal dorsal horn. Nociception starts at the peripheral nociceptor, which is activated by a noxious stimulus, transmitting the signal to the dorsal horn. There, the primary afferent synapse onto the second order neuron, transmitting the signal to various brain regions involved in the processing of pain, like the somatosensory cortex, amygdala, periaqueductal grey and cingulate cortex [19]. Modulation of the incoming nociceptive information 
in the spinal cord is possible via the descending pathways (serotonergic and/or noradrenergic fibers) which originate from supraspinal centres (including the rostroventral medulla and locus coeruleus) $[19,20]$. DA can also modulate nociception at the level of the spinal cord as well as at various brain regions (e.g. PAG) [21-23]. In this review we will focus on the influence of DA at the spinal cord level. For supraspinal modulation, the reader is referred to reviews on this topic (e.g. by P.B. Wood 2008 or Mitsi and colleagues 2016) [11, 24].

DA receptors are present throughout the spinal cord and are expressed both presynaptically (primary afferents) and postsynaptically (second order neuron) in the "pain-gate" with D2 receptors as the dominantly expressed receptor subtype [25-29]. Expression patterns of the DA receptor differ per subtype, D2 and D5 receptors are expressed abundantly throughout the spinal cord, in both the ventral and dorsal horn. However, the D1, D3 and D4 receptor are more sparsely expressed and restricted to specific regions either in the dorsal horn or in the motor neurons in the ventral horn [27, 29]. There are two known variants of the D2 receptor; a long and short variant. The long variant is predominantly expressed postsynaptically and mediates the postsynaptic signalling via the PKA and AKT pathways while the short variant is expressed mainly presynaptically and regulates the phosphorylation of tyrosine hydroxylase (key enzyme in the production of DA, fig. 1) mediating the production of DA [30-32].

DA binds to members of two families of G-protein coupled receptors: D1-like receptor (D1LR) family (including the D1 and D5 receptors) which are stimulatory, and the D2-like receptor (D2LR) family (consisting of the D2, D3 and D4 receptors) which are inhibitory [26]. DA binding directly facilitates (D1LRs) or inhibits (D2LRs) nociceptive signal transduction (Figure 1) [12, 13, 21, 33, 34]. The different subtypes of receptors can group together and form heteromers, which have a distinct working mechanism in which both receptors are needed to elicit their effect. Due to their specialized composition, heteromers are unique 
pharmacological targets [31, 35]. At spinal cord level, it has been shown that D1D3 heteromers are present throughout the grey matter, with their expression under influence of DA concentration. Co-activation of this heteromer leads to antagonistic interaction with adenylyl cyclase (AC) [35].

Dopamine is synthetized in the A11 descending neuron and released into the synaptic cleft where it binds to either the D2-like or the D1-like receptors to inhibit or activate the downstream signalling cascade mediated by AC [26, 27, 36, 37]. It is proposed that the noradrenaline transporter (NET) removes the dopamine from the synaptic cleft as it has been reported that there is no dopamine transporter in the spinal cord and COMT presence has been confirmed in the primary afferent (Figure 1) [36-40].

The effect of DA in the spinal cord is determined by the concentration of DA combined with the difference in affinity for the D1 receptor and D2 receptors. DA has a slightly higher affinity for the D2 receptor than the D1 receptor resulting in a preferential activation of $\mathrm{D} 2$ receptor at low concentration and inhibition of the signal transduction [41-43]. Furthermore, D2 receptor are more abundantly present in the spinal cord compared to D1 receptor but the D1 receptor have a more direct effect which leads to the following effects: (1) A low spinal DA concentration $( \pm 1 \mu \mathrm{M})$ results in inhibition of nociceptive signal transduction as it activates the D2 receptor, (2) a medium spinal DA-concentration $(10-50 \mu \mathrm{M})$ results in activation of nociceptive signal transduction as it activates the D1 receptor as well for which DA has a slightly lower affinity and (3) a high spinal DA concentration $(>100 \mu \mathrm{M})$ will inhibit nociceptive signal transduction through the abundance of D2 receptor [41, 43-46]. It has been demonstrated that there is a sexual dimorphism in the expression of D1 and D5 receptors leading to a higher expression in males than in females. Furthermore, both receptors are involved in maintaining chronic pain states, where the D1 receptor is more involved in females and the D5 receptor in males [47]. 


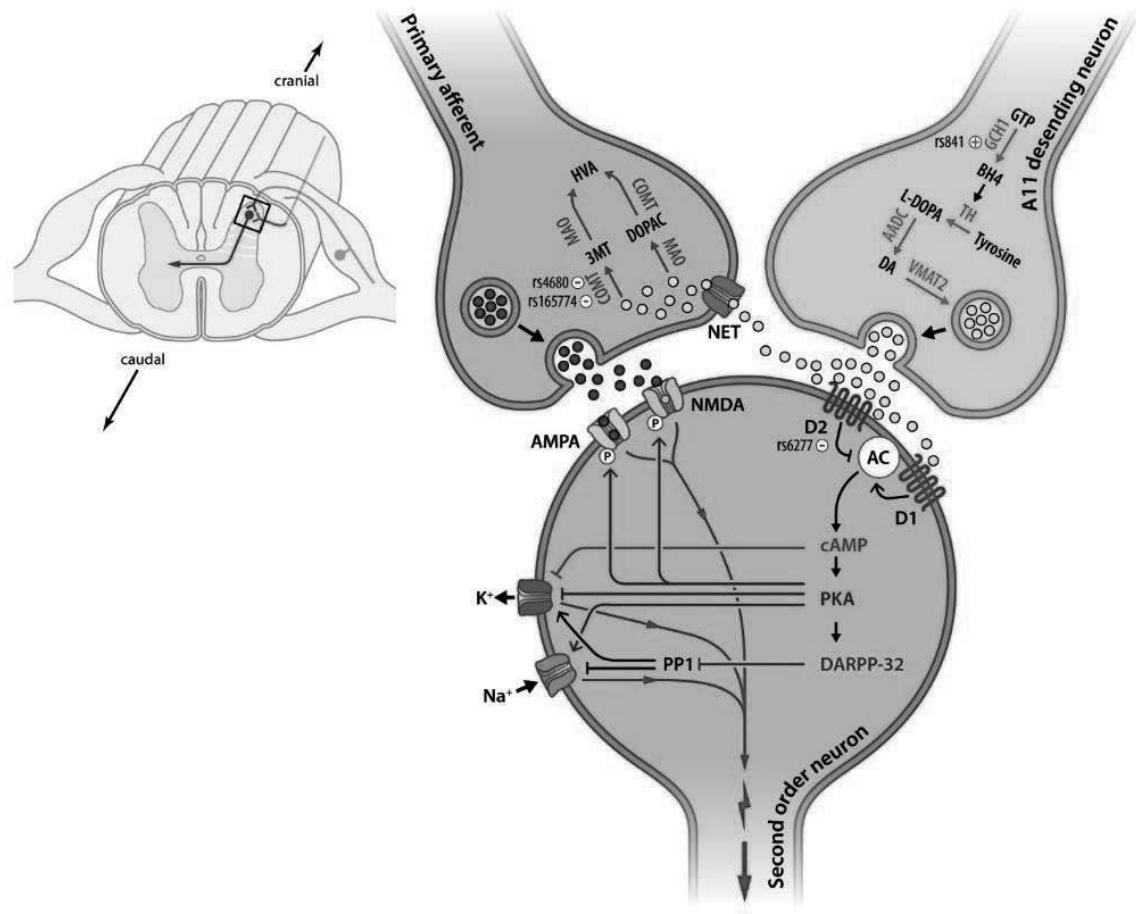

Figure 1: Genetic variations and dopaminergic neuromodulation in spinal cord nociceptive network. This figure illustrates DA-neurotransmission between primary afferents, descending neurons and the second order pain transmission neurons in the spinal dorsal horn. SNPs in DA-neurotransmission are shown as rs numbers. Rs841 is located in GCH1 and decreases expression of GCH1 affecting the production of dopamine. Rs6277 is located in DRD2 (D2 receptor) and decreases the stability of the mRNA thereby decreasing the expression of the D2 receptor. Rs4680 and rs 165774 are both located in COMT and both decrease the enzymatic activity of COMT. Each of these variations are located at key points in the dopaminergic neurotransmission and influence the effect of dopamine on nociception by altering the signalling cascade.

Abbreviations: $3 M T=3$-methoxytyramine, $A C=$ adenylyl cyclase, $A M P A=\alpha$-amino-3-hydroxy-5-methyl-4isoxazolepropionic acid, $A A D C=$ Aromatic $L$-amino acid decarboxylase, $c A M P=$ cyclic adenosine monophosphate, BH4 = Tetrabydrobiopterin, COMT = catechol-O-methyltransferase, D1 = Dopamine 1-like receptor,$D 2=$ Dopamine 2-like receptor, DARPP-32 = dopamine- and cAMP-regulated neuronal phosphoprotein, DA = Dopamine, DOPAC = 3,4Dihydroxyphenylacetic acid, GCH1 = GTP cyclohydrolase 1, GTP = guanosine triphosphate, HVA = HomoVanillic Acid, $K+=$ Potassium channel, $L-D O P A=$ levodopa, MAO = MonoAmine oxidase, Na+ = Sodium channel, $N E T=$ Norepinephrine transporter, NMDA = N-Methyl-D-aspartic acid, $P K A=$ Protein Kinase A, PP1 = Protein Phosphatase 1, $r s \#=$ reference SNP number, $S N P=$ Single Nucleotide polymorphism, $T H=$ Tyrosine Hydroxylase, VMAT2 = vesicular monoamine transporter 2 . 


\section{Search strategy}

An extensive PubMed search was conducted to find literature related to Dopamine, Pain or Chronic postsurgical pain, genetics and modulation of dopamine. The search term was as follows: (( "Dopamine"[Mesh] OR "Receptors, Dopamine"[Mesh] OR Dopamine) AND (Nociception OR Analgesia OR "Pain"[Mesh] OR "Chronic Pain"[Mesh] OR "persistent pain" OR "postoperative pain”) AND (genetic)) OR (((COMT AND Nociception) OR (COMT AND Pain)) AND (genetic)) OR (((GCH1 AND Nociception) OR (GCH1 AND Pain)) AND (genetic))))) OR ( Genetic AND dopamine AND Chronic Pain) OR (Genetic AND dopamine AND Postoperative Pain) OR (polymorphism AND "Dopamine" and "receptor")). Special attention was given to include different aspects of pain (e.g. chronic pain, nociception) and the combination with different genes involved in DA-neurotransmission. The search resulted in 2897 hits, of which titles and abstracts were screened for relevance. Articles were selected if their focus was on either pain sensitivity, development of CPSP or analgesic requirements in human studies. To supplement this search, we used the Human Pain Genes Database (HPGD) to identify hits which were not noted by our search and checked the references of the articles which were included [48]. This resulted in a total of 36 articles (see Table 1 ).

\section{Pathophysiology of CPSP}

Both tissue trauma (nerve transection) and inflammation resulting from incision and exposing tissues during surgery can lead to sensitization of the nociceptive system and consequently resulting in chronification and thus CPSP [1, 49]. The local inflammatory pain is mediated by cytokines released at surgical site and leads to peripheral sensitization $[49,50]$. Especially during major surgeries, there is an increased chance of damage to the nerves which eventually results in a neuropathic pain phenotype, which is difficult to treat $[1,5,49]$. As it is shown 
that nerve-sparing surgeries are not always preventive of CPSP, other processes, including neuroplasticity of the nociceptive system, might play an additional and important role in development of CPSP [51]. Peripheral and central sensitization mechanisms can lead to maladaptive neuroplasticity in the spinal cord and central nervous system including disinhibition and descending facilitation via monoamines, including DA $[19,20,52]$. The central sensitization process is primarily through the AMPA receptor but an injury or surgery causes a prolonged pain signal, which subsequently activates the NMDA receptor [19]. DA binding to the D1LR receptor modulates phosphorylation of the AMPA and NMDA receptor and thereby affects central sensitization (see Figure1) [20, 26].

\section{Genetic variations in DA and chronic postsurgical pain}

A Single Nucleotide Polymorphism (SNP) in the DNA is a sequence variation whereby a single nucleotide in the genome is different. A SNP can result in different effects on cellular processes. A missense SNP causes a different amino acid to be built into the protein affecting its function, a synonymous SNP could affect mRNA stability leading to an altered translation, SNPs in the promotor region could affects expression levels and even SNPs outside genes can have an effect on protein functioning. The mechanism through which a SNP is able to affect the gene expression level or protein functioning depends on the location of the SNP. A SNP in the promotor region is able to change the motif for the transcription factor to bind leading to a more enhanced or decreased binding of the transcription factor altering the transcription of DNA into RNA. A SNP may introduce a new methylation site at either the promotor or enhancer region altering the binding of the transcription factor as well. SNPs in the intronic region can affect the splicing of the mRNA causing a different composition of the protein [53]. Most of the SNPs studied in chronic pain research do not directly cause pain but can modulate pain sensitivity, susceptibility to chronic pain or analgesic requirements [54]. 
Clinical and pre-clinical studies have demonstrated the importance of DA in nociception and the modulating effect of various SNPs within genes associated with DA-neurotransmission and their effect on (chronic) pain $[14,55,56]$. Three genes within the DA-neurotransmission (catechol-O-methyltransferase (COMT), GTP cyclohydrolase 1 (GCH1)), DA receptor 2 (DRD2)) have shown strongest associations with baseline pain sensitivity and CPSP and are interesting targets for pharmacological modulation. Table 1 provides an overview of current evidence on SNPs associated with DA-neurotransmission and pain sensitivity, development of CPSP and analgesic requirements.

Table 1 (next page): Result of the individual association studies with pain sensitivity, CPSP and analgesic requirement. (next page) Dopaminergic neurotransmission and genetic variations: SNP's and the direction of the effect of the minor alleles and the amount of positive, negative or neutral associations is visualized per gene of interest, and depicted as "0" (no significant association), "+” (an increase in this domain), “-"(a decrease in this domain) or " $\emptyset$ " (this variant was not tested within this domain). Missense variant: different base pair and a different amino acid in the protein, Synonymous variant: different base pair but same amino acid, intronic variant: different base pair but not expressed in protein. 


\begin{tabular}{|c|c|c|c|c|c|c|}
\hline GENE & $S N P$ & VARIANT & $\begin{array}{c}\text { PAIN } \\
\text { SENSITIVITY }\end{array}$ & $\begin{array}{c}\text { DEVELOPMENT OF } \\
\text { CPSP }\end{array}$ & $\begin{array}{c}\text { ANALGESIC } \\
\text { REQUIREMENT }\end{array}$ & REFERENCES \\
\hline \multirow{21}{*}{$\begin{array}{l}\text { CATECHOL-O- } \\
\text { METHYLTRANSFERASE } \\
(\text { COMT })\end{array}$} & rs737866 & Intronic & 0 & $\varnothing$ & $\begin{array}{c}0 \\
(2 x 0)\end{array}$ & 60,95 \\
\hline & rs737865 & Intronic & 0 & ø & 0 & 60 \\
\hline & rs1544325 & Intronic & 0 & $\varnothing$ & 0 & 60 \\
\hline & rs8185002 & Intronic & 0 & $\varnothing$ & 0 & 60 \\
\hline & rs174675 & Intronic & 0 & $\varnothing$ & 0 & 60 \\
\hline & rs5993882 & Intronic & 0 & $\varnothing$ & 0 & 60 \\
\hline & rs740603 & Intronic & 0 & ø & $\begin{array}{c}+ \\
(1 x+, 1 \times 0)\end{array}$ & 60,95 \\
\hline & rs4646312 & Intronic & 0 & 0 & 0 & 60,100 \\
\hline & rs4633 & Synonymous & $\begin{array}{c}0 \\
(2 \times 0)\end{array}$ & $\begin{array}{c}? \\
(1 x+, 1 x-, 1 x 0)\end{array}$ & $\begin{array}{c}? \\
(1 x+, 1 x-, 3 \times 0)\end{array}$ & $\begin{array}{c}55,58,60,89,92,93,96, \\
98,99,104\end{array}$ \\
\hline & rs2239393 & Intronic & 0 & $\varnothing$ & $\begin{array}{c}+ \\
(1 x+, 1 x 0)\end{array}$ & 60,95 \\
\hline & rs 4818 & Synonymous & $\begin{array}{c}+ \\
(1 x+, 1 x 0)\end{array}$ & $\begin{array}{c}+ \\
(1 x+, 3 \times 0)\end{array}$ & $\begin{array}{c}+ \\
(3 x+, 3 x 0)\end{array}$ & $\begin{array}{c}55,58,60,89,92,93,95, \\
96,98,99,104\end{array}$ \\
\hline & rs 4680 & Missense & $\begin{array}{c}+ \\
(6 x+, 5 \times 0)\end{array}$ & $\begin{array}{c}? \\
(1 x+, 1 x-, 5 x 0)\end{array}$ & $\begin{array}{c}? \\
(5 x+, 5 x-, 4 x 0)\end{array}$ & $\begin{array}{c}55,57,58,60,62-68,71 \\
89-91,93-98,100,102- \\
107\end{array}$ \\
\hline & rs4646316 & Intronic & $\begin{array}{c}+ \\
(1 x+, 1 \times 0)\end{array}$ & $\varnothing$ & 0 & 60,69 \\
\hline & rs165774 & Intronic & $\begin{array}{c}- \\
(2 x-)\end{array}$ & $\varnothing$ & $\begin{array}{c}0 \\
(2 \times 0)\end{array}$ & $55,59,60$ \\
\hline & rs174696 & Intronic & 0 & $\varnothing$ & $\begin{array}{c}0 \\
(2 \times 0)\end{array}$ & 55,60 \\
\hline & rs9306235 & Intronic & 0 & $\varnothing$ & 0 & 60 \\
\hline & rs9332377 & Intronic & 0 & $\varnothing$ & 0 & 60 \\
\hline & rs6269 & Intronic & $\begin{array}{c}? \\
(1 x+, 1 x-)\end{array}$ & $\begin{array}{c}- \\
(2 x-, 3 \times 0)\end{array}$ & $\begin{array}{c}+ \\
(2 x+, 1 \times 0)\end{array}$ & $\begin{array}{c}58,69,89,92,93,95,96, \\
99,100,104\end{array}$ \\
\hline & rs2097903 & Intronic & 0 & $\varnothing$ & $\varnothing$ & 58 \\
\hline & rs7287550 & Intronic & $\varnothing$ & ø & 0 & 95 \\
\hline & rs5746849 & Intronic & $\varnothing$ & $\varnothing$ & + & 95 \\
\hline \multirow[t]{7}{*}{ GTP CYCLOHYDROLASE 1} & rs3783641 & Intronic & - & $\begin{array}{c}0 \\
(2 \times 0)\end{array}$ & + & $74,92,93,100$ \\
\hline & rs998259 & Intronic & $\varnothing$ & 0 & $\varnothing$ & 100 \\
\hline & rs8004445 & Intronic & ø & 0 & $\varnothing$ & 100 \\
\hline & rs12147422 & Intronic & ø & 0 & $\varnothing$ & 100 \\
\hline & rs9671371 & Intronic & ø & 0 & $\varnothing$ & 100 \\
\hline & rs4411417 & Intronic & - & + & $\varnothing$ & 74,100 \\
\hline & rs752688 & Intronic & - & + & $\varnothing$ & 74,100 \\
\hline $\begin{array}{l}\text { DOPAMINE RECEPTOR D3 } \\
\text { (DRD3) }\end{array}$ & $\begin{array}{c}\text { rs6280 } \\
\text { rs3773679 }\end{array}$ & $\begin{array}{l}\text { Missense } \\
\text { Intronic }\end{array}$ & $\begin{array}{l}- \\
+ \\
+\end{array}$ & 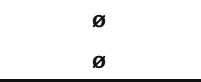 & ø & $\begin{array}{l}88 \\
81\end{array}$ \\
\hline \multirow{7}{*}{$\begin{array}{l}\text { DOPAMINE RECEPTOR D2 } \\
\text { (DRD2) }\end{array}$} & rs2734837 & Intronic & ø & 0 & $\varnothing$ & 100 \\
\hline & rs11608185 & Intronic & ø & 0 & $\varnothing$ & 100 \\
\hline & rs4936272 & Intronic & ø & 0 & $\varnothing$ & 100 \\
\hline & rs4648317 & Intronic & $\varnothing$ & + & $\varnothing$ & 100 \\
\hline & rs4322431 & Intronic & $\varnothing$ & 0 & $\varnothing$ & 100 \\
\hline & rs1076560 & Intronic & ø & 0 & $\varnothing$ & 100 \\
\hline & rs6277 & Synonymous & + & 0 & $\varnothing$ & 87,100 \\
\hline
\end{tabular}

$40 \mid C h$ a p ter 2 
Variations in dopaminergic neurotransmission genes alter baseline pain sensitivity

An often-reported gene associated with dopaminergic neurotransmission and pain sensitivity is COMT, a gene involved in degradation of DA and other catecholamines [57, 58] (see Figure 1). According to the HPGD, the COMT gene has been published most often in relation to pain, and in particular SNP rs4680 [48]. Several studies have demonstrated the involvement of COMT in pain sensitivity with haplotypes that account for differences in individual pain perception and chronification of pain (Table 1) [16, 59-70]. Furthermore, individual SNPs within COMT, most notably the Val158Met polymorphism (rs4680) and the corresponding haplotype, affect both the enzyme's biological activity, and the response to and requirements of opioids (Figure 1) [60, 63, 7173]. Another gene shown to be associated with dopaminergic neurotransmission and pain sensitivity is (GCH1) [64,74,75]. GCH1 is involved in the production $\mathrm{BH} 4$, a key molecule in the synthesis of DA. Several SNPs within GCH1 have been associated with a protective effect against various pain disorders $[64,76]$.

The protective effect against pain disorders is most likely due a decreased function of GCH1 and consequentially decreased production of $\mathrm{BH} 4$ [74, 77]. Higher concentrations of $\mathrm{BH} 4$ have been associated with more pain through altered dopamine metabolism amongst other mechanisms [74, 77, 78]. Interestingly, gene-gene interaction between COMT and GCH1 has been demonstrated to mediate the effect of rs 4680 within COMT on pain sensitivity, whereby the SNPs within $G C H 1$, also involved in the function of dopamine in neurotransmission, provided a protective effect [64]. While the minor allele of the polymorphism affecting the enzyme activity (rs4680) is present in both the high pain sensitivity haplotype and the low pain sensitivity haplotype, this results in a different phenotype. A potential explanation could lie in the difference between membrane-bound COMT and soluble COMT. Both are transcribed from the same 
genetic locus, but are regulated differently per tissue type. The composition of the haplotype around the rs 4680 could modify this tissue specific regulation leading to a more pain sensitive haplotype or a pain protective haplotype $[59,60]$. The exact role of COMT on pain sensitivity remains a matter of debate as it has been shown to be both protective factor as well as a risk factor, furthermore, psychological components could be involved as well [65-67, 79]. Recently, a study reported that the COMT polymorphism rs4680 was not associated with pain levels but with fear of pain, thus supporting a possible indirect psychological effect of COMT on pain [80].

Genetic variations in the receptor subtypes of the D2LRs have been shown to affect baseline pain sensitivity through functional alterations of the receptor [8187]. The synonymous SNP C957T (rs6277) within the D2 receptor decreases the stability of the D2 receptor, influences striatal and extra-striatal receptor availability, modulating the connectivity between brain structures [83-85, 88]. Furthermore, the D2 polymorphism rs6277 leads to increased baseline pain sensitivity and increased susceptibility to chronic pain [86]. Within the D3 receptor, rs6280 was shown to be protective for acute pain crises in sickle cell disease, and the D3 rs3773679 was associated with response to nociceptive stimuli when under analgesia $[81,82]$.

\section{Genetic variations affect the susceptibility to CPSP}

Genetic variations between individuals could explain much of the variability in CPSP. SNPs within GCH1, COMT and DRD2, all involved in the dopaminergic pathway (Figure 1), have been studied in a context of pain sensitivity but also in relation and association to CPSP. Multiple SNPs within COMT, rs4680 (Val158Met), rs4818, rs4633 and rs4633, are reported to be associated with lower incidence and intensity of CPSP and less opioid use in the acute phase after surgery (Table 1) [89-98]. Furthermore, the haplotype (rs4680 A, rs4633 C, rs4818 C, rs6269 G), was associated with a better clinical outcome and less pain one year 
after surgery, whereas other studies found this haplotype to be associated with higher pain ratings and worse clinical outcome[60, 89, 99]. However, some studies did not report any association between SNPs or haplotypes within COMT and CPSP/analgesic requirement or an opposite effect [57, 62, 63, 72, 89, 90, 92-96, 98107]. The direction of the effect of the rs 4680 allele does not seem to depend on the cohort of patients studied, as it has been associated with an increase and a decrease in analgesic requirement in different cohort of patients with cancer [72, 94, 95, 106]. Interestingly, it has been shown that the combination of SNPs in COMT and psychological factors are also involved in the susceptibility to CPSP [108]. Especially with COMT, there is evidence for a bio-psychosocial interaction influencing the psychological risk factors of and susceptibility to CPSP.

Most of the SNPs within GCH1 have been associated with protection against pain and this has been shown in CPSP as well $[76,100,109]$. Studies on discectomy, herniotomy and molar removal showed an association between the pain protective haplotype of GCH1 (rs3783641, rs8007267 and others) and less pain after surgery and faster recovery $[92,93,110]$. By contrast, studies on postoperative shoulder pain, mastectomy, hysterectomy, and hernia repair found no association with the individual SNPs or a higher risk of CPSP (Table 1) [92, 100, 111]. With postoperative shoulder pain, the effect of the SNP in GCH1 interacted with anxiety indicating that also GCH1 is involved in a bio-psycho-social interaction thereby affecting the susceptibility to CPSP. To our knowledge, the association of SNPs in the D1LR genes and CPSP has not been studied. A nominally significant association between SNPs in DRD2 (rs4648317 and rs12364283) and CPSP (after hernia repair, hysterectomy, and thoracotomy) has been reported [100].

Large-scale genetic studies are necessary to successfully identify which genetic variations are repeatedly associated with CPSP. Genome-wide association studies (GWAS) and next generation sequencing (NGS) could play an important role in elucidating which genetic variations within the DA-neurotransmission are 
involved in different processes of CPSP. For this, vast sample sizes are necessary and replication in different cohorts is needed.

\section{Modulation of DA-neurotransmission in pain and new treatment possibilities in CPSP}

Due to its role in nociception, DA neurotransmission makes an interesting target for the pharmacological modulation of chronic pain, including prevention of chronification of postsurgical pain and with that treatment of CPSP (Figure 1). Several pre-clinical and clinical studies have investigated the therapeutic potential of modulating DA neurotransmission in the anti-nociceptive action of morphine, anti-psychotic, anti-depressant, and anti-asthma medication [13, 112-121]. As clinical research in other disorders has shown the potential of modulation of DAneurotransmission as a therapeutic for pain we include this in our review. Finally, we focus at implications for new treatments in CPSP.

\section{Direct modulation of DA-neurotransmission in pain}

Pharmacological intervention and modulation of DA-neurotransmission in chronic pain has primarily been shown by the use of the D1LR and D2LR (ant-) agonists. Pre-clinical studies show that application of D2LR agonist either intrathecally (i.t.) or via chronic subcutaneous infusion, provide an analgesic effect, and this is reversed by D2LR antagonist application [21, 46, 122]. D1LR agonist applied directly on the spinal cord induced sensitisation of C-fibres, which can be reversed by antagonists. Furthermore, D1LRs are involved in the protein synthesis phase of sensitisation and thereby modulate the chronification of pain [123]. In addition to direct binding and modulation of D2LR or D1LR, pharmacotherapy can be directed at the dopamine reuptake process (see Figure 1). Increasing the DA concentration by inhibiting the DA-reuptake can be established with administration of selective and non-selective monoamine reuptake inhibitors like bupropion, duloxetine or milnacipran $[117,119,120]$. The anti-nociceptive 
effect of reuptake inhibitors applied intraperitoneally (i.p.) and i.t. on pain is partially mediated via DA as increasing the concentration of DA results in an inhibition of the nociceptive transmission $[117,119$, 120]. Furthermore, i.t. application of D2LR antagonist Sulpiride counteracted the effect of the re-uptake inhibitors, further strengthening the role of DA $[117,119,120]$. Besides reuptake inhibitors, DA also (partially) mediates the anti-nociceptive properties of aripiprazole (partial DA agonist, anti-psychotic) and theophylline (alters DA release, anti-asthma medication) $[115,116,124]$.

Clinical studies have shown bupropion to be an effective analgesic in neuropathic pain, but not in chronic low back pain without a neuropathic component [118, $125,126]$. Clinical research in other disorders has shown the potential of modulation of DA-neurotransmission as a therapeutic for pain. In Restless Leg Syndrome (RLS) pain and lowered pain thresholds is often a comorbidity occurring with the unpleasant sensation in the legs and the urge to move [127, 128]. Patients with RLS are often treated with DA agonist to alleviate their RLS symptoms long term treatment with DA agonist (L-DOPA, pramipexole (D2LR agonist) or cabergoline (D2 receptor agonist)) ameliorated their pain threshold, decreased hyperalgesia and improved their tactile sensations [129-133]. In Parkinson's disease (PD), 30\%-60\% of the patients report pain in some form and therefore pain is considered a major non-motor symptom of PD [121, 134, 135]. The role of DA on pain in PD has been investigated and treatment with L-DOPA was shown to be effective $[121,136,137]$. Most patients with PD fluctuate between "on" condition (medication is at an effective dose) and "off" condition (PD symptoms re-emerge) [138]. Patients experience a lower pain threshold in the "off" condition compared to the "on" condition indicating the effect of dopaminergic medication on pain $[121,136,137]$. Nevertheless, genetic heterogeneity in PD patients, as there are different forms of PD with different clinical presentations, might affect the outcome of L-DOPA treatment on pain [139, 140]. The use and injection of a non-selective dopamine antagonist apo-morphine did not 
significantly modify pain thresholds in PD patients compared to controls [133, 141].

\section{Indirect modulation of DA-neurotransmission in pain}

Indirect modulation of DA-neurotransmission is possible in various ways: a nonDA receptor is activated, like for instance the opioid receptor, and this has an effect on the DA receptor functioning and thereby affects the nociception or the activation of the DA receptor has an effect on other receptors (e.g. the NMDA) and affects their neurotransmission and role in nociception.

Morphine administration (i.p. or i.t.) leads to an increase in D2 receptor expression in the spinal cord, improved the interactions between opioid receptors and D2 receptors and it has been demonstrated that morphine-induced sensitisation can be reversed by blocking of the D2 receptor [112, 114]. Furthermore, a neuropathic pain condition leads to enhanced interaction between the DA receptors (D1LR (facilitatory in nociception) and D2 receptor (inhibitory in nociception)) and opioids $[12,13]$. The D2 receptor co-localizes with the $\mu$ opioid receptors (MOR) in neuropathic pain, and the anti-nociceptive effect of the D2 receptor agonist (quinpirole) is counteracted by a subclinical dose of MOR antagonist CTOP. Moreover, the co-administration of a D2 receptor agonist (quinpirole) and a MOR agonist (DAMGO) provided effective analgesia at a subclinical dose [13]. This effect occurs due to co-localization of D2 receptors and MOR on the same excitatory neurons and activation of these receptors leads to similar downstream effects including as potassium channel opening, which then results in inhibition of the nociceptive signal transduction [13]. This clinically relevant finding suggests that modulation of DA neurotransmission affects morphine binding to MOR and this may result in further reduction of morphine dose for treatment of chronic neuropathic pain. 
In neuropathic pain conditions, D1LRs have been reported to modulate central sensitisation (CS) processes via the NMDA receptor (Figure 1). Ablation of dopaminergic neurons showed involvement of D1LRs (facilitatory to nociception) in the initiation and maintenance of CS through modulation of the NMDA receptor and thereby facilitating a painful response to a subthreshold stimulus, D1LR antagonist (SCH 23390) can prevent this process [33, 142]. Furthermore, sustained D1LR activation, although initially anti-nociceptive, impairs opioid receptor functioning, which is then counteracted by D1LR antagonist SCH 23390[12, 34]. This effect occurs due to co-localization of D1LR and NMDA on the same excitatory neurons and juxta-localization of D1LR presynaptically and MOR postsynaptically. The postsynaptic D1LR is involved in phosphorylation of the NMDA receptor which potentiates the NMDA receptor (see Figure 1) [33]. Sustained presynaptic D1LR activation increases the release of met-encephalin and impairs the postsynaptic MOR due to prolonged activation [12]. The combination of these mechanisms results in a loss of inhibition as well as a potentiation of NMDA receptor and ultimately the facilitation of chronification of pain.

In the spinal cord, DA modulates the GABAergic interneurons in neuropathic pain conditions. Chronic pain increases the expression of neuroligin 2, a synaptic adhesion molecule located within inhibitory synapses [143]. This neuroligin 2 protein has a preference to form synapses between GABAergic and Dopaminergic neurons, causing mismatched synapses to be formed in chronic pain conditions. Inhibition of neuroligin 2 reverses the pain facilitation caused by D1LRs described above and restores the pronociceptive properties of a $\mathrm{GABA}_{\mathrm{A}}$ antagonist $[47,143]$. The impairment of neuroligin 2 is likely to be a good target to treat both the disinhibition mediated by GABAergic interneurons as well as the maintenance of chronic pain states by D1LRs. 


\section{CPSP and modulation of DA-neurotransmission?}

Direct and indirect modulation of DA-neurotransmission have been shown to be involved in analgesia and chronification of pain and could therefore potentially be applied in CPSP.

\section{Prevention of CPSP}

The possibility to indirectly modulate the central sensitisation through D1LRs is especially relevant for the prevention of CPSP as current treatment strategies are relatively ineffective [33, 142, 144]. Research suggests that administration of D1LR antagonists (inhibiting facilitation of nociception) during surgery could prevent the initiation and maintenance of central sensitisation and could thereby prevent the chronification of the postsurgical pain [33, 142]. Activation of the D1LRs is required for the sensitisation process to occur. Without this activation, and antagonism by D1LR antagonist SCH 23390, the NMDA receptor will not be phosphorylated which is a crucial step in the central sensitisation process (Figure 1) $[33,142]$.

\section{Treatment of CPSP}

Direct modulation of DA-neurotransmission through D2LRs agonism (inhibition of nociception) and reuptake inhibitors (increasing DA concentration and preferential D2LR activation) are interesting options for the treatment of CPSP (Figure 1). D2LRs agonist quinpirole have been shown to reduce hyperalgesia in both acute pain and in chronic neuropathic pain in animal models [13, 21, 122]. DA agonists Pramipexole and cabergoline reduce comorbid pain symptoms in other disorders, and reuptake inhibitor bupropion has been shown effective in neuropathic pain $[125,131-133]$.

In the treatment of CPSP, the synergy between opioid receptors and D2LRs (both involved in the inhibition of nociception) form an interesting perspective. 
Simultaneous administration of D2LR agonists and morphine have been shown to be effective at subclinical dosages in treatment of pain [13]. The use of subclinical dosages is clinically very relevant as it does result in a decrease in overall opioid use and opioid-related side effects such as opioid induced hyperalgesia and opioid withdrawal symptoms.

\section{Future Perspectives}

Clinical effectiveness of DA focussed pharmacological interventions has been shown in other disorders, but evidence of effectiveness in CPSP prevention and/or treatment is currently lacking and further research is needed [121, 129-133, 136, 137]. Clinical studies on the genetics of DA-neurotransmission need to be replicated in follow-up GWAS and Next Generation Sequencing (NGS) studies on CPSP. Furthermore, new DA-related targets have to be identified and screened for their potential in analgesia. Newly developed nociceptive screening assays in zebrafish assays allow fast and quick screening of new pharmacological treatment strategies [145-148]. Additionally, zebrafish are excellent for testing the effect of genetic variations (e.g. identified in GWAS or NGS studies on CPSP) and could be used to determine the effect of genetic variations on effectiveness of different treatment strategies [145]. These pharmacogenomic strategies can subsequently be tested in rodents and translated to clinical practice [149].

\section{Concluding remarks}

Dopamine-neurotransmission and variations within COMT-gene (risk factor), GCH1-gene (protective) and DRD2-gene (risk factor) have been reported to be associated with a variability in pain sensitivity, development of CPSP and analgesic requirement. Pharmacotherapy focussed at DA-neurotransmission has a high potential in prevention (via D1LRs) and treatment (via D2LRs and DA reuptake inhibitors) of CPSP. 
The current evidence, as summarized here, provides ample evidence for the involvement of DA in the development of CPSP. Further research should focus on the translation of preclinical findings on DA and chronic postsurgical pain into clinical practice through two different approaches. Firstly, implementing the knowledge on genetic variation into currently existing prediction models, consisting of known risk factors, of CPSP which then may further improve the accuracy of the prediction. It has been shown that the addition of a single polymorphism (SNP rs4818 in COMT) to a prediction model of CPSP did enhance, although not significantly, the prediction power from $78 \%$ to $82 \%$ [150]. Lastly, studies assessing pharmacological interventions targeted at genetic variation are needed. Understanding the genetic risk factors of CPSP could optimize pharmacological treatment during the peri-operative period. Counteracting the biological effects of those SNPs involved in DA neurotransmission through peri-operative pharmacological intervention then may decrease the prevalence and chronification of postsurgical pain.

\section{Declaration of interests}

The authors declare that they have no conflict of interest'

\section{Funding}

This work was supported by funds made available by Department of Anaesthesiology (Maastricht University Medical Center ${ }^{+}\left(\mathrm{MUMC}^{+}\right)$, and School of Mental Health, and Neuroscience (MHeNS, University of Maastricht).

\section{Author contributions}

RvR, EJ and NvdH were all involved in the concept, design and interpretation of this review, whereby RvR drafted the manuscript and EJ and $\mathrm{NvdH}$ were involved in critically revising the manuscript. All authors have given their final approval to the manuscript.

\section{Acknowledgement}

We would like to thank Rogier Trompert Medical Art for Fig 1. 


\section{References}

1. Kehlet H, Jensen TS, Woolf CJ: Persistent postsurgical pain: risk factors and prevention. The Lancet 2006, 367(9522):1618-1625.

2. Simanski CJ, Althaus A, Hoederath S, Kreutz KW, Hoederath P, Lefering R, Pape-Köhler C, Neugebauer EA: Incidence of chronic postsurgical pain (CPSP) after general surgery. Pain Medicine 2014, 15(7):1222-1229.

3. Parsons B, Schaefer C, Mann R, Sadosky A, Daniel S, Nalamachu S, Stacey BR, Nieshoff EC, Tuchman M, Anschel A: Economic and humanistic burden of post-trauma and postsurgical neuropathic pain among adults in the United States. Journal of pain research 2013, 6:459.

4. Katz J, Seltzer Ze: Transition from acute to chronic postsurgical pain: risk factors and protective factors. Expert Rev Neurother 2009, 9(5):723-744.

5. Hoofwijk DM, Fiddelers A, Peters ML, Stessel B, Kessels A, Joosten EA, Gramke H-F, Marcus M: Prevalence and Predictive Factors of Chronic Postsurgical Pain and Poor Global Recovery One Year after Outpatient Surgery. The Clinical journal of pain 2015.

6. Rawal N: Current issues in postoperative pain management. European journal of anaesthesiology 2016, 33(3):160-171.

7. Wick EC, Grant MC, Wu CL: Postoperative Multimodal Analgesia Pain Management With Nonopioid Analgesics and Techniques: A Review. JAMA surgery 2017, 152(7):691697.

8. Dunkman WJ, Manning MW: Enhanced Recovery After Surgery and Multimodal Strategies for Analgesia. The Surgical clinics of North America 2018, 98(6):1171-1184.

9. Thapa P, Euasobhon P: Chronic postsurgical pain: current evidence for prevention and management. The Korean journal of pain 2018, 31(3):155-173.

10. Antypa N, Drago A, Serretti A: The role of COMT gene variants in depression: Bridging neuropsychological, behavioral and clinical phenotypes. Neurosci Biobehav Rev 2013, 37(8):1597-1610.

11. Wood PB: Role of central dopamine in pain and analgesia. Expert Review of Neurotherapeutics 2008, 8(5):781-797.

12. Aira Z, Barrenetxea T, Buesa I, del Caño GG, Azkue JJ: Dopamine D1-like Receptors Regulate Constitutive, $\mu$-Opioid Receptor-Mediated Repression of Use-Dependent Synaptic Plasticity in Dorsal Horn Neurons: More Harm than Good? The Journal of Neuroscience 2016, 36(20):5661-5673.

13. Aira Z, Barrenetxea T, Buesa I, Gómez-Esteban JC, Azkue JJ: Synaptic upregulation and superadditive interaction of dopamine $\mathrm{D} 2$-and $\mu$-opioid receptors after peripheral nerve injury. PAIN@ 2014, 155(12):2526-2533.

14. Hoofwijk DMN, van Reij RRI, Rutten BP, Kenis G, Buhre WF, Joosten EA: Genetic polymorphisms and their association with the prevalence and severity of chronic postsurgical pain: a systematic review. British Journal of Anaesthesia 2016, 117(6):708-719. 
15. Blanchet PJ, Brefel-Courbon C: Chronic pain and pain processing in Parkinson's disease. Progress in neuro-psychopharmacology \& biological psychiatry 2018, 87(Pt B):200-206.

16. Tammimaki A, Mannisto PT: Catechol-O-methyltransferase gene polymorphism and chronic human pain: a systematic review and meta-analysis. Pharmacogenet Genomics 2012, 22(9):673-691.

17. Sharples SA, Koblinger K, Humphreys JM, Whelan PJ: Dopamine: a parallel pathway for the modulation of spinal locomotor networks. Front Neural Circuits 2014, 8:55.

18. Stanton CH, Holmes AJ, Chang SWC, Joormann J: From Stress to Anhedonia: Molecular Processes through Functional Circuits. Trends in Neurosciences 2018, 42(1):23-42.

19. Basbaum AI, Bautista DM, Scherrer G, Julius D: Cellular and molecular mechanisms of pain. Cell 2009, 139(2):267-284.

20. Millan MJ: Descending control of pain. Progress in Neurobiology 2002, 66(6):355-474.

21. Taniguchi W, Nakatsuka T, Miyazaki N, Yamada H, Takeda D, Fujita T, Kumamoto E, Yoshida M: In vivo patch-clamp analysis of dopaminergic antinociceptive actions on substantia gelatinosa neurons in the spinal cord. Pain 2011, 152(1):95-105.

22. Bissonette GB, Roesch MR: Development and function of the midbrain dopamine system: what we know and what we need to. Genes, brain, and behavior 2016, 15(1):62-73.

23. Taylor NE, Pei J, Zhang J, Vlasov KY, Davis T, Taylor E, Weng FJ, Van Dort CJ, Solt K, Brown EN: The Role of Glutamatergic and Dopaminergic Neurons in the Periaqueductal Gray/Dorsal Raphe: Separating Analgesia and Anxiety. eNeuro 2019, 6(1).

24. Mitsi V, Zachariou V: Modulation of pain, nociception, and analgesia by the brain reward center. Neuroscience 2016, 338:81-92.

25. Lu Y, Doroshenko M, Lauzadis J, Kanjiya MP, Rebecchi MJ, Kaczocha M, Puopolo M: Presynaptic Inhibition of Primary Nociceptive Signals to Dorsal Horn Lamina I Neurons by Dopamine. The Journal of Neuroscience 2018, 38(41):8809.

26. Neve KA, Seamans JK, Trantham-Davidson H: Dopamine Receptor Signaling. Journal of Receptors and Signal Transduction 2004, 24(3):165-205.

27. Zhu H, Clemens S, Sawchuk M, Hochman S: Expression and distribution of all dopamine receptor subtypes $(\mathrm{D}(1)-\mathrm{D}(5))$ in the mouse lumbar spinal cord: a real-time polymerase chain reaction and non-autoradiographic in situ hybridization study. Neuroscience 2007, 149(4):885-897.

28. Kaur J, Khararjian A, Coleman RA, Constantinescu CC, Pan ML, Mukherjee J: Spinal cord dopamine D2/D3 receptors: in vivo and ex vivo imaging in the rat using (18)F/(11)Cfallypride. Nuclear medicine and biology 2014, 41(10):841-847.

29. Zhu H, Clemens S, Sawchuk M, Hochman S: Unaltered D1, D2, D4, and D5 dopamine receptor mRNA expression and distribution in the spinal cord of the D3 receptor knockout mouse. Journal of comparative physiology A, Neuroethology, sensory, neural, and behavioral physiology 2008, 194(11):957-962.

30. Lindgren N, Usiello A, Goiny M, Haycock J, Erbs E, Greengard P, Hokfelt T, Borrelli E, Fisone G: Distinct roles of dopamine D2L and D2S receptor isoforms in the regulation of 
protein phosphorylation at presynaptic and postsynaptic sites. Proceedings of the National Academy of Sciences of the United States of America 2003, 100(7):4305-4309.

31. Beaulieu JM, Espinoza S, Gainetdinov RR: Dopamine receptors - IUPHAR Review 13. British journal of pharmacology 2015, 172(1):1-23.

32. De Mei C, Ramos M, Iitaka C, Borrelli E: Getting specialized: presynaptic and postsynaptic dopamine D2 receptors. Curr Opin Pharmacol 2009, 9(1):53-58.

33. Aira Z, Barrenetxea T, Buesa I, Martinez E, Azkue JJ: Spinal D1-like dopamine receptors modulate NMDA receptor-induced hyperexcitability and NR1 subunit phosphorylation at serine 889. Neurosci Lett 2016, 618:152-158.

34. Buesa I, Aira Z, Azkue JJ: Regulation of Nociceptive Plasticity Threshold and DARPP-32 Phosphorylation in Spinal Dorsal Horn Neurons by Convergent Dopamine and Glutamate Inputs. PLoS One 2016, 11(9):e0162416.

35. Samir S, Yllanes AP, Lallemand P, Brewer KL, Clemens S: Morphine responsiveness to thermal pain stimuli is aging-associated and mediated by dopamine D1 and D3 receptor interactions. Neuroscience 2017, 349:87-97.

36. Koblinger K, Füzesi T, Ejdrygiewicz J, Krajacic A, Bains JS, Whelan PJ: Characterization of A11 neurons projecting to the spinal cord of mice. PloS one 2014, 9(10):e109636.

37. Barraud Q, Obeid I, Aubert I, Barriere G, Contamin H, McGuire S, Ravenscroft P, Porras G, Tison F, Bezard E et al: Neuroanatomical study of the A11 diencephalospinal pathway in the non-human primate. PLoS One 2010, 5(10):e13306.

38. Pappas SS, Behrouz B, Janis KL, Goudreau JL, Lookingland KJ: Lack of D2 receptor mediated regulation of dopamine synthesis in A11 diencephalospinal neurons in male and female mice. Brain Res 2008, 1214:1-10.

39. Rojo ML, Rodríguez-Gaztelumendi A, Pazos Á, Díaz Á: Differential adaptive changes on serotonin and noradrenaline transporters in a rat model of peripheral neuropathic pain. Neuroscience Letters 2012, 515(2):181-186.

40. Hong J, Shu-Leong H, Tao X, Lap-Ping Y: Distribution of catechol-O-methyltransferase expression in human central nervous system. Neuroreport 1998, 9(12):2861-2864.

41. Roth BL, Lopez E, Patel S, Kroeze WK: The multiplicity of serotonin receptors: uselessly diverse molecules or an embarrassment of riches? The Neuroscientist 2000, 6(4):252-262.

42. Helmuth L: Netwatch. Science 2000, 287(5453):543-543.

43. Abdallah K, Monconduit L, Artola A, Luccarini P, Dallel R: GABAAergic inhibition or dopamine denervation of the A11 hypothalamic nucleus induces trigeminal analgesia. Pain 2015, 156(4):644-655.

44. Clemens S, Rye D, Hochman S: Restless legs syndrome: revisiting the dopamine hypothesis from the spinal cord perspective. Neurology 2006, 67(1):125-130.

45. Clemens S, Belin-Rauscent A, Simmers J, Combes D: Opposing modulatory effects of D1and D2-like receptor activation on a spinal central pattern generator. Journal of neurophysiology 2012, 107(8):2250-2259. 
46. Tamae A, Nakatsuka T, Koga K, Kato G, Furue H, Katafuchi T, Yoshimura M: Direct inhibition of substantia gelatinosa neurones in the rat spinal cord by activation of dopamine D2-like receptors. The Journal of Physiology 2005, 568(1):243-253.

47. Megat S, Shiers S, Moy JK, Barragan-Iglesias P, Pradhan G, Seal RP, Dussor G, Price TJ: A Critical Role for Dopamine D5 Receptors in Pain Chronicity in Male Mice.J Neurosci 2018, 38(2):379-397.

48. Meloto CB, Benavides R, Lichtenwalter RN, Wen X, Tugarinov N, Zorina-Lichtenwalter K, Chabot-Doré A-J, Piltonen MH, Cattaneo S, Verma V: The Human Pain Genetics Database (HPGDB): a resource dedicated to human pain genetics research. Pain 2017.

49. Pak DJ, Yong RJ, Kaye AD, Urman RD: Chronification of Pain: Mechanisms, Current Understanding, and Clinical Implications. Curr Pain Headache Rep 2018, 22(2):9.

50. Ren K, Dubner R: Interactions between the immune and nervous systems in pain. Nature medicine 2010, 16:1267.

51. Maguire MF, Latter JA, Mahajan R, Beggs FD, Duffy JP: A study exploring the role of intercostal nerve damage in chronic pain after thoracic surgery. European journal of cardiothoracic surgery : official journal of the European Association for Cardio-thoracic Surgery 2006, 29(6):873-879.

52. Chapman CR, Vierck CJ: The Transition of Acute Postoperative Pain to Chronic Pain: An Integrative Overview of Research on Mechanisms. The Journal of Pain 2017, 18(4):359.e351359.e338.

53. Huang Q: Genetic study of complex diseases in the post-GWAS era. Journal of genetics and genomics = Yi chuan $x$ ue bao 2015, 42(3):87-98.

54. James SK: Chronic postsurgical pain: is there a possible genetic link? British journal of pain 2017, 11(4):178-185.

55. Qadri YJ, Bortsov AV, Orrey DC, Swor RA, Peak DA, Jones JS, Rathlev NK, Lee DC, Domeier RM, Hendry PL et al: Genetic Polymorphisms in the Dopamine Receptor 2 Predict Acute Pain Severity after Motor Vehicle Collision. The Clinical journal of pain 2014:10.1097/AJP.0000000000000167.

56. Foulkes T, Wood JN: Pain genes. PLoS genetics 2008, 4(7):e1000086.

57. De Gregori M, Diatchenko L, Ingelmo PM, Napolioni V, Klepstad P, Belfer I, Molinaro V, Garbin G, Ranzani GN, Alberio G et al: Human Genetic Variability Contributes to Postoperative Morphine Consumption. The Journal of Pain 2016, 17(5):628-636.

58. Zorina-Lichtenwalter K, Meloto CB, Khoury S, Diatchenko L: Genetic predictors of human chronic pain conditions. Neuroscience 2016.

59. Diatchenko L, Nackley AG, Slade GD, Bhalang K, Belfer I, Max MB, Goldman D, Maixner W: Catechol-O-methyltransferase gene polymorphisms are associated with multiple painevoking stimuli. Pain 2006, 125(3):216-224.

60. Diatchenko L, Slade GD, Nackley AG, Bhalang K, Sigurdsson A, Belfer I, Goldman D, Xu $\mathrm{K}$, Shabalina SA, Shagin D et al: Genetic basis for individual variations in pain perception and the development of a chronic pain condition. Human molecular genetics 2005, 14(1):135-143. 
61. Meloto CB, Segall SK, Smith S, Parisien M, Shabalina SA, Rizzatti-Barbosa CM, Gauthier J, Tsao D, Convertino M, Piltonen MH et al: COMT gene locus: new functional variants. Pain 2015, 156(10):2072-2083.

62. Kambur O, Kaunisto MA, Tikkanen E, Leal SM, Ripatti S, Kalso EA: Effect of catechol-omethyltransferase-gene (COMT) variants on experimental and acute postoperative pain in 1,000 women undergoing surgery for breast cancer. Anesthesiology 2013, 119(6):1422-1433.

63. Jensen KB, Lonsdorf TB, Schalling M, Kosek E, Ingvar M: Increased Sensitivity to Thermal Pain Following a Single Opiate Dose Is Influenced by the COMT val158met Polymorphism. PLOS ONE 2009, 4(6):e6016.

64. Smith SB, Reenilä I, Männistö PT, Slade GD, Maixner W, Diatchenko L, Nackley AG: Epistasis between polymorphisms in COMT, ESR1, and GCH1 influences COMT enzyme activity and pain. PAIN® 2014, 155(11):2390-2399.

65. Loggia ML, Jensen K, Gollub RL, Wasan AD, Edwards RR, Kong J: The Catechol-OMethyltransferase (COMT) val158met Polymorphism Affects Brain Responses to Repeated Painful Stimuli. PLOS ONE 2011, 6(11):e27764.

66. Finan PH, Zautra AJ, Davis MC, Lemery-Chalfant K, Covault J, Tennen H: COMT moderates the relation of daily maladaptive coping and pain in fibromyalgia. PAIN® 2011, 152(2):300-307.

67. Kim H, Neubert JK, San Miguel A, Xu K, Krishnaraju RK, Iadarola MJ, Goldman D, Dionne RA: Genetic influence on variability in human acute experimental pain sensitivity associated with gender, ethnicity and psychological temperament. Pain 2004, 109(3):488496.

68. Mobascher A, Brinkmeyer J, Thiele H, Toliat MR, Steffens M, Warbrick T, Musso F, Wittsack HJ, Saleh A, Schnitzler A et al: The val158met polymorphism of human catecholO-methyltransferase (COMT) affects anterior cingulate cortex activation in response to painful laser stimulation. Mol Pain 2010, 6:32.

69. Desmeules J, Chabert J, Rebsamen M, Rapiti E, Piguet V, Besson M, Dayer P, Cedraschi C: Central pain sensitization, COMT Val158Met polymorphism, and emotional factors in fibromyalgia.J Pain 2014, 15(2):129-135.

70. Kim H, Mittal DP, Iadarola MJ, Dionne RA: Genetic predictors for acute experimental cold and heat pain sensitivity in humans. J Med Genet 2006, 43(8):e40.

71. Nackley AG, Shabalina SA, Tchivileva IE, Satterfield K, Korchynskyi O, Makarov SS, Maixner W, Diatchenko L: Human Catechol-O-Methyltransferase Haplotypes Modulate Protein Expression by Altering mRNA Secondary Structure. Science 2006, 314(5807):19301933.

72. Rakvag TT, Klepstad P, Baar C, Kvam TM, Dale O, Kaasa S, Krokan HE, Skorpen F: The Val158Met polymorphism of the human catechol-O-methyltransferase (COMT) gene may influence morphine requirements in cancer pain patients. Pain 2005, 116(1-2):73-78.

73. Zubieta J-K, Heitzeg MM, Smith YR, Bueller JA, Xu K, Xu Y, Koeppe RA, Stohler CS, Goldman D: COMT val158met genotype affects $\mu$-opioid neurotransmitter responses to a pain stressor. Science 2003, 299(5610):1240-1243. 
74. Latremoliere A, Costigan M: GCH1, BH4 and Pain. Current pharmaceutical biotechnology 2011, 12(10):1728-1741.

75. Campbell CM, Edwards RR, Carmona C, Uhart M, Wand G, Carteret A, Kim YK, Frost J, Campbell JN: Polymorphisms in the GTP cyclohydrolase gene (GCH1) are associated with ratings of capsaicin pain. Pain 2009, 141(1-2):114-118.

76. Lotsch J, Belfer I, Kirchhof A, Mishra BK, Max MB, Doehring A, Costigan M, Woolf CJ, Geisslinger G, Tegeder I: Reliable screening for a pain-protective haplotype in the GTP cyclohydrolase 1 gene (GCH1) through the use of 3 or fewer single nucleotide polymorphisms. Clin Chem 2007, 53(6):1010-1015.

77. Costigan M, Latremoliere A, Woolf CJ: Analgesia by inhibiting tetrahydobiopterin synthesis. Current Opinion in Pharmacology 2012, 12(1):92-99.

78. Bjorklund T, Hall H, Breysse N, Soneson C, Carlsson T, Mandel RJ, Carta M, Kirik D: Optimization of continuous in vivo DOPA production and studies on ectopic DA synthesis using rAAV5 vectors in Parkinsonian rats. J Neurochem 2009, 111(2):355-367.

79. Nicholl BI, Holliday KL, Macfarlane GJ, Thomson W, Davies KA, O'neill TW, Bartfai G, Boonen S, Casanueva F, Finn JD: No evidence for a role of the catechol-Omethyltransferase pain sensitivity haplotypes in chronic widespread pain. Annals of the rheumatic diseases 2010, 69(11):2009-2012.

80. Forsberg JT, Gjerstad J, Flaten MA, Aslaksen PM: Influence of catechol-o-methyltransferase Val158Met on fear of pain and placebo analgesia. Pain 2017.

81. Jhun E, He Y, Yao Y, Molokie RE, Wilkie DJ, Wang ZJ: Dopamine D3 receptor Ser9Gly and catechol-o-methyltransferase Val158Met polymorphisms and acute pain in sickle cell disease. Anesth Analg 2014, 119(5):1201-1207.

82. Storm H, Stoen R, Klepstad P, Skorpen F, Qvigstad E, Raeder J: Nociceptive stimuli responses at different levels of general anaesthesia and genetic variability. Acta Anaesthesiol Scand 2013, 57(1):89-99.

83. Hirvonen Mika M, Laakso A, Någren K, Rinne Juha O, Pohjalainen T, Hietala J: C957T polymorphism of dopamine $\mathrm{D} 2$ receptor gene affects striatal DRD2 in vivo availability by changing the receptor affinity. Synapse 2009, 63(10):907-912.

84. Duan J, Wainwright MS, Comeron JM, Saitou N, Sanders AR, Gelernter J, Gejman PV: Synonymous mutations in the human dopamine receptor D2 (DRD2) affect mRNA stability and synthesis of the receptor. Human molecular genetics 2003, 12(3):205-216.

85. Smith CT, Dang LC, Buckholtz JW, Tetreault AM, Cowan RL, Kessler RM, Zald DH: The impact of common dopamine D2 receptor gene polymorphisms on D2/3 receptor availability: C957T as a key determinant in putamen and ventral striatum. Translational psychiatry 2017, 7:e1091.

86. Jaaskelainen SK, Lindholm P, Valmunen T, Pesonen U, Taiminen T, Virtanen A, Lamusuo $\mathrm{S}$, Forssell H, Hagelberg N, Hietala J et al: Variation in the dopamine D2 receptor gene plays a key role in human pain and its modulation by transcranial magnetic stimulation. Pain 2014, 155(10):2180-2187. 
87. Potvin S, Grignon S, Marchand S: Human evidence of a supra-spinal modulating role of dopamine on pain perception. Synapse 2009, 63(5):390-402.

88. Hirvonen MM, Lumme V, Hirvonen J, Pesonen U, Någren K, Vahlberg T, Scheinin H, Hietala J: C957T polymorphism of the human dopamine D2 receptor gene predicts extrastriatal dopamine receptor availability in vivo. Progress in Neuro-Psychopharmacology and Biological Psychiatry 2009, 33(4):630-636.

89. Rut M, Machoy-Mokrzynska A, Reclawowicz D, Sloniewski P, Kurzawski M, Drozdzik M, Safranow K, Morawska M, Bialecka M: Influence of variation in the catechol-Omethyltransferase gene on the clinical outcome after lumbar spine surgery for one-level symptomatic disc disease: a report on 176 cases. Acta Neurochir (Wien) 2014, 156(2):245252.

90. Kolesnikov Y, Gabovits B, Levin A, Voiko E, Veske A: Combined catechol-Omethyltransferase and $\mu$-opioid receptor gene polymorphisms affect morphine postoperative analgesia and central side effects. Anesthesia \& Analgesia 2011, 112(2):448453.

91. Candiotti KA, Yang Z, Buric D, Arheart K, Zhang Y, Rodriguez Y, Gitlin MC, Carvalho E, Jaraba I, Wang L: Catechol-o-methyltransferase polymorphisms predict opioid consumption in postoperative pain. Anesthesia \& Analgesia 2014, 119(5):1194-1200.

92. Belfer I, Dai F, Kehlet H, Finelli P, Qin L, Bittner R, Aasvang EK: Association of functional variations in COMT and GCH1 genes with postherniotomy pain and related impairment. Pain 2015, 156(2):273-279.

93. Lee PJ, Delaney P, Keogh J, Sleeman D, Shorten GD: Catecholamine-o-methyltransferase polymorphisms are associated with postoperative pain intensity. The Clinical journal of pain 2011, 27(2):93-101.

94. Reyes-Gibby CC, Shete S, Rakvag T, Bhat SV, Skorpen F, Bruera E, Kaasa S, Klepstad P: Exploring joint effects of genes and the clinical efficacy of morphine for cancer pain: OPRM1 and COMT gene. Pain 2007, 130(1-2):25-30.

95. Rakvag TT, Ross JR, Sato H, Skorpen F, Kaasa S, Klepstad P: Genetic variation in the catechol-O-methyltransferase (COMT) gene and morphine requirements in cancer patients with pain. Mol Pain 2008, 4:64.

96. Sadhasivam S, Chidambaran V, Olbrecht VA, Esslinger HR, Zhang K, Zhang X, Martin LJ: Genetics of pain perception, COMT and postoperative pain management in children. Pharmacogenomics 2014, 15(3):277-284.

97. Nielsen LM, Christrup LL, Sato H, Drewes AM, Olesen AE: Genetic Influences of OPRM1, OPRD1 and COMT on Morphine Analgesia in a Multi-Modal, Multi-Tissue Human Experimental Pain Model. Basic \& clinical pharmacology \& toxicology 2017, 121(1):6-12.

98. Tan E, Lim E, Ocampo C, Allen J, Sng B, Sia A: Common variants of catechol-Omethyltransferase influence patient-controlled analgesia usage and postoperative pain in patients undergoing total hysterectomy. The pharmacogenomics journal 2016, 16(2):186-192.

99. Dai F, Belfer I, Schwartz CE, Banco R, Martha JF, Tighioughart H, Tromanhauser SG, Jenis LG, Kim DH: Association of catechol-O-methyltransferase genetic variants with outcome 
in patients undergoing surgical treatment for lumbar degenerative disc disease. The Spine Journal 2010, 10(11):949-957.

100. Montes A, Roca G, Sabate S, Lao JI, Navarro A, Cantillo J, Canet J, Group GS: Genetic and Clinical Factors Associated with Chronic Postsurgical Pain after Hernia Repair, Hysterectomy, and Thoracotomy: A Two-year Multicenter Cohort Study. Anesthesiology 2015, 122(5):1123-1141.

101. Dimova V, Lötsch J, Hühne K, Winterpacht A, Heesen M, Parthum A, Weber PG, Carbon R, Griessinger N, Sittl R: Association of genetic and psychological factors with persistent pain after cosmetic thoracic surgery. Journal of pain research 2015, 8:829.

102. Thomazeau J, Rouquette A, Martinez V, Rabuel C, Prince N, Laplanche JL, Nizard R, Bergmann JF, Perrot S, Lloret-Linares C: Predictive Factors of Chronic Post-Surgical Pain at 6 Months Following Knee Replacement: Influence of Postoperative Pain Trajectory and Genetics. Pain Physician 2016, 19(5):E729-741.

103. Thomazeau J, Rouquette A, Martinez V, Rabuel C, Prince N, Laplanche J, Nizard R, Bergmann J, Perrot S, Lloret-Linares C: Acute pain Factors predictive of post-operative pain and opioid requirement in multimodal analgesia following knee replacement. European Journal of Pain 2015.

104. Henker RA, Lewis A, Dai F, Lariviere WR, Meng L, Gruen GS, Sereika SM, Pape H, Tarkin IS, Gowda I et al: The associations between OPRM 1 and COMT genotypes and postoperative pain, opioid use, and opioid-induced sedation. Biological research for nursing 2013, 15(3):309-317.

105. Kolesnikov Y, Gabovits B, Levin A, Veske A, Qin L, Dai F, Belfer I: Chronic pain after lower abdominal surgery: do catechol-O-methyl transferase/opioid receptor $\boldsymbol{\mu}-1$ polymorphisms contribute? Mol Pain 2013, 9:19.

106. Matsuoka H, Makimura C, Koyama A, Fujita Y, Tsurutani J, Sakai K, Sakamoto R, Nishio K, Nakagawa K: Prospective replication study implicates the catechol-O-methyltransferase $\mathrm{Val}(158)$ Met polymorphism as a biomarker for the response to morphine in patients with cancer. Biomedical reports 2017, 7(4):380-384.

107. Hickey OT, Nugent NF, Burke SM, Hafeez P, Mudrakouski AL, Shorten GD: Persistent pain after mastectomy with reconstruction. Journal of clinical anesthesia 2011, 23(6):482488.

108. George SZ, Wallace MR, Wright TW, Moser MW, Greenfield WH, 3rd, Sack BK, Herbstman DM, Fillingim RB: Evidence for a biopsychosocial influence on shoulder pain: pain catastrophizing and catechol-O-methyltransferase (COMT) diplotype predict clinical pain ratings. Pain 2008, 136(1-2):53-61.

109. Tegeder I, Adolph J, Schmidt H, Woolf CJ, Geisslinger G, Lötsch J: Reduced hyperalgesia in homozygous carriers of a GTP cyclohydrolase 1 haplotype. European Journal of Pain 2008, 12(8):1069-1077.

110. Tegeder I, Costigan M, Griffin RS, Abele A, Belfer I, Schmidt H, Ehnert C, Nejim J, Marian C, Scholz J et al: GTP cyclohydrolase and tetrahydrobiopterin regulate pain sensitivity and persistence. Nature medicine 2006, 12(11):1269-1277. 
111. George SZ, Parr J, Wallace MR, Wu S, Borsa P, Dai Y, Fillingim RB: Biopsychosocial influence on exercise-induced injury: genetic and psychological combinations are predictive of shoulder pain phenotypes. The Journal of Pain 2014, 15(1):68-80.

112. Zarrindast MR, Asgari-Afshar A, Sahebgharani M: Morphine-induced antinociception in the formalin test: sensitization and interactions with D1 and D2 dopamine receptors and nitric oxide agents. Behavioural pharmacology 2007, 18(3):177-184.

113. Pappas SS, Kennedy T, Goudreau JL, Lookingland KJ: Opioid-mediated regulation of A11 diencephalospinal dopamine neurons: pharmacological evidence of activation by morphine. Neuropharmacology 2011, 61(4):614-621.

114. Dai WL, Xiong F, Yan B, Cao ZY, Liu WT, Liu JH, Yu BY: Blockade of neuronal dopamine D2 receptor attenuates morphine tolerance in mice spinal cord. Scientific reports 2016, 6:38746.

115. Almeida-Santos AF, Ferreira RC, Duarte ID, Aguiar DC, Romero TR, Moreira FA: The antipsychotic aripiprazole induces antinociceptive effects: Possible role of peripheral dopamine D2 and serotonin 5-HT1A receptors. Eur J Pharmacol 2015, 765:300-306.

116. Katyal J, Gupta YK: Dopamine release is involved in antinociceptive effect of theophylline. The International journal of neuroscience 2012, 122(1):17-21.

117. Chen M, Hoshino H, Saito S, Yang Y, Obata H: Spinal dopaminergic involvement in the antihyperalgesic effect of antidepressants in a rat model of neuropathic pain. Neuroscience Letters 2017, 649(Supplement C):116-123.

118. Katz J, Pennella-Vaughan J, Hetzel RD, Kanazi GE, Dworkin RH: A randomized, placebocontrolled trial of bupropion sustained release in chronic low back pain. The Journal of Pain 2005, 6(10):656-661.

119. Hoshino H, Obata H, Nakajima K, Mieda R, Saito S: The antihyperalgesic effects of intrathecal bupropion, a dopamine and noradrenaline reuptake inhibitor, in a rat model of neuropathic pain. Anesthesia \& Analgesia 2015, 120(2):460-466.

120. Rosenberg MB, Carroll FI, Negus SS: Effects of monoamine reuptake inhibitors in assays of acute pain-stimulated and pain-depressed behavior in rats. The Journal of Pain 2013, 14(3):246-259.

121. Brefel-Courbon C, Payoux P, Thalamas C, Ory F, Quelven I, Chollet F, Montastruc JL, Rascol O: Effect of levodopa on pain threshold in Parkinson's disease: A clinical and positron emission tomography study. Movement Disorders 2005, 20(12):1557-1563.

122. Cobacho N, de la Calle JL, Paino CL: Dopaminergic modulation of neuropathic pain: analgesia in rats by a D2-type receptor agonist. Brain Res Bull 2014, 106:62-71.

123. Yang HW, Zhou LJ, Hu NW, Xin WJ, Liu XG: Activation of spinal d1/d5 receptors induces late-phase LTP of C-fiber-evoked field potentials in rat spinal dorsal horn. Journal of neurophysiology 2005, 94(2):961-967.

124. Dethy S, Laute MA, Togasaki DM, Przedborski S, Damhaut P, Thiry P, Hildebrand J, Goldman S: Systemic and intrastriatal theophylline have opposite effects on dopamine and dopamine metabolites measured by intrastriatal microdialysis in the rat. Neurosci Lett 1996, 208(3):159-162. 
125. Semenchuk MR, Sherman S, Davis B: Double-blind, randomized trial of bupropion SR for the treatment of neuropathic pain. Neurology 2001, 57(9):1583-1588.

126. Semenchuk MR, Davis B: Efficacy of sustained-release bupropion in neuropathic pain: an open-label study. Clin J Pain 2000, 16(1):6-11.

127. Edwards RR, Quartana PJ, Allen RP, Greenbaum S, Earley CJ, Smith MT: Alterations in pain responses in treated and untreated patients with restless legs syndrome: associations with sleep disruption. Sleep medicine 2011, 12(6):603-609.

128. Goulart LI, Rodrigues RND, Peres MFP: Restless Legs Syndrome and Pain Disorders: What's in common? Current pain and headache reports 2014, 18(11):461.

129. Stiasny-Kolster K, Magerl W, Oertel W, Möller J, Treede RD: Static mechanical hyperalgesia without dynamic tactile allodynia in patients with restless legs syndrome. Brain : a journal of neurology 2004, 127(4):773-782.

130. Stiasny-Kolster K, Pfau DB, Oertel WH, Treede R-D, Magerl W: Hyperalgesia and functional sensory loss in restless legs syndrome. PAIN® 2013, 154(8):1457-1463.

131. Hornyak M, Sohr M, Busse M: Evaluation of painful sensory symptoms in restless legs syndrome: experience from two clinical trials. Sleep medicine 2011, 12(2):186-189.

132. Ferini-Strambi L, Marelli S: Pharmacotherapy for restless legs syndrome. Expert opinion on pharmacotherapy 2014, 15(8):1127-1138.

133. Millan MJ, Maiofiss L, Cussac D, Audinot V, Boutin J-A, Newman-Tancredi A: Differential Actions of Antiparkinson Agents at Multiple Classes of Monoaminergic Receptor. I. A Multivariate Analysis of the Binding Profiles of 14 Drugs at 21 Native and Cloned Human Receptor Subtypes. Journal of Pharmacology and Experimental Therapeutics 2002, 303(2):791804.

134. Chaudhuri KR, Schapira AH: Non-motor symptoms of Parkinson's disease: dopaminergic pathophysiology and treatment. The Lancet Neurology 2009, 8(5):464-474.

135. Cury R, Galhardoni R, Fonoff E, Pérez Lloret S, Dos Santos Ghilardi M, Barbosa E, Teixeira M, Ciampi de Andrade D: Sensory abnormalities and pain in Parkinson disease and its modulation by treatment of motor symptoms. European journal of pain 2016, 20(2):151165.

136. Schestatsky P, Kumru H, Valls-Solé J, Valldeoriola F, Marti MJ, Tolosa E, Chaves ML: Neurophysiologic study of central pain in patients with Parkinson disease. Neurology 2007, 69(23):2162-2169.

137. Marques A, Chassin O, Morand D, Pereira B, Debilly B, Derost P, Ulla M, Lemaire JJ, Durif F: Central pain modulation after subthalamic nucleus stimulation. A crossover randomized trial 2013, 81(7):633-640.

138. Salat D, Tolosa E: Levodopa in the treatment of Parkinson's disease: current status and new developments. Journal of Parkinson's disease 2013, 3(3):255-269.

139. Grashorn W, Schunke O, Buhmann C, Forkmann K, Diedrich S, Wesemann K, Bingel U: Influence of dopaminergic medication on conditioned pain modulation in Parkinson's disease patients. PloS one 2015, 10(8):e0135287. 
140. Vela L, Cano-de-la-Cuerda R, Fil A, Muñoz-Hellín E, Ortíz-Gutiérrez R, Macías-Macías Y, Fernández-de-las-Peñas C: Thermal and mechanical pain thresholds in patients with fluctuating Parkinson's disease. Parkinsonism \& related disorders 2012, 18(8):953-957.

141. Dellapina E, Gerdelat-Mas A, Ory-Magne F, Pourcel L, Galitzky M, Calvas F, SimonettaMoreau M, Thalamas C, Payoux P, Brefel-Courbon C: Apomorphine effect on pain threshold in Parkinson's disease: A clinical and positron emission tomography study. Movement Disorders 2011, 26(1):153-157.

142. Kim J-YV, Tillu DV, Quinn TL, Mejia GL, Shy A, Asiedu MN, Murad E, Schumann AP, Totsch SK, Sorge RE: Spinal dopaminergic projections control the transition to pathological pain plasticity via a D1/D5-mediated mechanism. The Journal of Neuroscience 2015, 35(16):6307-6317.

143. Kim JY, Megat S, Moy JK, Asiedu MN, Mejia GL, Vagner J, Price TJ: Neuroligin 2 regulates spinal GABAergic plasticity in hyperalgesic priming, a model of the transition from acute to chronic pain. Pain 2016, 157(6):1314-1324.

144. Chaparro LE, Smith SA, Moore RA, Wiffen PJ, Gilron I: Pharmacotherapy for the prevention of chronic pain after surgery in adults. The Cochrane database of systematic reviews 2013(7):Cd008307.

145. Eijkenboom I, Sopacua M, Otten ABC, Gerrits MM, Hoeijmakers JGJ, Waxman SG, Lombardi R, Lauria G, Merkies ISJ, Smeets HJM et al: Expression of pathogenic SCN9A mutations in the zebrafish: A model to study small fiber neuropathy. Experimental Neurology 2018, 311:257-264.

146. Lopez-Luna J, Al-Jubouri Q, Al-Nuaimy W, Sneddon LU: Impact of analgesic drugs on the behavioural responses of larval zebrafish to potentially noxious temperatures. Applied Animal Behaviour Science 2017, 188:97-105.

147. Ellis LD, Berrue F, Morash M, Achenbach JC, Hill J, McDougall JJ: Comparison of cannabinoids with known analgesics using a novel high throughput zebrafish larval model of nociception. Behav Brain Res 2018, 337:151-159.

148. Curtright A, Rosser M, Goh S, Keown B, Wagner E, Sharifi J, Raible DW, Dhaka A: Modeling nociception in zebrafish: a way forward for unbiased analgesic discovery. PloS one 2015, 10(1):e0116766.

149. Cui G, Xin Q, Tseng HHL, Hoi MP, Wang Y, Yang B, Choi I, Wang Y, Yuan R, Chen Ket al: A novel $\mathrm{Ca}+$ current blocker promotes angiogenesis and cardiac healing after experimental myocardial infarction in mice. Pharmacological Research 2018, 134:109-117.

150. Hoofwijk DMN, van Reij RRI, Rutten BPF, Kenis G, Theunissen M, Joosten EA, Buhre WF, van den Hoogen NJ: Genetic polymorphisms and prediction of chronic post-surgical pain after hysterectomy-a subgroup analysis of a multicenter cohort study. Acta Anaesthesiol Scand 2019, 63(8):1063-1073. 
62|C hapter 2 
CHAPTER 3

\section{The association between genome-wide polymorphisms and chronic postoperative pain: a prospective observational study}

R. R. I. van Reij, D. M. N. Hoofwijk, B. P. F. Rutten, L. Weinhold, M. Leber, E. A. J. Joosten, A. Ramirez, N. J. van den Hoogen, on behalf of the Italian Pain Group

Anaesthesia 2020, 75 Suppl 1:e111-e120.

PMID 31903573, Doi:10.1111/anae.14832

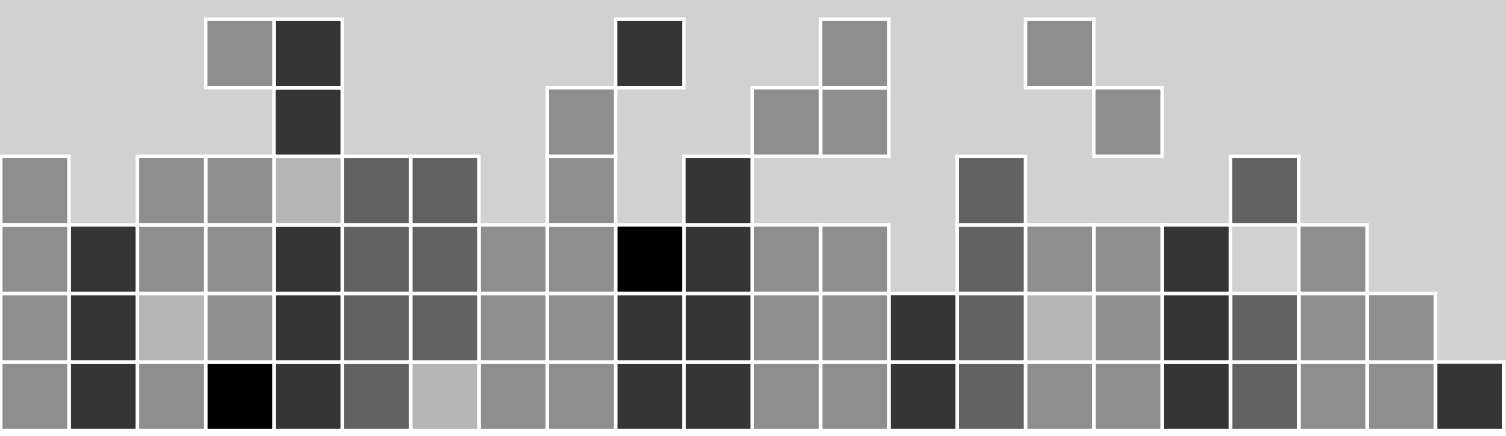


$64 \mid \mathrm{C}$ h a pter 3 


\section{Summary}

Chronic Post-Surgical Pain (CPSP) is common and can have a negative impact on quality of life. Recent studies show that genetic risk factors are likely to play a role, although only gene targeted analysis has been used to date. This is the first Genome-Wide Association Study (GWAS) to identify Single Nucleotide Polymorphisms (SNPs) associated with the development of CPSP based on two independent cohorts. In a discovery cohort, 330 women scheduled for hysterectomy were genotyped. A case-control association analysis compared patients without CPSP and the thirty four who had severe CPSP three months after surgery. No SNPs reached genome-wide significance, but several showed suggestive associations with CPSP $\left(\mathrm{P}<1 \times 10^{-5}\right)$. SNPs with significance $\mathrm{P}<1 \times 10^{-5}$ were followed up in a replication cohort consisting of 203 men and women scheduled for orthopaedic or abdominal surgery. Ten of these patients developed severe CPSP. A SNP in NAV3 was significantly replicated with CPSP in the replication cohort ( $\mathrm{p}=0.009$ ) with a trend towards statistical significance for $R S U 1$ $(\mathrm{p}=0.07)$. Meta-analysis revealed that two loci (IQGAP1 and CRTC3) were significantly associated with CPSP at three months (IQGAP1 $\mathrm{p}=3.93 \times 10^{-6}$ $\beta=2.3863$, CRTC3 $p=2.26 \times 10^{-6}, \beta=2.4209$ ). The present GWAS provides initial evidence for genetic risk factors of CPSP and supports follow-up studies.

Keywords: Chronic pain; genome-wide association study; risk factors 


\section{Introduction}

Moderate to severe Chronic Post-Surgical Pain (CPSP) is a debilitating condition affecting between 5 and $85 \%$ of patients undergoing surgery and has a large negative impact on the quality of life (QoL) and socioeconomic status [1-3]. It is defined as "pain developed or increased after a surgical procedure, which is present for at least three months, and affecting the QoL” $[4,5]$. Furthermore, the pain is localized to the surgical field or projected innervation area of a nerve and other causes for the pain must have been excluded [4, 6]. Both clinical (e.g. type of surgery) and demographic (e.g. psychosocial status) risk factors have been described but these do not explain all the observed variance. So far, a good understanding of genetic risk factors for CPSP is still lacking $[1,7]$.

The underlying biology of CPSP and genetic heritability is complex and not yet fully understood [8]. However, twin studies in pelvic and low back pain have indicated the importance of genetics in chronic pain phenotypes with an estimated heritability of 40\% [9, 10]. Association studies focusing on candidate genes have suggested a possible role for COMT, GCH1, and KCNS1 among others [11-13], but a recent systematic review showed conflicting results for all the genes tested [14]. We tried to identify genetic polymorphisms in the human genome associated with CPSP three months after surgery by performing a genome-wide association study (GWAS) using a unique discovery CPSP cohort of patients undergoing hysterectomy [15]. The advantage of this cohort is the homogenous population consisting of only women (age 18-65, malignancies excluded) [16, 17]. Promising candidates were then further explored in a replication cohort of orthopaedic and abdominal surgeries to verify our findings. Combining different clinical cohorts leads to the identification of genetic risk factors associated with CPSP in general and each individual cohort gives information on surgery specific risk factors, as shown before in migraine research [18]. A meta-analysis of the 
discovery and the replication cohort was conducted to investigate the combined effects of both studies.

\section{Methods}

This study was approved by our local Medical Ethical Committee (both discovery and replication study) and all participants gave written informed consent.

An elaborate description of recruitment and data collection protocols for the discovery cohort has been published elsewhere [15]. In brief, a multicentre prospective cohort study was conducted, recruiting patients from four hospitals in the Netherlands. Patients undergoing hysterectomy for benign indications between September 2010 and January 2014 were included in the study. Inclusion criteria were: age between 18 and 65 y; fluency in the Dutch language; elective surgery; and total or subtotal hysterectomy with or without oophorectomy using all types of surgical approach. Exclusion criteria consisted of: illiteracy; history of cancer; and cognitive impairment. Furthermore, patients who reported a malignancy or underwent another surgical procedure during the first postoperative year were not analysed. Peripheral blood samples were collected before hysterectomy and genomic DNA was isolated at the clinical genetics department of Maastricht University Medical Center.

For the replication study, two multicentre prospective cohort studies were conducted recruiting patients from three hospitals in Italy. In both studies, peripheral blood samples were collected during surgery and genomic DNA was isolated. Inclusion criteria of the orthopaedic cohort consisted of adult patients of all sexes undergoing total knee arthroplasty with ASA physical status 1-3. All patients enrolled had the same regional anaesthesia procedure in order to reduce any bias related to anaesthesia treatment and difference in intra-operative pain. Patients were excluded if there were contra-indications to regional anaesthesia, 
unstable neurological diseases, diabetes or pre-surgical pain and if regional anaesthesia block was not effective.

The protocol of the abdominal surgery trial has been already published [19]. Inclusion of the abdominal surgery cohort comprised adult patients of all sexes scheduled for major abdominal or urological surgery without regional anaesthesia, ASA physical status 1-3 and HIV negative. Exclusion criteria consisted of: previous regular use of opioids; history of alcohol/drug abuse; postoperative hospitalisation with sedation/ventilation; severe renal or hepatic impairment; cardiac, neurological and cognitive disorders; abnormal coagulation; low platelet count; BMI $>30 \mathrm{~kg} \cdot \mathrm{m}^{-2}$, allergy to the drugs studied, diabetes and presurgical pain.

Samples were genotyped at the Department of Genomics at the Life and Brain Center, University of Bonn using the Illumina PsychArray (Infinium PsychArray24 v1.2 Bead Chip, Illumina Inc., San Diego, (CA, USA)) which contains enrichment in genetic variants associated with psychiatric conditions. A strong psychological component is present in pain and several genes in psychiatric disorders have been associated with chronic postoperative pain as well as identified through the Pain Genes database (e.g. COMT and OPRM1) [20-22]. Psychological predictors are an important risk factor for chronic postoperative pain $[15,23,24]$. We believe this approach offers greater potential to identify genetic variants with phenotypic effects in chronic postoperative pain. The array includes 265,000 proven tag single-nucleotide polymorphisms (SNPs) found on the Infinium Core-24 Bead Chip, 245,000 markers from the Infinium Exome-24 Bead Chip and 50,000 additional markers associated with common psychiatric disorders.

Genotypes were called using BeadStudio (Genome Studio v2011.1, Illumina San Diego (CA, USA)). Basic quality control was done using Plink (Plink-1.9) [25, 26]. The quality control parameters consisted of: SNP call rate $<0.95$; subject call rate 
of $<0.95$; deviation of Hardy-Weinberg equilibrium $\left(\mathrm{p}<1 \times 10^{-6}\right)$; and removal of rare variants with a minor allele frequency $<0.01$. Heterozygosity of the subjects was tested and outliers ( \pm 3 SD from the mean heterozygosity rate) were removed (see also Supporting Information Fig. S1). No relatedness and sex inconsistencies were found within our cohort. After basic quality control, all AT or CG SNPs were removed from the SNP set. After these control steps, the SNPs were pruned to remove SNPs in linkage disequilibrium $\left(\mathrm{R}^{2}>0.2\right)$, principal components analysis was performed using the Aberrant Package in $\mathrm{R}$, and the first two principal components were analysed for outliers. Together with the principal component analysis, the ancestry and ethnicity of the subjects was determined using HapMap data (as described by ENIGMA) (Fig. 2) [27]. After quality control, the data were prepared for imputation by checking for flipped strands, allele assignments and position of SNPs and converted into variant call format files.

Genotype imputation was performed using the imputation stepwise approach implemented in Minimac3 (https:/genome.sph.umich.edu/wiki/Minimac3, University of Michigan, Ann Arbor, MI, USA) and Eagle2 (https://data.broadinstitute.org/alkesgroup/Eagle, v2.3, Broad Institute, Cambridge, MA, USA) using default parameters with European HRC reference panel (http://www.haplotype-reference-consortium.org, version r1.1 2016) [2830]. Quality control on the imputed dataset was performed with the following parameters: genotype probability $>0.9$, imputation accuracy $>0.5$, INFO-score $>$ 0.4 and minor allele frequency and genotyping rate was checked again. Regional association plots were made to see the linkage disequilibrium of the significantly associated SNPs and their association with chronic postoperative pain using Locuszoom (http://locuszoom.org, University of Michigan, Ann Arbor, MI, USA) [31].

The primary outcome measured in this cohort was the highest surgery-related pain score at rest during the last week at 3 months after surgery measured by the 
numeric rating scale (NRS) [15]. Based on the primary outcome measure, patients were divided into a non-pain (NRS $=0)$ and a chronic postoperative pain (NRS > 3 ) group to perform an extreme phenotype analysis to increase the power. Patients with mild pain (NRS between 1 and 3) score were not included in the genetic analysis. The gene dosages were tested for an association with chronic postoperative pain using an additive logistic regression model. To decrease falsepositives, the maximum threshold of $\lambda$ was set at 1.08 [32]. Genome-wide significance was set at $\mathrm{p}<5 \times 10^{-8}$ and the analysis was run using SNPTEST (https://mathgen.stats.ox.ac.uk/genetics_software/snptest/snptest.html, v2.5.4, Oxford University, Oxford, UK) [32, 33]. Single-nucleotide polymorphisms with a p value $<1 \times 10^{-5}$ were selected as suggestive association SNPs for replication [34]. The same statistical tests were used for the discovery and the replication cohort. Next, the discovery and the replication cohort's association SNP results were used to perform a random-effects meta-analysis in Plink. As the study design of the two cohorts was different, and some covariates (e.g. age) differed significantly between the cohorts, we chose to perform a random-effects meta-analysis. Bonferroni correction was applied to account for multiple testing.

Power calculation for this study was conducted and based on the primary aim of the study and not for the genetic testing, which was a secondary aim. Therefore, this study is underpowered for a genome-wide analysis study and, as a consequence, there is a risk of a type- 1 error which should be taken into account when interpreting the results [15]. 
Elective hysterectomy patients $n=1595$ (MUMC+ 342, CzE 533, MMC 510, OMC210)

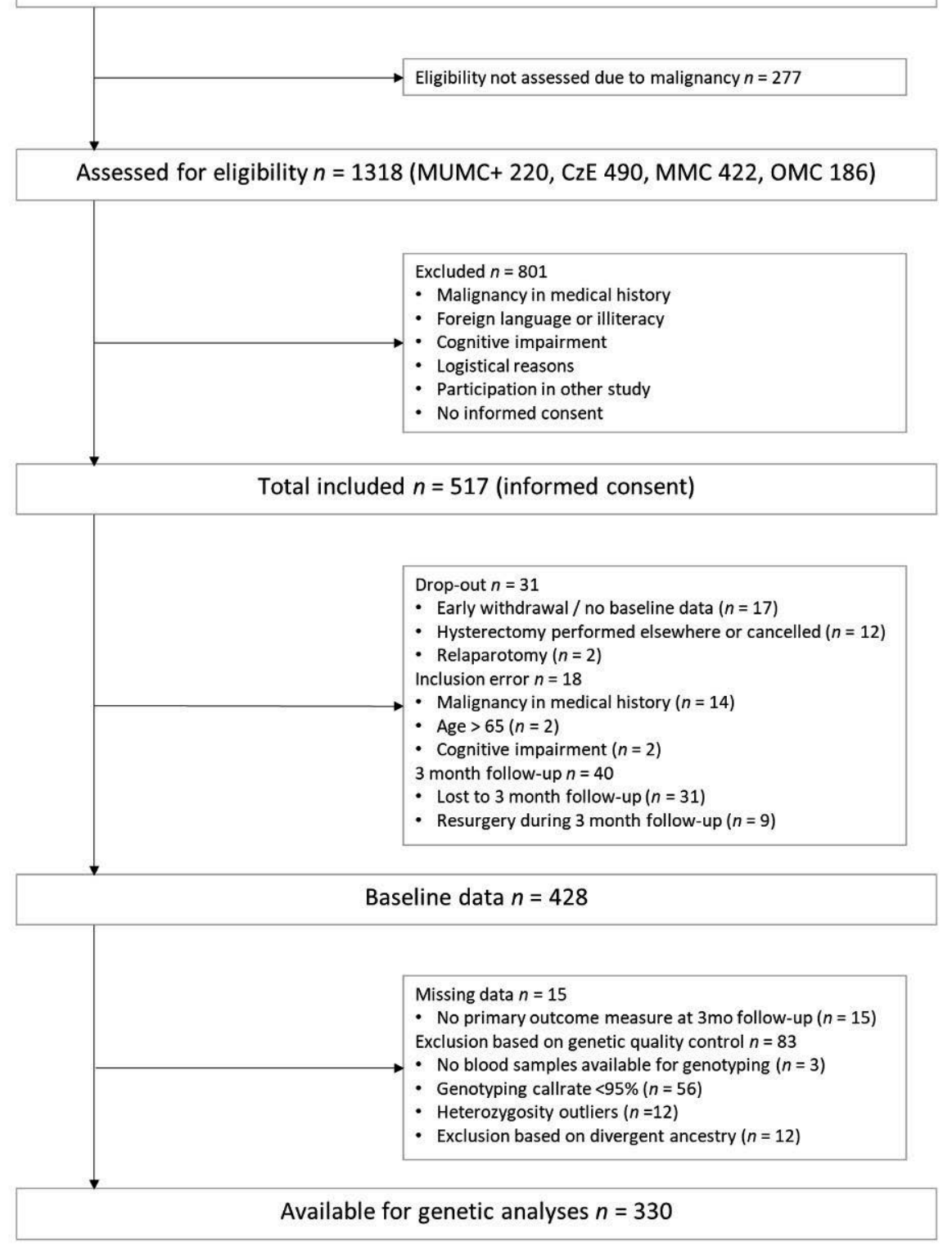

Figure 1 Patient inclusion in the discovery cohort.MUMC+, Maastricht University Medical Center+; CzE, Catharina Hospital Eindhoven; MMC, Maxima Medical Center Veldhoven; OMC, Orbis Medical Center Sittard Geleen; $n$, sample size. 


\section{Results}

Figure 1 shows the flow chart for inclusion, follow-up and genetic quality control, which is an extended version of the flow chart of our previous publication [15]. After quality control, samples from 330 patients were available for genetic analysis. Baseline pain and peri-operative characteristics can be found in Table 1. Out of the 330 patients included in the analyses, $269(81.5 \%)$ reported no pain (NRS $=0$ ) related to the hysterectomy at the 3 month follow-up, 27 (8.1\%) reported mild pain (NRS between 1 and 3 ) and 34 (10.3\%) reported moderate to severe pain $(\mathrm{NRS}>3)$.

The replication cohort underwent a variety of orthopaedic and abdominal surgeries (pooled in this cohort). The total cohort consisted of 249 patients of which samples of 203 patients ( 67 men and 136 women) were available for genetic analysis. Out of these 203 patients, 157 received no intervention and 46 received an infusion of steroids (methylprednisolone) in the first 7 days. A total of 190 patients were available for genetic analysis. It was decided to continue with the women without intervention leading to 106 women included in the study. After quality control, the results of 99 patients were available for genetic analysis. Baseline pain and peri-operative characteristics can be found in Table 1. Out of the 99 patients included in the analyses, $39(39.4 \%)$ reported no pain (NRS =0) related to the hysterectomy at the 3-month follow-up, 37 (37.4\%) reported mild pain (NRS between 1 and 3 ) and $11(11.1 \%)$ reported moderate to severe pain (NRS > 3). 
Table 1: baseline and perioperative patient characteristics of all patients available for genetic analysis.

Numbers represent mean (SD, Standard Deviation) or number (\%). Missing data is reflected in the percentages.

\begin{tabular}{|c|c|c|}
\hline & Discovery cohort $(\mathrm{n}=330)$ & Replication cohort $(n=99)$ \\
\hline \multicolumn{3}{|l|}{ Gender } \\
\hline Female & $330(100 \%)$ & $99(100 \%)$ \\
\hline Age & $46.9(7.2)$ & $69.3(9.6)$ \\
\hline \multicolumn{3}{|l|}{ Asa physical class } \\
\hline I & $179(54.2 \%)$ & $4(16.6 \%) \#$ \\
\hline Ii & $135(40.9 \%)$ & $9(37.5 \%) \#$ \\
\hline Iii & $4(1.2 \%)$ & $6(25.0 \%) \#$ \\
\hline $\begin{array}{l}\text { Pre-surgical pain } \\
\text { (surgical indication } \\
\text { related) }\end{array}$ & & \\
\hline Nrs 0-3 & $161(48.8 \%)$ & $99(100 \%)$ \\
\hline Nrs $4-10$ & $169(51.2 \%)$ & Patients with pre-surgical pain excluded \\
\hline $\begin{array}{l}\text { Pain at rest at pacu } \\
\text { (acutely after surgery) \#\# }\end{array}$ & & \\
\hline Nrs $0-3$ & $162(49.1 \%)$ & $64(64.6 \%)$ \\
\hline Nrs 4-10 & $133(40.3 \%)$ & $31(31.3 \%)$ \\
\hline $\begin{array}{l}\text { Pain at postsurgical day } 4 \\
\text { (highest nrs last } 24 \text { hours) }\end{array}$ & & \\
\hline Nrs $0-3$ & $179(54.2 \%)$ & $74(74.7 \%)$ \\
\hline Nrs 4-10 & $111(33.6 \%)$ & $6(6.06 \%)$ \\
\hline $\begin{array}{l}\text { Pain at } 3 \text { months (highest } \\
\text { nrs last week) }\end{array}$ & & \\
\hline Nrs $0-3$ & $296(89.7 \%)$ & $76(76.7 \%)$ \\
\hline Nrs 4-10 & $34(10.3 \%)$ & $11(11.1 \%)$ \\
\hline
\end{tabular}

Abbreviations: NRS numeric rating scale, $n$ sample size, PACU post-anaesthesia care unit

\# ASA scores only available for the patients who underwent abdominal or urological surgery $(n=24)$

\# Pain at PACU was measured at $1 \mathrm{hr}$ after surgery for discovery cohort, $0 \mathrm{hr}$ for the abdominal and urological surgeries and after 6 hours for orthopaedic surgery. 


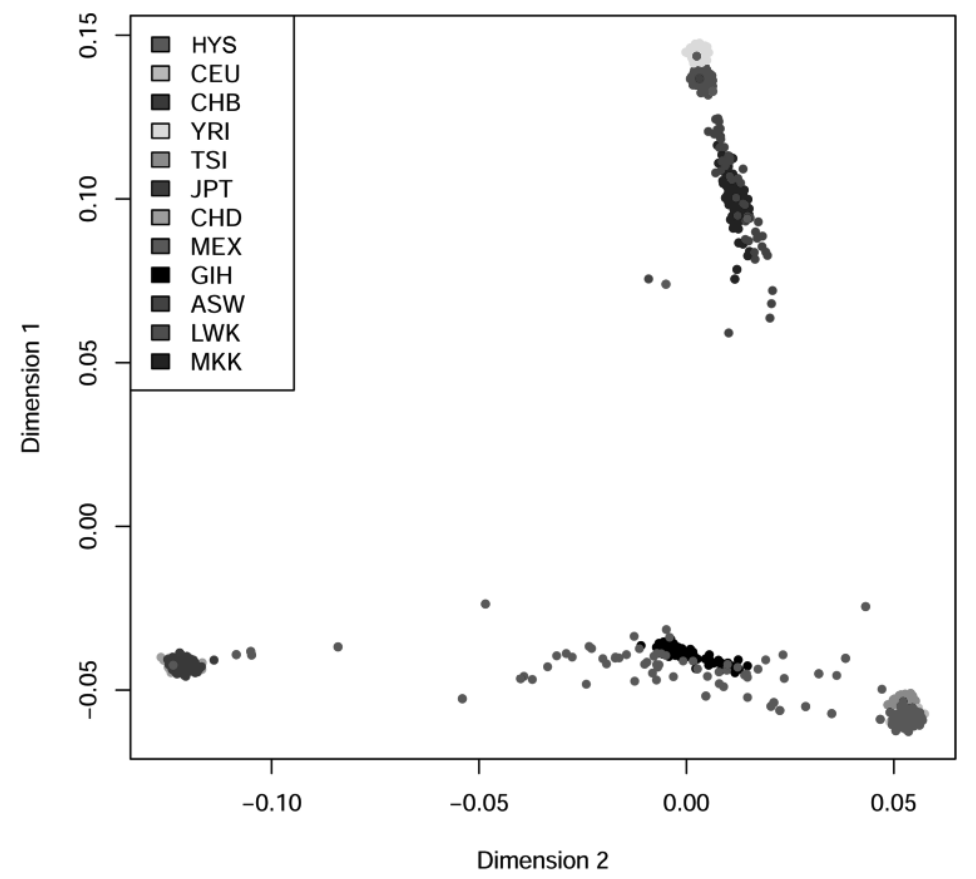

Figure 2 Ancestry plot based on the multidimension scaling method described by ENIGMA and population defined by HapMap. The discovery cohort (HYS) is plotted amongst the populations defined by HapMap. CEU, Utah residents with European ancestry; CHB, Han Chinese from Beijing, China; YRI, Yoruba from Ibadan, Nigeria; TSI, Italian from Tuscany, Italy; JPT, Japanese from Tokyo, Japan; CHD, Chinese from Denver, Colorado, USA; MEX, Mexican ancestry in Los Angeles, California, USA; GIH, Gujarati Indians from Houston, Texas; ASW, African ancestry from Southwest USA; LWK, Luhya from Webuye, Kenya; MKK, Maasai from Kinyawa, Kenya.

Ethnicity of both cohorts was checked using the HapMap data and was determined to be of European background (Fig. 2). Subjects deviating from this background were not analysed during quality control (discovery cohorts $\mathrm{n}=12$, replication cohort $\mathrm{n}=4$ ).

After quality control and imputation, 6,293,655 SNPs were included analysis. Overall association results are depicted in Fig. 3a. The QQ plot showed no apparent deviation from the null distribution of $\mathrm{p}$ values (Fig. $3 \mathrm{~b}$ ) and the genomic inflation factor (Fig. $3 \mathrm{~b}, \lambda_{\mathrm{GC}}=1.065$ ) indicated only a slight inflation of the model without covariates. Although none of the SNPs tested reached the 
threshold for genome-wide significance $\left(\mathrm{p}<5 \times 10^{-8}\right.$, Fig 3a), several reached a suggestive level of association (107 SNPs with $\mathrm{p}<1 \times 10^{-5}$, Fig 3a) which were further analysed and labelled as 'SNPs of interest'. Results of the top loci are shown in Table 2 and all SNPs were annotated using GRCh37.p13. A SNP cluster tagged by rs62281806 in $F N D C 3 B$ was the most significant hit $\left(\mathrm{p}=5.5 \times 10^{-7}\right)$. Other genes tagged by SNPs included EDNRA, NAV3, TLL2, RSU1, IQGAP1, TMEM63B, PJA2, CRTC3 and DLG2. None of these genes have been associated with chronic postoperative pain before, according to a recent systematic review [14]. The detailed results of the discovery cohort (SNPs $\mathrm{p}<0.05)$ are available on request from the corresponding author.

In the discovery cohort, no SNP reached the threshold for genome-wide significance. We decided to replicate only those SNPs in the replication cohort which showed a suggestive association $\left(\mathrm{p}<1 \times 10^{-5}\right)$ with the phenotype to increase the power [34]. The SNPs ( $n=107)$ showing suggestive association in the discovery cohort were further evaluated in an independent replication cohort. Results of the top replication loci are shown in Table 2 and the complete results in the Supporting Information Table S1. The SNP (rs118184265) in NAV3 showed nominal significance $(\mathrm{p}<0.01)$ with chronic postoperative pain at 3 months and two SNPs within RSU1 (rs7894047, rs7893777) showed a trend towards statistical significance $(\mathrm{p}=0.068)$. As the number of patients was limited, we decided to increase the cases by including all women with mild pain at 3 months (NRS $>0$ ). The NAV3 SNP remained significant although somewhat decreased $(\mathrm{p}=0.014)$ and the RSU1 SNPs became significant ( $\mathrm{p}=0.049$ ) (see also Supporting Information Table S2). The direction of the effect in the replication study is reversed compared with the discovery cohort. 
A
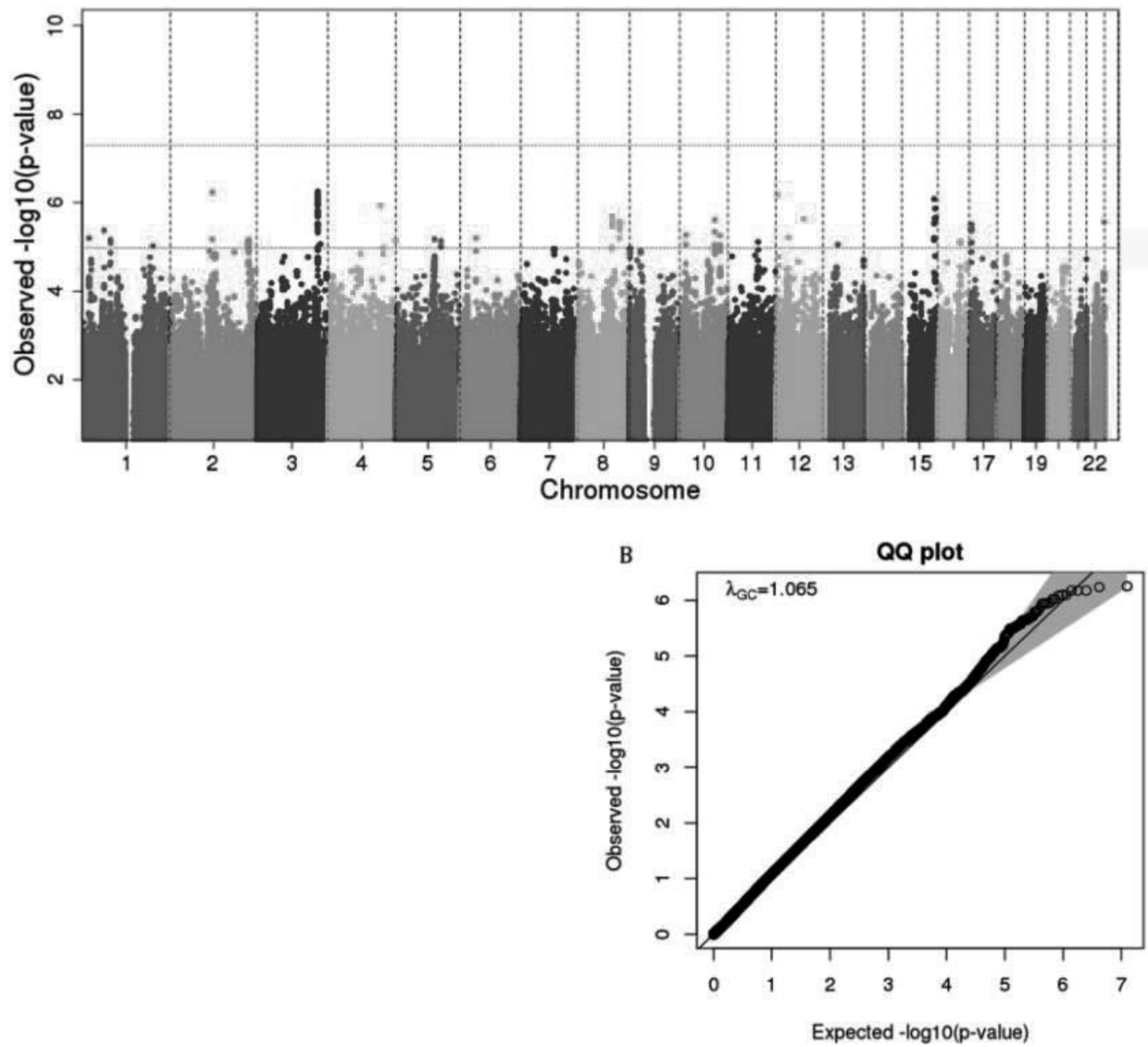

Figure 3: Manhattan plot and quantile-quantile plot representing the results of the genome-wide association analysis of the discovery cohort. (a) Manhattan plot representing the association between single-nucleotide polymorphism (SNP) genotype and chronic postoperative pain at 3 months after surgery in patients with a Caucasian ancestry. The negative log10 p values ( $y$-axis) are plotted against their chromosomal positions ( $x$ axis). The red dotted line indicates the genome-wide significance level $\left(p>5.0 \times 10^{-8}\right)$, the blue dotted line indicates the SNPs of interest level $\left(p>1.0 \times 10^{-5}\right)$. (b) QQplot of genotyped and imputed SNPs. Observed $p$ values are plotted against the expected p values. The lambda of 1.065 indicates a small genomic inflation corroborated by the near perfect correlation between the observed and expected p values. Figures were created using the quality control of GWAS data package in $R$. 
The SNPs studied in both the discovery and the replication cohort $(\mathrm{n}=96)$ were analysed in a random-effects meta-analysis to see the overall effects. Results of the top loci are shown in Table 2 and the complete results in the Supporting Information Table S3. The most significant SNP was rs117119665 in CRTC3 ( $\mathrm{p}=$ $2.26^{-6}, \beta=2.4209$, adjusted $\left.\mathrm{p}=2.41^{-4}\right)$. The second significant SNP was rs1145324 in IQGAP1 ( $\mathrm{p}=3.93^{-6}, \beta=2.3863$, adjusted $\left.\mathrm{p}=4.20^{-4}\right)$. Several nominally significant associations were found $(\mathrm{rs} 11655475$ and $\mathrm{rs} 4790802, \mathrm{p}<0.05)$ but these were not annotated to a gene. Both significant SNPs are located closely together on chromosome 15 within a region of low recombination (Fig. 4). To test whether the two SNPs (rs117119665 and rs1145324) are independent or part of the same locus, we performed a conditional analysis of each SNP with the other SNP as covariate. This analysis showed that the association with chronic postoperative pain disappeared $(\mathrm{p}>0.1)$ and, thus, the SNPs are not independent. There is a possible involvement of rs4347600 in CRTC3 as well but this SNP was not tested in the replication cohort and could, therefore, not be entered into the metaanalysis (Fig. 4). 


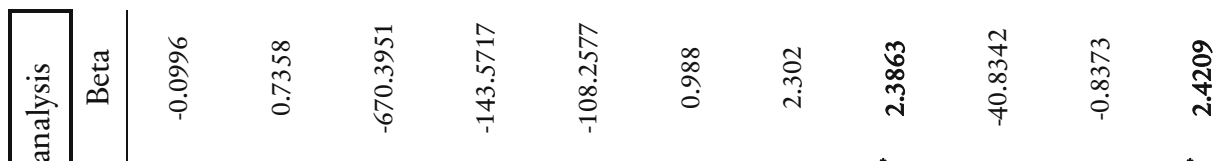

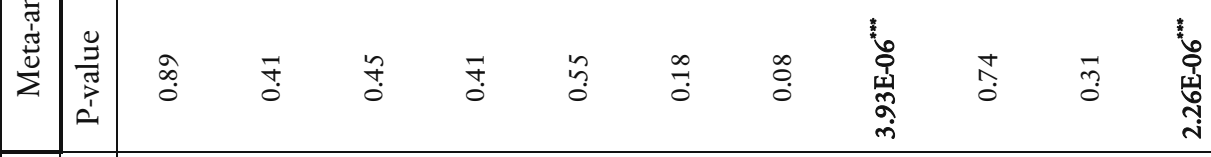

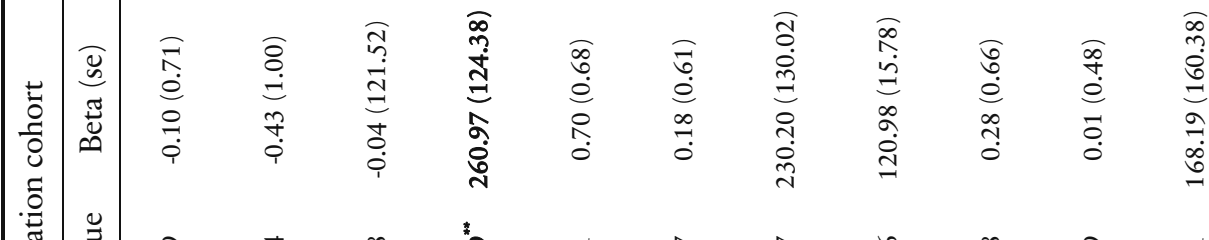

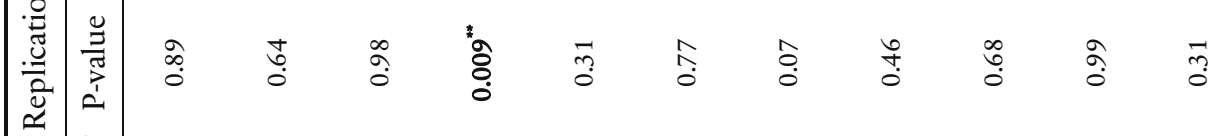

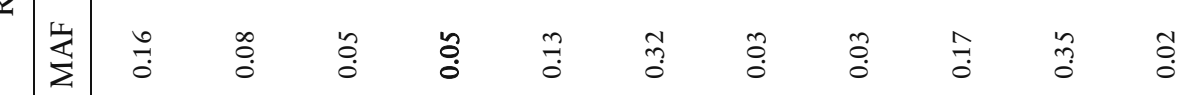

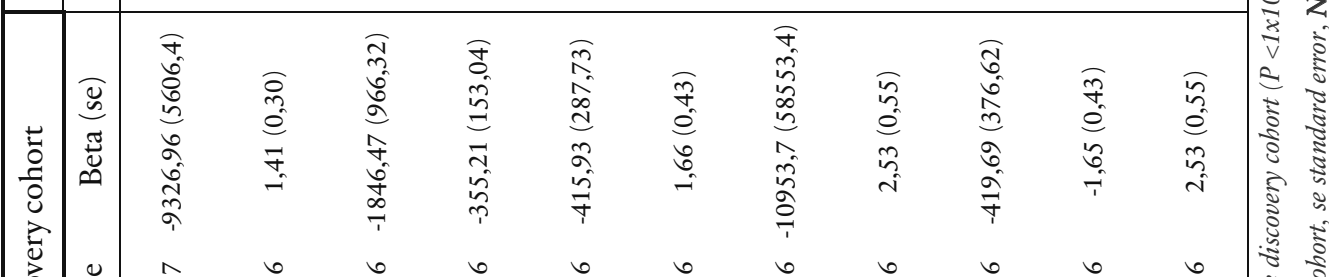

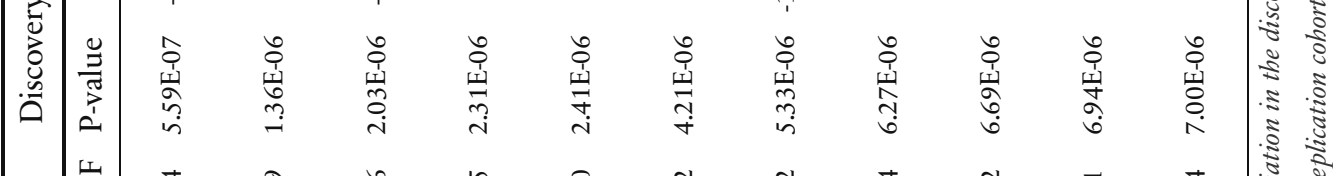

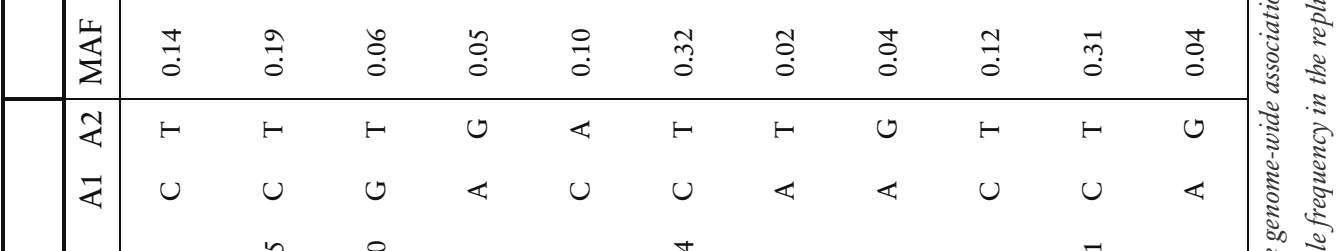

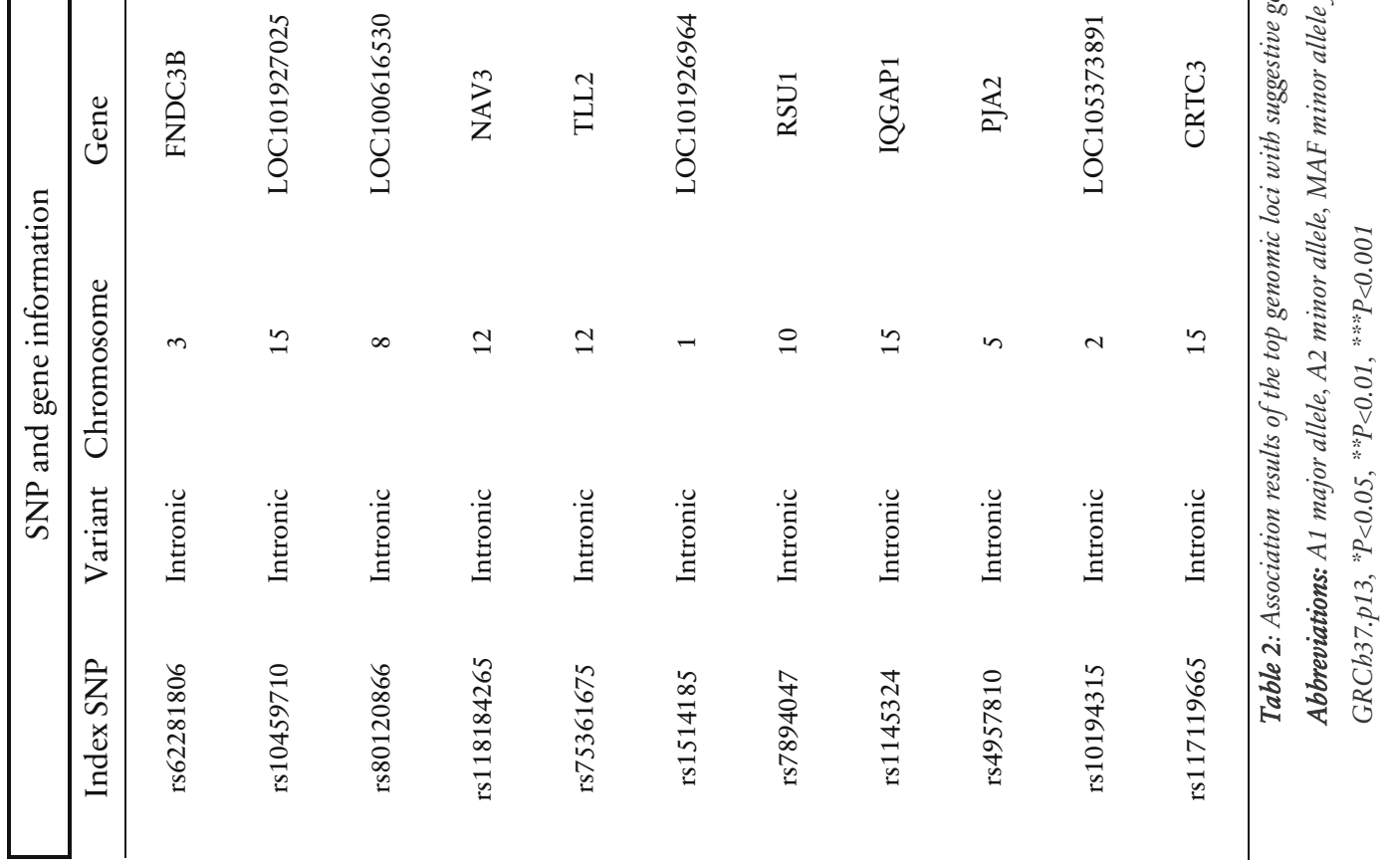


CRTC3 and IQGAP1

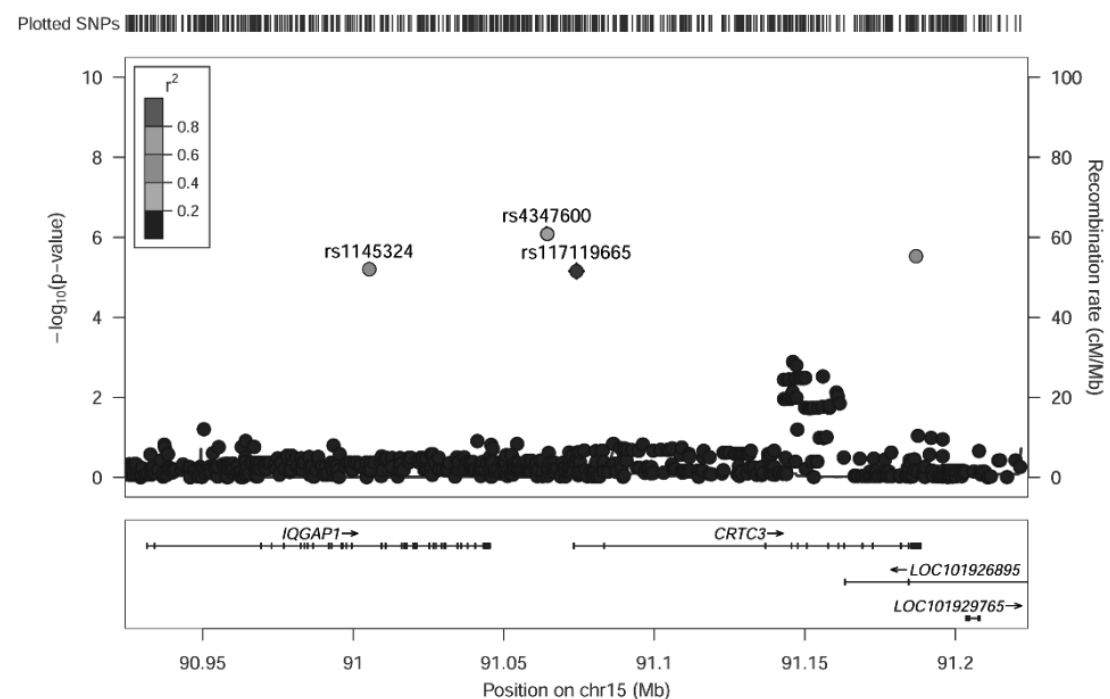

Figure 4 Regional association plot for single-nucleotide polymorphism (SNPs) within CRTC3 and IQGAP1 and their association with chronic postoperative pain. The plot shows the chromosomal position of the SNPs (based on 1000 genomes Nov 2014 EUR) in the respective region against the - $\log _{10} P$ values. The SNP with the highest p value in the meta-analysis is represented as a purple diamond. The other SNPs are colour coded according to the extent of linkage disequilibrium with those specific SNPs

\section{Discussion}

One locus (NAV3) of the SNPs of interest was associated with chronic postoperative pain in the replication cohort. Two loci (CRTC3 and IQGAP1) were significantly associated with chronic postoperative pain in the meta-analysis of the discovery and replication cohort. Unfortunately, the sample size of the discovery cohort was too small and, thus, the study was underpowered. The replication cohort and meta-analysis partially overcome this problem but results should be interpreted cautiously. Nevertheless, the study provides an initial insight to genome-wide risk factors of chronic postoperative pain.

The meta-analysis indicated two genes (CRTC3 and IQGAP1) as risk loci for the development of chronic postoperative pain. However, neither has been associated with pain before according to the Pain Genes Database and the Human Pain 
Genetics Database [22, 35]. CREB-regulated transcription co-activator 3 (CRTC3) is expressed in a variety of tissues including the nervous system, is involved in regulation of CREB-dependent transcription of genes and inhibits adenylyl cyclase in response to catecholamine signalling [36,37]. It has been associated with several abdominal disorders such as Crohn's and inflammatory bowel disease and cognitive information processing [38-40]. IQ motif containing GTPase-activating protein 1 (IQGAP1) is expressed throughout the body including the nervous system, and is involved in cytoskeleton regulation, signalling molecules and cell motility [36]. It has been associated with immune system functioning and multiple sclerosis [41, 42]. Interestingly, two genome-wide association studies found both CRTC3 and IQGAP1 associated with their primary outcome measure (heel bone mineral density and neutrophil percentage of white cells, respectively) indicating a possible synergism or interaction between the two genes [42, 43]. In our study, the SNPs in both genes are in linkage disequilibrium with each other and influence the development of chronic postoperative pain together. Their involvement in the immune system is supportive of postoperative infection being a risk factor for the development of chronic postoperative pain, as previously shown [15].

In addition, a significant association of a SNP in NAV3 (neuron navigator 3) with chronic postoperative pain was noted in the replication cohort, which was part of the SNPs of interest in the discovery cohort. NAV3 is a gene predominantly expressed within the central and peripheral nervous systems, is involved in axonal growth and is upregulated $24 \mathrm{~h}$ after brain injury [44]. Another SNP in NAV3, found to be upregulated in degenerating Alzheimer's disease [45], has been associated with brain development and neuronal differentiation [46]. Interestingly, the $N A V 3$ gene has been associated with complex regional pain syndrome [47]. However, the direction of the effect of NAV3 differed between the discovery (protective effect) and replication cohort (risk effect) which could be due to several reasons. One of these could be that the effect of SNPs is subtype 
specific as already shown in migraine [18]. The replication cohort consisted of a variety of surgeries, while the discovery cohort was focused on hysterectomy, although the hysterectomy approach did differ slightly between hospitals. Furthermore, the limited sample size could skew results to one side and large-scale follow-up and meta-analyses should further verify the direction and the size of the effect.

Genetic studies and GWAS in particular, face several difficulties in the field of chronic postoperative pain. The first challenge is unifying the phenotype and the sub-phenotypes of chronic postoperative pain [3]. Several efforts have been made to improve the phenotyping of chronic postoperative pain $[4,6]$. The most recent effort for the new International Classification of Diseases-11 made a further step by specifically defining the sub types of chronic postoperative pain with detailed symptoms per sub-phenotype [3]. Migraine research has done this subclassification before and a recent genome-wide association meta-analysis identified subtype-specific risk loci, which is a good example of the direction the field should pursue [18]. Combining various indications of chronic postoperative pain helps to identify which SNPs or loci are subtype specific and which are associated with chronic postoperative pain in general. The second challenge is acquiring an adequate sample size, which was rather small in this study. The sample size to find trustworthy results should be multiplied at least a 100-fold, which is not feasible for individual research groups. Instead, following the example of migraine [18], large consortia should be formed to make large sample sizes possible. Combining uniform and detailed (sub-)phenotypes of chronic postoperative pain with a sufficient sample size would make genome-wide association in chronic postoperative pain a success.

Our study provides a foundation for follow-up genome-wide association studies on chronic postoperative pain. Our analysis only focused on the female sex, but data are available on men and women. Both the detailed information available on 
both cohorts as well as the availability of both sexes makes this study an ideal starting point for follow-up research. Although none of the SNPs studied reach genome-wide significance, various suggestive signals were identified and replicated in an independent cohort. There are some differences between the discovery cohort and replication cohort, which could influence the results. Firstly, the replication cohort included men and women and approximately $20 \%$ received an intervention consisting of methylprednisolone infusion next to the standard postoperative medical regime, whereas the discovery cohort consisted of only women without extra interventions. Women have a higher chance of developing chronic postoperative pain than men $[48,49]$. To overcome this difference, we decided to analyse only the women in the cohort who did not undergo methylprednisolone infusion. Secondly, there was a significant 20-year mean age difference between the discovery and the replication cohorts. Younger age is a risk factor for chronic postoperative pain and should be corrected for where possible [48]. To correct for age, a random-effects instead of a fixed effects meta-analysis was conducted as the study design and influential covariates differed between studies.

Currently, a significant portion of the variance in the risk of developing chronic postoperative pain remains to be elucidated, despite the already comprehensively studied psychological, clinical and baseline characteristic risk factors [1, 17, 23]. The identification of genetic risk factors will be a key step towards identifying people at risk of chronic postoperative pain and devising new treatment strategies based on optimised prediction modelling. Although this genome-wide association study alone did not yield genome-wide significant SNPs, the meta-analysis indicated two risk loci for the development of chronic postoperative pain and the replication study provided additional evidence for two loci. Future studies in larger cohorts of patients with chronic postoperative pain will help to elucidate the underlying genetics. Expanding to other surgery types may uncover susceptibility factors for chronic postoperative pain independent of the surgery 
intervention and possibly subtype-specific loci. Finally, characterisation of the pathways related to chronic postoperative pain has the potential for developing therapeutic approaches to prevent it.

\section{Acknowledgements}

We thank all the participants in this study for their contribution. The discovery cohort was registered at the Dutch trial registry under the number NTR2702 (http://www.trialregister.nl/trialreg/index.asp). The replication cohort was registered at the Clinical Trials registry under the numbers NCT02002663 and NCT01989351 (https://clinicaltrials.gov/ct2/home).This work was supported by funds made available by Department of Anaesthesiology (Maastricht University Medical Center+ (MUMC+), and School of Mental Health, and Neuroscience (MHeNS, University of Maastricht) and the Italian Health Ministry ('New nanotechnology and biomedical approaches to improve postoperative pain treatment reducing risks related to opioids'). No competing interests declared. $\mathrm{NvdH}$ is now employed at Hotchkiss Brain Institute, University of Calgary, Calgary, AB, Canada. 


\section{Appendix 1}

Additional contributors: G. Kenis, M. Theunissen, M. Knapp, S. HeilmannHeimbach, M. M. Nöthen, P. Hoffman, M. Schmid and W. F. F. A. Buhre.

The Italian Pain Group comprises: M. Allegri, E. Bassoricci, S Bettinelli, D. Bugada, V.L.E. Cedrati, G. Cappelleri, C. Compagnone, M. De Gregori, R. Fumagalli, S. Grimaldi, M. Mantelli, M. Molinaro, and M. Zorzetto.

\section{Appendix 2}

COMT, catechol-O-methyltransferase; GCH1, GTP cyclobydrolase 1; OPRM1, opioid receptor ти 1; EDNRA, endothelin receptor type A; NAV3, neuron navigator 3; TLL2, tolloid-like protein 2; RSU1, ras suppressor protein 1; TMEM63B, transmembrane protein 63B; PJA2, praja ring finger ubiquitin ligase 2; DLG2, discs large MAGUK scaffold protein 2; FNDC3B, fibronectin type-3 domain containing 3B; KCNS1, potassium voltage-gated channel modifier subfamily $S$ member 1

\section{Supporting Information}

Additional supporting information may be found online in the Supporting Information section.

Figure S1. Heterozygosity plot showing the heterozygosity rate plotted against the number of missing SNPs per individual.

Table S1. Logistic regression analysis results for the replication cohort extreme case analysis (NRS >3) versus no pain group $(N R S=0)$.

Table S2. Logistic regression analysis results for the replication cohort with all patients with pain included $(N R S>0)$ versus no pain group $(N R S=0)$.

Table S3. Random effects meta-analysis results of discovery and replication cohort. 


\section{References}

1. Kehlet H, Jensen TS, Woolf CJ: Persistent postsurgical pain: risk factors and prevention. The Lancet 2006, 367(9522):1618-1625.

2. Parsons B, Schaefer C, Mann R, Sadosky A, Daniel S, Nalamachu S, Stacey BR, Nieshoff EC, Tuchman M, Anschel A: Economic and humanistic burden of post-trauma and postsurgical neuropathic pain among adults in the United States. Journal of pain research 2013, 6:459.

3. Schug SA, Lavand'homme P, Barke A, Korwisi B, Rief W, Treede R-D, Pain TITftCoC: The IASP classification of chronic pain for ICD-11: chronic postsurgical or posttraumatic pain. PAIN 2019, 160(1):45-52.

4. Werner M, Kongsgaard U: I. Defining persistent post-surgical pain: is an update required? British journal of anaesthesia 2014, 113(1):1-4.

5. Macrae W: Chronic pain after surgery. British Journal of Anaesthesia 2001, 87(1):88-98.

6. Macrae W: Chronic post-surgical pain: 10 years on. British journal of anaesthesia 2008, 101(1):77-86.

7. Katz J, Seltzer Ze: Transition from acute to chronic postsurgical pain: risk factors and protective factors. Expert Rev Neurother 2009, 9(5):723-744.

8. Clarke H, Katz J, Flor H, Rietschel M, Diehl SR, Seltzer Z: Genetics of chronic post-surgical pain: a crucial step toward personal pain medicine. Canadian Journal of Anesthesia 2015, 62(3):294-303.

9. Battié MC, Videman T, Levalahti E, Gill K, Kaprio J: Heritability of low back pain and the role of disc degeneration. PAIN 2007, 131(3):272-280.

10. Zondervan KT, Cardon LR, Kennedy SH, Martin NG, Treloar SA: Multivariate Genetic Analysis of Chronic Pelvic Pain and Associated Phenotypes. Behavior Genetics 2005, 35(2):177-188.

11. Montes A, Roca G, Sabate S, Lao JI, Navarro A, Cantillo J, Canet J, Group GS: Genetic and Clinical Factors Associated with Chronic Postsurgical Pain after Hernia Repair, Hysterectomy, and Thoracotomy: A Two-year Multicenter Cohort Study. Anesthesiology 2015, 122(5):1123-1141.

12. Costigan M, Belfer I, Griffin RS, Dai F, Barrett LB, Coppola G, Wu T, Kiselycznyk C, Poddar M, Lu Y et al: Multiple chronic pain states are associated with a common amino acid-changing allele in KCNS1. Brain : a journal of neurology 2010, 133(9):2519-2527.

13. Belfer I, Dai F, Kehlet H, Finelli P, Qin L, Bittner R, Aasvang EK: Association of functional variations in COMT and GCH1 genes with postherniotomy pain and related impairment. Pain 2015, 156(2):273-279.

14. Hoofwijk DMN, van Reij RRI, Rutten BP, Kenis G, Buhre WF, Joosten EA: Genetic polymorphisms and their association with the prevalence and severity of chronic postsurgical pain: a systematic review. British Journal of Anaesthesia 2016, 117(6):708-719.

15. Theunissen M, Peters ML, Schepers J, Maas JW, Tournois F, van Suijlekom HA, Gramke H-F, Marcus MA: Recovery 3 and 12 months after hysterectomy: epidemiology and 
predictors of chronic pain, physical functioning, and global surgical recovery. Medicine 2016, 95(26):e3980.

16. Gramke HF, de Rijke JM, van Kleef M, Raps F, Kessels AG, Peters ML, Sommer M, Marcus MA: The prevalence of postoperative pain in a cross-sectional group of patients after daycase surgery in a university hospital. The Clinical Journal of Pain 2007, 23(6):543-548.

17. Hoofwijk DM, Fiddelers A, Peters ML, Stessel B, Kessels A, Joosten EA, Gramke H-F, Marcus M: Prevalence and Predictive Factors of Chronic Postsurgical Pain and Poor Global Recovery One Year after Outpatient Surgery. The Clinical journal of pain 2015.

18. Gormley P, Anttila V, Winsvold BS, Palta P, Esko T, Pers TH, Farh K-H, Cuenca-Leon E, Muona M, Furlotte NA et al: Meta-analysis of 375,000 individuals identifies 38 susceptibility loci for migraine. Nature genetics 2016, 48(8):856-866.

19. Bugada D, De Gregori M, Compagnone C, Muscoli C, Raimondi F, Bettinelli S, Avanzini MA, Cobianchi L, Peloso A, Baciarello M: Continuous wound infusion of local anesthetic and steroid after major abdominal surgery: study protocol for a randomized controlled trial. Trials 2015, 16(1):357.

20. Witte AV, Flöel A: Effects of COMT polymorphisms on brain function and behavior in health and disease. Brain Research Bulletin 2012, 88(5):418-428.

21. George SZ, Wallace MR, Wright TW, Moser MW, Greenfield WH, 3rd, Sack BK, Herbstman DM, Fillingim RB: Evidence for a biopsychosocial influence on shoulder pain: pain catastrophizing and catechol-O-methyltransferase (COMT) diplotype predict clinical pain ratings. Pain 2008, 136(1-2):53-61.

22. LaCroix-Fralish ML, Ledoux JB, Mogil JS: The Pain Genes Database: An interactive web browser of pain-related transgenic knockout studies. Pain 2007, 131(1):3. e1-3. e4.

23. Theunissen M, Peters ML, Bruce J, Gramke H-F, Marcus MA: Preoperative anxiety and catastrophizing: a systematic review and meta-analysis of the association with chronic postsurgical pain. The Clinical journal of pain 2012, 28(9):819-841.

24. Hinrichs-Rocker A, Schulz K, Järvinen I, Lefering R, Simanski C, Neugebauer EAM: Psychosocial predictors and correlates for chronic post-surgical pain (CPSP) - A systematic review. European Journal of Pain 2009, 13(7):719-730.

25. Purcell S, Neale B, Todd-Brown K, Thomas L, Ferreira MA, Bender D, Maller J, Sklar P, de Bakker PI, Daly MJ et al: PLINK: a tool set for whole-genome association and populationbased linkage analyses. American journal of human genetics 2007, 81(3):559-575.

26. Chang CC, Chow CC, Tellier LC, Vattikuti S, Purcell SM, Lee JJ: Second-generation PLINK: rising to the challenge of larger and richer datasets. Gigascience 2015, 4(1):7.

27. ENIGMA2 1KGP Cookbook (v3) [online] [http://enigma.ini.usc.edu/wp-content/uploads/2012/07/ENIGMA2_1KGP_cookbook_v3. pdf]

28. Das S, Forer L, Schonherr S, Sidore C, Locke AE, Kwong A, Vrieze SI, Chew EY, Levy S, McGue $\mathrm{M}$ et al: Next-generation genotype imputation service and methods. Nature genetics 2016, 48(10):1284-1287. 
29. Loh PR, Danecek P, Palamara PF, Fuchsberger C, Y AR, H KF, Schoenherr S, Forer L, McCarthy S, Abecasis GR et al: Reference-based phasing using the Haplotype Reference Consortium panel. Nature genetics 2016, 48(11):1443-1448.

30. McCarthy S, Das S, Kretzschmar W, Delaneau O, Wood AR, Teumer A, Kang HM, Fuchsberger C, Danecek P, Sharp K et al: A reference panel of 64,976 haplotypes for genotype imputation. Nature genetics 2016, 48(10):1279-1283.

31. Pruim RJ, Welch RP, Sanna S, Teslovich TM, Chines PS, Gliedt TP, Boehnke M, Abecasis GR, Willer CJ: LocusZoom: regional visualization of genome-wide association scan results. Bioinformatics 2010, 26(18):2336-2337.

32. Hirschhorn JN, Daly MJ: Genome-wide association studies for common diseases and complex traits. Nature Reviews Genetics 2005, 6(2):95-108.

33. Marchini J, Howie B, Myers S, McVean G, Donnelly P: A new multipoint method for genome-wide association studies by imputation of genotypes. Nature genetics 2007, 39(7):906-913.

34. Bacchelli E, Cainazzo MM, Cameli C, Guerzoni S, Martinelli A, Zoli M, Maestrini E, Pini LA: A genome-wide analysis in cluster headache points to neprilysin and PACAP receptor gene variants. The Journal of Headache and Pain 2016, 17(1):114.

35. Meloto CB, Benavides R, Lichtenwalter RN, Wen X, Tugarinov N, Zorina-Lichtenwalter K, Chabot-Doré A-J, Piltonen MH, Cattaneo S, Verma V: The Human Pain Genetics Database (HPGDB): a resource dedicated to human pain genetics research. Pain 2017.

36. Fagerberg L, Hallstrom BM, Oksvold P, Kampf C, Djureinovic D, Odeberg J, Habuka M, Tahmasebpoor S, Danielsson A, Edlund K et al: Analysis of the human tissue-specific expression by genome-wide integration of transcriptomics and antibody-based proteomics. Molecular \& cellular proteomics 2014, 13(2):397-406.

37. Song Y, Altarejos J, Goodarzi MO, Inoue H, Guo X, Berdeaux R, Kim J-H, Goode J, Igata M, Paz JC: CRTC3 links catecholamine signalling to energy balance. Nature 2010, 468(7326):933.

38. Ibrahim-Verbaas CA, Bressler J, Debette S, Schuur M, Smith AV, Bis JC, Davies G, Trompet $\mathrm{S}$, Smith JA, Wolf C et al: GWAS for executive function and processing speed suggests involvement of the CADM2 gene. Molecular psychiatry 2016, 21(2):189-197.

39. Broce I, Karch CM, Wen N, Fan CC, Wang Y, Tan CH, Kouri N, Ross OA, Höglinger GU, Muller U: Immune-related genetic enrichment in frontotemporal dementia: An analysis of genome-wide association studies. PLoS medicine 2018, 15(1):e1002487.

40. Huang H, Fang M, Jostins L, Mirkov MU, Boucher G, Anderson CA, Andersen V, Cleynen I, Cortes A, Crins F: Fine-mapping inflammatory bowel disease loci to single-variant resolution. Nature 2017, 547(7662):173.

41. Beecham AH, Patsopoulos NA, Xifara DK, Davis MF, Kemppinen A, Cotsapas C, Shah TS, Spencer C, Booth D, Goris A et al: Analysis of immune-related loci identifies 48 new susceptibility variants for multiple sclerosis. Nature genetics 2013, 45(11):1353-1360. 
42. Astle WJ, Elding H, Jiang T, Allen D, Ruklisa D, Mann AL, Mead D, Bouman H, RiverosMckay F, Kostadima MA et al: The Allelic Landscape of Human Blood Cell Trait Variation and Links to Common Complex Disease. Cell 2016, 167(5):1415-1429.e1419.

43. Kim SK: Identification of $\mathbf{6 1 3}$ new loci associated with heel bone mineral density and a polygenic risk score for bone mineral density, osteoporosis and fracture. PLoS One 2018, 13(7):e0200785.

44. Coy JF, Wiemann S, Bechmann I, Bachner D, Nitsch R, Kretz O, Christiansen H, Poustka A: Pore membrane and/or filament interacting like protein 1 (POMFIL1) is predominantly expressed in the nervous system and encodes different protein isoforms. Gene 2002, 290(12):73-94.

45. Shioya M, Obayashi S, Tabunoki H, Arima K, Saito Y, Ishida T, Satoh J: Aberrant microRNA expression in the brains of neurodegenerative diseases: miR-29a decreased in Alzheimer disease brains targets neurone navigator 3. Neuropathology and Applied Neurobiology 2010, 36(4):320-330.

46. Halder D, Mandal C, Lee BH, Lee JS, Choi MR, Chai JC, Lee YS, Jung KH, Chai YG: PCDHB14- and GABRB1-like nervous system developmental genes are altered during early neuronal differentiation of NCCIT cells treated with ethanol. Human \& Experimental Toxicologie 2015, 34(10):1017-1027.

47. Janicki PK, Alexander GM, Eckert J, Postula M, Schwartzman RJ: Analysis of Common Single Nucleotide Polymorphisms in Complex Regional Pain Syndrome: Genome Wide Association Study Approach and Pooled DNA Strategy. Pain Medicine 2016, 17(12):23442352.

48. Kim DH, Pearson-Chauhan KM, McCarthy RJ, Buvanendran A: Predictive Factors for Developing Chronic Pain After Total Knee Arthroplasty. The Journal of Arthroplasty 2018, 33(11):3372-3378.

49. Wang Y, Liu Z, Chen S, Ye X, Xie W, Hu C, Iezzi T, Jackson T: Pre-surgery beliefs about pain and surgery as predictors of acute and chronic post-surgical pain: A prospective cohort study. International Journal of Surgery 2018, 52:50-55. 
CHAPTER 4

\title{
Risk loci associated with chronic post-surgical pain uncovered using meta-analysis and transcriptome-wide Mendelian Randomization
}

\author{
R. R. I. van Reij, S. Khoury, M. Parisien, I. Belfer, \\ N. J. van den Hoogen, E. A. J. Joosten, L. Diatchenko
}


$90 \mid C h$ a pter 4 


\section{Abstract}

Chronic Post-Surgical Pain (CPSP), or pain developed or increased after a surgical procedure present for at least 3 months, affects between $5-85 \%$ of patients undergoing surgery. A recent GWAS study identified two potential risk loci in a small cohort. Although GWAS analysis provides insights into association between SNPs and CPSP, it does not provide evidence on causality. In the current study, expression quantitative trait loci (eQTLs) are used to further elucidate the genetic risk factors of CPSP and their working mechanisms. We conducted a large-scale meta-analysis across various CPSP cohorts and study the possible mechanisms via eQTLs and Mendelian randomization.

The statistical analysis included a comparison of the severe CPSP (NRS $>3$ ) with the no-CPSP group (NRS=0) and continuous phenotype (NRS 0-10). Metaanalysis of the different cohorts was conducted using METAL in a fixed approach weighted by standard errors. Transcriptome-wide Mendelian randomization (TWMR) approach was used to combine SNP association with CPSP and eQTLs in different tissues.

Performing the meta-analysis on half of the cohorts led to the identification of the first genome-wide significant hit (rs17882261) for CPSP. The TWMR approach led to the identification of genes (SNAP29, RPA2) which potentially causally associated with CPSP in multiple tissues.

Increasing the sample size of the initial GWAS study led to the identification of the first genome-wide significant locus for CPSP. TWMR analysis identified two genes with potential causally associated with CPSP in multiple tissues and expressed either in nervous tissues or immune cells. The present study provides a major step forward in genetic studies identifying genetic risk factors in CPSP.

Key words: TWMR, GWAS, CPSP, SNP 


\section{Introduction}

Chronic Post-Surgical Pain (CPSP) is a debilitating condition affecting between 5 and $85 \%$ of patients undergoing surgery. CPSP has a large negative impact on the quality of life (QoL) and socioeconomic status of the affected patients [1-3]. Both clinical (e.g. type of surgery) and demographic (e.g. psychosocial status) risk factors have been described to predispose to CPSP, but these do not explain all the observed variance. So far, a good understanding about genetic risk factors for CPSP is still lacking $[1,4]$. The underlying biology of CPSP is complex and not yet fully understood and genetic heritability of CPSP is not yet known [5]. Studies in other chronic pain syndromes have shown that chronic pain is moderately heritable with estimates ranging from 30-70\% with a median of 45\% [5-9]. Candidate gene-based studies on CPSP have shown conflicting evidence [10-13]. Thus far, one genome-wide association study (GWAS) has been conducted which found one potential genetic risk locus after replication of the top hits [14]. Unfortunately, this study was underpowered for a GWAS and larger scale studies are necessary to identify risk loci for CPSP.

Only a small fraction of the disease associated SNPs has been examined functionally and the mechanisms underlying the associations explored [15]. Most of the disease-associated SNPs identified in GWAS are located in non-proteincoding regions (e.g. intronic or intergenic regions) and affect the phenotype through other mechanisms than altering the protein coding sequence [15]. One of the predominant mechanisms is altering gene expression [15]. Gene expression is a quantitative trait which is influenced by many factors among which SNPs contained in expression quantitative trait loci (eQTLs) [16]. Most genes have multiple eQTLs and the interaction between the eQTLs affects the gene expression [17].

The effect of a SNP on gene expression (eQTL) is tissue-specific [18]. Recent studies have identified a clear link between neuro-inflammation and chronic pain 
$[14,19,20]$. Therefore, not only neuronal tissues are interesting in the context of CPSP but also whole blood as a marker for the immune system [21].Combining CPSP GWAS summary results with cell-type specific eQTL data can suggest credible candidate loci for the prioritization of functional studies [22].

Mendelian randomization (MR) is a statistical approach whereby the causal relation between an instrument (SNP) in combination with a biological trait (eQTL) is explored on an outcome (e.g. CPSP) [23]. This technique can identify potentially causal SNPs to follow up in further functional assays. MR has three assumption about the instruments that need to be met: 1) sizable association with the exposure, 2) no association with any confounder of the relationship between exposure and outcome and 3) should only be associated with the outcome through the exposure [22]. A recent study has led to the development of transcriptomewide Mendelian randomization (TWMR) which meets the assumptions of MR better than previous efforts [22].

The aim of this study was to identify genetic factors associated with the severity of CPSP. To do so, we first performed a meta-analysis of three independent surgical cohorts, which combined sample size ( $\mathrm{n}=954)$ increased power to detect risk loci. Then, we hypothesized that risk for CPSP was partly conferred in a cell-specific fashion via transcriptional mechanisms. We used the transcriptome-wide Mendelian randomization approach (TWMR) to screen the entirety of the metaanalysis results for prioritization of functional SNP using eQTL.

\section{Methods}

The protocol for this study was reviewed and approved by the local Medical Ethical Committees of each independent cohort and all participants gave written informed consent. The discovery cohort was registered at the Dutch trial registry under the number NTR2702 (http://www.trialregister.nl/trialreg/index.asp). The 
replication cohort was registered at the Clinical Trials registry under the number NCT02002663 and NCT01989351 (https://clinicaltrials.gov/ct2/home).

\section{Patient enrolment}

An elaborate description of patient recruitment, sample and data collection protocols for the three cohorts has been published previously [14, 24-26]. In brief, a multicentre cohort study was conducted in four hospitals in the Netherlands (hysterectomies, Hys), three hospitals in Italy (abdominal surgeries and knee replacements, AbKnee) and one hospital in Pittsburgh USA (mastectomies, PMPS). DNA-samples were genotyped at the Department of Genomics at the Life and Brain Center, University of Bonn using the Illumina PsychArray (Infinium PsychArray-24 v1.2 Bead Chip, Illumina Inc., USA) for the Hys and AbKnee cohorts. The PMPS cohort was genotyped using the UK Biobank Axiom platform on samples derived from lymph node tissue, blood or saliva at the Genome center at McGill University.

\section{Genotyping and GWAS analysis}

Genotypes were called using BeadStudio (Genome Studio v2011.1, Illumina). Basic quality control was done using Plink (Plink-1.9) [27, 28]. The quality control parameters consisted of: SNP call rate $<0.95$, subject call rate of $<0.95$, and deviation of Hardy-Weinberg equilibrium $\left(\mathrm{P}<1 \times 10^{-6}\right)$ and removal of rare variants with a minor allele frequency $(\mathrm{MAF})<0.05$. Heterozygosity of the subjects was tested and outliers $( \pm 3$ SD from the mean heterozygosity rate) were removed. Genotype imputation for the all cohorts was performed using the stepwise imputation approach implemented in Minimac3 (https://genome.sph.umich.edu/wiki/Minimac3; University of Michigan, Ann Arbor, USA) and Eagle2 (https://data.broadinstitute.org/alkesgroup/Eagle/; Broad Institute, Cambridge, USA v2.3) using default parameter settings and a European HRC reference panel (http://www.haplotype-reference-consortium.org/; version 
r1.1 2016 ) [29-31]. Genome-wide association analysis was carried out using Plink (Plink-1.9) [27, 28]. The primary outcome measured in the Dutch and USA cohorts was the highest surgery-related pain score measured by the Numeric Rating Scale (NRS), recorded at rest during the last week, three months postsurgery $[14,24]$. The primary outcome measured in the Italian cohorts was the average surgery-related pain score measured by the Numeric Rating Scale (NRS), recorded at rest during the last week, three months post-surgery [14]. The primary outcome measure was assessed on a continuous scale.

\section{Meta-analysis}

Meta-analysis of the three cohorts was conducted using METAL software [32]. A fixed-effects standard error weighted meta-analysis was conducted with Bonferroni correction applied to account for multiple testing. Before metaanalysis all datasets and effects were aligned to the 500k UK biobank release to ensure matching effect alleles and direction of effects.

\section{Transcriptome-wide Mendelian randomization}

For the TWMR analysis, four different eQTL datasets were used: Whole blood, cervical spinal cord, and cortex datasets from GTEx V7 and DRG dataset described by Parisien et al., [33, 34]. The TWMR approach was adapted from Porcu et al., [22]. Briefly, SNPs were assigned to genes if they were within $100 \mathrm{~kb}$ of that gene. Next, the eQTLs were identified per tissue and per gene and checked whether they were eQTLs for other genes as well. Followed by pruning of the selected eQTLs based on an $r^{2}$ threshold of 0.1, the remaining SNPs were introduced into the TWMR script as provided by the manuscript [22]. During pruning, the SNP with the highest association to CPSP in the meta-analysis was kept in the analysis. Celltype and Tissue specific Protein expression of the genes significantly associated with CPSP in the TWMR was assessed using data from the protein abundance database [35]. The following human databases were assessed: B cells, CD4 T cells, 
CD8 T cells, NK cells, Monocytes, Plasma, Platelet, Spinal Cord, Frontal Cortex, Cerebral Cortex and Whole brain. If proteins were expressed in B cells, CD4 T cells, CD8 T cells, NK cells, Monocytes, Plasma or Platelet database it was determined as present in immune cells. Protein expression in Frontal Cortex and Cerebral Cortex was determined as present in cortex. Protein expression in Spinal Cord, Frontal Cortex, Cerebral Cortex and Whole Brain was determined as present in neuronal tissue.

\section{Results}

In total, genetic data was available on 841 patients after quality controls spread across the three cohorts (Hysterectomy cohort $n=303$, Abdominal and Knee replacement cohorts $n=77$, PMPS cohorts $n=461$ ). Out of the 841 patient included in the analysis, 204 developed moderate to severe CPSP (NRS $>3,24 \%$ ) and 637 controls minor to no CPSP (NRS $<4,76 \%$ ).

Ethnicity of all cohorts was checked using HapMap data and subject deviating from Caucasian background were excluded. After quality control, imputation, and datasets alignment, roughly 5 million SNPs per cohort were included in the meta-analysis. Overall association results are depicted in figure 1a. The QQ plot shows no apparent deviation from the null hypothesis of the $\mathrm{p}$ values distribution (figure $1 \mathrm{~b}$, lambda $=1.02$ ). One locus reached the genome-wide significance threshold $\left(\mathrm{p}=2.83 \mathrm{e}^{-8}, \beta=-1.46\right.$, se $=0.26$, rs17882261) with the closest located gene being SFTPA2 (surfactant protein 2A) (table 1). This locus was associated in two of three cohorts (Hys and AbKnee) but the allelic frequency was too low in the PMPS cohort to be tested. Other possible risk loci were identified but these did not reach genome-wide significance (table 1 ). 

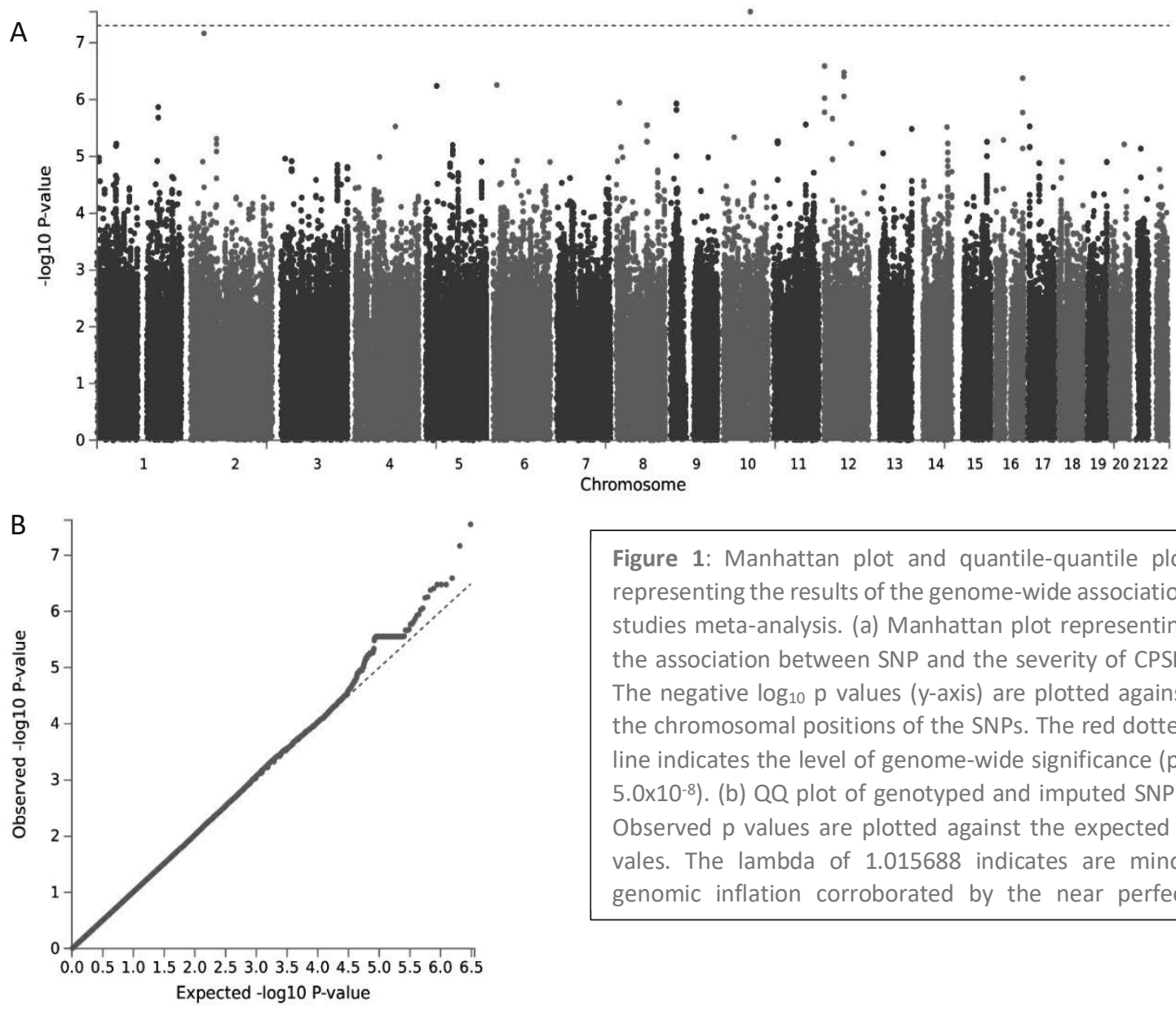

Figure 1: Manhattan plot and quantile-quantile plot representing the results of the genome-wide association studies meta-analysis. (a) Manhattan plot representing the association between SNP and the severity of CPSP. The negative $\log _{10} p$ values ( $y$-axis) are plotted against the chromosomal positions of the SNPs. The red dotted line indicates the level of genome-wide significance $(p<$ $\left.5.0 \times 10^{-8}\right)$. (b) QQ plot of genotyped and imputed SNPs. Observed $p$ values are plotted against the expected $p$ vales. The lambda of 1.015688 indicates are minor genomic inflation corroborated by the near perfect 


\begin{tabular}{|c|c|c|c|c|c|c|c|}
\hline $\begin{array}{c}\text { MARKER } \\
\text { NAME }\end{array}$ & $B$ & $S E$ & $\begin{array}{c}P- \\
V A L U E\end{array}$ & DIRECTION & HETPVAL & GENE 1 & $\begin{array}{c}G E N E \\
2\end{array}$ \\
\hline rs17882261 & -1.46 & 0.26 & $2.83^{\mathrm{E}-8}$ & $-?$ & 0.01 & SFTPA2 & - \\
\hline rs146170439 & 2.38 & 0.44 & $6.82^{\mathrm{E}-8}$ & ?+? & 1 & - & - \\
\hline rs11062375 & 1.08 & 0.21 & $2.56^{\mathrm{E}-07}$ & +++ & 0.22 & ITFG2 & - \\
\hline rs1795902 & 0.64 & 0.12 & $3.33^{\mathrm{E}-07}$ & $++?$ & 0.26 & SLC16A7 & - \\
\hline rs1693614 & -0.64 & 0.12 & $3.33^{\mathrm{E}-07}$ & $-?$ & 0.26 & SLC16A7 & - \\
\hline rs4760299 & 0.64 & 0.12 & $3.33^{\mathrm{E}-07}$ & $++?$ & 0.26 & SLC16A7 & - \\
\hline rs1693616 & 0.63 & 0.12 & $3.90^{\mathrm{E}-07}$ & $++?$ & 0.25 & SLC16A7 & - \\
\hline rs80036206 & 2.53 & 0.50 & $4.19^{\mathrm{E}-07}$ & $? ?+$ & 1 & SLC38A8 & - \\
\hline rs58672943 & -1.19 & 0.24 & $5.53^{\mathrm{E}-07}$ & $-?$ & 0.10 & - & - \\
\hline rs75714914 & 1.74 & 0.35 & $5.73^{\mathrm{E}-07}$ & $?+?$ & 1 & LOC105374715 & - \\
\hline rs1693622 & -0.61 & 0.12 & $8.78^{\mathrm{E}-07}$ & $-?$ & 0.18 & SLC16A7 & - \\
\hline rs17834697 & 0.99 & 0.20 & $9.41^{\mathrm{E}-07}$ & +++ & 0.55 & NRIP2 & ITFG2 \\
\hline rs79107778 & -1.58 & 0.32 & $1.13^{\mathrm{E}-06}$ & $-? ?$ & 1 & XKR6 & - \\
\hline rs7035861 & -0.65 & 0.13 & $1.18^{\mathrm{E}-06}$ & -- & 0.05 & - & - \\
\hline rs72712948 & 1.10 & 0.23 & $1.36^{\mathrm{E}-06}$ & ++ ? & 0.53 & - & - \\
\hline rs10810872 & -0.70 & 0.15 & $1.52^{\mathrm{E}-06}$ & - & 0.13 & - & - \\
\hline rs11062371 & -0.98 & 0.20 & $1.67^{\mathrm{E}-06}$ & - & 0.58 & NRIP2 & ITFG 2 \\
\hline rs13380582 & -2.35 & 0.49 & $1.69^{\mathrm{E}-06}$ & $? ?-$ & 1 & SLC38A8 & - \\
\hline rs56155031 & -1.08 & 0.23 & $2.07^{\mathrm{E}-06}$ & $-?$ & 0.46 & - & - \\
\hline rs1871553 & 1.86 & 0.39 & $2.16^{\mathrm{E}-06}$ & $?+?$ & 1 & SSPN & - \\
\hline rs2046066 & -1.86 & 0.39 & $2.16^{\mathrm{E}-06}$ & $?-?$ & 1 & SSPN & - \\
\hline rs7304527 & 1.86 & 0.39 & $2.16^{\mathrm{E}-06}$ & $?+?$ & 1 & SSPN & - \\
\hline
\end{tabular}


Table 1 (previous page): Results of the meta-analysis on the summary statistics of three independent chronic postsurgical pain cohorts. Results are shown per SNP including the direction of the SNP in the various cohorts, heterozygosity across the cohorts and associated genes. The order in the direction column is Hys cohort, AbKnee cohort and PMPS cohort. SE = standard error, HetPval = p-value of the heterogeneity of minor allele frequencies, $+=$ minor allele is associated with an increased severity of CPSP, - minor allele is associated with a decrease severity of CPSP and ? = minor allele was not tested in that cohort. HUGO gene symbols are: integrin alpha FG-GAP repeat containing 2, ITFG2; solute carrier family 16, member 7, SLC16A7; Surfactant protein 2A, SFTPA2; nuclear receptor interacting protein 2, NRIP2; solute carrier family 38 member 8, SLC38A8; X Kell Blood Group Precursor-Related Family, Member 6, XKR6.

To assess the potential causal relationship between SNPs associated with severity of CPSP we employed TWMR. In this approach the summary statistics of the meta-analysis were used as instrument variables, the association of those same SNPs and gene-expression in the four tissues studied was set as exposure variable and the severity of CPSP as outcome. The TWMR approach meets most of the assumptions of Mendelian randomization as it takes into account both the association between SNPs and gene-expression per tissue and clusters the SNPs and gene-expression data which is related to overcome pleiotropy.

In total, 1,391 unique potential causative genes were associated significantly with CPSP, 5 were significantly associated in all for tissue expression sets and 21 genes were significant in all the neuronal tissues (supplementary table 1, 2 and 3). In whole blood 250 potential causative genes were associated with CPSP, 579 in the cortex, 392 in the spinal cord and 423 in the DRG (figure 2 a-d, figure 3 ). The 5 genes significantly associated with CPSP in the TWMR analysis across all 4 tissues were DFNA5, NTPCR, HEATR3, NSA2 and SFXN4 (table 2). All the genes show significant association levels in all four tissues. Rs6883420 (NSA2) is the only SNP involved in all the eQTL blocks across the tissues. The 21 genes significantly associated with CPSP in the TWMR analysis across all 4 tissues were DFNA5, NTPCR, HEATR3, NSA2, SFXN4, SNAP29, EPCAM, C9orf89, PITRM1, VPS8, DCXR, SLC2A8, STYXL1, ATP5G2, SLC25A34, RPA2, ULK4, NKAIN4, PEX5, TMPRSS5 and EPHX2 (table 3). Rs113768745 (SNAP29), rs4744176 (C9orf89), 
rs62289500 (VSP8), rs41301427 (STYXL1) and rs6883420 (NSA2) were SNPs involved in all the eQTL blocks in the neuronal tissues (table 3 ).

Table 2: TWMR analysis results of the genes significantly associated with CPSP in all tissues. Results of the $T W M R$ analysis are given per tissues including the SNPs forming the eQTL block entered into the analysis. $e Q T L=$ expression quantitative trait loci, HUGO ID =human genome organisation $i d, S N P=$ single nucleotide polymorphism, DRG = dorsal root ganglion, $S C=$ spinal cord .

\begin{tabular}{|c|c|c|c|c|c|c|c|c|}
\hline $\begin{array}{l}\text { HUGO } \\
I D\end{array}$ & $\begin{array}{l}\text { Blood p- } \\
\text { value }\end{array}$ & $\begin{array}{l}\text { eQTL SNPs } \\
\text { blood }\end{array}$ & $\begin{array}{l}D R G p- \\
\text { value }\end{array}$ & $\begin{array}{l}\text { eQTL SNPs } \\
\text { in the DRG }\end{array}$ & $\begin{array}{l}S C p- \\
\text { value }\end{array}$ & $\begin{array}{l}\text { eQTL SNPs } \\
\text { in the SCc }\end{array}$ & $\begin{array}{l}\text { Cortex } p- \\
\text { value }\end{array}$ & $\begin{array}{l}\text { eQTL SNPs } \\
\text { in the cortex }\end{array}$ \\
\hline DFNAS & $2.78 \mathrm{E}-07$ & $\begin{array}{l}\text { rs2721777, } \\
\text { rs17208431, } \\
\text { rs1476521 }\end{array}$ & $\begin{array}{r}9.90 \mathrm{E}- \\
65\end{array}$ & $\begin{array}{l}\text { rs2074142, } \\
\text { rs7809654, } \\
\text { rs34081711 }\end{array}$ & $\begin{array}{r}1.84 \mathrm{E}- \\
06\end{array}$ & rs2721777 & $2.42 \mathrm{E}-09$ & $\begin{array}{l}\text { rs } 2074142, \\
\text { rs } 79724368, \\
\text { rs } 10270198, \\
\text { rs } 2721806\end{array}$ \\
\hline SFXN4 & $1.31 \mathrm{E}-08$ & $\begin{array}{l}\text { rs11198804, } \\
\text { rs12774592, } \\
\text { rs12414175, } \\
\text { rs11198805 }\end{array}$ & $\begin{array}{r}6.33 \mathrm{E}- \\
12\end{array}$ & rs7923486 & $\begin{array}{r}1.13 \mathrm{E}- \\
09\end{array}$ & rs7923486 & 7.32E-12 & $\begin{array}{l}\text { rs11198804, } \\
\text { rs11198805 }\end{array}$ \\
\hline NTPCR & $3.71 \mathrm{E}-07$ & $\begin{array}{l}\text { rs743196, } \\
\text { rs72759978, } \\
\text { rs16858464, } \\
\text { rs6676972 }\end{array}$ & $\begin{array}{r}2.57 \mathrm{E}- \\
11\end{array}$ & rs743196 & $\begin{array}{r}1.75 \mathrm{E}- \\
21\end{array}$ & rs 17355525 & 4.65E-20 & $\begin{array}{l}\text { rs743196, } \\
\text { rs72759978 }\end{array}$ \\
\hline HEATR 3 & 2.35E-08 & rs35098361 & $\begin{array}{r}1.41 \mathrm{E}- \\
08\end{array}$ & rs71138029 & $\begin{array}{r}5.53 \mathrm{E}- \\
16\end{array}$ & rs35098361 & 7.47E-16 & rs35098361 \\
\hline NSA2 & $5.37 \mathrm{E}-09$ & $\begin{array}{l}\text { rs6883420, } \\
\text { rs3968877 }\end{array}$ & $\begin{array}{r}3.90 \mathrm{E}- \\
08\end{array}$ & rs6883420 & $\begin{array}{r}1.29 \mathrm{E}- \\
07\end{array}$ & rs6883420 & 6.67E-08 & rs6883420 \\
\hline
\end{tabular}



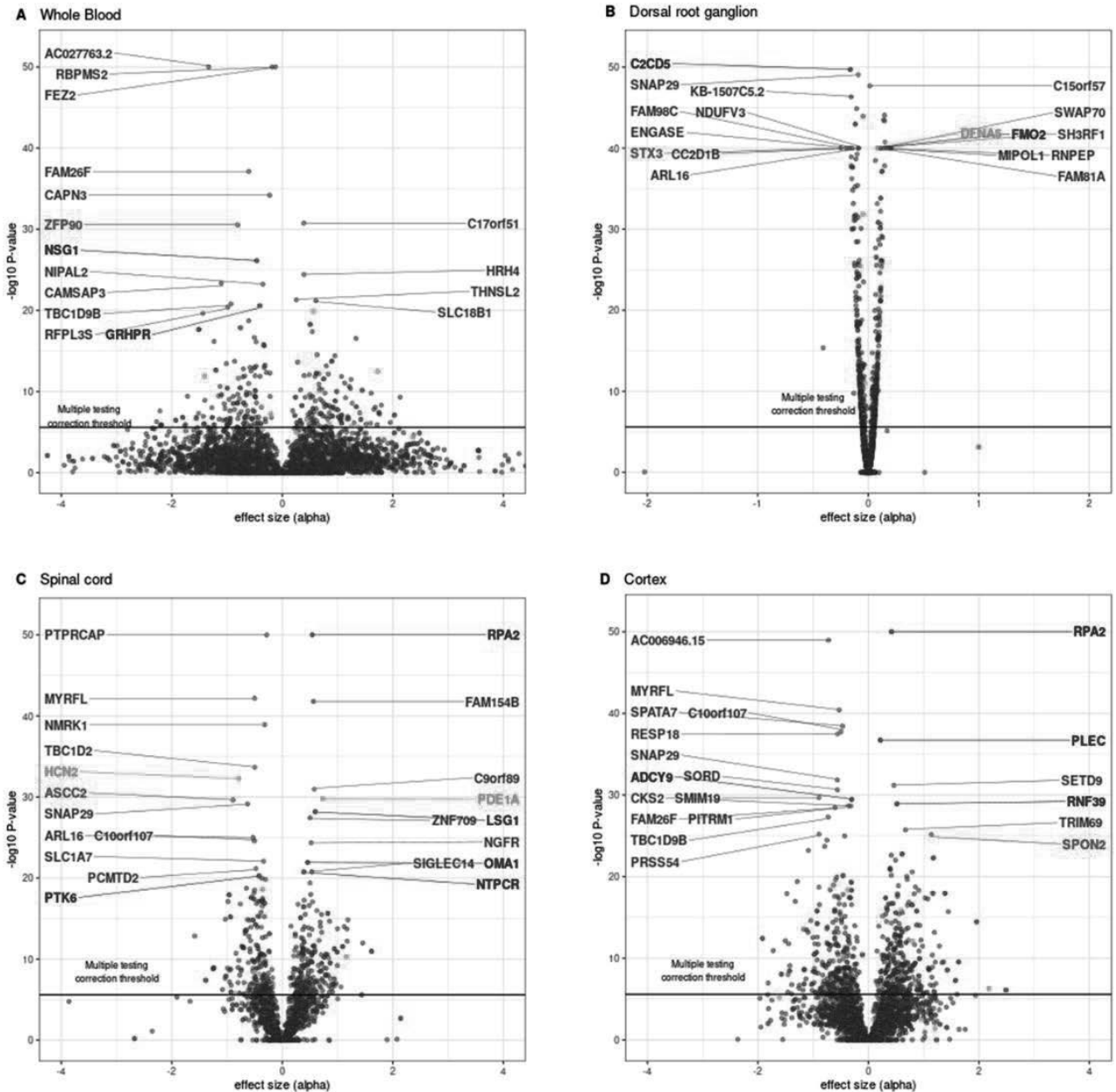

Expressed in $=$ Other = Neuronal tssue $=$ Imrune cells $=$ mmrune cells and Neuronal fssue

Figure 2: Volcano plots of the TWMR analysis results per tissue. (a) TWMR analysis result in whole blood. $-\log _{10}$ TWMR association p-value plotted on $y$-axis against the effect size alpha on the $x$-axis. Top 15 genes are annotated and all genes are identified based on protein expression in either neuronal tissue, immune cells, both or other. (b) TWMR analysis results in the dorsal root ganglion. $-\log _{10}$ TWMR association p-value plotted on $y$-axis against the effect size alpha on the $x$-axis. Top 17 genes are annotated and all genes are identified based on the protein expression in the cortex. (c) TWMR analysis results in the Spinal cord. $-\log _{10}$ TWMR association p-value plotted on $y$-axis against the effect size alpha on the $x$-axis. Top 22 genes are annotated and all genes are identified based on the protein expression in the spinal cord. (d) TWMR analysis results in the cortex. $-\log _{10}$ TWMR association p-value plotted on $y$-axis against the effect size alpha on the $x$-axis. Top 20 genes are annotated and all genes are identified based on the protein expression in either neuronal tissue, immune cells, both or other. 


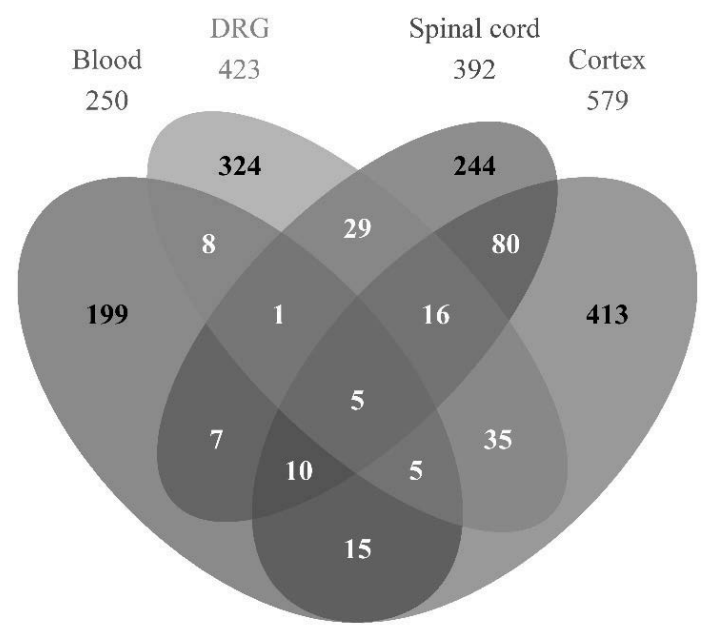

Figure 3: Venn diagram showing the number of overlapping genes across the four $\mathrm{QTL}$ datasets tested in the TWMR analysis. Four distinct eQTL datasets were used in the analysis (Blood, DRG, Spinal cord and Cortex). The number under each category indicates the number of significant genes per category whereas the numbers in the Venn diagram indicates the overlap across the tissues.

Table 3 (next page): TWMR analysis results of the genes significantly associated with CPSP in neuronal tissue. Results of the TWMR analysis are given per tissues including the SNPs forming the eQTL block entered into the analysis. eQTL = expression quantitative trait loci, ENSG ID = Ensembl ID, HUGO ID =human genome organisation id, $S N P=$ single nucleotide polymorphism, DRG = dorsal root ganglion, $S C=$ spinal cord. 


\begin{tabular}{|c|c|c|c|c|c|c|}
\hline HUGO ID & $\begin{array}{l}D R G p- \\
\text { value }\end{array}$ & $\begin{array}{l}\text { eQTL SNPs in } \\
\text { the DRG }\end{array}$ & $\begin{array}{l}S C p- \\
\text { value }\end{array}$ & $\begin{array}{l}\text { eQTL SNPs in } \\
\text { the SCc }\end{array}$ & $\begin{array}{l}\text { Cortex } p- \\
\text { value }\end{array}$ & $\begin{array}{l}\text { eQTL SNPs } \\
\text { in the cortex }\end{array}$ \\
\hline DFNA5 & $9.90 \mathrm{E}-65$ & $\begin{array}{l}\text { rs2074142, } \\
\text { rs7809654, } \\
\text { rs34081711 }\end{array}$ & $1.84 \mathrm{E}-06$ & rs2721777 & $2.42 \mathrm{E}-09$ & $\begin{array}{l}\text { rs2074142, } \\
\text { rs79724368, } \\
\text { rs10270198, } \\
\text { rs2721806 }\end{array}$ \\
\hline SNAP29 & $8.77 E-50$ & $\begin{array}{l}\text { rs113768745, } \\
\text { rs178068 }\end{array}$ & 7.19E-30 & rs113768745 & $1.40 \mathrm{E}-32$ & rs113768745 \\
\hline EPCAM & $1.35 \mathrm{E}-32$ & $\begin{array}{l}\text { rs4953495, } \\
\text { rs7581007 }\end{array}$ & $2.45 \mathrm{E}-19$ & rs77131614 & $4.32 \mathrm{E}-19$ & rs77131614 \\
\hline C9ORF89 & $2.87 \mathrm{E}-26$ & $\begin{array}{l}\text { rs4744176, } \\
\text { rs13286624 }\end{array}$ & $1.09 E-31$ & $\begin{array}{l}\text { rs4744176, } \\
\text { rs2027585 }\end{array}$ & 3.30E-12 & $\begin{array}{l}\text { rs4744176, } \\
\text { rs2027585 }\end{array}$ \\
\hline PITRM1 & $6.70 \mathrm{E}-21$ & rs7898754 & $5.94 \mathrm{E}-07$ & rs9423505 & $2.12 \mathrm{E}-29$ & $\begin{array}{l}\text { rs11251754, } \\
\text { rs76496015, } \\
\text { rs7898754, } \\
\text { rs7903088 }\end{array}$ \\
\hline VPS8 & $9.01 \mathrm{E}-21$ & rs62289500 & $1.18 \mathrm{E}-18$ & rs62286934 & $6.82 \mathrm{E}-14$ & $\begin{array}{l}\text { rs62286934, } \\
\text { rs7640976 }\end{array}$ \\
\hline$D C X R$ & $7.88 \mathrm{E}-20$ & rs72861756 & $3.54 \mathrm{E}-17$ & rs56001523 & $1.20 \mathrm{E}-06$ & rs56001523 \\
\hline$S L C 2 A B$ & $1.43 \mathrm{E}-15$ & rs10987643 & $1.28 \mathrm{E}-11$ & rs1138740 & $1.60 \mathrm{E}-06$ & $\begin{array}{l}\text { rs1138740, } \\
\text { rs17464948 }\end{array}$ \\
\hline STYXL1 & $1.68 \mathrm{E}-15$ & rs41301427 & $1.45 \mathrm{E}-10$ & rs41301427 & $5.04 \mathrm{E}-09$ & $\begin{array}{l}\text { rs41301427, } \\
\text { rs3779419 }\end{array}$ \\
\hline ATP5G2 & $2.44 \mathrm{E}-15$ & rs7312853 & $2.69 \mathrm{E}-10$ & rs11170643 & $3.51 \mathrm{E}-11$ & rs11170643 \\
\hline SFXN4 & $6.33 \mathrm{E}-12$ & rs7923486 & $1.13 \mathrm{E}-09$ & rs7923486 & 7.32E-12 & $\begin{array}{l}\text { rs11198804, } \\
\text { rs11198805 }\end{array}$ \\
\hline NTPCR & $2.57 \mathrm{E}-11$ & rs743196 & $1.75 \mathrm{E}-21$ & rs17355525 & $4.65 \mathrm{E}-20$ & $\begin{array}{l}\text { rs743196, } \\
\text { rs72759978 }\end{array}$ \\
\hline SLC25A34 & $2.78 \mathrm{E}-11$ & rs937592 & $1.48 \mathrm{E}-10$ & rs35365738 & $3.01 \mathrm{E}-13$ & rs35365738 \\
\hline RPA2 & $1.11 \mathrm{E}-10$ & rs28904914 & $4.60 \mathrm{E}-56$ & rs17185052 & $1.23 \mathrm{E}-65$ & rs17185052 \\
\hline ULK4 & $3.40 \mathrm{E}-10$ & rs7652369 & 4.41E-12 & rs145684897 & $3.88 \mathrm{E}-11$ & $\begin{array}{l}\text { rs145684897, } \\
\text { rs994439 }\end{array}$ \\
\hline HEATR3 & $1.41 \mathrm{E}-08$ & rs71138029 & $5.53 \mathrm{E}-16$ & rs35098361 & 7.47E-16 & rs35098361 \\
\hline NKAIN4 & $2.66 \mathrm{E}-08$ & rs6011700 & $2.83 \mathrm{E}-10$ & rs147378830 & $6.17 \mathrm{E}-08$ & $\begin{array}{l}\text { rs58229940, } \\
\text { rs2281566 }\end{array}$ \\
\hline NSA2 & $3.90 \mathrm{E}-08$ & rs6883420 & $1.29 \mathrm{E}-07$ & rs6883420 & $6.67 \mathrm{E}-08$ & rs6883420 \\
\hline PEX5 & $9.53 \mathrm{E}-08$ & rs7975045 & 7.61E-08 & rs1450962 & $6.37 \mathrm{E}-07$ & rs1450962 \\
\hline TMPRSS5 & $1.45 \mathrm{E}-07$ & rs4938050 & $3.15 \mathrm{E}-07$ & rs4938050 & $3.84 \mathrm{E}-11$ & rs7103478 \\
\hline EPHX2 & $2.04 \mathrm{E}-06$ & rs4149259 & $5.25 \mathrm{E}-07$ & rs1126452 & $2.52 \mathrm{E}-09$ & $\begin{array}{l}\text { rs7816586, } \\
\text { rs28368998 }\end{array}$ \\
\hline
\end{tabular}




\section{Discussion}

The results of this study present the first genome-wide significant risk locus for chronic postsurgical pain in a meta-analysis of three different cohorts. Furthermore, the TWMR analysis has shown tissue-specific potential causal genes to be significantly associated with CPSP. Five genes showed a significant association across all tissues (whole blood, cortex, spinal cord and DRG) and 21 genes showed a significant association in all neuronal tissue (cortex, spinal cord and DRG).

A fixed effect meta-analysis weighted by the standard error was performed on the summary statistics of GWAS data of three independent cohorts (Hys, AbKnee and PMPS). The findings indicate a possible risk locus for CPSP centred on rs17882261 with the nearest gene being surfactant protein 2A (SFTPA2). This SNP has not been associated before in any GWAS or study on pain $[36,37]$.

The TWMR analysis with multiple instruments and multiple exposures identified potential causal genes associated with CPSP. The power of the TWMR analysis is the possibility to identify tissue specific associated genes by focusing on single tissue results as well as identifying trends across tissues. In this study, two tissue sets (Whole blood focusing on immune cells and neuronal tissue comprised of DRG, spinal cord and cortex tissue) were used to prioritize potential causal genes associated with CPSP. 5 genes were associated with CPSP in the TWMR analysis in both tissue sets (DFNA5, SFXN4, NTPCR, HEATR3 and NSA2). Rs6883420 in NSA2 is a potential candidate as it was in the eQTL block for each tissue. In the neuronal tissue, 21 genes were identified who were associated with CPSP in the TWMR analysis. Of these genes, rs113768745 (SNAP29), rs4744176 (C9orf89), rs62289500 (VSP8), rs41301427 (STYXL1) and rs6883420 (NSA2) were SNPs involved in all the eQTL blocks in the neuronal tissues. Rs62289500 (VPS8) is an intronic variant within Vacuolar Protein Sorting-Associated Protein 8 Homolog and this gene has been associated the immune system, brain morphology and 
cognitive performance [36]. Rs113768745 (SNAP29) is an intronic variant within synaptosome associated protein 29 and members of this gene family have been associated with fibromyalgia [37, 38]. Loss of SNAP29 has been associated with a decrease in endocytic recycling within the cell and a decrease in cell motility. This led to a dysfunctional wound healing and neurological abnormalities [39, 40]. Furthermore, SNAP29 is involved in synaptic vesicle trafficking, specifically inhibiting synaptic transmission in an activity dependent manner and involved in mast cell phagocytosis $[41,42]$. This combined evidence indicates a modulatory role for fine-tuning cellular growth and immune cell functioning and alterations to the expression of this gene could affect repair mechanisms contributing to the development of chronic pain. The other genes have not been associated in any GWAS or study on pain $[36,37]$. These findings suggest a potential role for both the immune system and nervous system in the pathophysiology of CPSP.

The findings of this study could be utilised in clinical practice in risk prediction modelling. Polygenic risk scores (PRS) are computed by the sum of risk alleles for a given phenotype weighted by the effect size estimate provided by a GWAS and it indicates an increased or decreased likelihood in developing a phenotype [43]. PRSs have been successfully applied in prediction and response to medication of both psychological disorders and migraine [44-48]. Research in diabetes and oncology have shown that PRSs could have a higher predictive accuracy than currently available prediction models [49]. Combining the clinical and genetic risk predictions could lead to an additive effect whereby both influence each other. A recent clinical prediction model on CPSP showed an increase in predictive power by adding a single SNP to the model [50]. Although this increase was not significant, including a complete PRS would definitively lead to a significantly improved prediction model [50]. 
The potential causative genes for CPSP identified in this study are not definitive yet. More efforts are necessary to shed light on the biological mechanisms of these association [15]. However, these results do function as a prioritized list of SNPs and genes to follow-up upon. Experimental studies in in vitro models (i.e. cell cultures) and in vivo models (e.g. zebrafish or mice) are necessary to understand the biological effects of altered gene-expression both on cellular level and on the whole organism [51]. Recent techniques, including CRISPR-Cas9, have made it possible to introduce specific mutations and study there effects. As these techniques mature, their specificity and effectiveness will increase further [51-53]. Furthermore, larger sample size is necessary in both the GWAS studies on CPSP and the eQTL datasets. Larger sample sizes will lead to better estimate of association, effects sizes and in the case of eQTL datasets better inventory of possible pleiotropic effects [22]. This will lead to a better prioritization and more accurate results.

In conclusion, this study has identified the first genome-wide significant locus associated with the severity of CPSP and both tissue specific as well as combined tissue set specific potential causative genes. The identified locus and genes are in need of further functional follow-up studies to identify underlying biological mechanisms and confirm the potential causal relationship. Larger sample sizes and follow-up studies are necessary to further increase the accuracy and efficiency of the techniques employed in this study. 


\section{Acknowledgement}

This work was supported by funds made available by Department of Anaesthesiology (Maastricht University Medical Center+ (MUMC+), and School of Mental Health, and Neuroscience (MHeNS, University of Maastricht). This project has been supported by the Foundation "De Drie Lichten" in The Netherlands. This work was funded by the Canadian Excellence Research Chairs (CERC09) to Luda Diatchenko.

We would like to thank all the medical centers participating in this research and providing data consisting of Italian Pain Group, University of Pittsburgh, McGill University and Maastricht University Medical Center+.

Dr. Belfer contributed to this article in her personal capacity. The views expressed are her own and do not necessarily represent the views of the National Institutes of Health or the United States Government. 


\section{References}

1. Kehlet H, Jensen TS, Woolf CJ: Persistent postsurgical pain: risk factors and prevention. The Lancet 2006, 367(9522):1618-1625.

2. Parsons B, Schaefer C, Mann R, Sadosky A, Daniel S, Nalamachu S, Stacey BR, Nieshoff EC, Tuchman M, Anschel A: Economic and humanistic burden of post-trauma and postsurgical neuropathic pain among adults in the United States. Journal of pain research 2013, 6:459.

3. Schug SA, Lavand'homme P, Barke A, Korwisi B, Rief W, Treede R-D, Pain TITftCoC: The IASP classification of chronic pain for ICD-11: chronic postsurgical or posttraumatic pain. PAIN 2019, 160(1):45-52.

4. Katz J, Seltzer Ze: Transition from acute to chronic postsurgical pain: risk factors and protective factors. Expert Rev Neurother 2009, 9(5):723-744.

5. Clarke H, Katz J, Flor H, Rietschel M, Diehl SR, Seltzer Z: Genetics of chronic post-surgical pain: a crucial step toward personal pain medicine. Canadian Journal of Anesthesia 2015, 62(3):294-303.

6. Burri A, Ogata S, Rice D, Williams FMK: Twelve-year follow-up of chronic pain in twins: Changes in environmental and genetic influence over time. European journal of pain (London, England) 2018.

7. Carvalho ESA, Harmer AR, Pinheiro MB, Madrid-Valero JJ, Ferreira M, Ordonana JR, P HF: Does the heritability of chronic low back pain depend on how the condition is assessed? European journal of pain (London, England) 2019, 23(9):1712-1722.

8. Battié MC, Videman T, Levalahti E, Gill K, Kaprio J: Heritability of low back pain and the role of disc degeneration. PAIN 2007, 131(3):272-280.

9. Zondervan KT, Cardon LR, Kennedy SH, Martin NG, Treloar SA: Multivariate Genetic Analysis of Chronic Pelvic Pain and Associated Phenotypes. Behavior Genetics 2005, 35(2):177-188.

10. Hoofwijk DMN, van Reij RRI, Rutten BP, Kenis G, Buhre WF, Joosten EA: Genetic polymorphisms and their association with the prevalence and severity of chronic postsurgical pain: a systematic review. British Journal of Anaesthesia 2016, 117(6):708-719.

11. Montes A, Roca G, Sabate S, Lao JI, Navarro A, Cantillo J, Canet J, Group GS: Genetic and Clinical Factors Associated with Chronic Postsurgical Pain after Hernia Repair, Hysterectomy, and Thoracotomy: A Two-year Multicenter Cohort Study. Anesthesiology 2015, 122(5):1123-1141.

12. Costigan M, Belfer I, Griffin RS, Dai F, Barrett LB, Coppola G, Wu T, Kiselycznyk C, Poddar M, Lu Y et al: Multiple chronic pain states are associated with a common amino acid-changing allele in KCNS1. Brain : a journal of neurology 2010, 133(9):2519-2527.

13. Belfer I, Dai F, Kehlet H, Finelli P, Qin L, Bittner R, Aasvang EK: Association of functional variations in COMT and GCH1 genes with postherniotomy pain and related impairment. Pain 2015, 156(2):273-279. 
14. van Reij RRI, Hoofwijk DMN, Rutten BPF, Weinhold L, Leber M, Joosten EAJ, Ramirez A, van den Hoogen NJ, Italian Pain G: The association between genome-wide polymorphisms and chronic postoperative pain: a prospective observational study. Anaesthesia 2020, 75 Suppl 1:e111-e120.

15. Gallagher MD, Chen-Plotkin AS: The Post-GWAS Era: From Association to Function. The American Journal of Human Genetics 2018, 102(5):717-730.

16. Albert FW, Kruglyak L: The role of regulatory variation in complex traits and disease. Nat Rev Genet 2015, 16(4):197-212.

17. Rockman MV, Kruglyak L: Genetics of global gene expression. Nature Reviews Genetics 2006, 7:862.

18. Consortium G: Genetic effects on gene expression across human tissues. Nature 2017, 550:204.

19. Ji RR, Nackley A, Huh Y, Terrando N, Maixner W: Neuroinflammation and Central Sensitization in Chronic and Widespread Pain. Anesthesiology 2018, 129(2):343-366.

20. Ji RR, Chamessian A, Zhang YQ: Pain regulation by non-neuronal cells and inflammation. Science 2016, 354(6312):572-577.

21. Schramm K, Marzi C, Schurmann C, Carstensen M, Reinmaa E, Biffar R, Eckstein G, Gieger C, Grabe HJ, Homuth G et al: Mapping the genetic architecture of gene regulation in whole blood. PLoS One 2014, 9(4):e93844.

22. Porcu E, Rüeger S, Lepik K, e QC, Consortium B, Santoni FA, Reymond A, Kutalik Z: Mendelian randomization integrating GWAS and eQTL data reveals genetic determinants of complex and clinical traits. Nature communications 2019, 10(1):3300-3300.

23. Davey Smith G, Ebrahim S: 'Mendelian randomization': can genetic epidemiology contribute to understanding environmental determinants of disease?*. International Journal of Epidemiology 2003, 32(1):1-22.

24. Theunissen M, Peters ML, Schepers J, Maas JW, Tournois F, van Suijlekom HA, Gramke H-F, Marcus MA: Recovery 3 and 12 months after hysterectomy: epidemiology and predictors of chronic pain, physical functioning, and global surgical recovery. Medicine 2016, 95(26):e3980.

25. Bugada D, De Gregori M, Compagnone C, Muscoli C, Raimondi F, Bettinelli S, Avanzini MA, Cobianchi L, Peloso A, Baciarello M: Continuous wound infusion of local anesthetic and steroid after major abdominal surgery: study protocol for a randomized controlled trial. Trials 2015, 16(1):357.

26. Belfer I, Schreiber KL, Shaffer JR, Shnol H, Blaney K, Morando A, Englert D, Greco C, Brufsky A, Ahrendt G et al: Persistent postmastectomy pain in breast cancer survivors: analysis of clinical, demographic, and psychosocial factors. J Pain 2013, 14(10):1185-1195.

27. Purcell S, Neale B, Todd-Brown K, Thomas L, Ferreira MA, Bender D, Maller J, Sklar P, de Bakker PI, Daly MJ et al: PLINK: a tool set for whole-genome association and populationbased linkage analyses. American journal of human genetics 2007, 81(3):559-575.

28. Chang CC, Chow CC, Tellier LC, Vattikuti S, Purcell SM, Lee JJ: Second-generation PLINK: rising to the challenge of larger and richer datasets. Gigascience 2015, 4(1):7. 
29. Das S, Forer L, Schonherr S, Sidore C, Locke AE, Kwong A, Vrieze SI, Chew EY, Levy S, McGue $\mathrm{M}$ et al: Next-generation genotype imputation service and methods. Nature genetics 2016, 48(10):1284-1287.

30. Loh PR, Danecek P, Palamara PF, Fuchsberger C, Y AR, H KF, Schoenherr S, Forer L, McCarthy S, Abecasis GR et al: Reference-based phasing using the Haplotype Reference Consortium panel. Nature genetics 2016, 48(11):1443-1448.

31. McCarthy S, Das S, Kretzschmar W, Delaneau O, Wood AR, Teumer A, Kang HM, Fuchsberger C, Danecek P, Sharp K et al: A reference panel of 64,976 haplotypes for genotype imputation. Nature genetics 2016, 48(10):1279-1283.

32. Willer CJ, Li Y, Abecasis GR: METAL: fast and efficient meta-analysis of genomewide association scans. Bioinformatics 2010, 26(17):2190-2191.

33. Parisien M, Khoury S, Chabot-Doré A-J, Sotocinal SG, Slade GD, Smith SB, Fillingim RB, Ohrbach R, Greenspan JD, Maixner W et al: Effect of Human Genetic Variability on Gene Expression in Dorsal Root Ganglia and Association with Pain Phenotypes. Cell Reports 2017, 19(9):1940-1952.

34. Consortium G: The Genotype-Tissue Expression (GTEx) pilot analysis: multitissue gene regulation in humans. Science 2015, 348(6235):648-660.

35. Wang M, Herrmann CJ, Simonovic M, Szklarczyk D, von Mering C: Version 4.0 of PaxDb: Protein abundance data, integrated across model organisms, tissues, and cell-lines. Proteomics 2015, 15(18):3163-3168.

36. Buniello A, MacArthur JAL, Cerezo M, Harris LW, Hayhurst J, Malangone C, McMahon A, Morales J, Mountjoy E, Sollis E: The NHGRI-EBI GWAS Catalog of published genomewide association studies, targeted arrays and summary statistics 2019. Nucleic acids research 2019, 47(D1):D1005-D1012.

37. Meloto CB, Benavides R, Lichtenwalter RN, Wen X, Tugarinov N, Zorina-Lichtenwalter K, Chabot-Doré A-J, Piltonen MH, Cattaneo S, Verma V: The Human Pain Genetics Database (HPGDB): a resource dedicated to human pain genetics research. Pain 2017.

38. Balkarli A, Sengul C, Tepeli E, Balkarli H, Cobankara V: Synaptosomal-associated protein 25 (Snap-25) gene polymorphism frequency in fibromyalgia syndrome and relationship with clinical symptoms. BMC musculoskeletal disorders 2014, 15:191.

39. Keser V, Lachance JB, Alam SS, Lim Y, Scarlata E, Kaur A, Zhang TF, Lv S, Lachapelle P, O'Flaherty C et al: Snap29 mutant mice recapitulate neurological and ophthalmological abnormalities associated with 22q11 and CEDNIK syndrome. Communications biology 2019, 2:375.

40. Rapaport D, Lugassy Y, Sprecher E, Horowitz M: Loss of SNAP29 impairs endocytic recycling and cell motility. PLoS One 2010, 5(3):e9759.

41. Wesolowski J, Caldwell V, Paumet F: A novel function for SNAP29 (synaptosomalassociated protein of $29 \mathrm{kDa}$ ) in mast cell phagocytosis. PLoS One 2012, 7(11):e49886.

42. Su Q, Mochida S, Tian JH, Mehta R, Sheng ZH: SNAP-29: a general SNARE protein that inhibits SNARE disassembly and is implicated in synaptic transmission. Proceedings of the National Academy of Sciences of the United States of America 2001, 98(24):14038-14043. 
43. Choi SW, Mak TSH, O'reilly P: A guide to performing Polygenic Risk Score analyses. BioRxiv 2018:416545.

44. Kogelman LJA, Esserlind A-L, Francke Christensen A, Awasthi S, Ripke S, Ingason A, Davidsson OB, Erikstrup C, Hjalgrim H, Ullum $\mathrm{H}$ et al: Migraine polygenic risk score associates with efficacy of migraine-specific drugs. Neurol Genet 2019, 5(6):e364-e364.

45. Ward J, Graham N, Strawbridge RJ, Ferguson A, Jenkins G, Chen W, Hodgson K, Frye M, Weinshilboum R, Uher $\mathrm{R}$ et al: Polygenic risk scores for major depressive disorder and neuroticism as predictors of antidepressant response: Meta-analysis of three treatment cohorts. PLOS ONE 2018, 13(9):e0203896.

46. Ruderfer DM, Kirov G, Chambert K, Moran JL, Owen MJ, O'Donovan MC, Sklar P, Purcell SM: A family-based study of common polygenic variation and risk of schizophrenia. Molecular Psychiatry 2011, 16(9):887-888.

47. Kauppi K, Westlye LT, Tesli M, Bettella F, Brandt CL, Mattingsdal M, Ueland T, Espeseth T, Agartz I, Melle I et al: Polygenic Risk for Schizophrenia Associated With Working Memory-related Prefrontal Brain Activation in Patients With Schizophrenia and Healthy Controls. Schizophrenia Bulletin 2014, 41(3):736-743.

48. Levine ME, Crimmins EM, Prescott CA, Phillips D, Arpawong TE, Lee J: A Polygenic Risk Score Associated with Measures of Depressive Symptoms Among Older Adults. Biodemography and Social Biology 2014, 60(2):199-211.

49. Martin AR, Kanai M, Kamatani Y, Okada Y, Neale BM, Daly MJ: Clinical use of current polygenic risk scores may exacerbate health disparities. Nature genetics 2019, 51(4):584-591.

50. Hoofwijk DMN, van Reij RRI, Rutten BPF, Kenis G, Theunissen M, Joosten EA, Buhre WF, van den Hoogen NJ: Genetic polymorphisms and prediction of chronic post-surgical pain after hysterectomy-a subgroup analysis of a multicenter cohort study. Acta Anaesthesiol Scand 2019, 63(8):1063-1073.

51. Cannon ME, Mohlke KL: Deciphering the Emerging Complexities of Molecular Mechanisms at GWAS Loci. The American Journal of Human Genetics 2018, 103(5):637-653.

52. Thakore PI, D'ippolito AM, Song L, Safi A, Shivakumar NK, Kabadi AM, Reddy TE, Crawford GE, Gersbach CA: Highly specific epigenome editing by CRISPR-Cas9 repressors for silencing of distal regulatory elements. Nature methods 2015, 12(12):1143.

53. Zhang F, Wen Y, Guo X: CRISPR/Cas9 for genome editing: progress, implications and challenges. Human molecular genetics 2014, 23(R1):R40-R46. 
112 | Chapter 4 
CHAPTER 5

\section{Polygenic risk scores indicates genetic overlap between peripheral pain syndromes and Chronic Postsurgical Pain}

R. R. I. van Reij, J-W. Voncken, E. A. J. Joosten,

N. J. van den Hoogen

Neurogenetics 2020, 1-11.

PMID 32377986, Doi: 10.1007/s10048-02०-0७614-5

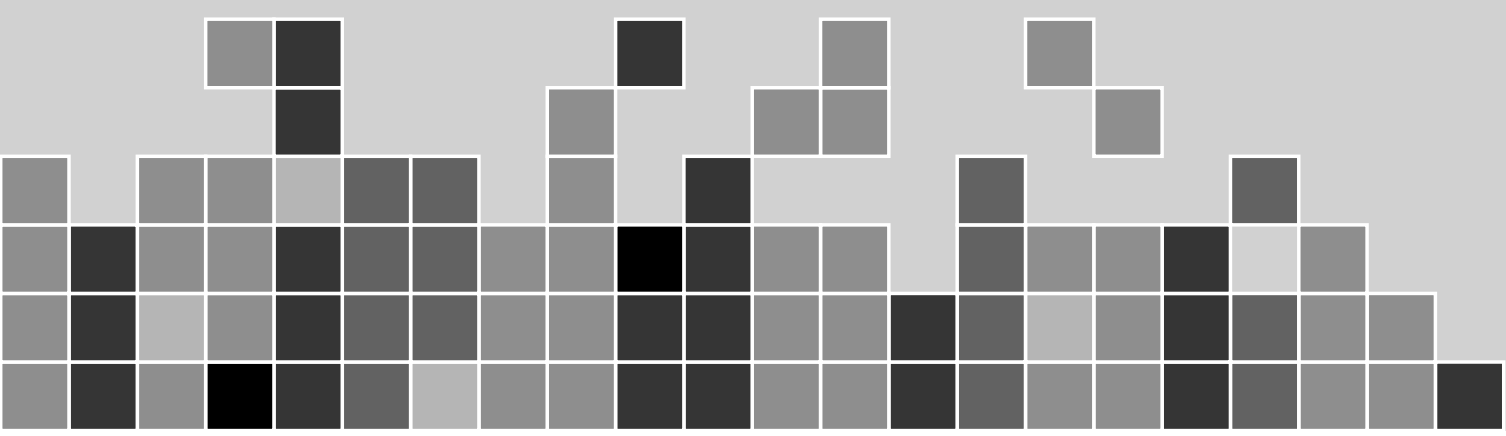


$114 \mid$ Chapter 5 


\begin{abstract}
Chronic Post-Surgical Pain (CPSP) is a debilitating chronic pain condition that has a substantial effect on quality of life. CPSP shows considerable clinical overlap with different chronic peripheral pain syndromes which suggests a shared aetiology. However, why some patients develop CPSP whereas others do not, and the nature of underlying molecular processes that contribute to chronic pain, are incompletely understood. This study aims to assess whether different chronic pain syndromes show genetic overlap with CPSP and to provide relevant biological context for potential chromic pain markers of CPSP.
\end{abstract}

To analyse the genetic overlap between CPSP and chronic peripheral pain syndromes, recent GWAS studies were combined for polygenic risk scores (PRS) analysis, using patients who developed CPSP and those who did not as a starting point. Biological contextualisation of shared genetic markers overlap between CPSP and chronic pain syndromes was assessed using Gene Ontology (GO) and Pathway Scoring Algorithm (PASCAL).

A significant genetic overlap was found between 3 of CPSP and chronic pain disorders: Sciatica ( $\mathrm{p}$ value threshold $\left.=0.00025, \mathrm{R}^{2}=0.03, \mathrm{p}=0.045\right)$, Chronic widespread pain ( $\mathrm{p}$ value threshold $=0.003, R^{2} 0.06, p=0.003$ ) and Rheumatoid arthritis ( $\mathrm{p}$ value threshold $=$ $0.0177, \mathrm{R}^{2}=0.04, \mathrm{p}=0.017$ ). No significant genetic overlap was found with osteoarthritis, cluster headache and migraine. The GO analyses suggested an aetiological involvement of genetic markers that control neurological signalling (specifically sodium channels) and inflammatory response.

In conclusion, this study is the first to report genetic overlap between regulatory processes implicated in CPSP and chronic peripheral pain syndromes. The genes involved in the genetic overlap are related to the regulation of neurological signalling and inflammatory responses. Enhanced understanding of mechanisms underlying chronification of pain will aid the development of new preventative therapeutic strategies for CPSP.

Key words: PRS, chronic pain, CPSP, SNP 


\section{Introduction}

Chronic Post-Surgical Pain (CPSP) is a debilitating chronic pain condition that affects patients who underwent surgery and has a substantial effect on the quality of life (QoL) and socioeconomic status [1-3]. CPSP is defined as "pain developed or increased after a surgical procedure, which is present for at least three months, and affecting the QoL" $[4,5]$. Depending on the type of surgery, 5-85\% of the patients may experience pain localized to the surgical field or the projected innervation area of a nerve $[4,6]$. Clinical (e.g. type/duration of surgery), demographical (e.g. age, biological sex) and psychological (e.g. anxiety) risk factors of CPSP can account for $78 \%$ of the variance in the development of CPSP $[7,8]$. Although recent evidence (both GWAS and gene-targeted studies) defines a potential role for genetic risk factors in CPSP, the limited CPSP sample size in comparison to studies of other chronic pain syndromes has thus far not provided clear candidate genes for CPSP [9-12]. While increasing sample size for GWAS analyses holds the potential for unambiguous identification of genetic risk factors, genetic mechanisms underlying CPSP may be probed indirectly by determination of common genetic factors with other pain syndromes. Polygenic risk scores (PRS) allow testing for genetic correlation (i.e. overlap) between different phenotypes $[13,14]$. Establishing the intersection and/or overlap of genetic networks between various chronic pain syndromes may help define common mechanisms in chronic pain and provide starting points for functional and intervention studies.

CPSP shows considerable overlap with different chronic peripheral pain syndromes (CPPs), among which sciatic pain, chronic widespread pain, osteoarthritis and rheumatoid arthritis with regard to demographical and psychological risk factors: chronic pain occurs most often in women, is associated with age and with psychological syndromes [15-17].

Although such observational studies suggest a shared aetiology between CPSP and chronic peripheral pain syndromes, the identity and interplay of underlying 
genetic causes and molecular processes that contribute to chronic pain, are incompletely understood [15-17]. Therefore, this study aims to assess whether different chronic pain syndromes show genetic overlap with CPSP and to provide relevant biological context for potential genetic risk factors. Ultimately, identification of novel targets is expected to pave the way for a better understanding of cellular and molecular mechanisms in CPSP and provide therapeutic opportunities.

\section{Methods}

To assess whether chronic pain syndrome show genetic overlap with CPSP, we assessed several available datasets against a discovery and replication cohort of CPSP patients. The protocol for this study was reviewed and approved by the local Medical Ethical Committees (both discovery and replication study); all participants have provided written informed consent. The discovery cohort was registered at the Dutch trial registry under the number NTR2702 (http://www.trialregister.nl/trialreg/index.asp). The replication cohort was registered at the Clinical Trials registry under the number NCT02002663 and NCT01989351 (https://clinicaltrials.gov/ct2/home).

\section{Genome-wide association analysis}

An elaborate description of patient recruitment, sample and data collection protocols for the discovery and replication cohorts has been published elsewhere $[8,9,18]$. In brief, a multicentre cohort study was conducted in four hospitals in the Netherlands (discovery cohort, $n=303$ ) and three hospitals in Italy (replication cohort, $n=77$ ). DNA-samples were genotyped at the Department of Genomics at the Life and Brain Center, University of Bonn using the Illumina PsychArray (Infinium PsychArray-24 v1.2 Bead Chip, Illumina Inc., USA). Genotypes were called using BeadStudio (Genome Studio v2011.1, Illumina). Basic quality control was done using Plink (Plink-1.9) [19, 20]. 
The quality control parameters consisted of: SNP call rate $<0.95$, subject call rate of $<0.95$, deviation of Hardy-Weinberg equilibrium $\left(\mathrm{P}<1 \times 10^{-6}\right)$ and removal of rare variants with a minor allele frequency $<0.01$. Heterozygosity of the subjects was tested and outliers $( \pm 3$ SD from the mean heterozygosity rate) were removed. Genotype imputation was performed using the stepwise imputation approach implemented in Minimac3 (https://genome.sph.umich.edu/wiki/Minimac3; University of Michigan, Ann Arbor, USA) and Eagle2 (https://data.broadinstitute.org/alkesgroup/Eagle/; Broad Institute, Cambridge, USA v2.3) using default parameter settings and a European HRC reference panel (http://www.haplotype-reference-consortium.org/; version r1.1 2016 ) [21-23].

$\begin{array}{llllll}\text { GWAS was carried } & \text { out using } & \text { SNPTEST } & \text { v2.5.4 }\end{array}$ (https://mathgen.stats.ox.ac.uk/genetics_software/snptest/snptest.html; Oxford University, Oxford, United Kingdom) [24, 25]. The primary outcome measured in the discovery cohort was the highest surgery-related pain score measured by a Numeric Rating Scale (NRS), recorded at rest during the last week, three months post- surgery $[8,9]$. Based on the primary outcome measure, patients were divided into a non-CPSP $(\mathrm{NRS}=0)$ and a CPSP $(\mathrm{NRS}>3)$ group.

\section{Cohort selection for polygenic risk score calculation}

To analyse the genetic overlap between CPSP and chronic peripheral pain syndromes, recent GWAS studies were used to form PRS scores in order to differentiate between patients who developed CPSP and those who did not. Using PubMed, we identified 6 GWAS reports on chronic pain syndromes (sciatic pain, migraine, chronic widespread pain, osteoarthritis, rheumatoid arthritis and cluster headache) meeting the inclusion criteria $[11,12,26-30]$ : The headache related disorders (migraine and cluster headache) were selected as negative control due to a different pathophysiology [31, 32]. 7,208 SNPs were reported as summary statistics in migraine, of which 214 were present after pruning in the discovery cohort and 207 after pruning in the replication cohort [11]. 14,167 SNPs were 
reported as summary statistics in cluster headache, of which 6,906 were present after pruning in the discovery cohort and 7,438 after pruning in the replication cohort [28]. 89 SNPs were reported as summary statistics in chronic widespread pain, of which 34 were present after pruning in the discovery cohort and 35 after pruning in the replication cohort [26]. 129 SNPs were reported as summary statistics in osteoarthritis, of which 74 were present after pruning in the discovery cohort and 76 after pruning in the replication cohort [27]. 297,081 SNPs were reported as summary statistics in rheumatoid arthritis, of which 50,294 were present after pruning in the discovery cohort and 51,834 after pruning in the replication cohort [29]. 380,066 SNPs were reported as summary statistics in sciatica, of which 20,744 were present after pruning in the discovery cohort and 19,053 after pruning in the replication cohort [12]. All SNPs included in the analysis per study per cohort can be found in supplementary file 1 .

Table 1 Articles included in the PRS analysis

\begin{tabular}{|c|c|c|c|c|c|c|}
\hline AUTHOR & $Y E A R$ & CONDITION & POPULATION & SEX & $\begin{array}{l}\text { SAMPLE SIZE } \\
\text { (CASES-CONTROLS) }\end{array}$ & $\begin{array}{l}\text { SNPS } \\
\text { REPORTED }\end{array}$ \\
\hline van Reij et al., & 2019 & $\begin{array}{l}\text { Chronic Post- } \\
\text { Surgical Pain }\end{array}$ & $\begin{array}{l}\text { European } \\
\text { Ancestry }\end{array}$ & Women & $\begin{array}{l}439 \\
(45-394)\end{array}$ & $6,241,991$ \\
\hline Gormley et al., & 2016 & Migraine & $\begin{array}{l}\text { European } \\
\text { ancestry }\end{array}$ & $\begin{array}{l}\text { Men \& } \\
\text { Women }\end{array}$ & $\begin{array}{l}375,752 \\
(59,674-316,078)\end{array}$ & 7,208 \\
\hline Bacchelli et al., & 2016 & $\begin{array}{l}\text { Cluster } \\
\text { Headache }\end{array}$ & Italian & $\begin{array}{l}\text { Men \& } \\
\text { Women }\end{array}$ & $\begin{array}{l}458 \\
(99-359)\end{array}$ & 14,167 \\
\hline Peters et al., & 2013 & $\begin{array}{l}\text { Chronic } \\
\text { widespread } \\
\text { pain }\end{array}$ & $\begin{array}{l}\text { European } \\
\text { ancestry }\end{array}$ & Women & $\begin{array}{l}16,568 \\
(2,788-13,780)\end{array}$ & 89 \\
\hline Zeggini et al., & 2012 & Osteoarthritis & $\begin{array}{l}\text { European } \\
\text { ancestry }\end{array}$ & $\begin{array}{l}\text { Men \& } \\
\text { Women }\end{array}$ & $\begin{array}{l}50,411 \\
(7,473-42,938)\end{array}$ & 129 \\
\hline Plenge et al., & 2007 & $\begin{array}{l}\text { Rheumatoid } \\
\text { arthritis }\end{array}$ & $\begin{array}{l}\text { North America } \\
\text { and Sweden }\end{array}$ & $\begin{array}{l}\text { Men \& } \\
\text { Women }\end{array}$ & $\begin{array}{l}3,372 \\
(1522-1850)\end{array}$ & 297,081 \\
\hline Lemmela et al., & 2016 & Sciatica & Finnish & $\begin{array}{l}\text { Men \& } \\
\text { Women }\end{array}$ & $\begin{array}{l}3,961 \\
(291-3,671)\end{array}$ & 380,066 \\
\hline
\end{tabular}




\section{Shared genetic background analysis}

The polygenic risk score analysis tool PRSice, was used to determine genetic overlap between chronic pain syndromes and CPSP [33]. Summary statistics of published studies on chronic pain syndromes were used as 'reference dataset and the data of the discovery and replication cohorts after quality control (described in the original publication) as 'target phenotype' sample [9, 11, 12, 26-29]. The target phenotype was considered a dichotomous variable, defined as presence of CPSP (yes or no) and the base phenotypes were used to differentiate between presence and absence of CPSP.

PRS analysis settings comprised pruning based on linkage disequilibrium $\left(\mathrm{r}^{2}>0.1\right)$ within a $250 \mathrm{~kb}$ window and incrementally increasing summary statistic $p$-value threshold starting at $\mathrm{p}<0.0001$ (increasing with increments of 0.00005 ) [34]. This determines optimal SNPs fit with regard to predicting polygenic risk score. Identical parameters were used for the discovery and replication cohorts.

\section{Pathway analysis}

Biological context for potential genetic overlap between CPSP and chronic pain syndromes was assessed using Pathway Scoring Algorithm (PASCAL) [35]. The input data consisted of all SNPs of significant PRSs for both the discovery cohort and the replication cohort using p-values reported in the original publications [12, 26, 29]. Pathway scoring was done using the biological processes (BPGO), molecular function (MFGO) and cell component (CCGO) databases of the gene ontology resource $(\mathrm{GO})[36,37]$. Pathway enrichment was assessed by comparing enrichment score of the provided gene-sets with a random sampling permutationbased distribution per pathway. To correct for multiple testing the empirical $p$ values of the PASCAL enrichment were corrected using the p.adjust function with false discovery rate (FDR) in $\mathrm{R}[38,39]$. Clustering of GO terms were visualized using REVIGO based on GO id's and PASCAL p-values with similarity set to 
small, similarity measure to SimRel and using the uniport database as a reference [40].

\section{Statistics}

GWAS data was analysed using logistic regression and the p-values were corrected for the number of SNPs analysed using Bonferroni correction. PRSice was used to determine polygenic risk scores of SNPs obtained from analysis of the base dataset weighted by their respective effect sizes [34]. The PRS scores were calculated assuming an additive model with the following equation:

$$
\mathrm{PRS} j=\frac{\mathrm{S} i \times \mathrm{G} i j}{\mathrm{M} j}
$$

Where $S$ denotes the summary statistics for the effective allele of SNP $i$, G denotes the number of effective alleles observed for individual $j$ for SNP $i$ and M denotes the number of alleles included in the PRS of the individual $j$. Significance was set at $\mathrm{p} \leq 0.05$. All graphs were visualized using $\mathrm{R}$ [39].

\section{Results}

Analysis of genetic overlap between chronic pain syndromes and CPSP discovery cohort

PRS was used to assess genetic overlap between the chronic pain phenotypes and the discovery cohort of CPSP. A significant genetic overlap was found between 3 of CPSP and chronic pain disorders: Sciatica ( $\mathrm{p}$ value threshold $=0.00025, \mathrm{R}^{2}=$ $0.03, \mathrm{p}=0.045$ ), Chronic widespread pain ( $\mathrm{p}$ value threshold $=0.003, \mathrm{R}^{2} 0.06, \mathrm{p}=$ 0.003 ) and Rheumatoid arthritis ( $\mathrm{p}$ value threshold $=0.0177, \mathrm{R}^{2}=0.04, \mathrm{p}=0.017$ ). No significant genetic overlap was found with osteoarthritis, cluster headache and migraine (Figure 1, supplementary table 1). This finding suggested significant genetic overlap between sciatica, chronic widespread pain and rheumatoid arthritis and CPSP but no genetic overlap between cluster headache, migraine and osteoarthritis and CPSP. 


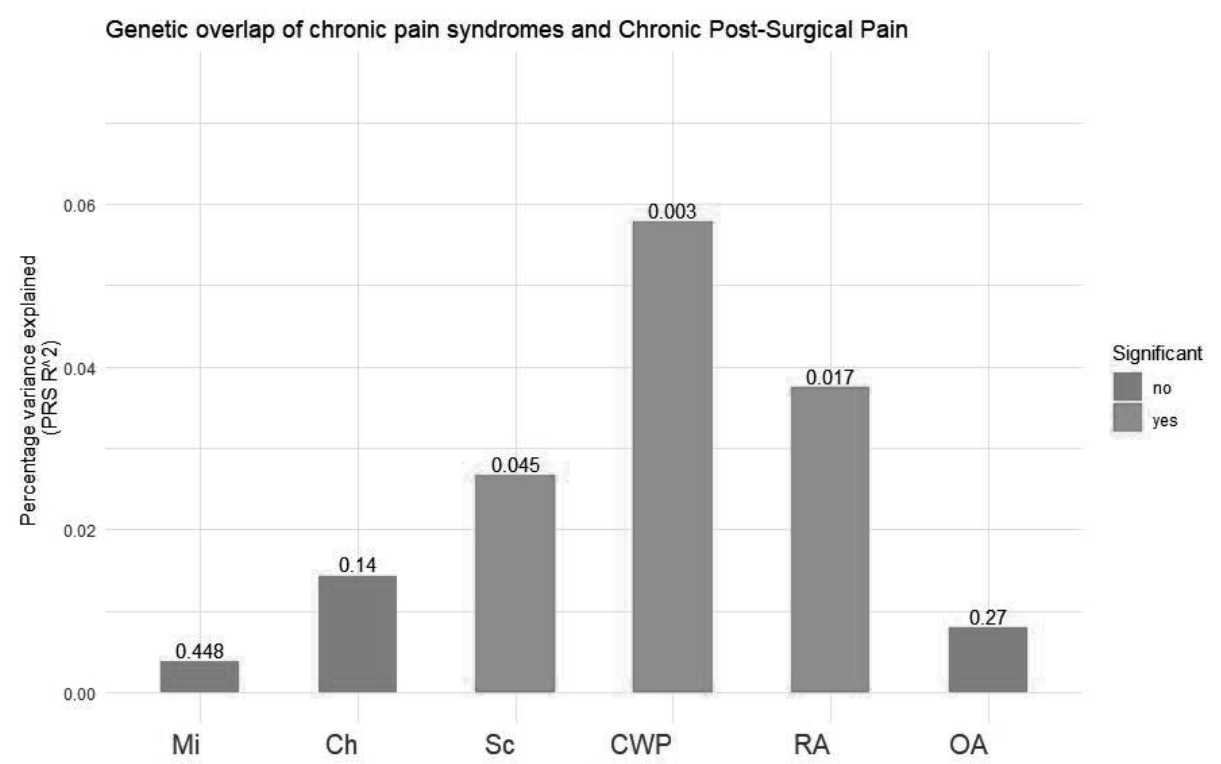

Figure 1: graphic representation of the genetic overlap between different chronic pain syndromes and CPSP discovery cohort. $Y$ axis depicts variance explained by the polygenic risk score, $x$ axis depicts the different phenotypes and the numbers indicate the p-values of the polygenic risk scores. $M i=$ migraine, $S c=s c i a t i c a$, $C W P=$ chronic widespread pain, $R A=$ rheumatoid arthritis, $O A=$ osteoarthritis.

\section{Validation of genetic overlap in CPSP replication cohort}

To validate the discovery cohort-based findings on genetic overlap between CPSP and chronic pain syndromes, the PRS analysis was independently repeated in the replication cohort. Consistent with the outcome of the discovery cohort, a significant genetic overlap was observed with four of the chronic pain disorders and CPSP: Sciatica ( $\mathrm{p}$ value threshold $=0.00385, \mathrm{R}^{2}=0.08, \mathrm{p}=0.045$ ), Chronic widespread pain ( $\mathrm{p}$ value threshold $=0.141, \mathrm{R}^{2} 0.21, \mathrm{p}=0.0003$ ), Rheumatoid arthritis ( $\mathrm{p}$ value threshold $=0.3549, \mathrm{R}^{2}=0.23, \mathrm{p}=0.002$ ) and Osteoarthritis $(\mathrm{p}$ value threshold $=0.0001, \mathrm{R}^{2}=0.11, \mathrm{p}=0.022$ ) (Figure 2 , supplementary table 2 ). No significant genetic overlap was found between cluster headache and migraine and CPSP. 


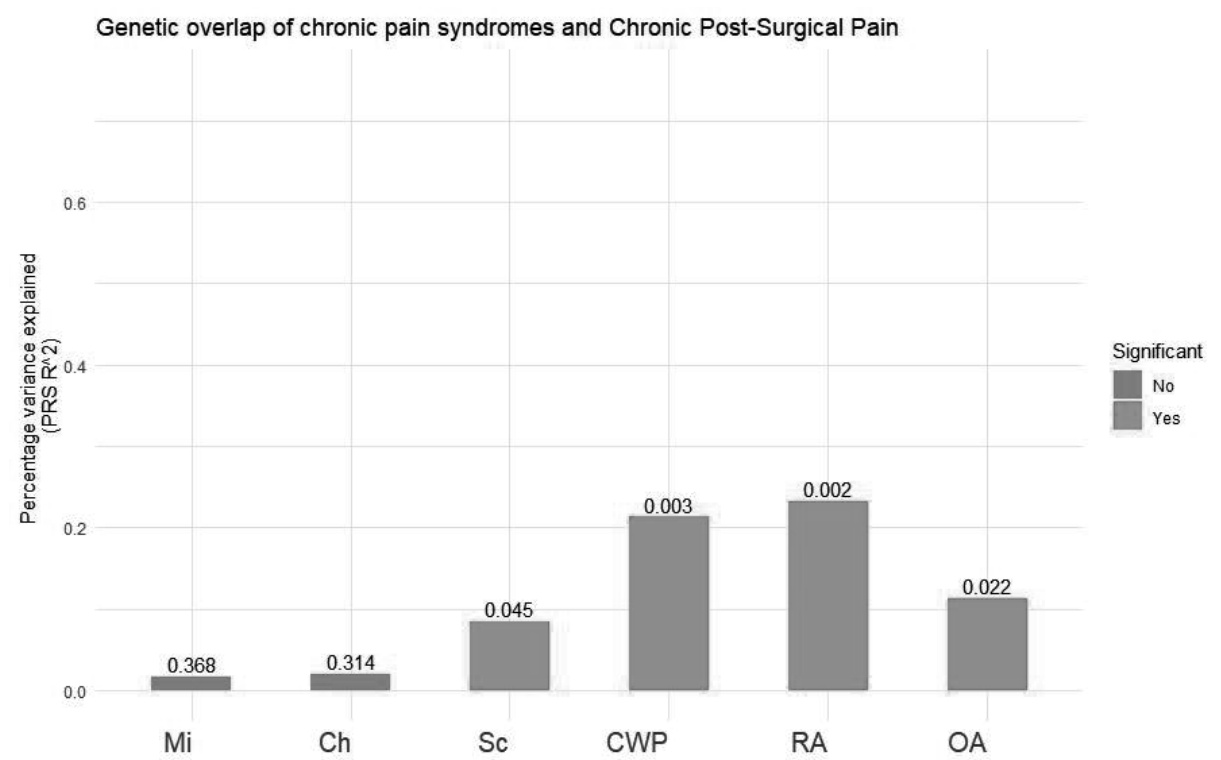

Figure 2: graphic representation of the genetic overlap between three chronic pain syndromes and CPSP replication cohort. $Y$ axis depicts variance explained by the polygenic risk score, $x$ axis depicts the different phenotypes and the numbers indicate the p-values of the polygenic risk scores. $M i=$ migraine, $S c=s c i a t i c a$, $C W S=$ chronic widespread pain, $R A=$ rheumatoid arthritis, $O A=$ osteoarthritis.

Pathway analysis of genes associated with significant polygenic risk scores

To assess the biological context defined by common genetic markers of chronic pain disorders and CPSP an exploratory pathway analysis was performed cohorts using Pathway Scoring Algorithm (PASCAL) [35]. In agreement with published instruction, pathway analysis was limited to SNPs that showed significant genetic overlap in both the discovery and replication cohorts [35]. The findings of the PASCAL analysis were clustered using REVIGO [40]. BPGO revealed enrichment for 3 terms at $\mathrm{FDR}<1 \%, 17$ terms at $\mathrm{FDR}<=5 \%, 9$ terms at $\mathrm{FDR}<=10 \%$ and 26 terms at FDR $<=15 \%$ (figure 3a, supplemental table 3). These terms clustered into 4 main clusters: Protein phosphorylation, Positive regulation of signalling, Response to cytokine and Cation transport (supplemental figure 1). CCGO revealed enrichment for 1 term at FDR $<1 \%$, and 1 term at FDR $<5 \%$ (figure $3 \mathrm{~b}$, supplemental table 4). The terms associated with cellular components clustered into 3 main clusters: 
Endoplasmatic reticulum, Sodium channel complex, intrinsic component of plasma membrane (supplemental figure 2). MFGO revealed enrichment for 3 terms at FDR $<10 \%$ (figure 3c, supplementary table 5). The terms associated with molecular functions clustered into 5 main clusters: Identical protein binding, Phosphoric ester bydrolase activity, Metal ion transmembrane transporter activity, Phosphatidylinositol binding and Sodium channel regulator activity (supplemental figure 3). Taken together, the clusters identified by the GO analyses suggested an aetiological involvement of genetic markers that control neurological signalling and inflammatory response. 

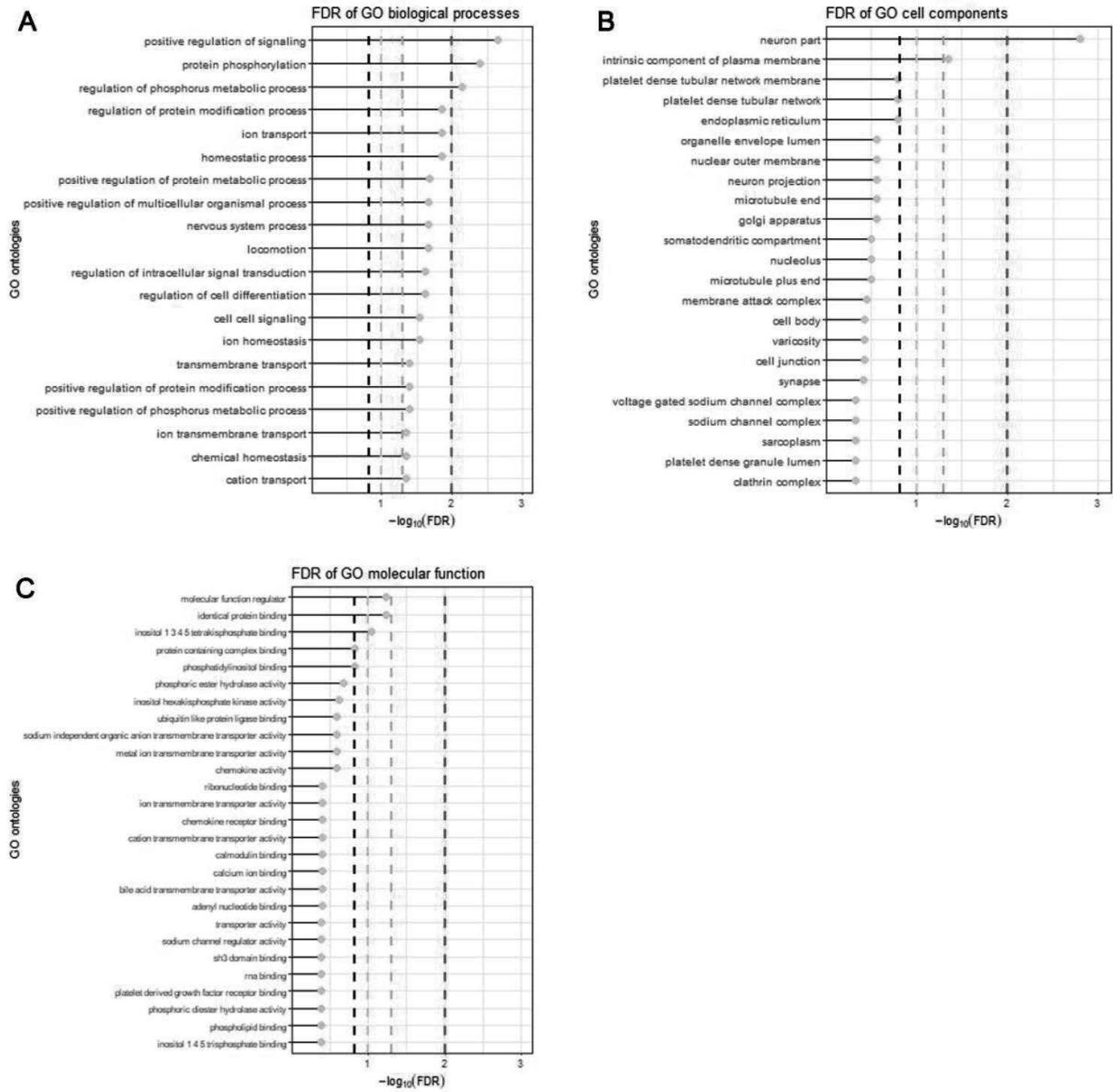

Figure 3: graphic representation of $G O$ analyses on genetic factors with significant PRS scores. Lollipop plots represent the top 20 associations of GO terms with the respective GO databases. Dotted lines represent FDRs of 15\% (black), 10\% (yellow), 5\% (orange) and $1 \%$ (red), respectively. 


\section{Discussion}

The present report is the first to study genetic overlap between different chronic peripheral pain syndromes (CPPs) and CPSP based on polygenic risk score (PRS) analysis. We hypothesized that CPSP shares biological mechanisms and hence genetic factors with some of the known chronic pain syndromes (sciatic pain, chronic widespread pain, osteoarthritis and rheumatoid arthritis). Polygenic risk score analyses show significant genetic overlap between CPSP and CPPs (sciatica, chronic widespread pain and rheumatoid arthritis) but not with osteoarthritis or common headache phenotypes (migraine or cluster headache). Functional enrichment analysis using PASCAL and REVIGO implicate the genes identified in the genetic overlap to be involved in regulation of neurological signalling and inflammatory response.

\section{Shared mechanisms in CPSP and peripheral pain syndromes}

The three CPP subtypes that showed genetic overlap with CPSP in both cohorts are known to affect peripheral nerves directly $[16,17,41]$. Sciatica involves nerve compression such as intervertebral disc rupture (the most common cause of sciatica) and other non-spinal causes of sciatica (e.g. gynaecologic causes or traumatic injury) [16]. In chronic widespread pain, both central and peripheral sensitization play a role, involving peripheral acid-sensing ion channels, decreased density of epidermal nerve fibres and pro-inflammatory cytokines [41, 42]. Rheumatoid arthritis (RA) originates in the immune system: pain originates from the affected joints, where inflammatory cytokines sensitize peripheral nociceptors or modify receptor activation thresholds [17]. All the processes underlying the above mentioned chronic peripheral pain syndromes have been associated with the chronification of postsurgical pain as well [43].

Chronic headache disorders (migraine and cluster headache) show a different pathophysiology. In these disorders there is a clear involvement of the vasculature 
and part of the pathophysiology seems to stem from an asynchrony in cortical processing [31, 32]. Migraine occurs mostly in women and pain develops by an interplay between vasculature, nerve innervation of both dura and skull and central nervous processing [31]. Cluster headaches $(\mathrm{CH})$ classifies as a severe headache disorder occurring mostly in men, where the pathophysiology is thought to comprise synchronised abnormal activity in the hypothalamus, trigeminal vasculature and central nervous processing [32]. CGRP is a key player in both cluster headaches and migraine pathophysiology which is a potent vasodilator but was also shown to modulate activity of trigeminal neurons [31, 32]. Our genetic analyses suggest CPSP is aetiologically distinct from $\mathrm{CH}$ and migraine; the link between vasculature and nervous systems may explain these differences.

Consistent with the results in our study, comparative twin studies report only a low phenotypic correlation between CWP and migraine indicating them to be aetiologically distinct subgroups. However, a high correlation between CWP and low back pain was found indicative of an overlap between two different CPPs and more closely related aetiologically $[44,45]$. This provides further evidences for the lack of genetic overlap between CPSP and headache related disorders.

Comparison and genetic overlap between CPSP and Osteoarthritis (OA) resulted in ambiguous outcome, as it showed no consistent genetic overlap with the CPSP cohorts used. OA, is caused by a degenerative articular cartilage condition and also involves the immune system, matrix proteins and metalloproteinases [46, 47]. The pathophysiology of the disease is diverse and complex, and frequently involves increased innervation and vascularization in the diseased joint [47]. The discovery cohort consists solely of patients who underwent a hysterectomy whereas the replication cohort is a mixture of knee and abdominal surgeries [46]. Since the knee is often affected in osteoarthritis, it could be that the genetic overlap is due to the location of the surgery indicating more of a genetic overlap between the 
indication for the surgery and OA than CPSP and OA [46]. Secondly, the inconsistency could be due to a difference in sample size between cohorts: the sample size of the replication cohort is roughly $1 / 3$ of the size of the discovery cohort. The size of the target sample (the discovery and replication cohorts in this study) is correlated with the reliability of the variance explained [48]. This indicates that genetic overlap found with the discovery cohort is a better estimate for the true genetic overlap. Therefore, pathway analysis was conducted without inclusion of the SNPs underlying the significant genetic overlap between OA and CPSP.

GO analysis on the genetic overlap of CPSP with CPP subtypes (RA, CWP, sciatica) resulted in the identification of 4 common biological processes clusters, 3 cellular components clusters and 5 molecular functions clusters that could provide insight in shared aetiology [35, 40]. Pathway analysis of the SNPs underlying the genetic overlap between peripheral pain syndromes and CPSP indicated involvement of neuronal processes: nervous system process, neuron part sodium channel activity, and of inflammatory response: response to cytokine, response to wounding, regulation of immune system process. These findings are consistent with published reports on the interaction of the neuronal and inflammatory reaction in the aetiology of chronic pain [49-53]. In CPPs the communication between neurons and the immune system has been well documented [49-53]. This is consistent with what is known about the pathophysiology of CPPs and CPSP. Both in CPSP and CPPs, neuroinflammation (via glial cells) plays a key role in the maintenance of central sensitization [54-58]. The communication between nociceptive afferents and glial cells is bidirectional, whereby by both can release cytokines and chemokines that modulate the response of the other [56]. When activated, nociceptive afferents release fractalkine which binds to glial cells [54, 58]. Consequently the glial cells release IL1 $\beta$ which leads to increased sodium channel activity and subsequent hyperalgesia and allodynia [54, 56, 58]. Central sensitization is a fundamental process in the chronification of pain and both 
neuronal signalling and inflammatory response play a key role in this process [59, 60]. Central sensitisation occurs due to increased and continuous action potentials coming from the nociceptive afferents most often caused by a combination of local inflammatory processes and tissue or nerve damage $[59,60]$.

The genetic overlap across CPPs may ultimately be translated to clinical practice. Polygenic risk scores have been used in migraine cohorts to not only identify patients likely to develop migraine but also to identify sub clusters of patients who respond to certain classes of medication [61]. This same approach was tried in psychological disorders where they combined major depression disorders and neuroticism to predict efficacy of antidepressant drugs and although not significant they showed that a greater genetic load for MDD and neuroticism was associated with a less favourable response to antidepressants [62]. Secondly, the PRS can be integrated into currently available clinical prediction models. In diabetes and prostate cancer, the predictive accuracy is higher than the currently available clinical models [63]. A recent clinical prediction model on CPSP increased the predictive power of by including a single SNP into the prediction model [7]. This increase in predictive power was not significant but including a complete PRS into the prediction model would significantly improve the clinical prediction modelling $[52,54,62,64]$

\section{Limitations}

This is the first study that combines published GWAS datasets to study genetic overlap across chronic pain phenotypes and CPSP. A limitation is the fact that the number of SNPs included in published GWAS analyses does vary substantially between studies. Ideally, the input-set of SNPs for PRS analysis is the entire GWAS dataset, as more SNPs can lead to a better PRS score: a PRS has more predictive power if more causal SNPs are included in the combined score [33, 48]. Some studies were omitted from the current study as only the top hits were reported [6567]. This complicates and limits accurate PRS assessment as the technique requires 
genome-wide input [68]. The recommendation to include all summary statistics (preferably raw data) as part of publications will enhance transparency and robustness of analyses and interpretation. A second limitation of this study is the sample size of the various studies included in the analyses. As for accurate measurements sample sizes of above 2000 people are preferred, small sample size will lead to an inflation of the explained variance [48]. For the current analysis, two small studies (Table 1) were underpowered [9, 28]; the other studies were sufficiently powered for the analyses. To overcome the small sample size in the discovery cohort, the analysis was repeated in an independent replication cohort.

The herein presented pathway analysis provides a starting point for functional studies on pathways and mechanisms involved in CPSP to substantiate the potentially shared aetiology of CPSP and CPP syndromes. Future research aimed at understanding the impact of genetic variations on the development of CPSP should include functional aspects of genetic networks and corresponding regulatory processes in chronic pain. Functional aspects of both coding and noncoding SNPs should be elucidated to fully understand the impact of genetic variation on the development of chronic pain. Studies on the effects of genetic variation on protein function, cell signalling and cell and organismal physiology should further clarify their mechanistic connection to chronic peripheral pain syndromes, among which CPSP.

\section{Conclusion}

In conclusion, this study is the first to report genetic overlap between regulatory processes implicated in CPSP and chronic peripheral pain syndromes (CPP). The genes identified in the genetic overlap and the factors involved in chronification of postoperative pain are related to the regulation of neurological signalling and inflammatory responses. Enhanced understanding of mechanisms underlying chronification of pain will aid the development of new preventative therapeutic strategies for CPSP. 
Supplementary Table 1: optimal p-value results PRS scores for CPSP prediction in discovery cohort based on pain phenotypes

\begin{tabular}{|c|c|c|c|c|c|c|}
\hline Phenotype & Threshold & $P R S \_r^{2}$ & Coefficient & $\begin{array}{l}\text { Standar } \\
\text { derror }\end{array}$ & Pvalue & Num snps \\
\hline Cluster headache & 0.0226 & 0.014247 & 94.313 & 63.8321 & 0.14 & 3429 \\
\hline Migraine & 0.0001 & 0.003774 & 132.164 & 174.162 & 0.448 & 214 \\
\hline Sciatica & 0.00025 & 0.026629 & -42.692 & 21.3395 & 0.045 & 267 \\
\hline $\begin{array}{l}\text { Chronic } \\
\text { widespread pain }\end{array}$ & 0.0875 & 0.0294922 & 0.033183 & 23.0474 & 10.8211 & 6 \\
\hline $\begin{array}{l}\text { Rheumatoid } \\
\text { arthritis }\end{array}$ & 0.0177 & 0.03742 & 348.111 & 146.096 & 0.017 & 2771 \\
\hline Osteoarthritis & 0.0001 & 0.007937 & -31.5548 & 28.6297 & 0.27 & 74 \\
\hline
\end{tabular}

Supplementary Table 2: optimal p-value results PRS scores for CPSP prediction in replication cohort based on pain phenotypes

\begin{tabular}{|c|c|c|c|c|c|c|}
\hline Phenotype & Threshold & $P R S \_r^{2}$ & Coefficient & $\begin{array}{l}\text { Standar } \\
\text { derror }\end{array}$ & Pvalue & Num snps \\
\hline Cluster headache & 0.02865 & 0.020731 & 110.979 & 110.166 & 0.314 & 4557 \\
\hline Migraine & 0.0001 & 0.016748 & 245.526 & 272.742 & 0.368 & 207 \\
\hline \multirow[t]{2}{*}{ Sciatica } & 0.00385 & 0.0847342 & 293.388 & 146.183 & 0.04475 & 2149 \\
\hline & & & & & 06 & \\
\hline Chronic & 0.141 & 0.213118 & -95.548 & 31.8452 & 0.00269 & 12 \\
\hline widespread pain & & & & & 638 & \\
\hline Rheumatoid & 0.3549 & 0.232604 & -4111.97 & 1334.35 & 0.00205 & 28117 \\
\hline arthritis & & & & & 877 & \\
\hline Osteoarthritis & 0.0001 & 0.113215 & -105.29 & 45.9319 & 0.022 & 76 \\
\hline
\end{tabular}

Abbreviations: $P R S=$ polygenic risk score, Num_SNP = number of SNPs included in the significant polygenic risk score. 


\section{References}

1. Kehlet H, Jensen TS, Woolf CJ: Persistent postsurgical pain: risk factors and prevention. The Lancet 2006, 367(9522):1618-1625.

2. Parsons B, Schaefer C, Mann R, Sadosky A, Daniel S, Nalamachu S, Stacey BR, Nieshoff EC, Tuchman M, Anschel A: Economic and humanistic burden of post-trauma and postsurgical neuropathic pain among adults in the United States. Journal of pain research 2013, 6:459.

3. Schug SA, Lavand'homme P, Barke A, Korwisi B, Rief W, Treede R-D, Pain TITftCoC: The IASP classification of chronic pain for ICD-11: chronic postsurgical or posttraumatic pain. PAIN 2019, 160(1):45-52.

4. Werner M, Kongsgaard U: I. Defining persistent post-surgical pain: is an update required? British journal of anaesthesia 2014, 113(1):1-4.

5. Macrae W: Chronic pain after surgery. British Journal of Anaesthesia 2001, 87(1):88-98.

6. Macrae W: Chronic post-surgical pain: 10 years on. British journal of anaesthesia 2008, 101(1):77-86.

7. Hoofwijk DMN, van Reij RRI, Rutten BPF, Kenis G, Theunissen M, Joosten EA, Buhre WF, van den Hoogen NJ: Genetic polymorphisms and prediction of chronic post-surgical pain after hysterectomy-a subgroup analysis of a multicenter cohort study. Acta Anaesthesiol Scand 2019, 63(8):1063-1073.

8. Theunissen M, Peters ML, Schepers J, Maas JW, Tournois F, van Suijlekom HA, Gramke H-F, Marcus MA: Recovery 3 and 12 months after hysterectomy: epidemiology and predictors of chronic pain, physical functioning, and global surgical recovery. Medicine 2016, 95(26):e3980.

9. van Reij RRI, Hoofwijk DMN, Rutten BPF, Weinhold L, Leber M, Joosten EAJ, Ramirez A, van den Hoogen NJ, Italian Pain G: The association between genome-wide polymorphisms and chronic postoperative pain: a prospective observational study. Anaesthesia 2020, 75 Suppl 1:e111-e120.

10. Hoofwijk DMN, van Reij RRI, Rutten BP, Kenis G, Buhre WF, Joosten EA: Genetic polymorphisms and their association with the prevalence and severity of chronic postsurgical pain: a systematic review. British Journal of Anaesthesia 2016, 117(6):708-719.

11. Gormley P, Anttila V, Winsvold BS, Palta P, Esko T, Pers TH, Farh K-H, Cuenca-Leon E, Muona M, Furlotte NA et al: Meta-analysis of 375,000 individuals identifies 38 susceptibility loci for migraine. Nature genetics 2016, 48(8):856-866.

12. Lemmela S, Solovieva S, Shiri R, Benner C, Heliovaara M, Kettunen J, Anttila V, Ripatti S, Perola M, Seppala I et al: Genome-Wide Meta-Analysis of Sciatica in Finnish Population. PLoS One 2016, 11(10):e0163877.

13. Bralten J, van Hulzen KJ, Martens MB, Galesloot TE, Arias Vasquez A, Kiemeney LA, Buitelaar JK, Muntjewerff JW, Franke B, Poelmans G: Autism spectrum disorders and autistic traits share genetics and biology. Mol Psychiatry 2018, 23(5):1205-1212. 
14. Du Rietz E, Coleman J, Glanville K, Choi SW, O'Reilly PF, Kuntsi J: Association of Polygenic Risk for Attention-Deficit/Hyperactivity Disorder With Co-occurring Traits and Disorders. Biological psychiatry Cognitive neuroscience and neuroimaging 2018, 3(7):635-643.

15. van Hecke O, Torrance N, Smith BH: Chronic pain epidemiology and its clinical relevance. Br J Anaesth 2013, 111(1):13-18.

16. Ropper AH, Zafonte RD: Sciatica. New England Journal of Medicine 2015, 372(13):12401248.

17. Walsh DA, McWilliams DF: Mechanisms, impact and management of pain in rheumatoid arthritis. Nature Reviews Rheumatology 2014, 10:581.

18. Bugada D, De Gregori M, Compagnone C, Muscoli C, Raimondi F, Bettinelli S, Avanzini MA, Cobianchi L, Peloso A, Baciarello M: Continuous wound infusion of local anesthetic and steroid after major abdominal surgery: study protocol for a randomized controlled trial. Trials 2015, 16(1):357.

19. Purcell S, Neale B, Todd-Brown K, Thomas L, Ferreira MA, Bender D, Maller J, Sklar P, de Bakker PI, Daly MJ et al: PLINK: a tool set for whole-genome association and populationbased linkage analyses. American journal of human genetics 2007, 81(3):559-575.

20. Chang CC, Chow CC, Tellier LC, Vattikuti S, Purcell SM, Lee JJ: Second-generation PLINK: rising to the challenge of larger and richer datasets. Gigascience 2015, 4(1):7.

21. Das S, Forer L, Schonherr S, Sidore C, Locke AE, Kwong A, Vrieze SI, Chew EY, Levy S, McGue $\mathrm{M}$ et al: Next-generation genotype imputation service and methods. Nature genetics 2016, 48(10):1284-1287.

22. Loh PR, Danecek P, Palamara PF, Fuchsberger C, Y AR, H KF, Schoenherr S, Forer L, McCarthy S, Abecasis GR et al: Reference-based phasing using the Haplotype Reference Consortium panel. Nature genetics 2016, 48(11):1443-1448.

23. McCarthy S, Das S, Kretzschmar W, Delaneau O, Wood AR, Teumer A, Kang HM, Fuchsberger C, Danecek P, Sharp K et al: A reference panel of 64,976 haplotypes for genotype imputation. Nature genetics 2016, 48(10):1279-1283.

24. Hirschhorn JN, Daly MJ: Genome-wide association studies for common diseases and complex traits. Nature Reviews Genetics 2005, 6(2):95-108.

25. Marchini J, Howie B, Myers S, McVean G, Donnelly P: A new multipoint method for genome-wide association studies by imputation of genotypes. Nature genetics 2007, 39(7):906-913.

26. Peters MJ, Broer L, Willemen HLDM, Eiriksdottir G, Hocking LJ, Holliday KL, Horan MA, Meulenbelt I, Neogi T, Popham M et al: Genome-wide association study meta-analysis of chronic widespread pain: evidence for involvement of the 5p15.2 region. Annals of the Rheumatic Diseases 2013, 72(3):427.

27. Zeggini E, Panoutsopoulou K, Southam L, Rayner NW, Day-Williams AG, Lopes MC, Boraska V, Esko T, Evangelou E, Hoffman A et al: Identification of new susceptibility loci for osteoarthritis (arcOGEN): a genome-wide association study. Lancet (London, England) 2012, 380(9844):815-823. 
28. Bacchelli E, Cainazzo MM, Cameli C, Guerzoni S, Martinelli A, Zoli M, Maestrini E, Pini LA: A genome-wide analysis in cluster headache points to neprilysin and PACAP receptor gene variants. The Journal of Headache and Pain 2016, 17(1):114.

29. Plenge RM, Seielstad M, Padyukov L, Lee AT, Remmers EF, Ding B, Liew A, Khalili H, Chandrasekaran A, Davies LR et al: TRAF1-C5 as a risk locus for rheumatoid arthritis--a genomewide study. N Engl J Med 2007, 357(12):1199-1209.

30. Coordinators NR: Database resources of the National Center for Biotechnology Information. Nucleic acids research 2018, 46(D1):D8-D13.

31. Charles A: The pathophysiology of migraine: implications for clinical management. The Lancet Neurology 2018, 17(2):174-182.

32. Hoffmann J, May A: Diagnosis, pathophysiology, and management of cluster headache. The Lancet Neurology 2018, 17(1):75-83.

33. Choi SW, O'Reilly PF: PRSice-2: Polygenic Risk Score software for biobank-scale data. GigaScience 2019, 8(7).

34. Euesden J, Lewis CM, O'Reilly PF: PRSice: Polygenic Risk Score software. Bioinformatics 2015, 31(9):1466-1468.

35. Lamparter D, Marbach D, Rueedi R, Kutalik Z, Bergmann S: Fast and rigorous computation of gene and pathway scores from SNP-based summary statistics. PLoS computational biology 2016, 12(1):e1004714.

36. Ashburner M, Ball CA, Blake JA, Botstein D, Butler H, Cherry JM, Davis AP, Dolinski K, Dwight SS, Eppig JT: Gene ontology: tool for the unification of biology. Nature genetics 2000, 25(1):25.

37. Consortium GO: The gene ontology resource: 20 years and still GOing strong. Nucleic acids research 2018, 47(D1):D330-D338.

38. Benjamini Y, Yekutieli D: The control of the false discovery rate in multiple testing under dependency. Ann Statist 2001, 29(4):1165-1188.

39. Team RC: R: A Language and Environment for Statistical Computing. In. Vienna Austria: R Foundation for Statistical Computing; 2019.

40. Supek F, Bošnjak M, Škunca N, Šmuc T: REVIGO Summarizes and Visualizes Long Lists of Gene Ontology Terms. PLOS ONE 2011, 6(7):e21800.

41. Sluka KA, Clauw DJ: Neurobiology of fibromyalgia and chronic widespread pain. Neuroscience 2016, 338:114-129.

42. Hess A, Axmann R, Rech J, Finzel S, Heindl C, Kreitz S, Sergeeva M, Saake M, Garcia M, Kollias G: Blockade of TNF- $\alpha$ rapidly inhibits pain responses in the central nervous system. Proceedings of the National Academy of Sciences 2011, 108(9):3731-3736.

43. Chapman CR, Vierck CJ: The Transition of Acute Postoperative Pain to Chronic Pain: An Integrative Overview of Research on Mechanisms. The Journal of Pain 2017, 18(4):359.e351359.e338.

44. Vehof J, Zavos HMS, Lachance G, Hammond CJ, Williams FMK: Shared genetic factors underlie chronic pain syndromes. Pain 2014, 155(8):1562-1568. 
45. Malkin I, Williams FMK, LaChance G, Spector T, MacGregor AJ, Livshits G: Low back and common widespread pain share common genetic determinants. Annals of human genetics 2014, 78(5):357-366.

46. Martel-Pelletier J, Barr AJ, Cicuttini FM, Conaghan PG, Cooper C, Goldring MB, Goldring SR, Jones G, Teichtahl AJ, Pelletier J-P: Osteoarthritis. Nature Reviews Disease Primers 2016, 2(1):16072.

47. Thakur M, Dickenson AH, Baron R: Osteoarthritis pain: nociceptive or neuropathic? Nature reviews Rheumatology 2014, 10(6):374-380.

48. Marees AT, de Kluiver H, Stringer S, Vorspan F, Curis E, Marie-Claire C, Derks EM: A tutorial on conducting genome-wide association studies: Quality control and statistical analysis. International journal of methods in psychiatric research 2018, 27(2):e1608.

49. Nieto FR, Clark AK, Grist J, Hathway GJ, Chapman V, Malcangio M: Neuron-immune mechanisms contribute to pain in early stages of arthritis. Journal of neuroinflammation 2016, 13(1):96.

50. Chavan SS, Pavlov VA, Tracey KJ: Mechanisms and Therapeutic Relevance of Neuroimmune Communication. Immunity 2017, 46(6):927-942.

51. McAllen RM, Cook AD, Khiew HW, Martelli D, Hamilton JA: The interface between cholinergic pathways and the immune system and its relevance to arthritis. Arthritis research \& therapy 2015, 17:87.

52. Pinho-Ribeiro FA, Verri WA, Jr., Chiu IM: Nociceptor Sensory Neuron-Immune Interactions in Pain and Inflammation. Trends in immunology 2017, 38(1):5-19.

53. Parisien M, Samoshkin A, Tansley SN, Piltonen MH, Martin LJ, El-Hachem N, Dagostino C, Allegri M, Mogil JS, Khoutorsky A et al: Genetic pathway analysis reveals a major role for extracellular matrix organization in inflammatory and neuropathic pain. Pain 2019.

54. Guillot X, Semerano L, Decker P, Falgarone G, Boissier M-C: Pain and immunity. Joint Bone Spine 2012, 79(3):228-236.

55. Ikeda H, Kiritoshi T, Murase K: Contribution of microglia and astrocytes to the central sensitization, inflammatory and neuropathic pain in the juvenile rat. Molecular pain 2012, 8:43-43.

56. Ji R-R, Nackley A, Huh Y, Terrando N, Maixner W: Neuroinflammation and Central Sensitization in Chronic and Widespread Pain. Anesthesiology 2018, 129(2):343-366.

57. Nieto FR, Clark AK, Grist J, Hathway GJ, Chapman V, Malcangio M: Neuron-immune mechanisms contribute to pain in early stages of arthritis. Journal of neuroinflammation 2016, 13(1):96-96.

58. Shen Y, Li D, Li B, Xi P, Zhang Y, Jiang Y, Xu Y, Chen H, Xiong Y: Up-Regulation of CX3CL1 via STAT3 Contributes to SMIR-Induced Chronic Postsurgical Pain. Neurochemical Research 2018, 43(3):556-565.

59. Pak DJ, Yong RJ, Kaye AD, Urman RD: Chronification of Pain: Mechanisms, Current Understanding, and Clinical Implications. Current Pain and Headache Reports 2018, 22(2):9. 
60. Merskey H: Part III pain terms, a current list with definitions and notes on usage. Classification of chronic pain-descriptions of chronic pain syndromes and definitions of pain terms 1994:207-214.

61. Kogelman LJA, Esserlind A-L, Francke Christensen A, Awasthi S, Ripke S, Ingason A, Davidsson $\mathrm{OB}$, Erikstrup C, Hjalgrim $\mathrm{H}$, Ullum $\mathrm{H}$ et al: Migraine polygenic risk score associates with efficacy of migraine-specific drugs. Neurol Genet 2019, 5(6):e364-e364.

62. Ward J, Graham N, Strawbridge RJ, Ferguson A, Jenkins G, Chen W, Hodgson K, Frye M, Weinshilboum R, Uher $\mathrm{R}$ et al: Polygenic risk scores for major depressive disorder and neuroticism as predictors of antidepressant response: Meta-analysis of three treatment cohorts. PLOS ONE 2018, 13(9):e0203896.

63. Chapela D, Sousa S, Martins I, Cristovao AM, Pinto P, Corte-Real S, Saude L: A zebrafish drug screening platform boosts the discovery of novel therapeutics for spinal cord injury in mammals. Scientific reports 2019, 9(1):10475.

64. Lavand'homme P: The progression from acute to chronic pain. Current Opinion in Anesthesiology 2011, 24(5):545-550.

65. Janicki PK, Alexander GM, Eckert J, Postula M, Schwartzman RJ: Analysis of Common Single Nucleotide Polymorphisms in Complex Regional Pain Syndrome: Genome Wide Association Study Approach and Pooled DNA Strategy. Pain Medicine 2016, 17(12):23442352.

66. Docampo E, Escaramis G, Gratacos M, Villatoro S, Puig A, Kogevinas M, Collado A, Carbonell J, Rivera J, Vidal J et al: Genome-wide analysis of single nucleotide polymorphisms and copy number variants in fibromyalgia suggest a role for the central nervous system. Pain 2014, 155(6):1102-1109.

67. Sanders AE, Jain D, Sofer T, Kerr KF, Laurie CC, Shaffer JR, Marazita ML, Kaste LM, Slade GD, Fillingim RB et al: GWAS Identifies New Loci for Painful Temporomandibular Disorder: Hispanic Community Health Study/Study of Latinos. Journal of dental research 2017, 96(3):277-284.

68. Choi SW, Mak TSH, O'reilly P: A guide to performing Polygenic Risk Score analyses. BioRxiv 2018:416545. 
CHAPTER 6

\section{Dopamine-neurotransmission and nociception in zebrafish: an antinociceptive role of Dopamine Receptor drd2a}

R. R. I. van Reij, M. M. A. Salmans, I. Eijkenboom,

N. J. van den Hoogen, E. A. J. Joosten, J. M. Vanoevelen

Under review PAIN; major revisions

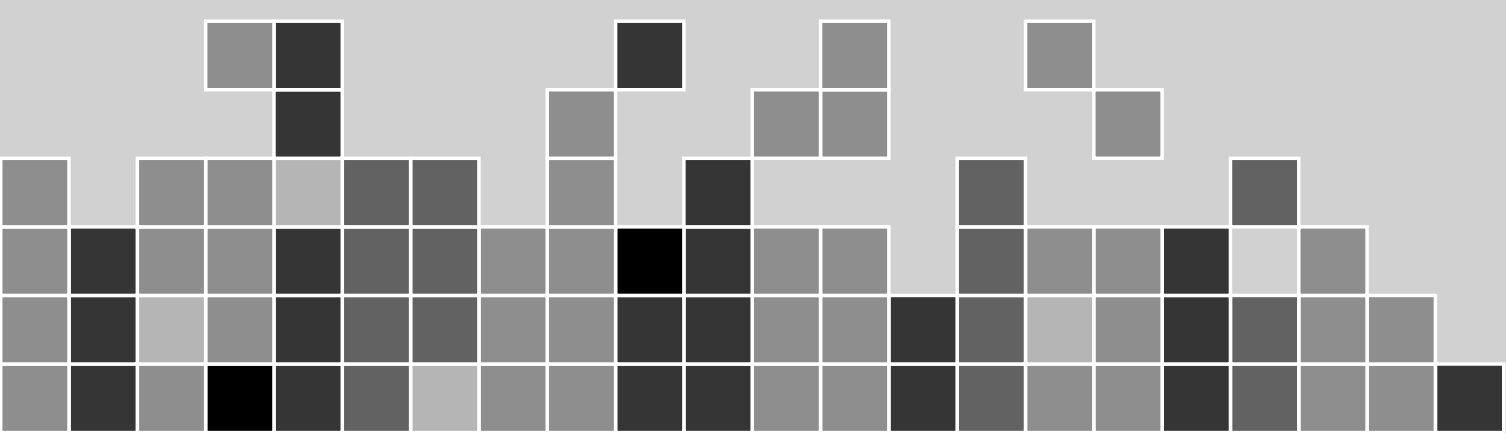


138 | Chapter 6 


\section{Abstract}

Dopamine (DA) is an important modulator in nociception and analgesia. Spinal DA receptors are involved in descending modulation of the nociceptive transmission. Genetic variations within DA neurotransmission have been associated with altered pain sensitivity and development of chronic pain syndromes. The variant rs6277 in dopamine receptor 2 a $(d r d 2 a)$ has been associated with a decreased D2 receptor availability and increased nociception. The aim of this study is to further characterize the role of DA neurotransmission in nociception and the anti-nociceptive function of $d r d 2 a$. The phenotype caused by rs6277 was modelled in zebrafish larvae using morpholino's and the effect on nociception was tested using a validated behavioural assay. The anti-nociceptive role of $d r d 2 a$ was tested using pharmacological intervention of D2 agonist Quinpirole. The experiments demonstrate that a decrease in $d r d 2 a$ expression results in a pro-nociceptive behavioural phenotype $(\mathrm{p}=0.016)$ after a heat stimulus. Furthermore, agonism of $d r d 2 a$ with agonist Quinpirole $(0.2 \mu \mathrm{M})$ results in dose-dependent anti-nociception $(\mathrm{p}=0.035)$ after a heat stimulus. From these results it is concluded that the dopamine receptor $d r d 2 a$ is involved in antinociceptive behaviour in zebrafish. The model allows further screening and testing of genetic variation and treatment involved in nociception.

\section{Keywords}

DRD2, danio rerio, morpholino, quinpirole, pharmacology, pain 


\section{Introduction}

Worldwide, 1 in 5 people suffer from chronic pain [1]. The treatment of pain remains a major clinical challenge, partly due to a lack of knowledge on the involvement of different neurotransmitter systems in nociception. The neurotransmitter Dopamine (DA) seems an important modulator in analgesic processes, acute and chronic pain both at spinal and supraspinal levels [2-9]. Several genes in the DA-neurotransmission have been associated with the chronification of pain [10-12]. Hence, it is important to understand the exact mechanism by which DA-neurotransmission affects nociception and the involvement of genetic variation herein.

The external development of zebrafish larvae it is possible to easily manipulate the development and genetics of the organism $[13,14]$. Moreover, as the zebrafish is an organism with a fully sequenced genome, it is an ideal model to study the effect of genetic variation on nociception in a time and cost-effective manner $[13,15$, 16]. The zebrafish sensory nervous system has shown to have many similarities with vertebrates including descending modulation of nociception [17-21]. The zebrafish model allows a direct high-throughput approach. Furthermore, it was recently shown that zebrafish could also be used as a model for assessing nociceptive processes [22, 23].

DA receptors are present throughout the spinal cord in humans and are expressed both in pre- and post-synaptic neurons. There are two classes of DA receptors, the D1 receptor family and D2 receptor family. The D1 receptor family is excitatory whereas the D2 receptor family is inhibitory [24] with D2 receptors as the dominantly expressed receptor subtype [24, 25]. As zebrafish underwent an evolutionary genome duplication event, the vast majority of genes is present in duplicate [26]. The $d r d 2 a, d r d 2 b$ genes are the zebrafish orthologues of human $D R D 2$ whereby drd2b is more abundantly expressed in the brain of the zebrafish and $\mathrm{drd} 2 \mathrm{a}$ is preferentially expressed in the spinal cord [27]. 
The single nucleotide polymorphism (SNP) rs6277 which is a non-protein-altering genetic variant, is one of the most studied genetic variants in DRD2 in humans $[28,29]$. SNP rs6277 accelerates mRNA decay and has been associated with a decreased DA D2 receptor availability in the brain [30, 31]. A decrease in DA D2 receptor availability has been associated with nociception and chronic pain [3234]. Hence, a link between genetic variants altering the availability of DA D2 receptors and an augmented pain response in humans is suggested.

The aim of this study is to further characterize the anti-nociceptive role of DAneurotransmission in nociception via modulation of the $\mathrm{drd} 2 \mathrm{a}$ receptor in a zebrafish model. This will be modelled via gene knockdown of $d r d 2 a$ in larval zebrafish using established morpholino oligomers and pharmacological intervention [35]. Behavioural parameters will be used to quantify the effects of drd2a mediated neurotransmission on nociception in zebrafish. It is hypothesized that the activation of the drd2a receptor will be anti-nociceptive whereas as a decrease in drd2a receptors will result in a pro-nociceptive response.

\section{Methods}

\section{Zebrafish husbandry}

Zebrafish (Danio rerio) were housed and raised at Maastricht University. Zebrafish

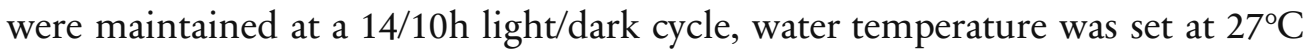
and adults were fed twice a day [15]. For mating, the males and females were separated by a divider the day prior to collection. At the day of collection in the morning during the light cycle, the animals were placed in the same compartment to allow mating to take place. Eggs were collected using a fine-meshed strainer and transferred to petri dishes containing E3 medium [36].

The zebrafish line dat:EGFP was developed and characterized by $\mathrm{Xi}$ and colleagues [37]. In this line, the promotor of the dopamine transporter (dat) gene drives GFP expression. As a consequence, DA neurons in the brain are tagged with a 
fluorescent mark in vivo. Experimenters ( $\mathrm{RvR}$ and $\mathrm{MS}$ ) were blinded for the conditions during the experiments until analysis.

\section{Morpholino experiments}

Expression of the $d r d 2 a$ gene was suppressed using a previously described translation block $d r d 2 a$ antisense morpholino [35]. Antisense and control (mismatch) morpholino were ordered with the following sequences: $d r d 2 a$ morpholino 5'-AGG CAT ACG CTG TGA AGA CTT CCA T-3'; mismatch $d r d 2 a$ 5'AGC CAT AGG GTG TGA ACA GTT CCA T-5' (Gene Tools, LLC, Philomath, OR, USA). The complimentary sequence of the ATG start site is underlined in each sequence. For injection, the morpholino's were diluted in 1x Danieau and 1:10 dilution of rhodamine. Each 1-2 cell stage embryo was injected with $2 \mathrm{nl}$ of morpholino solution.

At $24 \mathrm{~h}$ after injection, the injection success rate and survival rate was assessed under the fluorescent microscope (DMI 4000B, Leica, Wetzlar, Germany). At 72h after injection the morphology of the developing embryos was checked using a dissection microscope as a quality control measure.

\section{Zebrabox experiments}

To quantify nociception in the zebrafish we measured temperature sensitivity and in particular noxious heat induced locomotion on the fifth day after fertilization (5dpf). This was assessed with an add-on, developed in-house, to the ZebraBox system (Viewpoint, Lyon, France and Maastricht Instruments BV., Maastricht, the Netherlands) [15]. We used the same set-up and parameters as described and validated earlier [15]. Briefly, animals were placed in 48 wells plate containing 500 $\mu \mathrm{l}$ E3 medium in the water compartment and allowed to adapt to their surroundings for $30 \mathrm{~min}$ in the dark. This period was followed by 10 minutes baseline measurement followed by the experimental phase with the temperature increase. Baseline temperature was set at $28.5^{\circ} \mathrm{C}$ and was increased in the 
experimental phase to $41^{\circ} \mathrm{C}$. The temperature increase difference between the arena containing the water and the wells containing the fish is $\pm 1^{\circ} \mathrm{C}$. During experiments, conditions were rotated over the 48 wells plate to reduce location bias. The ZebraBox software uses contrast differences between water and the zebrafish larvae to detect the size of the larvae. A camera records movement of the larvae and the activity of the larvae is determined by the amount pixels that change from one frame to the next.

\section{Pharmacological experiments}

To determine the effect of $\mathrm{drd} 2 \mathrm{a}$ on nociception we used the DRD2 agonist Quinpirole (QP). (-)-quinpirole hydrochloride (QP) was purchased from Sigma Aldrich (St. Louis, MO USA).The drug was dissolved in milli-Q and diluted in E3 medium to reach the final concentration within the range of $0.2-8 \mu \mathrm{M}$ based on previous literature [38]. The optimal dose was determined in a series of pilot experiments. During the pharmacological experiments, the fish were incubated 10 min prior to the start of the adaptation phase of the experiment. This period was chosen as longer periods of incubation could lead to motor effects which we wanted to avoid [38]. QP was also diluted to the same concentration in the 48 wells plate as during the incubation period. Thus, the animals were exposed to QP during the experiments. E3 medium was used as vehicle control. During experiments conditions were rotated over the 48 wells plate to reduce location bias.

\section{Statistics}

$\mathrm{R}$ was used to carry out the statistical analyses. For the comparison of different morphologies during the optimisation of the morpholino experiments, a twosample t-test was used. For the behavioural experiments, the timeline was divided in different sets: acclimatisation phase (0-30 $\mathrm{min})$, baseline phase $(30-40 \mathrm{~min})$, experimental phase (40-60 $\mathrm{min})$. The peak activity time (45-50 $\mathrm{min}$ ) was analysed 
to detect differences in nociception. Activity of the fish was standardized per fish to account for the variability between different individual larvae.

Analysis of behavioural data was done using a linear mixed effect (lme) model in the nlme (nlme: Linear and Nonlinear Mixed Effects Models) package [39]. Activity was determined in a linear regression model by group and time assuming a random intercept for each individual fish. Data were considered to be significant when the calculated $\mathrm{p}$-value $<0.05$. All data are presented as average \pm standard error of the mean (SEM).

\section{Results}

\section{Optimization of the drd2a Morpholino}

Before we can determine the effect of the $d r d 2 a$ knockdown on temperature sensitivity with our assay, the dosage of the $d r d 2 a$ morpholino had to be optimised. To determine the optimal dose of the morpholino, the morphologies of the fish had to be consistent with the literature describing this morpholino and have a significantly higher proportion of affected fish compared to the noninjected (NI) controls [35]. The two morphologies described in the literature were heart oedema and growth retardation.

A range of $2 \mathrm{ng}$ until $10 \mathrm{ng}$ was tested and morphology was assessed at $3 \mathrm{dpf}$. All the doses tested had a proportion of fish with the described phenotype (Figure1). The 10ng $d r d 2 a$ morpholino had a significantly higher fraction of affected zebrafish compared to the NI control ( $\mathrm{p}=0.037, \mathrm{t}=3.16$, 95\% CI 1.42-27.20). None of the other dosages of $d r d 2 a$ or mismatch morpholino's had a significantly higher fraction of affected zebrafish ( $\mathrm{p}>0.05)$. 


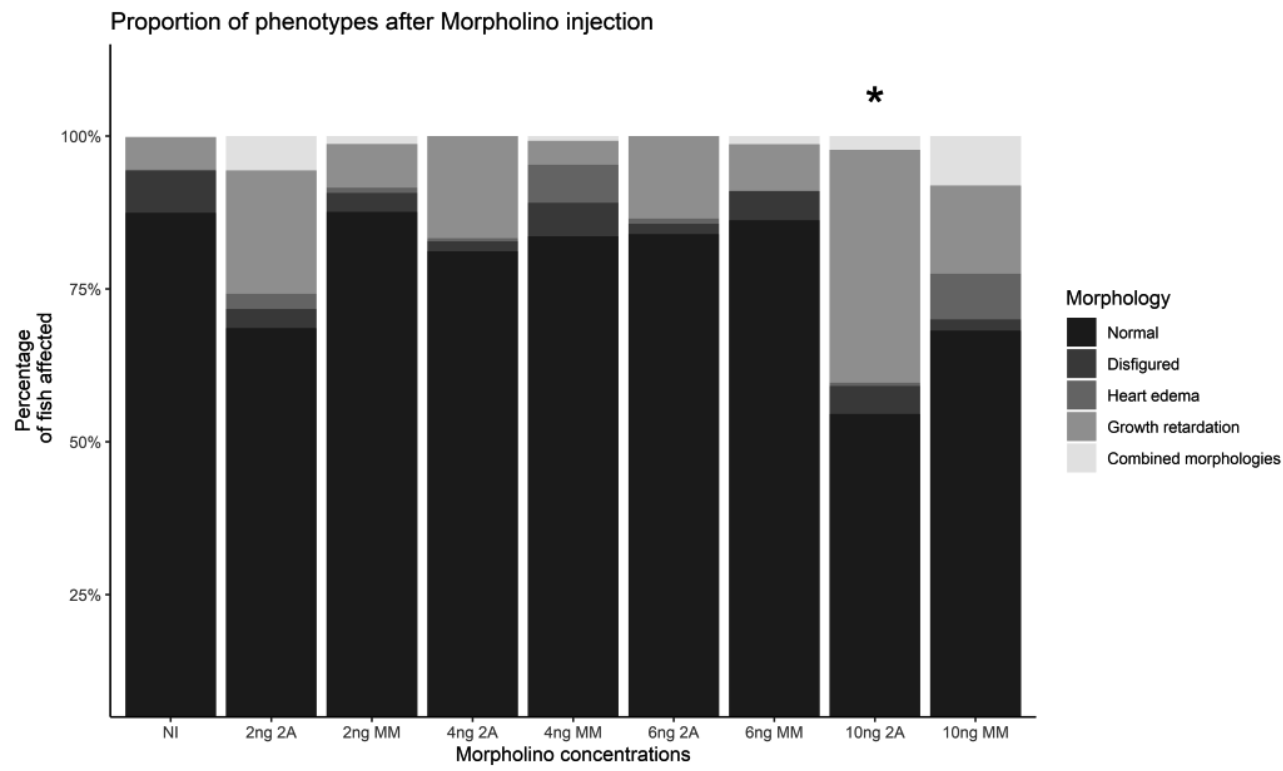

Figure 1: The proportion of phenotypes after morpholino injection are depicted in percentages affected per condition. $N^{2 n g 2 a}=159, N^{2 n g M M}=225, N^{4 n g} 2 a=366, N^{4 n g M M}=128, N^{6 n g} 2 a=230, N^{6 n g M M}=145, N^{10 n g 2 a}$ $=176, N^{10 n g M M a}=160, N^{N I}=1376 . N I=$ non-injected controls, $2 A=d r d 2$ a morpholino, $M M=$ mismatched morpholino, dose is presented before the type of morpholino. ${ }^{*}=P<0.05$

\section{Morpholino behavioural experiments}

A dose of $10 \mathrm{ng}(5 \mathrm{ng} / \mathrm{nl})$ was determined to be the optimal dose and used in the behavioural experiments. The behavioural response of the zebrafish larvae ( $5 \mathrm{dpf})$ to the temperature change was assessed in the zebrafish exhibiting the normal phenotype to minimise the effect of morphology on the behavioural read-out. All three groups responded with an increase of their activity in response to the temperature increase (Figure 2).

At baseline (30-40 minutes) no significant differences in activity between the three conditions is observed. During the peak activity phase of the experimental period (45-50 $\mathrm{min})$ a significant increase in activity in the $d r d 2 a$ morpholino group is noted as compared to the non-injected control group (figure $2, \mathrm{p}=0.016, \mathrm{t}=2.45$, 
$\beta=1294.036)$. No difference in activity between control morpholino and the noninjected control $(\mathrm{p}=0.947, \mathrm{t}=-0.07, \beta=-36.335)$ is observed. As reported in earlier studies the activity of the larvae gradually declined after reaching a maximum [15].

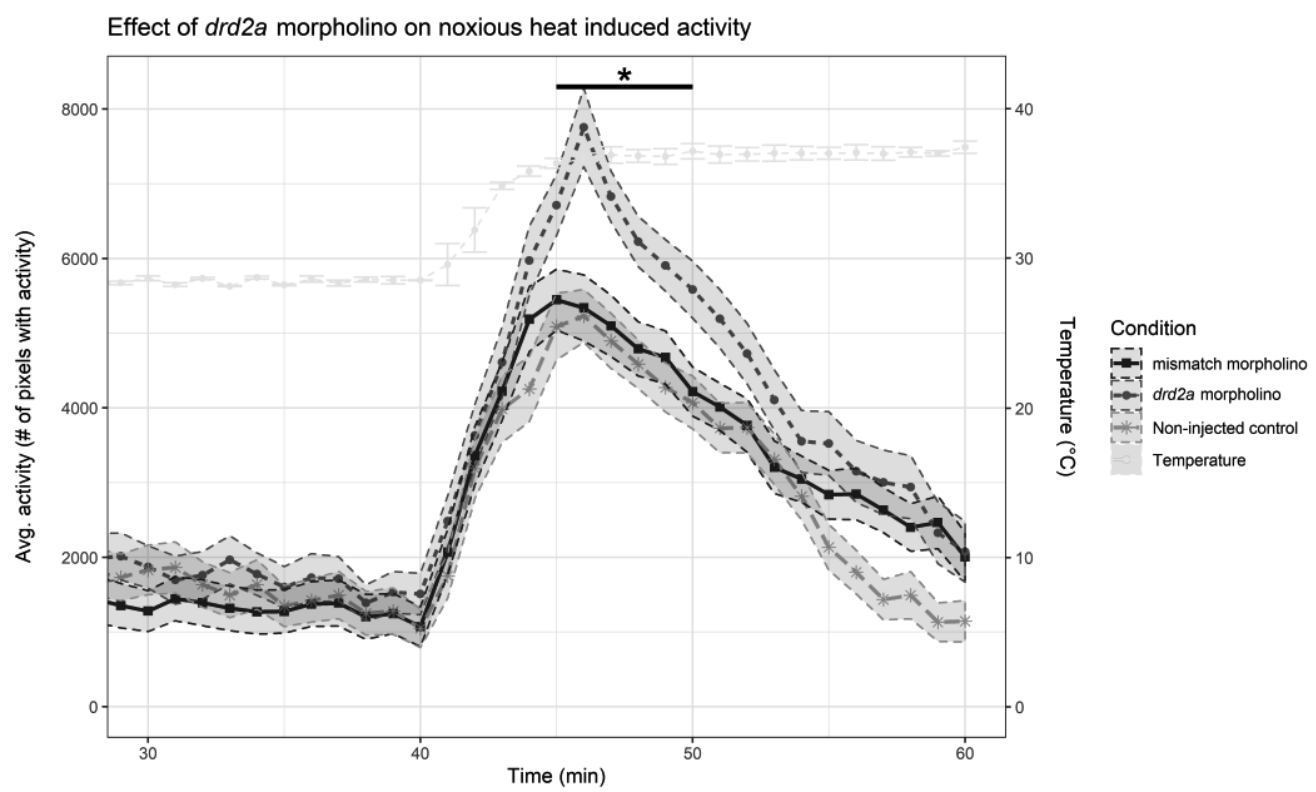

Figure 2: Effect drd2a and control of morpholino's on noxious heat induced activity. At $5 d p f$, larvae injected with drd2a or mismatch morpholino were exposed to an increase in water temperature. This resulted in a significant higher activity of the zebrafish larvae injected with the drd2a morpholino. No significant

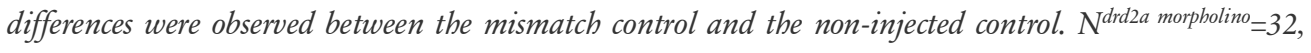
$n^{\text {mismatch morpholino }}=29, n^{\text {non-injected control }}=32$ divided over three different experiments. 


\section{Drd2a agonist concentration optimization}

Next, to study the effect of activation of the drd2a receptor on nociception an agonist is used. To determine the optimal concentration a range of concentrations $(0.2 \mu \mathrm{M}-8 \mu \mathrm{M})$ of QP was tested based on the available literature [38]. To be considered for follow-up experiments the concentrations should not lead to motor effects visible in a significantly different baseline and should have a significant effect on activity during the peak effect phase. This was tested using a two-sample t-test between experimental concentrations and control group.

There were significant differences in average baseline activity compared to control for the concentrations $4 \mu \mathrm{M}\left(\mathrm{p}=1.88^{-13}\right)$ and $8 \mu \mathrm{M}\left(\mathrm{p}=5.4^{-16}\right)$ (Figure 3 left side). There was no significant difference between control and $0.2 \mu \mathrm{M}(\mathrm{p}=0.18)$ and $1 \mu \mathrm{M}(\mathrm{p}=0.074)$. No significant effect on average peak activity was found for the concentrations $4 \mu \mathrm{M}(\mathrm{p}=0.86)$ and $8 \mu \mathrm{M}(\mathrm{p}=0.86)$. There was a significant decrease in average peak activity for the concentration of $0.2 \mu \mathrm{M}\left(\mathrm{p}=1.4^{-5}\right)$ and $1 \mu \mathrm{M}(\mathrm{p}=$ 0.021 ) (figure 3 right hand side).

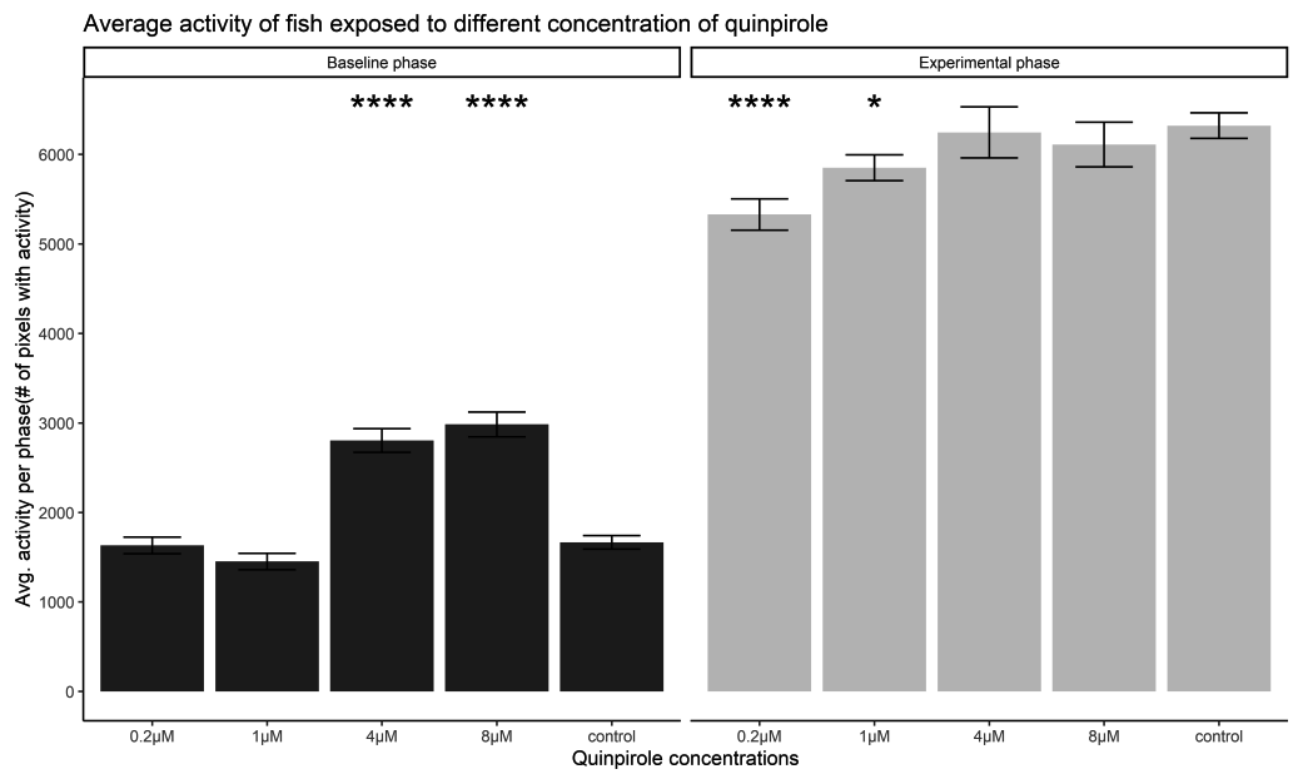


Figure 3 (previous page): comparison of average baseline and peak activity of zebrafish larvae at $5 d p f$ exposed to quinpirole and control condition. A significant difference in baseline activity was observed in the concentrations 4 and $8 \mu M(p<0.0001)$ compared to control. No significant change was observed in the baseline activity of 0.2 and $1 \mu \mathrm{M}(p=0.18)$ compared to control. There was a significant decrease in the average peak activity of larvae exposed to $0.2 \mu \mathrm{M}(p<0.05)$. No significant differences compared to control were found for the other concentrations. ${ }^{*} p<0.05,{ }^{* * * *} p<0.0001 . n^{0.2 \mu M}=40, n^{1 \mu M}=47, n 4^{\mu M}=31, n^{8 \mu M}=29$, $n^{\text {control }}=71$.

\section{Pharmacological behavioural experiments}

The concentration of $0.2 \mu \mathrm{M}$ QP was determined to be optimal and used in the behavioural experiments. The behavioural response of the zebrafish larvae ( $5 \mathrm{dpf})$ to the temperature change was assessed in the zebrafish exhibiting the normal phenotype to minimise the effect of morphology on the behavioural read-out. Both groups responded with an increase of their activity in response to the temperature increase (Figure 4).

At baseline (30-40 minutes) there were no significant differences in activity between the two conditions. However, during the peak activity phase of the experimental phase (45-50min) a significant decrease in activity is noted in the QP group as compared to the control group (figure $4, \mathrm{p}=0.035, \mathrm{t}=-2.13, \beta=-958.178$ ). As observed in earlier studies the activity of the larvae gradually declined after reaching a maximum [15]. 


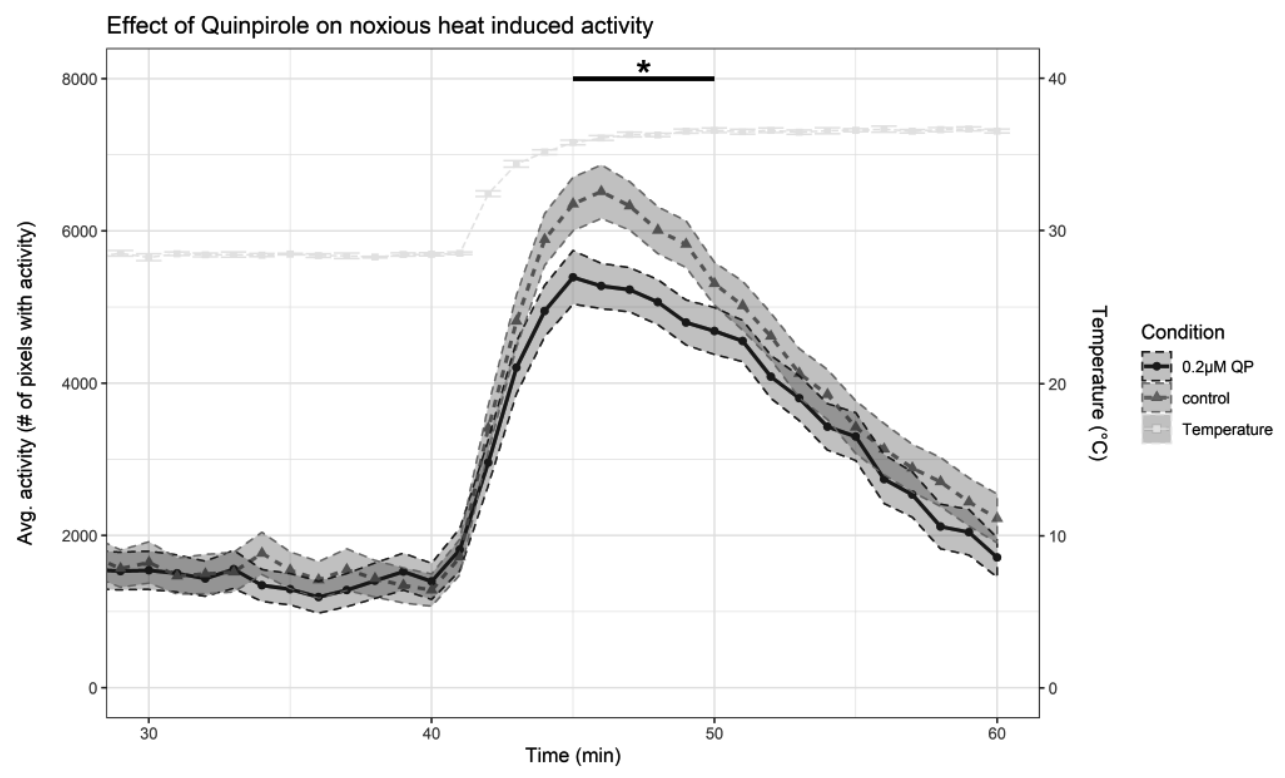

Figure 4: Effect of Quinpirole on noxious heat induced activity increased. At 5dpf, larvae were exposed to either quinpirole or control E3 medium followed by an increase in water temperature. This resulted in a significantly lower activity of the zebrafish larvae exposed to Quinpirole. No significant differences were observed between the mismatch control and the non-injected control. $n^{\text {quinpirole }}=70, n^{\text {control }}=74$.

\section{Discussion}

The aim of this study was to further characterize the anti-nociceptive function of dopamine receptor 2 a (drd $2 \mathrm{a})$. The results of our experiments indicate that knockdown of the inhibitory $d r d 2 a$ gene leads to pro-nociceptive behaviour in zebrafish. Furthermore, the activation of the drd2a receptor via application of agonist QP leads to anti-nociceptive behaviour. From this, we conclude that the $\operatorname{drd} 2 \mathrm{a}$ is involved in modulation of nociception in zebrafish providing further insight in the role of the DA receptor 2 in pain in humans.

Pharmacological modulation of the D2 receptor in rodents clearly demonstrated a role for DA in nociception and specifically the anti-nociceptive effects of the D2 receptor [40-42]. Furthermore, genetic variants have been associated with a 
decrease in D2 receptor availability and pain phenotypes [30-34]. The present study is the first to show a causative link between a decrease in D2 receptor expression and pro-nociceptive behaviour. The present findings not only validate prior studies but also provides a framework for future genetic screening in zebrafish. Several techniques are available (incl. morpholino's, CRISPR and mRNA overexpression) to test the functional effects of known and unknown variants associated with pain phenotypes [28, 42-44]. In this study, we modelled the phenotype associated with a variant with known functional effects to proof the causation between variant and behaviour.

It has been shown that dopamine plays an important role in pain and nociception in different clinical phenotypes $[8,45]$. This study provides further evidence for the role of a dopamine receptor expression and a pharmacological intervention on nociception. Pharmacological intervention using QP is an interesting option in the clinical phenotypes which show an altered nociceptive threshold due to an aberrant dopaminergic neurotransmission (e.g. pain in Parkinson's disease) [10, 46, 47]. Specifically QP could provide relief in "OFF" periods when administered in subclinical dosages to counteract the decreased nociceptive threshold and central pain symptoms associated with the decrease in dopamine levels [47]. However, patients carrying the SNP rs6277 would most likely not benefit from $\mathrm{QP}$, as the decrease in receptor availability could prevent the QP from exerting its effects on the dopaminergic neurotransmission [48].

The zebrafish is an excellent model to assess the functional effects of genetic variations. In the pain field, a zebrafish model of small-fibre neuropathy (SFN) in which the pathogenicity of certain known pathological variants was tested, has recently been described [15]. In the present study, an established antisense morpholino is used to downregulate the expression of the DA receptor 2A [35]. This knockdown of the DA receptor $2 \mathrm{~A}$ leads to decreased expression of DA receptor $2 \mathrm{~A}$, and models the human phenotype of genetic variation based on SNP 
rs6277. In humans, this SNP results in a decrease in DA 2 receptor availability and is associated with chronic pain disorders [30-34].

An important aspect in this study is the modelling of nociception in zebrafish. Zebrafish have a functional nociceptive sensory system from $16 \mathrm{hpf}$ onwards [19, 21]. In addition, zebrafish possess a functional opioid system, nociceptors, descending neuronal control and brain structures to process and respond to potentially noxious external stimuli $[19,49-51]$. So far, zebrafish have been shown to respond to thermal and chemical nociceptive signals, as well as analgesics [15, $18,19,22,52-55]$.

These approaches can be beneficial to research pipelines as they provide easy and fast screening and are easily translated to other model organisms or humans. This robust response of zebrafish larvae to nociceptive stimuli and attenuation of the effect in response to pharmacological intervention indicates the validity of zebrafish as model for nociception. The customized zebrafish behavioural testing system Zebrabox has been extensively validated for thermal nociception as described by Eijkenboom and colleagues [15]. It is important to note that in this zebrafish nociception model, the altered activity of the zebrafish larvae in response to an increase in temperature is robust, providing a decent window to see effects. Therefore, the Zebrabox is the ideal method to assess thermal nociception in zebrafish.

When comparing human dopamine receptor families to their zebrafish counterparts, a sequence homology of $\pm 70 \%$ is observed whereby the transmembrane segments are conserved [27]. The zebrafish genome is duplicated in comparison to the human genome leading to a duplication of the genes available. While some of these duplications have been lost in evolution, other orthologues developed new functionality [26]. The zebrafish genome contains two genes for the dopamine D2 receptor $(d r d 2 a$ and $d r d 2 b)$. The expression of $\operatorname{drd} 2 \mathrm{a}$ and $\mathrm{drd} 2 \mathrm{~b}$ differs with respect to both location and developmental stage of 
expression in the zebrafish CNS [56]. The expression of drd2a in zebrafish has been shown to be detectable from 8 hours post fertilisation (hpf) onwards, while spinal cord shows expression of $\mathrm{drd} 2 \mathrm{a}$ at $36 \mathrm{hpf}[57,58]$. Drd2b receptor is detectable from $24 \mathrm{hpf}$ and mainly expressed in tectum, tegmentum and telencephalon [57]. Large similarity has been reported between zebrafish drd2a and drd2b expression patterns and mammalian D2 receptors [56]. This makes the zebrafish an excellent model to study the effect of DA neurotransmission on different processes, including nociception. The differential distribution and targeting of $d r d 2 a$ and $d r d 2 b$ allows to investigate the effect of DA in specific CNS structures.

During development, the DA system in zebrafish larvae is sensitive to external influences. With respect to the use of $d r d 2 a$ morpholino it is important to note that growth retardation and heart oedema have been described [35]. With our morphological examinations, we observed both growth retardation and heart oedema phenotypes developing in the zebrafish larvae (see Figure 1). At the optimal morpholino concentration of $10 \mathrm{ng}(5 \mathrm{ng} / \mathrm{nl})$ the proportion of fish with these phenotypes was significantly higher than in the control groups as seen previously (see Figure 1). This confirms that we have the same phenotype in the zebrafish as the phenotypes mentioned in the study where the morpholino was originally described [35].

In addition, studies have shown that (ant)agonism of the dopaminergic receptors can specifically affect locomotion [38, 57-59]. The effect of DA on locomotion is a crucial aspect as the behavioural assay in this study is based on locomotion of the zebrafish larvae and it could interfere with the effect on nociception. In our study we noted a significant increase in baseline locomotion (at 40-50 min of exposure) during exposure to the intermediate dosages of $4 \mu \mathrm{M}$ and $8 \mu \mathrm{M}$, as reported previously [38]. No effect of the lower dosages $(0.2 \mu \mathrm{M}$ and $1 \mu \mathrm{M})$ on baseline locomotion was noted. Therefore, we conclude that the results of QP on 
nociception in the temperature nociception assay are not confounded by a locomotion effect of QP.

There are some limitations to this study. The first issue is the indirect modelling of the functional effects of rs6277. This SNP normally promotes mRNA decay leading to a decreased expression of the receptor. Overexpressing mRNA with rs6277 in zebrafish would therefore not lead to the matching phenotype as more DA receptor mRNA is present next to the already transcribed $d r d 2$ mRNA. Therefore, the morpholino approach was chosen to model the clinical phenotype as closely as possible. Although there is significant overlap between the human and the zebrafish genome, there are differences between zebrafish and human genomes including two different orthologues of the D2 receptor [27, 60]. Drd2a is the gene mostly expressed in the spinal cord here is the first modulation relay station in the transduction of the nociceptive signal (the spinal pain-gate)[61]. The nociceptive system and spinal pain-gate seems well conserved between fish and vertebrates $[17,21,51,62]$. The spinal pain-gate modulates the nociceptive signal transduction, making spinally expressed drd2a the best candidate to study in nociception $[27,56]$. Second issue is the large variability seen in the behaviour of the zebrafish. Zebrafish are outbred animals, which already indicates genetic variability, and they respond differently to the conditions in the experiments. To account for this variability all experiments were executed using multiple runs.

In conclusion, we report a causative link between D2 receptor expression and nociception in zebrafish. With these experiments the genetic variants in humans phenotype and DA neurotransmission characterized by SNP rs6277 was modelled in vivo in a zebrafish using a morpholino targeted at $d r d 2 a$. Future studies could use this established zebrafish nociception assay to functionally asses the effect of genetic variations on morphology, behaviour and pharmacological intervention screening. 


\section{Declaration of interest}

Declarations of interest: none

\section{Acknowledgements}

We would like to thank A. Gonzalez, E. Lambrichs and J. Grashorn for their technical support during the project. We also thank the lab of Dr. Ekker for sharing the dat-GFP zebrafish line.

Funding: This work was supported by funds made available by Department of Anaesthesiology (Maastricht University Medical Center+ (MUMC+), and School of Mental Health, and Neuroscience (MHeNS, University of Maastricht). 


\section{References}

1. Goldberg DS, McGee SJ: Pain as a global public health priority. BMC Public Health 2011, 11(1):770.

2. Sharples SA, Koblinger K, Humphreys JM, Whelan PJ: Dopamine: a parallel pathway for the modulation of spinal locomotor networks. Front Neural Circuits 2014, 8:55.

3. Stanton CH, Holmes AJ, Chang SWC, Joormann J: From Stress to Anhedonia: Molecular Processes through Functional Circuits. Trends in Neurosciences 2018, 42(1):23-42.

4. Taniguchi W, Nakatsuka T, Miyazaki N, Yamada H, Takeda D, Fujita T, Kumamoto E, Yoshida $\mathrm{M}$ : In vivo patch-clamp analysis of dopaminergic antinociceptive actions on substantia gelatinosa neurons in the spinal cord. Pain 2011, 152(1):95-105.

5. Bissonette GB, Roesch MR: Development and function of the midbrain dopamine system: what we know and what we need to. Genes, brain, and behavior 2016, 15(1):62-73.

6. Taylor NE, Pei J, Zhang J, Vlasov KY, Davis T, Taylor E, Weng FJ, Van Dort CJ, Solt K, Brown EN: The Role of Glutamatergic and Dopaminergic Neurons in the Periaqueductal Gray/Dorsal Raphe: Separating Analgesia and Anxiety. eNeuro 2019, 6(1).

7. Antypa N, Drago A, Serretti A: The role of COMT gene variants in depression: Bridging neuropsychological, behavioral and clinical phenotypes. Neurosci Biobehav Rev 2013, 37(8):1597-1610.

8. Wood PB: Role of central dopamine in pain and analgesia. Expert Review of Neurotherapeutics 2008, 8(5):781-797.

9. Aira Z, Barrenetxea T, Buesa I, Gómez-Esteban JC, Azkue JJ: Synaptic upregulation and superadditive interaction of dopamine $\mathrm{D} 2$-and $\mu$-opioid receptors after peripheral nerve injury. PAIN® 2014, 155(12):2526-2533.

10. Blanchet PJ, Brefel-Courbon C: Chronic pain and pain processing in Parkinson's disease. Progress in neuro-psychopharmacology \& biological psychiatry 2018, 87(Pt B):200-206.

11. Tammimaki A, Mannisto PT: Catechol-O-methyltransferase gene polymorphism and chronic human pain: a systematic review and meta-analysis. Pharmacogenet Genomics 2012, 22(9):673-691.

12. Hoofwijk DMN, van Reij RRI, Rutten BP, Kenis G, Buhre WF, Joosten EA: Genetic polymorphisms and their association with the prevalence and severity of chronic postsurgical pain: a systematic review. British Journal of Anaesthesia 2016, 117(6):708-719.

13. Kalueff AV, Echevarria DJ, Stewart AM: Gaining translational momentum: More zebrafish models for neuroscience research. Progress in Neuro-Psychopharmacology and Biological Psychiatry 2014, 55:1-6.

14. Lieschke GJ, Currie PD: Animal models of human disease: zebrafish swim into view. Nat Rev Genet 2007, 8(5):353-367.

15. Eijkenboom I, Sopacua M, Otten ABC, Gerrits MM, Hoeijmakers JGJ, Waxman SG, Lombardi R, Lauria G, Merkies ISJ, Smeets HJM et al: Expression of pathogenic SCN9A mutations in the zebrafish: A model to study small fiber neuropathy. Experimental Neurology 2018, 311:257-264. 
16. Nasevicius A, Ekker SC: Effective targeted gene / knockdown/' in zebrafish. Nat Genet 2000, 26(2):216-220.

17. Reinig S, Driever W, Arrenberg AB: The Descending Diencephalic Dopamine System Is Tuned to Sensory Stimuli. Current Biology 2017, 27(3):318-333.

18. Correia AD, Cunha SR, Scholze M, Stevens ED: A Novel Behavioral Fish Model of Nociception for Testing Analgesics. Pharmaceuticals 2011, 4(4):665.

19. Sneddon LU, Braithwaite VA, Gentle MJ: Do fishes have nociceptors? Evidence for the evolution of a vertebrate sensory system. Proceedings of the Royal Society of London Series B: Biological Sciences 2003, 270(1520):1115.

20. Schweitzer J, Löhr H, Filippi A, Driever W: Dopaminergic and noradrenergic circuit development in zebrafish. Developmental Neurobiology 2012, 72(3):256-268.

21. Malafoglia V, Bryant B, Raffaeli W, Giordano A, Bellipanni G: The zebrafish as a model for nociception studies. Journal of Cellular Physiology 2013, 228(10):1956-1966.

22. Curtright A, Rosser M, Goh S, Keown B, Wagner E, Sharifi J, Raible DW, Dhaka A: Modeling nociception in zebrafish: a way forward for unbiased analgesic discovery. PloS one 2015, 10(1):e0116766.

23. Nguyen M, Stewart AM, Kalueff AV: Aquatic blues: Modeling depression and antidepressant action in zebrafish. Progress in Neuro-Psychopharmacology and Biological Psychiatry 2014, 55:26-39.

24. Neve KA, Seamans JK, Trantham-Davidson H: Dopamine Receptor Signaling. Journal of Receptors and Signal Transduction 2004, 24(3):165-205.

25. Lu Y, Doroshenko M, Lauzadis J, Kanjiya MP, Rebecchi MJ, Kaczocha M, Puopolo M: Presynaptic Inhibition of Primary Nociceptive Signals to Dorsal Horn Lamina I Neurons by Dopamine. The Journal of Neuroscience 2018, 38(41):8809.

26. Meyer A, Van de Peer Y: From 2R to 3R: evidence for a fish-specific genome duplication (FSGD). Bioessays 2005, 27(9):937-945.

27. Boehmler W, Obrecht-Pflumio S, Canfield V, Thisse C, Thisse B, Levenson R: Evolution and expression of D2 and D3 dopamine receptor genes in zebrafish. Developmental Dynamics 2004, 230(3):481-493.

28. Jaaskelainen SK, Lindholm P, Valmunen T, Pesonen U, Taiminen T, Virtanen A, Lamusuo $\mathrm{S}$, Forssell H, Hagelberg N, Hietala J et al: Variation in the dopamine D2 receptor gene plays a key role in human pain and its modulation by transcranial magnetic stimulation. Pain 2014, 155(10):2180-2187.

29. Zhang Y, Bertolino A, Fazio L, Blasi G, Rampino A, Romano R, Lee ML, Xiao T, Papp A, Wang D et al: Polymorphisms in human dopamine D2 receptor gene affect gene expression, splicing, and neuronal activity during working memory. Proceedings of the National Academy of Sciences of the United States of America 2007, 104(51):20552-20557.

30. Duan J, Wainwright MS, Comeron JM, Saitou N, Sanders AR, Gelernter J, Gejman PV: Synonymous mutations in the human dopamine receptor D2 (DRD2) affect mRNA stability and synthesis of the receptor. Human molecular genetics 2003, 12(3):205-216. 
31. Hirvonen MM, Lumme V, Hirvonen J, Pesonen U, Någren K, Vahlberg T, Scheinin H, Hietala J: C957T polymorphism of the human dopamine D2 receptor gene predicts extrastriatal dopamine receptor availability in vivo. Progress in Neuro-Psychopharmacology and Biological Psychiatry 2009, 33(4):630-636.

32. Martikainen IK, Hagelberg N, Mansikka H, Hietala J, Nagren K, Scheinin H, Pertovaara A: Association of striatal dopamine D2/D3 receptor binding potential with pain but not tactile sensitivity or placebo analgesia. Neurosci Lett 2005, 376(3):149-153.

33. Pertovaara A, Martikainen IK, Hagelberg N, Mansikka H, Någren K, Hietala J, Scheinin $\mathrm{H}$ : Striatal dopamine D2/D3 receptor availability correlates with individual response characteristics to pain. European Journal of Neuroscience 2004, 20(6):1587-1592.

34. Hagelberg N, Forssell H, Aalto S, Rinne JO, Scheinin H, Taiminen T, Nagren K, Eskola O, Jaaskelainen SK: Altered dopamine D2 receptor binding in atypical facial pain. Pain 2003, 106(1-2):43-48.

35. Liu N-A, Liu Q, Wawrowsky K, Yang Z, Lin S, Melmed S: Prolactin Receptor Signaling Mediates the Osmotic Response of Embryonic Zebrafish Lactotrophs. Molecular Endocrinology 2006, 20(4):871-880.

36. Nusslein-Volhard CD: R (2002) Zebrafish, A Practical Approach. New York, USA.

37. Xi Y, Yu M, Godoy R, Hatch G, Poitras L, Ekker M: Transgenic zebrafish expressing green fluorescent protein in dopaminergic neurons of the ventral diencephalon. Developmental dynamics : an official publication of the American Association of Anatomists 2011, 240(11):25392547.

38. Irons TD, Kelly PE, Hunter DL, MacPhail RC, Padilla S: Acute administration of dopaminergic drugs has differential effects on locomotion in larval zebrafish. Pharmacology Biochemistry and Behavior 2013, 103(4):792-813.

39. Pinheiro J, Bates D, DebRoy S, Sarkar D: nlme : Linear and Nonlinear Mixed Effects Models. In., vol. R package version 3.1-141; 2019.

40. Qing-Song L, Jian-Tian Q, Dafny N: D2 dopamine receptor involvement in spinal dopamine-produced antinociception. Life Sciences 1992, 51(19):1485-1492.

41. Dai WL, Xiong F, Yan B, Cao ZY, Liu WT, Liu JH, Yu BY: Blockade of neuronal dopamine D2 receptor attenuates morphine tolerance in mice spinal cord. Scientific reports 2016, 6:38746.

42. Cobacho N, de la Calle JL, Paino CL: Dopaminergic modulation of neuropathic pain: analgesia in rats by a D2-type receptor agonist. Brain Res Bull 2014, 106:62-71.

43. Irion U, Krauss J, Nusslein-Volhard C: Precise and efficient genome editing in zebrafish using the CRISPR/Cas9 system. Development (Cambridge, England) 2014, 141(24):48274830.

44. Ata H, Clark KJ, Ekker SC: The zebrafish genome editing toolkit. Methods in cell biology 2016, 135:149-170.

45. van Reij RRI, Joosten EAJ, van den Hoogen NJ: Dopaminergic neurotransmission and genetic variation in chronification of post-surgical pain. British Journal of Anaesthesia 2019. 
46. Brefel-Courbon C, Payoux P, Thalamas C, Ory F, Quelven I, Chollet F, Montastruc JL, Rascol O: Effect of levodopa on pain threshold in Parkinson's disease: A clinical and positron emission tomography study. Movement Disorders 2005, 20(12):1557-1563.

47. Chaudhuri KR, Schapira AH: Non-motor symptoms of Parkinson's disease: dopaminergic pathophysiology and treatment. The Lancet Neurology 2009, 8(5):464-474.

48. Cherubini E, Di Napoli A, Noto A, Osman GA, Esposito MC, Mariotta S, Sellitri R, Ruco L, Cardillo G, Ciliberto G et al: Genetic and Functional Analysis of Polymorphisms in the Human Dopamine Receptor and Transporter Genes in Small Cell Lung Cancer. Journal of Cellular Physiology 2016, 231(2):345-356.

49. Sneddon LU: Pain perception in fish: indicators and endpoints. ILAR journal 2009, 50(4):338-342.

50. Tay TL, Ronneberger O, Ryu S, Nitschke R, Driever W: Comprehensive catecholaminergic projectome analysis reveals single-neuron integration of zebrafish ascending and descending dopaminergic systems. Nature Communications 2011, 2:171.

51. Gonzalez-Nunez V, Rodríguez RE: The Zebrafish: A Model to Study the Endogenous Mechanisms of Pain. ILAR Journal 2009, 50(4):373-386.

52. Malafoglia V, Colasanti M, Raffaeli W, Balciunas D, Giordano A, Bellipanni G: Extreme Thermal Noxious Stimuli Induce Pain Responses in Zebrafish Larvae. Journal of Cellular Physiology 2014, 229(3):300-308.

53. Maximino C: Modulation of nociceptive-like behavior in zebrafish (Danio rerio) by environmental stressors. Psychology \& Neuroscience 2011, 4(1):149.

54. Prober DA, Zimmerman S, Myers BR, McDermott BM, Kim S-H, Caron S, Rihel J, SolnicaKrezel L, Julius D, Hudspeth AJ et al: Zebrafish TRPA1 Channels Are Required for Chemosensation But Not for Thermosensation or Mechanosensory Hair Cell Function. The Journal of Neuroscience 2008, 28(40):10102.

55. Taylor JC, Dewberry LS, Totsch SK, Yessick LR, DeBerry JJ, Watts SA, Sorge RE: A novel zebrafish-based model of nociception. Physiol Behav 2017, 174:83-88.

56. Maximino C, Herculano AM: A review of monoaminergic neuropsychopharmacology in zebrafish. Zebrafish 2010, 7(4):359-378.

57. Shontz EC, Souders II CL, Schmidt JT, Martyniuk CJ: Domperidone upregulates dopamine receptor expression and stimulates locomotor activity in larval zebrafish (Danio rerio). Genes, Brain and Behavior 2018, 17(4):e12460.

58. Barreto-Valer K, Lopez-Bellido R, Macho Sanchez-Simon F, Rodriguez RE: Modulation by cocaine of dopamine receptors through miRNA-133b in zebrafish embryos. PLoS One 2012, 7(12):e52701.

59. Boehmler W, Carr T, Thisse C, Thisse B, Canfield VA, Levenson R: D4 Dopamine receptor genes of zebrafish and effects of the antipsychotic clozapine on larval swimming behaviour. Genes Brain Behav 2007, 6(2):155-166.

60. Klee EW, Schneider H, Clark KJ, Cousin MA, Ebbert JO, Hooten WM, Karpyak VM, Warner DO, Ekker SC: Zebrafish: a model for the study of addiction genetics. Human Genetics 2012, 131(6):977-1008. 
61. Melzack R, Wall PD: Pain mechanisms: a new theory. Science 1965, 150(3699):971-979.

62. Braithwaite VA, Boulcott P: Pain perception, aversion and fear in fish. Diseases of Aquatic Organisms 2007, 75(2):131-138. 
$160 \mid$ Ch a p ter 6 


\section{CHAPTER 7}

\section{General Discussion}

R. R. I. van Reij

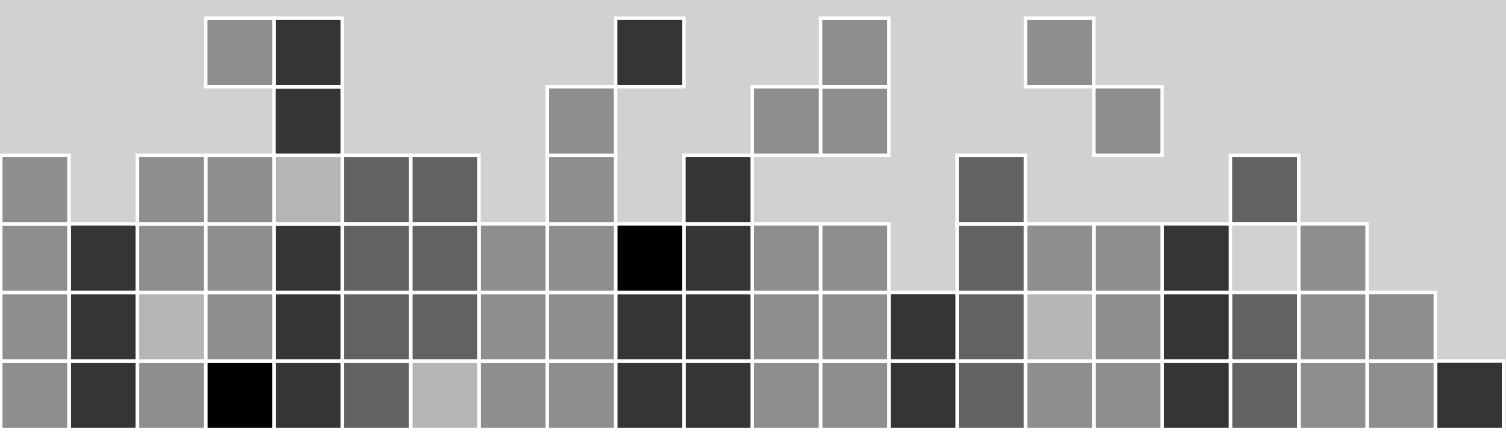


162|Chapter 7 
The aim of this thesis was to study the genetic risk factors of chronic post-surgical pain (CPSP) and to identify functional effects of genetic variation on nociception and chronic pain in both clinical and preclinical studies (see Chapter 1 Introduction page 11). Related to this aim various RQ's were formulated and then investigated in Chapters 2-6. In this General Discussion the RQ's and related findings will be discussed in a more general context and moreover the possible implications of the findings, critical considerations and future perspectives will be evaluated

\section{Research question 1: What is the role and impact of genetic variations related to dopaminergic neurotransmission in CPSP?}

Dopaminergic (DA) neurotransmission, most known for its involvement in reward, mood and locomotion, has been associated with nociception and chronic pain syndromes including CPSP but is often overlooked when it comes to analgesic treatment strategies [1-6]. DA is known to be important in stimulating as well as inhibiting nociception at the level of the spinal cord dorsal horn [7]. As DA has an important role in pain and is often overlooked in analgesia, we conducted a review of the available literature (see Chapter 2) and performed a preclinical study to model the effect of DA genetic variation on nociception (see Chapter 6).

From the literature review, we present a tri-phasic effect of DA concentration in the spinal cord due to differential affinity Of DA for either the D1-like or the D2like receptors (Chapter 2, Figure 1 page 36) [8-10]. In short, both a low and a high concentration of DA leads to inhibition of nociception of whereas a medium concentration tends to be excitatory $[8,10-13]$. The modulation of nociception in the spinal cord via DA receptors can either be direct (inhibition of the nociceptive transmission by $\mathrm{D} 2$ receptors or via sensitization of C-fibres by the D1 receptors) or indirect (synergy with opioid receptors of D2 receptors or synergy with NMDA receptors by D1 receptors) as seen in Figure 1, Chapter 2 [3, 4, 13-21]. 
Central sensitization (as explained in Chapter 1, page 10) is a process of deregulated communication between nociceptive afferent and pain transmission neurons [22, 23]. DA neurotransmission affects this process both in an inhibitory (D2 receptors) and facilitatory (D1 receptors) manner [7, 24]. D2 receptors can modulate the opioid receptor involved in inhibition of the pain transmission thereby preventing central sensitization [4]. However, activation of the D1 receptors potentiates the NMDA receptors leading to facilitation of central sensitization $[25,26]$.

Genetic variations within the DA-neurotransmission, specifically in COMT gene (risk factor), GCH1 gene (protective factor) and DRD2 gene (risk factor), have been associated with a variability in pain sensitivity, development of CPSP and analgesic requirement [24, 27-29]. Although there is still some ambiguity in the results between studies, fluctuations in either DA concentration, altered production due to SNPs in GCH1 or altered breakdown due to SNPs in COMT, or DA receptor availability, SNPs in DA receptors, affects nociception and the development of chronic pain [24, 27-29]. Therefore, studying DA-metabolism and neurotransmission could lead to new therapeutic options for treatment of chronic pain conditions including CPSP. One key aspect in the administration of drugs targeting the DA receptors are possible side effects on locomotion and mood or reward $[5,6]$. DA is for instance inherently linked to locomotion in all vertebrates [5]. In view of this, combining DA-focussed interventions with other interventions targeted at synergistically linked pathways might be an approach to decrease the optimal dosage to a subclinical dosage whereby locomotor and other side-effects are absent [4]. For instance, mu-opioid receptors and D2 receptors are functionally linked and co-administration of D2 agonist and morphine could decrease the dose necessary for an effect of both administered drugs thereby reducing side effects, as shown before [4]. 
To further examine the impact and role of genetic variations related to dopaminergic neurotransmission in CPSP, we modelled a clinical phenotype of decreased dopamine D2 receptor expression in zebrafish. The findings as in Chapter 6 show a pivotal role of D2 receptors in nociception. A decrease in D2 receptor expression led to pro-nociceptive behaviour in response to a noxious heat stimulus while application of Quinpirole, a D2 receptor agonist, resulted in an anti-nociceptive response (see Chapter 6 pages 145-149). With this a causal link between a decrease in D2 receptor expression and pro-nociceptive behaviour is shown. Clearly the results in Chapter 6 not only validate prior studies (Eijkenboom et al.,) but also provides a framework for future genetic screening and testing of drugs in zebrafish [30]. Several techniques in zebrafish are available (incl. morpholino's, CRISPR and mRNA overexpression) which allows to further test the functional effects of known and unknown variants associated with pain phenotypes [31, 32].

Critical considerations should be taken into account when interpreting the results of the zebrafish study in a context of analgesia and peri-operative pain. Zebrafish are an excellent model to study the effect of genetic variations and pharmacology on behavioural and morphological outcome parameters related to acute pain conditions. Unfortunately, as of yet, no studies on chronic pain conditions in zebrafish have been published. Chronic effect studies in zebrafish that have been presented deal with effects and toxicology of exposure to different compounds related to ethanol-induced effects or chronic hyperglycaemia $[33,34]$. Hence, a direct link between studying genetic variants in zebrafish and their effect in CPSP is currently lacking. Studying chronic disorders in zebrafish is challenging as zebrafish have a potent regenerative capacity and they recover within weeks from myocardial infarctions (i.e. heart attacks) and spinal cord injury [35-37]. Therefore, testing how genetic variants affect the development of chronic pain after surgery or peripheral nerve injury is not possible. On the other hand the effect on nerve sprouting and regeneration in a context of acute pain can be studied in zebrafish, 
which might yield interesting perspectives and therapeutic strategies [36-38]. Variants within the D2 receptor which are associated with altered baseline sensitivity are also associated with the development of chronic pain indicating that zebrafish can be used a high-throughput screening model for the effects on nociception in the acute phase [39]. These results then need to be tested in models of chronic postsurgical pain in rodents (e.g. thoracotomy and skin/muscle incision and retraction model (SMIR)) for effects on chronic pain, before clinical trials can commence $[40,41]$.

Translational use of zebrafish models for screening of pharmacological interventions has been shown in various research areas and drug responses were identical across species [42]. One area of pharmacological research for which zebrafish might be particularly interesting is drug repurposing. In this field, drugs, which are currently available for humans, are tested for other indications than originally intended. In the context of dopamine and pain, it might be interesting to look at drugs developed for Parkinson's disease as this disorder is characterized by a DA pathophysiology $[43,44]$. Recent studies have shown promising results in drug repurposing and combined with the interspecies validity shown in other studies, this might be a valuable application of zebrafish models [45-47].

The association on Dopamine and CPSP is based on gene-targeted studies on CPSP which chooses targets a priori. As explained in the introduction Chapter 1 (page 14), GWAS studies test a wide array of SNPs across the genome and are able to validate gene-targeted studies (e.g. the studies on DA and CPSP) but also lead to new findings and elucidate new mechanisms underlying a disease [48, 49]. Furthermore, a GWAS study has a higher resolution to detect variants with a modest effect on the phenotype and it genotypes variants outside of the coding regions of the genes [49]. 


\section{Research question 2: What are the genome-wide risk factors of CPSP and the related functional mechanisms?}

Our GWAS (Chapter 3) on genetic risk factors of CPSP (Chapter 3) gave an initial insight into the genome-wide risk factors of CPSP and identified the first potential risk locus [50]. The potential risk locus contains two genes (IQGAP1 and CRTC3) which were both associated with CPSP. CRTC3 is expressed in many tissues including neuronal tissue, is downstream of the catecholamine (e.g. dopamine) signalling and associated with both inflammatory disorders and neurological traits [51-55]. IQGAP1 is also expressed throughout the body including neuronal tissue, involved in signalling molecules and cell motility and associated with immune system functioning and multiple sclerosis [54, 56, 57]. In our study, the SNPs in both genes are in linkage disequilibrium (LD) with each other and influence the development of CPSP together. Their involvement in the immune system is supportive of postsurgical infection being a risk factor for the development of CPSP, as previously shown [58].

One of the disadvantages of a GWAS is the need for large sample sizes. Sufficiently large sample sizes are necessary to find smaller effects, especially if the minor allele frequency or effect size decreases $[49,59,60]$. The second challenge in GWAS studies and CPSP research in particular is the homogeneity in the phenotype. The incidence of CPSP varies across surgeries, ranging from 5\% to $85 \%[61,62]$. The type of surgery is one of the risk factors of developing CPSP and explains the large variation in incidence $[61,63,64]$. Surgeries in areas with more nerve innervation have larger risk of nerve damage leading to neuropathic symptoms as do surgeries requiring larger incisions and a longer duration [61, 63, 64]. On the other hand, not everybody exposed to a major surgery with a long duration and large incision develops CPSP, indicating a differential susceptibility to chronification of pain after nerve damage which might be explained by genetics. Depending on the surgery, different genes might be involved in the development of CPSP. 
As explained in the introduction Chapter 1 (page 10) central sensitization is a central process in the development of CPSP [22, 23]. Central sensitisation occurs due to increased and continuous action potentials coming from the nociceptive afferents most often caused by a combination of local inflammatory processes and tissue or nerve damage $[22,23]$. As, both inflammation and tissue damage are key components of CPSP, the composition of inflammatory processes and tissue/nerve damage underlying the CPSP could differ per surgery [61]. It is to be expected that this will be reflected in the genetic risk factors for different types of surgeries.

GWAS studies in migraine have shown that it is feasible to identify general genetic risk factors for all migraine subtypes combined and specific risk factors for migraine subtypes [65]. This only becomes feasible as soon as the sample size in each subtype is sufficiently large enough to have enough power on its own and if the combined sample is large enough to detect subtle effects in the general cohort [60]. Future GWAS studies on CPSP should thus be able to identify general genetic risk factors for CPSP as well as surgery specific risk factors.

Currently, the sample size in our first GWAS study on CPSP (Chapter 3) is not large enough to be able to differentiate between subtypes. Moreover, the results of a GWAS are merely associations and the associated SNPs need not be the causal variant associated with the phenotype [66]. For most complex diseases such as pain, associated SNPs are primarily found in non-coding areas making it difficult to assess possible causal relationships [66-68]. Further validation studies are necessary to identify potential causal SNPs and genes [66].Here we anticipated and in collaboration with Radboud University Medical Center and UniKlinikum Muenster initiated and started a larger scale follow-up (GWAS) study including all elective surgery patients. 
In order to relate the GWAS data and potential risk loci associated with CPSP to possible functional mechanisms, we used transcriptome-wide Mendelian randomization (TWMR) which combines GWAS and eQTL data (see Chapter 4). Combining the GWAS data (Chapter 3) with tissue specific eQTL data and TWMR led to the identification of tissues specific associations as well as genes associated with CPSP across multiple tissues. The findings suggest a potential causal relation of 5 genes with CPSP across all tissues studied (whole blood, DRG, cortex and spinal cord) and 21 genes with CPSP across neuronal tissues (see Chapter 4). Using the Pax protein expression database we were able to identify two genes (Synaptosome Associated Protein 29 (SNAP29) and Vacuolar Protein Sorting-Associated Protein 8 (VPS8)) [69]. VPS8 has been associated with the immune system functioning, brain morphology and cognitive performance [70]. SNAP29 and members of this gene family have been associated with fibromyalgia $[71,72]$. Loss of SNAP29 has been associated with a decrease in endocytic recycling within the cell and a decrease in cell motility. This has shown to result in dysfunctional wound healing and neurological abnormalities [73, 74]. Furthermore, SNAP29 is involved in synaptic vesicle trafficking, specifically inhibiting synaptic transmission in an activity dependent manner and involved in mast cell phagocytosis $[75,76]$. This combined evidence related to SNAP29 strongly suggests this protein plays a modulatory role in fine-tuning of cellular growth and immune cell functioning. Therefore, alterations in the expression of the gene coding for SNAP29 may affect repair mechanisms involved in and related to the development of chronic pain.

Future genetic studies on CPSP should take into account the complex biology underlying the phenotype. Increasing sample sizes is only part of the solution, also the eQTL datasets should be increased and further specified to incorporate different and more specific tissues. For example, studies on major psychiatric disorders have found tissue specific gene-expression effects and uncovered novel biological mechanisms using eQTLs [77-79]. Furthermore the associations found 
in a GWAS do not indicate causality while the TWMR approach does identify putative causal relations. Therefore, future functional studies are necessary to a clear overview of which SNPs and genes are causally involved in CPSP. Next to increasing sample sizes, also different ethnic populations should be taken into account. Complex phenotypes have a varying distribution across ethnic populations which is partly due to differences in allele frequencies, effect sizes and genetic architecture due to differential evolution [80-82]. Almost all of the GWASdata published to date have focussed on individuals of Caucasian descent [82]. As there are known differences across ethnicities it should be taken into account that this likely will affect possible associations in GWAS and eQTL studies [82, 83].

Studies on the genetic risk factor in psychiatric disorders have innovated the research field of neuro-genetics and led to new developments in application of functional genetics related to understanding underlying biological mechanisms [84-87]. This innovation was partly possible due to studying the shared genetic aetiology existing between the psychiatric disorders. There is a considerable amount of overlap in pain characteristics among chronic pain conditions: prevalence is higher in women, age is a risk factor, central sensitization plays a major role in all phenotypes and chronic pain conditions co-occur with psychological syndromes [88-90]. This overlap suggests a possible shared genetic aetiology between CPSP and different chronic pain disorders. 


\section{Research question 3: What is the shared genetic aetiology between different chronic pain disorders including CPSP and does this provide insights into the common biological mechanisms underlying chronic pain?}

Our analysis of the shared genetic aetiology of chronic pain syndromes (see Chapter 6) revealed a (possible) shared aetiology between CPSP and chronic peripheral pain syndromes (CPPs) but not with headache/migraine related pain syndromes. Pathway analysis indicated involvement of neuronal signalling and inflammatory response.

Gene ontology (GO) analysis on the genetic overlap of CPSP with chronic peripheral pain (CPP) subtypes (rheumatoid arthritis (RA), chronic widespread pain (CWP), sciatica) resulted in the identification of 4 common biological processes clusters, 3 cellular components clusters and 5 molecular functions clusters that could provide insight in a shared aetiology [91, 92]. Pathway analysis of the SNPs associated with the genetic overlap between CPP syndromes and CPSP strongly suggest involvement of neuronal processes: nervous system process, neuron part sodium channel activity, and of inflammatory response: response to cytokine, response to wounding, regulation of immune system process. These findings are consistent with published reports on the interaction of the neuronal and inflammatory reaction in the aetiology of chronic pain [93-97]. Both in CPPs and RA the communication between neurons and the immune system has been very well documented [93-97]. This is consistent with what is known about the pathophysiology of CPPs and CPSP. The three CPP subtypes that showed genetic overlap with CPSP in both cohorts are known to affect peripheral nerves directly [88, 90, 98]. As discussed in the introduction (Chapter 1), nerve damage is one of the phenomena underlying peripheral and central sensitisation in CPSP $[22,23]$. 
Unfortunately, the GO terms associated with the inflammatory response did not indicate any specific process or cell component to be involved in the genetic overlap between CPPs and CPSP. Future studies and larger sample sizes should be able to further establish the genetic overlap and may then eventually identify a specific component of the inflammatory response to be involved in both CPSP and CPPs. The GO terms associated with neuronal signalling, point to the involvement of sodium channels (e.g. sodium channel complex cluster in cellular components GO terms and sodium channel regulator activity cluster in molecular functions). Sodium channels are very heavily involved in pain as the sodium channels conduct the action potentials and thus the nociceptive signal from the periphery towards the brain [99]. The most well-known example of the relation between pain and sodium channels is congenital insensitivity to pain which is caused by a mutation within the sodium channel $1.7\left(\mathrm{Na}_{\mathrm{v}} 1.7\right)$ [100]. Genetic variations within sodium channels have been associated with multiple chronic pain conditions such as small fiber neuropathy, painful diabetic polyneuropathy and peripheral neuropathies [101-105]. However, genetic variations in the genes encoding for sodium channels have not (yet) been significantly associated with CPSP and only one study investigated the sodium channel gene SCN9 in relation to CPSP [29]. Although much effort has been put in development of drugs to modulate identified sodium channels (as related to specific clinical indications like small fiber neuropathy) this use and implementation has been hampered by significant side-effects [100, 106-108]. Non-selective sodium channel inhibitors can lead to an array of side effects due to the widespread use of sodium channels throughout the body [108]. Hence, the development of isoform specific sodium channel inhibitors might be the next step in personalized and precision medicine $[100,108]$. Zebrafish might play a role in this development as sodium channel mutations introduced in the zebrafish mimic the clinical phenotype [30]. 
Future research, incorporating larger sample sizes can utilise polygenic risk scores (PRS) can identify individual genes and genetic variation in clinical practice. This approach has been successful in migraine where the PRS identified patients likely to develop migraine as well as sub clusters of patients who respond to certain classes of medication [109]. A similar approach was used in psychological disorders for efficacy of antidepressants [84]. The combined use of PRS and larger GWAS studies as applied in migraine and psychological disorders may guide future research in CPSP and drug development.

Chapter 5 is the first study combining published GWAS datasets on pain to study genetic overlap across pain phenotypes and CPSP. A major limitation is the variability in the number of SNPs reported by the various GWAS studies. The input set of SNPs for a PRS analysis is often the complete GWAS data and more potentially causal SNPs in a PRS lead to more predictive power [110, 111]. Including only the top hit SNPs complicates and limits accurate PRS assessment and some studies were omitted from the current study for only reporting top SNPs [112]. The recommendation to include all summary statistics (preferably raw data) as part of publications may enhance transparency and robustness of analyses and interpretation. A second limitation of is the sample size of the various studies included in our analyses. Sample sizes larger than 2000 are preferred for the PRS analysis as lower sample sizes lead to an inflation of the explained variance [110]. To overcome the small sample size, a replication approach was chosen.

The herein presented pathway analysis (Chapter 5) provides a starting point for studies on mechanisms and pathways involved in CPSP and the potential shared aetiology of CPSP and CPP syndromes. Future research aimed at understanding the impact of genetic variations on the development of CPSP should include functional aspects of genetic networks and corresponding regulatory processes in chronic pain. Functional aspects of both coding and non-coding SNPs should be elucidated to fully understand the impact of genetic variation on the development 
of CPSP. Detailed studies on the effects of genetic variation on protein function, cell signalling and cell and organismal physiology are needed and then should further clarify their mechanistic connection to CPSP and CPP's.

\section{Framework for developing new treatment strategies and personalized medicine in CPSP}

Both clinical and preclinical studies are necessary to validate and functionally annotate the findings reported in this thesis. The future perspectives in the field of prediction and treatment of CPSP are discussed in the context of the translational framework. The starting point of this translational framework (figure1) is the clinical phenotype as described extensively in the introduction (Chapter 1) and throughout this dissertation.

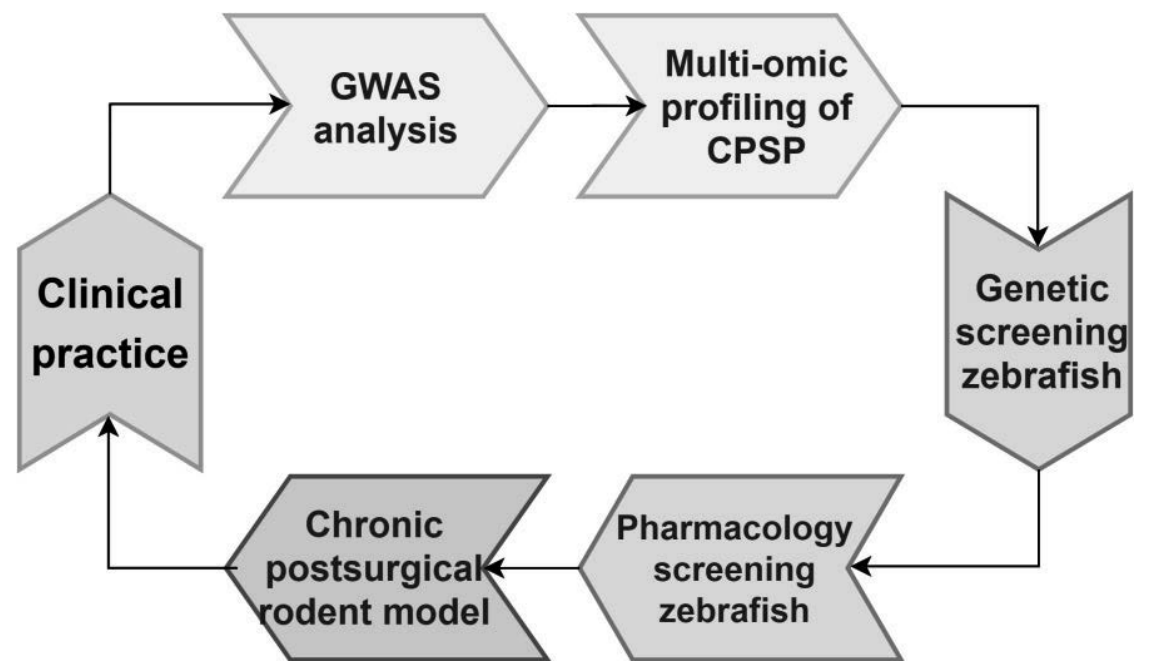

Figure 1: Framework for developing new therapeutic strategies and personalized medicine in CPSP. By starting from the clinical phenotypes (Green arrow) using a genomic and multi-omic (e.g. transcriptomics, ribosomal footprint profiling) approach (Yellow arrow), we hope to prioritize candidates for genetic screening in zebrafish and screening of pharmacological interventions tailored to the possible genetic risk factors (Blue arrows). These findings have to be tested in postsurgical animal models (Pink arrow) before translating those findings back to the clinical practice. 


\section{GWAS analysis of CPSP}

As explained in Chapter 3 (Page 66), most of the genetic studies on CPSP have been gene-targeted studies focussed on a small subset of genes. Performing GWASs on CPSP cohort will lead to the identification of genome-wide genetic risk factors of CPSP. Although, the first genome-wide significant risk locus for CPSP has been identified (rs17882261, SFTPA2) in Chapter 4, the current CPSPcohorts are not large enough to accurately identify multiple genome-wide significant SNPs and the current findings need to be replicated. A major focus should be on increasing the sample sizes of the CPSP-GWAS cohorts and thereby increasing the power of genetic studies. Large scale studies on migraine and on psychiatric disorders provide excellent examples of the possibilities of GWAS analysis in neuroscience leading to new insights and treatment options $[65,113$, 114]. To continue this, large scale collaborations are necessary to enlarge the sample sizes, leading to in depth identification of genetic risk factors, identification of subtype specific risk factors and prioritization of biological mechanisms $[65,113,114]$. Several initiatives have recently been started to form collaborations capable of collecting data on large cohorts of patients undergoing surgery (e.g. Horizon 2020 grant proposal PostOpOmics, Pain Predict Genetics project together with Radboud University and Muenster University, International collaboration with the Human Pain genetics lab at McGill University). The first results of the latter collaboration are reported in Chapter 4 which has already identified the first genome wide significant association with CPSP.

Part of the findings in GWAS studies can already be implemented in the clinic via integration into clinical CPSP prediction models Current clinical CPSP prediction models have shown to allow prediction of $78 \%$ of the variance in CPSP [115]. Up until recently, costs for clinical genetic testing were excessive and thus implementation into clinical practice not possible [116]. As genetic testing has become cheaper over the last years, cost-benefit increases and from now it is 
feasible to integrate genetic testing and implementation of the results into clinical prediction modelling. Furthermore, a systematic review on integration of SNPs in prediction models related to complex diseases recently showed an increase in the predictive accuracy [117]. Integration of one SNP into a clinical prediction model of CPSP also resulted into a led to an improvement in prediction accuracy from 78 to $81 \%$ [115]. Although promising it should be taken into consideration that the additional value of the integration of genetic analysis into prediction models depends on factors such as the genetic architecture of the disease [117].

\section{Multi-omic profiling of CPSP}

Although GWAS analysis provides insights into association between SNPs and CPSP, it does not provide evidence on causality [69]. SNPs associated with disease phenotypes often exert their effect through altering target gene expression [69]. A strong focus should be directed towards prioritization of potential causal variants associated with CPSP. Two techniques that could provide further insight in the relation between SNPs, biological mechanisms and CPSP are RNA-seq studies identifying eQTLs and ribosomal footprint profiling [118, 119]. eQTL studies allow identification of SNPs which are associated with the differential geneexpression of a specific gene $[66,118,120]$. The altered gene-expression could then lead to an altered protein expression which may affect several biological processes for pharmacological targeting $[66,118,120]$. On the other hand increased geneexpression does not necessarily equal increased protein expression as the translation of mRNA to protein can is dependent on several factors including ribosomal activity $[119,121,122]$. By combining ribosomal footprint profiling of the immune cells in the blood sample or biopsies of patients the level of mRNA can be assessed as well as how much of the mRNA is being translated into protein to gain further functional insights [119]. The use of these techniques will allow to prioritize likely candidates in the development of CPSP to be studied further in preclinical studies. Furthermore, this then could point towards biological 
mechanisms that subsequently are targeted by pharmacological interventions. The prioritized candidates identified by these approaches need to be tested in preclinical models to assess the functional effects and biological mechanisms.

\section{Genetic screening in zebrafish}

One of the largest challenges in genetic studies is the lack of functional annotations of all the SNPs that have been associated with a phenotype [66]. As discussed earlier, zebrafish are an excellent model for screening and this could also be applied to study the functionality of SNPs by reverse genetics using CRISPR/CAS9 [123]. The advantage of zebrafish over cell culture are that zebrafish are fully functional organisms and not a specific mix of cultured cells. This makes it possible to test effects of a genetic variation on the whole (nociceptive) system. The lack of complexity of cell cultures have been partially overcome by development of brain organoids and their main advantage is that it allows to culture the patient's own cells including its DNA profile [124, 125]. To study the functional effects of SNPs on neuronal functioning, it is important to be able to include physiological responses at a cellular/neuronal level. A combination of both calcium imaging and electrophysiology is technically possible in zebrafish and has been described in literature [126-128]. From this, it is expected that genetic screening in zebrafish combined with studies in human organoids will probably form the future fundament for analysis of studies on genetic risk factors in prediction and treatment of CPSP.

\section{Pharmacology screening in zebrafish}

Functional annotations found in zebrafish are targets for pharmacological screening. As discussed in Chapter 6 we showed that pharmacological intervention of a genetic phenotype is possible. In addition, it has been shown that most pharmacological intervention applied to zebrafish show similar effects as in humans [42]. The next step in this process is pharmacological intervention to 
counteract the functional effects of a genetic risk factor [129]. By applying a pharmacological intervention to genetically modulated zebrafish, the altered behavioural, morphological and/or physiological outcomes caused by the genetic risk factor can be treated. These findings need to be applied in a translational model of CPSP to test the findings before translating them back to the clinic.

\section{Chronic postsurgical rodent model}

As discussed above, zebrafish are not the optimal model to study chronic pain as their recovery trajectory is different from mammals [35-37]. Therefore, findings in zebrafish need to be translated to rodent models which mimic human surgeries. The thoracotomy model in rats, for example, leads to CPSP in 50\% of the rats which is comparable to the human incidence $[40,61,130,131]$. This and other surgeries (i.e. hind paw incision and SMIR) can be used to test the efficacy of pharmacological interventions in prevention and treatment of CPSP [132-134]. Mice have long been the preferred laboratory animal for studies on genetics due to the shorter reproductive cycle and genome editing techniques have been available since the 1980's $[135,136]$. Thoracotomies have been performed in mice but not tested in the context of CPSP $[137,138]$. To be able to study the effects of a pharmacological intervention in combination with genetics risk factors in rodents, the CPSP models in rats first need to be validated in mice. The alternative is genetic editing of rat strains, which has been done but is still developing and relatively expensive [139]. The next step is translating these findings back to the clinic. As discussed earlier (page 166), repurposing of drugs related to prevention or treatment of CPSP has great potential. 


\section{Concluding remarks}

This dissertation aimed to study the role of genetics in prediction and treatment of chronic postsurgical pain. In view of this, we started genetic screening and provided a genome-wide insight into the genetics of CPSP. This initial step identified the first potential risk loci and candidates for follow up studies. Furthermore, we have shown the important role of genetic variations related to dopaminergic neurotransmission in CPSP and preformed first steps in genetic and pharmacological screening in a zebrafish nociception model. With this dissertation a framework is provided for future studies and a combined and focussed clinical /pre-clinical approach aimed to develop personalized medicine in treatment of CPSP. 


\section{References}

1. Antypa N, Drago A, Serretti A: The role of COMT gene variants in depression: Bridging neuropsychological, behavioral and clinical phenotypes. Neurosci Biobehav Rev 2013, 37(8):1597-1610.

2. Wood PB: Role of central dopamine in pain and analgesia. Expert Review of Neurotherapeutics 2008, 8(5):781-797.

3. Aira Z, Barrenetxea T, Buesa I, del Caño GG, Azkue JJ: Dopamine D1-like Receptors Regulate Constitutive, $\mu$-Opioid Receptor-Mediated Repression of Use-Dependent Synaptic Plasticity in Dorsal Horn Neurons: More Harm than Good? The Journal of Neuroscience 2016, 36(20):5661-5673.

4. Aira Z, Barrenetxea T, Buesa I, Gómez-Esteban JC, Azkue JJ: Synaptic upregulation and superadditive interaction of dopamine D2-and $\mu$-opioid receptors after peripheral nerve injury. $P A I N \circledast 2$ 2014, 155(12):2526-2533.

5. Ryczko D, Dubuc R: Dopamine and the Brainstem Locomotor Networks: From Lamprey to Human. Frontiers in neuroscience 2017, 11:295.

6. Scott DJ, Stohler CS, Egnatuk CM, Wang H, Koeppe RA, Zubieta JK: Individual differences in reward responding explain placebo-induced expectations and effects. Neuron 2007, 55(2):325-336.

7. Millan MJ: Descending control of pain. Progress in Neurobiology 2002, 66 (6):355-474.

8. Roth BL, Lopez E, Patel S, Kroeze WK: The multiplicity of serotonin receptors: uselessly diverse molecules or an embarrassment of riches? The Neuroscientist 2000, 6(4):252-262.

9. Helmuth L: Netwatch. Science 2000, 287(5453):543-543.

10. Abdallah K, Monconduit L, Artola A, Luccarini P, Dallel R: GABAAergic inhibition or dopamine denervation of the A11 hypothalamic nucleus induces trigeminal analgesia. Pain 2015, 156(4):644-655.

11. Clemens S, Rye D, Hochman S: Restless legs syndrome: revisiting the dopamine hypothesis from the spinal cord perspective. Neurology 2006, 67(1):125-130.

12. Clemens S, Belin-Rauscent A, Simmers J, Combes D: Opposing modulatory effects of D1and D2-like receptor activation on a spinal central pattern generator. Journal of neurophysiology 2012, 107(8):2250-2259.

13. Tamae A, Nakatsuka T, Koga K, Kato G, Furue H, Katafuchi T, Yoshimura M: Direct inhibition of substantia gelatinosa neurones in the rat spinal cord by activation of dopamine D2-like receptors. The Journal of Physiology 2005, 568(1):243-253.

14. Taniguchi W, Nakatsuka T, Miyazaki N, Yamada H, Takeda D, Fujita T, Kumamoto E, Yoshida M: In vivo patch-clamp analysis of dopaminergic antinociceptive actions on substantia gelatinosa neurons in the spinal cord. Pain 2011, 152(1):95-105.

15. Cobacho N, de la Calle JL, Paino CL: Dopaminergic modulation of neuropathic pain: analgesia in rats by a D2-type receptor agonist. Brain Res Bull 2014, 106:62-71. 
16. Yang HW, Zhou LJ, Hu NW, Xin WJ, Liu XG: Activation of spinal d1/d5 receptors induces late-phase LTP of C-fiber-evoked field potentials in rat spinal dorsal horn. Journal of neurophysiology 2005, 94(2):961-967.

17. Dai WL, Xiong F, Yan B, Cao ZY, Liu WT, Liu JH, Yu BY: Blockade of neuronal dopamine D2 receptor attenuates morphine tolerance in mice spinal cord. Scientific reports 2016, 6:38746.

18. Zarrindast MR, Asgari-Afshar A, Sahebgharani M: Morphine-induced antinociception in the formalin test: sensitization and interactions with D1 and D2 dopamine receptors and nitric oxide agents. Behavioural pharmacology 2007, 18(3):177-184.

19. Hoshino H, Obata H, Nakajima K, Mieda R, Saito S: The antihyperalgesic effects of intrathecal bupropion, a dopamine and noradrenaline reuptake inhibitor, in a rat model of neuropathic pain. Anesthesia \& Analgesia 2015, 120(2):460-466.

20. Rosenberg MB, Carroll FI, Negus SS: Effects of monoamine reuptake inhibitors in assays of acute pain-stimulated and pain-depressed behavior in rats. The Journal of Pain 2013, 14(3):246-259.

21. Chen M, Hoshino H, Saito S, Yang Y, Obata H: Spinal dopaminergic involvement in the antihyperalgesic effect of antidepressants in a rat model of neuropathic pain. Neuroscience Letters 2017, 649(Supplement C):116-123.

22. Pak DJ, Yong RJ, Kaye AD, Urman RD: Chronification of Pain: Mechanisms, Current Understanding, and Clinical Implications. Current Pain and Headache Reports 2018, 22(2):9.

23. Merskey H: Part III pain terms, a current list with definitions and notes on usage. Classification of chronic pain-descriptions of chronic pain syndromes and definitions of pain terms 1994:207-214.

24. van Reij RRI, Joosten EAJ, van den Hoogen NJ: Dopaminergic neurotransmission and genetic variation in chronification of post-surgical pain. British Journal of Anaesthesia 2019, 123(6):853-864.

25. Aira Z, Barrenetxea T, Buesa I, Martinez E, Azkue JJ: Spinal D1-like dopamine receptors modulate NMDA receptor-induced hyperexcitability and NR1 subunit phosphorylation at serine 889. Neurosci Lett 2016, 618:152-158.

26. Buesa I, Aira Z, Azkue JJ: Regulation of Nociceptive Plasticity Threshold and DARPP-32 Phosphorylation in Spinal Dorsal Horn Neurons by Convergent Dopamine and Glutamate Inputs. PLoS One 2016, 11(9):e0162416.

27. Qadri YJ, Bortsov AV, Orrey DC, Swor RA, Peak DA, Jones JS, Rathlev NK, Lee DC, Domeier RM, Hendry PL et al: Genetic Polymorphisms in the Dopamine Receptor 2 Predict Acute Pain Severity after Motor Vehicle Collision. The Clinical journal of pain 2014:10.1097/AJP.0000000000000167.

28. Foulkes T, Wood JN: Pain genes. PLoS genetics 2008, 4(7):e1000086.

29. Hoofwijk DMN, van Reij RRI, Rutten BP, Kenis G, Buhre WF, Joosten EA: Genetic polymorphisms and their association with the prevalence and severity of chronic postsurgical pain: a systematic review. British Journal of Anaesthesia 2016, 117(6):708-719. 
30. Eijkenboom I, Sopacua M, Otten ABC, Gerrits MM, Hoeijmakers JGJ, Waxman SG, Lombardi R, Lauria G, Merkies ISJ, Smeets HJM et al: Expression of pathogenic SCN9A mutations in the zebrafish: A model to study small fiber neuropathy. Experimental Neurology 2018, 311:257-264.

31. Irion U, Krauss J, Nusslein-Volhard C: Precise and efficient genome editing in zebrafish using the CRISPR/Cas9 system. Development (Cambridge, England) 2014, 141(24):48274830 .

32. Ata H, Clark KJ, Ekker SC: The zebrafish genome editing toolkit. Methods in cell biology 2016, 135:149-170.

33. Tran S, Facciol A, Gerlai R: The Zebrafish, a Novel Model Organism for Screening Compounds Affecting Acute and Chronic Ethanol-Induced Effects. International review of neurobiology 2016, 126:467-484.

34. Dorsemans A-C, Lefebvre d'Hellencourt C, Ait-Arsa I, Jestin E, Meilhac O, Diotel N: Acute and Chronic Models of Hyperglycemia in Zebrafish: A Method to Assess the Impact of Hyperglycemia on Neurogenesis and the Biodistribution of Radiolabeled Molecules.J Vis Exp 2017(124):55203.

35. Cahill TJ, Choudhury RP, Riley PR: Heart regeneration and repair after myocardial infarction: translational opportunities for novel therapeutics. Nat Rev Drug Discov 2017, 16(10):699-717.

36. Mokalled MH, Patra C, Dickson AL, Endo T, Stainier DYR, Poss KD: Injury-induced ctgfa directs glial bridging and spinal cord regeneration in zebrafish. Science 2016, 354(6312):630-634.

37. Goldshmit Y, Sztal TE, Jusuf PR, Hall TE, Nguyen-Chi M, Currie PD: Fgf-dependent glial cell bridges facilitate spinal cord regeneration in zebrafish. J Neurosci 2012, 32(22):74777492.

38. Won SY, Choi BO, Chung KW, Lee JE: Zebrafish is a central model to dissect the peripheral neuropathy. Genes Genomics 2019, 41(9):993-1000.

39. Jaaskelainen SK, Lindholm P, Valmunen T, Pesonen U, Taiminen T, Virtanen A, Lamusuo $\mathrm{S}$, Forssell H, Hagelberg N, Hietala J et al: Variation in the dopamine D2 receptor gene plays a key role in human pain and its modulation by transcranial magnetic stimulation. Pain 2014, 155(10):2180-2187.

40. Buvanendran A, Kroin JS, Kerns JM, Nagalla SN, Tuman KJ: Characterization of a new animal model for evaluation of persistent postthoracotomy pain. Anesthesia \& Analgesia 2004, 99(5):1453-1460.

41. Flatters SJ: Characterization of a model of persistent postoperative pain evoked by skin/muscle incision and retraction (SMIR). PAIN® 2008, 135(1):119-130.

42. Margiotta-Casaluci L, Owen SF, Rand-Weaver M, Winter MJ: Testing the Translational Power of the Zebrafish: An Interspecies Analysis of Responses to Cardiovascular Drugs. Frontiers in pharmacology 2019, 10:893.

43. Chaudhuri KR, Schapira AH: Non-motor symptoms of Parkinson's disease: dopaminergic pathophysiology and treatment. The Lancet Neurology 2009, 8(5):464-474. 
44. Salat D, Tolosa E: Levodopa in the treatment of Parkinson's disease: current status and new developments. Journal of Parkinson's disease 2013, 3(3):255-269.

45. Chapela D, Sousa S, Martins I, Cristovao AM, Pinto P, Corte-Real S, Saude L: A zebrafish drug screening platform boosts the discovery of novel therapeutics for spinal cord injury in mammals. Scientific reports 2019, 9(1):10475.

46. Wittmann C, Reischl M, Shah AH, Kronfuss E, Mikut R, Liebel U, Grabher C: A Zebrafish Drug-Repurposing Screen Reveals sGC-Dependent and sGC-Independent ProInflammatory Activities of Nitric Oxide. PLoS One 2015, 10(10):e0137286.

47. Sourbron J, Partoens M, Scheldeman C, Zhang Y, Lagae L, de Witte P: Drug repurposing for Dravet syndrome in scn1Lab(-/-) mutant zebrafish. Epilepsia 2019, 60(2):e8-e13.

48. Yengo L, Sidorenko J, Kemper KE, Zheng Z, Wood AR, Weedon MN, Frayling TM, Hirschhorn J, Yang J, Visscher PM: Meta-analysis of genome-wide association studies for height and body mass index in approximately 700000 individuals of European ancestry. Human molecular genetics 2018, 27(20):3641-3649.

49. Manolio TA, Collins FS, Cox NJ, Goldstein DB, Hindorff LA, Hunter DJ, McCarthy MI, Ramos EM, Cardon LR, Chakravarti A: Finding the missing heritability of complex diseases. Nature 2009, 461(7265):747-753.

50. van Reij RRI, Hoofwijk DMN, Rutten BPF, Weinhold L, Leber M, Joosten EAJ, Ramirez A, van den Hoogen NJ, Italian Pain G: The association between genome-wide polymorphisms and chronic postoperative pain: a prospective observational study. Anaesthesia 2020, 75 Suppl 1:e111-e120.

51. Ibrahim-Verbaas CA, Bressler J, Debette S, Schuur M, Smith AV, Bis JC, Davies G, Trompet $\mathrm{S}$, Smith JA, Wolf C et al: GWAS for executive function and processing speed suggests involvement of the CADM2 gene. Molecular psychiatry 2016, 21(2):189-197.

52. Broce I, Karch CM, Wen N, Fan CC, Wang Y, Tan CH, Kouri N, Ross OA, Höglinger GU, Muller U: Immune-related genetic enrichment in frontotemporal dementia: An analysis of genome-wide association studies. PLoS medicine 2018, 15(1):e1002487.

53. Huang H, Fang M, Jostins L, Mirkov MU, Boucher G, Anderson CA, Andersen V, Cleynen I, Cortes A, Crins F: Fine-mapping inflammatory bowel disease loci to single-variant resolution. Nature 2017, 547(7662):173.

54. Fagerberg L, Hallstrom BM, Oksvold P, Kampf C, Djureinovic D, Odeberg J, Habuka M, Tahmasebpoor S, Danielsson A, Edlund $\mathrm{K}$ et al: Analysis of the human tissue-specific expression by genome-wide integration of transcriptomics and antibody-based proteomics. Molecular \& cellular proteomics 2014, 13(2):397-406.

55. Song Y, Altarejos J, Goodarzi MO, Inoue H, Guo X, Berdeaux R, Kim J-H, Goode J, Igata M, Paz JC: CRTC3 links catecholamine signalling to energy balance. Nature 2010, 468(7326):933.

56. Beecham AH, Patsopoulos NA, Xifara DK, Davis MF, Kemppinen A, Cotsapas C, Shah TS, Spencer C, Booth D, Goris A et al: Analysis of immune-related loci identifies 48 new susceptibility variants for multiple sclerosis. Nature genetics 2013, 45(11):1353-1360. 
57. Astle WJ, Elding H, Jiang T, Allen D, Ruklisa D, Mann AL, Mead D, Bouman H, RiverosMckay F, Kostadima MA et al: The Allelic Landscape of Human Blood Cell Trait Variation and Links to Common Complex Disease. Cell 2016, 167(5):1415-1429.e1419.

58. Theunissen M, Peters ML, Schepers J, Maas JW, Tournois F, van Suijlekom HA, Gramke H-F, Marcus MA: Recovery 3 and 12 months after hysterectomy: epidemiology and predictors of chronic pain, physical functioning, and global surgical recovery. Medicine 2016, 95(26):e3980.

59. Wang M, Xu S: Statistical power in genome-wide association studies and quantitative trait locus mapping. Heredity 2019, 123(3):287-306.

60. Nsengimana J, Bishop DT: Design considerations for genetic linkage and association studies. In: Statistical Human Genetics. edn.: Springer; 2017: 257-281.

61. Schug SA, Lavand'homme P, Barke A, Korwisi B, Rief W, Treede R-D, Pain TITftCoC: The IASP classification of chronic pain for ICD-11: chronic postsurgical or posttraumatic pain. PAIN 2019, 160(1):45-52.

62. Hoofwijk DM, Fiddelers A, Peters ML, Stessel B, Kessels A, Joosten EA, Gramke H-F, Marcus M: Prevalence and Predictive Factors of Chronic Postsurgical Pain and Poor Global Recovery One Year after Outpatient Surgery. The Clinical journal of pain 2015.

63. Kehlet H, Jensen TS, Woolf CJ: Persistent postsurgical pain: risk factors and prevention. The Lancet 2006, 367(9522):1618-1625.

64. Werner M, Kongsgaard U: I. Defining persistent post-surgical pain: is an update required? British journal of anaesthesia 2014, 113(1):1-4.

65. Gormley P, Anttila V, Winsvold BS, Palta P, Esko T, Pers TH, Farh K-H, Cuenca-Leon E, Muona M, Furlotte NA et al: Meta-analysis of 375,000 individuals identifies 38 susceptibility loci for migraine. Nature genetics 2016, 48(8):856-866.

66. Gallagher MD, Chen-Plotkin AS: The Post-GWAS Era: From Association to Function. The American Journal of Human Genetics 2018, 102(5):717-730.

67. Huang Q: Genetic study of complex diseases in the post-GWAS era. Journal of genetics and genomics = Yi chuan $x$ ue bao 2015, 42(3):87-98.

68. Kruglyak L: The road to genome-wide association studies. Nature Reviews Genetics 2008, 9(4):314-318.

69. Wang M, Herrmann CJ, Simonovic M, Szklarczyk D, von Mering C: Version 4.0 of PaxDb: Protein abundance data, integrated across model organisms, tissues, and cell-lines. Proteomics 2015, 15(18):3163-3168.

70. Buniello A, MacArthur JAL, Cerezo M, Harris LW, Hayhurst J, Malangone C, McMahon A, Morales J, Mountjoy E, Sollis E: The NHGRI-EBI GWAS Catalog of published genomewide association studies, targeted arrays and summary statistics 2019. Nucleic acids research 2019, 47(D1):D1005-D1012.

71. Balkarli A, Sengul C, Tepeli E, Balkarli H, Cobankara V: Synaptosomal-associated protein 25 (Snap-25) gene polymorphism frequency in fibromyalgia syndrome and relationship with clinical symptoms. BMC musculoskeletal disorders 2014, 15:191. 
72. Meloto CB, Benavides R, Lichtenwalter RN, Wen X, Tugarinov N, Zorina-Lichtenwalter K, Chabot-Doré A-J, Piltonen MH, Cattaneo S, Verma V: The Human Pain Genetics Database (HPGDB): a resource dedicated to human pain genetics research. Pain 2017.

73. Keser V, Lachance JB, Alam SS, Lim Y, Scarlata E, Kaur A, Zhang TF, Lv S, Lachapelle P, O'Flaherty C et al: Snap29 mutant mice recapitulate neurological and ophthalmological abnormalities associated with 22q11 and CEDNIK syndrome. Communications biology 2019, 2:375.

74. Rapaport D, Lugassy Y, Sprecher E, Horowitz M: Loss of SNAP29 impairs endocytic recycling and cell motility. PLoS One 2010, 5(3):e9759.

75. Wesolowski J, Caldwell V, Paumet F: A novel function for SNAP29 (synaptosomalassociated protein of $29 \mathrm{kDa}$ ) in mast cell phagocytosis. PLoS One 2012, 7(11):e49886.

76. Su Q, Mochida S, Tian JH, Mehta R, Sheng ZH: SNAP-29: a general SNARE protein that inhibits SNARE disassembly and is implicated in synaptic transmission. Proceedings of the National Academy of Sciences of the United States of America 2001, 98(24):14038-14043.

77. Cross-Disorder Group of the Psychiatric Genomics C: Identification of risk loci with shared effects on five major psychiatric disorders: a genome-wide analysis. Lancet (London, England) 2013, 381(9875):1371-1379.

78. Gerring ZF, Gamazon ER, Derks EM, Major Depressive Disorder Working Group of the Psychiatric Genomics C: A gene co-expression network-based analysis of multiple brain tissues reveals novel genes and molecular pathways underlying major depression. PLoS genetics 2019, 15(7):e1008245-e1008245.

79. Ward J, Tunbridge EM, Sandor C, Lyall LM, Ferguson A, Strawbridge RJ, Lyall DM, Cullen B, Graham N, Johnston KJA et al: The genomic basis of mood instability: identification of 46 loci in 363,705 UK Biobank participants, genetic correlation with psychiatric disorders, and association with gene expression and function. Molecular Psychiatry 2019.

80. Brown BC, Asian Genetic Epidemiology Network Type 2 Diabetes C, Ye CJ, Price AL, Zaitlen N: Transethnic Genetic-Correlation Estimates from Summary Statistics. American journal of human genetics 2016, 99(1):76-88.

81. Xue L, Pan C, Gu Z, Zhao S, Han B, Liu W, Yang S, Yu S, Sun Y, Liang J et al: Genetic heterogeneity of susceptibility gene in different ethnic populations: refining association study of PTPN22 for Graves' disease in a Chinese Han population. PloS one 2013, 8(12):e84514-e84514.

82. Zanetti D, Weale ME: Transethnic differences in GWAS signals: A simulation study. Annals of human genetics 2018, 82(5):280-286.

83. Mogil LS, Andaleon A, Badalamenti A, Dickinson SP, Guo X, Rotter JI, Johnson WC, Im HK, Liu Y, Wheeler HE: Genetic architecture of gene expression traits across diverse populations. PLoS Genet 2018, 14(8):e1007586.

84. Ward J, Graham N, Strawbridge RJ, Ferguson A, Jenkins G, Chen W, Hodgson K, Frye M, Weinshilboum R, Uher $\mathrm{R}$ et al: Polygenic risk scores for major depressive disorder and 
neuroticism as predictors of antidepressant response: Meta-analysis of three treatment cohorts. PLOS ONE 2018, 13(9):e0203896.

85. Witt SH, Streit F, Jungkunz M, Frank J, Awasthi S, Reinbold CS, Treutlein J, Degenhardt F, Forstner AJ, Heilmann-Heimbach S et al: Genome-wide association study of borderline personality disorder reveals genetic overlap with bipolar disorder, major depression and schizophrenia. Translational psychiatry 2017, 7(6):e1155.

86. Du Rietz E, Coleman J, Glanville K, Choi SW, O'Reilly PF, Kuntsi J: Association of Polygenic Risk for Attention-Deficit/Hyperactivity Disorder With Co-occurring Traits and Disorders. Biological psychiatry Cognitive neuroscience and neuroimaging 2018, 3(7):635-643.

87. Meyer-Lindenberg A, Tost H: Neural mechanisms of social risk for psychiatric disorders. Nat Neurosci 2012, 15(5):663-668.

88. Ropper AH, Zafonte RD: Sciatica. New England Journal of Medicine 2015, 372(13):12401248.

89. van Hecke O, Torrance N, Smith BH: Chronic pain epidemiology and its clinical relevance. BrJ Anaesth 2013, 111(1):13-18.

90. Walsh DA, McWilliams DF: Mechanisms, impact and management of pain in rheumatoid arthritis. Nature Reviews Rheumatology 2014, 10:581.

91. Supek F, Bošnjak M, Škunca N, Šmuc T: REVIGO Summarizes and Visualizes Long Lists of Gene Ontology Terms. PLOS ONE 2011, 6(7):e21800.

92. Lamparter D, Marbach D, Rueedi R, Kutalik Z, Bergmann S: Fast and rigorous computation of gene and pathway scores from SNP-based summary statistics. PLoS computational biology 2016, 12(1):e1004714.

93. Nieto FR, Clark AK, Grist J, Hathway GJ, Chapman V, Malcangio M: Neuron-immune mechanisms contribute to pain in early stages of arthritis. Journal of neuroinflammation 2016, 13 (1):96.

94. Chavan SS, Pavlov VA, Tracey KJ: Mechanisms and Therapeutic Relevance of Neuroimmune Communication. Immunity 2017, 46(6):927-942.

95. McAllen RM, Cook AD, Khiew HW, Martelli D, Hamilton JA: The interface between cholinergic pathways and the immune system and its relevance to arthritis. Arthritis research \& therapy 2015, 17:87.

96. Pinho-Ribeiro FA, Verri WA, Jr., Chiu IM: Nociceptor Sensory Neuron-Immune Interactions in Pain and Inflammation. Trends in immunology 2017, 38(1):5-19.

97. Parisien M, Samoshkin A, Tansley SN, Piltonen MH, Martin LJ, El-Hachem N, Dagostino C, Allegri M, Mogil JS, Khoutorsky A et al: Genetic pathway analysis reveals a major role for extracellular matrix organization in inflammatory and neuropathic pain. Pain 2019.

98. Sluka KA, Clauw DJ: Neurobiology of fibromyalgia and chronic widespread pain. Neuroscience 2016, 338:114-129.

99. Bennett DL, Clark AJ, Huang J, Waxman SG, Dib-Hajj SD: The Role of Voltage-Gated Sodium Channels in Pain Signaling. Physiological Reviews 2019, 99(2):1079-1151. 
100. Yang Y, Mis MA, Estacion M, Dib-Hajj SD, Waxman SG: NaV1.7 as a Pharmacogenomic Target for Pain: Moving Toward Precision Medicine. Trends in Pharmacological Sciences 2018, 39(3):258-275.

101. Blesneac I, Themistocleous AC, Fratter C, Conrad LJ, Ramirez JD, Cox JJ, Tesfaye S, Shillo PR, Rice AS, Tucker SJ: Rare NaV1. 7 variants associated with painful diabetic peripheral neuropathy. Pain 2018, 159(3):469.

102. Hoeijmakers JG, Faber CG, Lauria G, Merkies IS, Waxman SG: Small-fibre neuropathiesadvances in diagnosis, pathophysiology and management. Nature Reviews Neurology 2012, 8(7):369-379.

103. Sène D: Small fiber neuropathy: Diagnosis, causes, and treatment. Joint Bone Spine 2018, 85(5):553-559.

104. Sopacua M, Hoeijmakers JGJ, Merkies ISJ, Lauria G, Waxman SG, Faber CG: Small-fiber neuropathy: Expanding the clinical pain universe. J Peripher Nerv Syst 2019, 24(1):19-33.

105. Huang J, Han C, Estacion M, Vasylyev D, Hoeijmakers JG, Gerrits MM, Tyrrell L, Lauria G, Faber CG, Dib-Hajj SD: Gain-of-function mutations in sodium channel NaV1. 9 in painful neuropathy. Brain : a journal of neurology 2014, 137(6):1627-1642.

106. McKerrall SJ, Sutherlin DP: Nav1.7 inhibitors for the treatment of chronic pain. Bioorganic \& Medicinal Chemistry Letters 2018, 28(19):3141-3149.

107. Rahman W, Dickenson AH: Voltage gated sodium and calcium channel blockers for the treatment of chronic inflammatory pain. Neuroscience Letters 2013, 557:19-26.

108. Ma RSY, Kayani K, Whyte-Oshodi D, Whyte-Oshodi A, Nachiappan N, Gnanarajah S, Mohammed R: Voltage gated sodium channels as therapeutic targets for chronic pain. Journal of pain research 2019, 12:2709-2722.

109. Kogelman LJA, Esserlind A-L, Francke Christensen A, Awasthi S, Ripke S, Ingason A, Davidsson OB, Erikstrup C, Hjalgrim $\mathrm{H}$, Ullum $\mathrm{H}$ et al: Migraine polygenic risk score associates with efficacy of migraine-specific drugs. Neurol Genet 2019, 5(6):e364-e364.

110. Marees AT, de Kluiver H, Stringer S, Vorspan F, Curis E, Marie-Claire C, Derks EM: A tutorial on conducting genome-wide association studies: Quality control and statistical analysis. International journal of methods in psychiatric research 2018, 27 (2):e1608.

111. Choi SW, O'Reilly PF: PRSice-2: Polygenic Risk Score software for biobank-scale data. GigaScience 2019, 8(7).

112. Choi SW, Mak TSH, O'reilly P: A guide to performing Polygenic Risk Score analyses. BioRxiv 2018:416545.

113. Nagel M, Jansen PR, Stringer S, Watanabe K, de Leeuw CA, Bryois J, Savage JE, Hammerschlag AR, Skene NG, Muñoz-Manchado AB et al: Meta-analysis of genome-wide association studies for neuroticism in 449,484 individuals identifies novel genetic loci and pathways. Nature Genetics 2018, 50(7):920-927.

114. Howard DM, Adams MJ, Clarke T-K, Hafferty JD, Gibson J, Shirali M, Coleman JRI, Hagenaars SP, Ward J, Wigmore EM et al: Genome-wide meta-analysis of depression identifies 102 independent variants and highlights the importance of the prefrontal brain regions. Nature Neuroscience 2019, 22(3):343-352. 
115. Hoofwijk DMN, van Reij RRI, Rutten BPF, Kenis G, Theunissen M, Joosten EA, Buhre WF, van den Hoogen NJ: Genetic polymorphisms and prediction of chronic post-surgical pain after hysterectomy-a subgroup analysis of a multicenter cohort study. Acta Anaesthesiol Scand 2019, 63(8):1063-1073.

116. Abraham G, Inouye M: Genomic risk prediction of complex human disease and its clinical application. Current Opinion in Genetics \& Development 2015, 33:10-16.

117. Müller B, Wilcke A, Boulesteix A-L, Brauer J, Passarge E, Boltze J, Kirsten H: Improved prediction of complex diseases by common genetic markers: state of the art and further perspectives. Human Genetics 2016, 135(3):259-272.

118. Zeng B, Lloyd-Jones LR, Montgomery GW, Metspalu A, Esko T, Franke L, Vosa U, Claringbould A, Brigham KL, Quyyumi AA et al: Comprehensive Multiple eQTL Detection and Its Application to GWAS Interpretation. Genetics 2019, 212(3):905-918.

119. Ingolia NT: Ribosome Footprint Profiling of Translation throughout the Genome. Cell 2016, 165(1):22-33.

120. Zhang F, Lupski JR: Non-coding genetic variants in human disease. Human molecular genetics 2015, 24(R1):R102-110.

121. Xiao Z, Zou Q, Liu Y, Yang X: Genome-wide assessment of differential translations with ribosome profiling data. Nature communications 2016, 7:11194-11194.

122. Fritsch C, Herrmann A, Nothnagel M, Szafranski K, Huse K, Schumann F, Schreiber S, Platzer M, Krawczak M, Hampe J et al: Genome-wide search for novel human uORFs and $\mathrm{N}$-terminal protein extensions using ribosomal footprinting. Genome research 2012, 22(11):2208-2218.

123. Shah AN, Davey CF, Whitebirch AC, Miller AC, Moens CB: Rapid reverse genetic screening using CRISPR in zebrafish. Nature methods 2015, 12(6):535-540.

124. Gabriel E, Gopalakrishnan J: Generation of iPSC-derived Human Brain Organoids to Model Early Neurodevelopmental Disorders. J Vis Exp 2017(122):55372.

125. Tcw J: Human iPSC application in Alzheimer's disease and Tau-related neurodegenerative diseases. Neuroscience letters 2019, 699:31-40.

126. Winter MJ, Windell D, Metz J, Matthews P, Pinion J, Brown JT, Hetheridge MJ, Ball JS, Owen SF, Redfern WS et al: 4-dimensional functional profiling in the convulsant-treated larval zebrafish brain. Scientific reports 2017, 7(1):6581.

127. Eimon PM, Ghannad-Rezaie M, De Rienzo G, Allalou A, Wu Y, Gao M, Roy A, Skolnick J, Yanik MF: Brain activity patterns in high-throughput electrophysiology screen predict both drug efficacies and side effects. Nature communications 2018, 9(1):219-219.

128. Reinig S, Driever W, Arrenberg AB: The Descending Diencephalic Dopamine System Is Tuned to Sensory Stimuli. Current Biology 2017, 27(3):318-333.

129. de Abreu MS, Giacomini ACVV, Genario R, Dos Santos BE, da Rosa LG, Demin KA, Wappler-Guzzetta EA, Kalueff AV: Neuropharmacology, pharmacogenetics and pharmacogenomics of aggression: The zebrafish model. Pharmacological research 2019, 141:602-608. 
130. Strichartz GR, Wang JC-F, Blaskovich P, Ohri R: Mitigation of Experimental, Chronic Post-Thoracotomy Pain by Preoperative Infiltration of Local Slow-Release Bupivacaine Microspheres. Anesthesia \& Analgesia 2015, 120(6):1375-1384.

131. Wang H, Liu W, Cai Y, Ma L, Ma C, Luo A, Huang Y: Glutaminase 1 is a potential biomarker for chronic post-surgical pain in the rat dorsal spinal cord using differential proteomics. Amino acids 2015:1-12.

132. Shen Y, Li D, Li B, Xi P, Zhang Y, Jiang Y, Xu Y, Chen H, Xiong Y: Up-Regulation of CX3CL1 via STAT3 Contributes to SMIR-Induced Chronic Postsurgical Pain. Neurochemical Research 2018, 43(3):556-565.

133. Brennan TJ, Vandermeulen EP, Gebhart G: Characterization of a rat model of incisional pain. Pain 1996, 64(3):493-502.

134. Shin JW, Pancaro C, Wang CF, Gerner P: Low-dose systemic bupivacaine prevents the development of allodynia after thoracotomy in rats. Anesthesia \& Analgesia 2008, 107(5):1587-1591.

135. White $\mathrm{BH}$ : What genetic model organisms offer the study of behavior and neural circuits. Journal of neurogenetics 2016, 30(2):54-61.

136. Gao E, Lei YH, Shang X, Huang ZM, Zuo L, Boucher M, Fan Q, Chuprun JK, Ma XL, Koch WJ: A novel and efficient model of coronary artery ligation and myocardial infarction in the mouse. Circ Res 2010, 107(12):1445-1453.

137. Faller KME, McAndrew DJ, Schneider JE, Lygate CA: Refinement of analgesia following thoracotomy and experimental myocardial infarction using the Mouse Grimace Scale. Experimental physiology 2015, 100(2):164-172. 
$190 \mid$ Chapter 7 
CHAPTER 8

\section{Summary}

R. R. I. van Reij

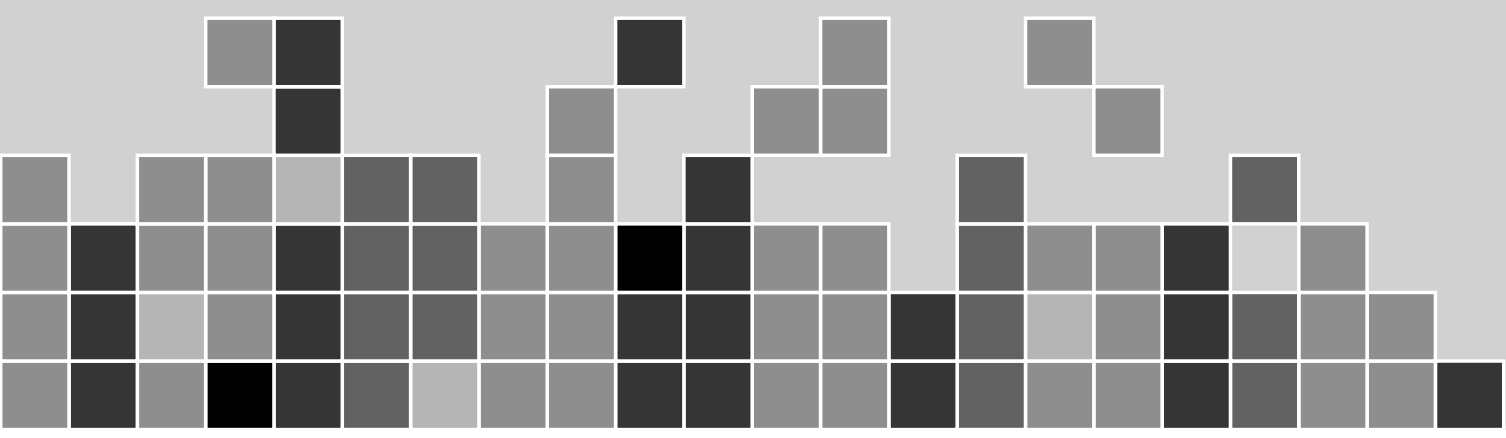


192 | Chapter 8 


\section{Summary}

Chronic Postsurgical Pain (CPSP) remains a major clinical problem affecting on average $20 \%$ of all patients undergoing surgery. CPSP has a major impact on the quality of life of both the patients affected and their relatives, and leads to an increase in health care consumption and associated costs. Although clinical, psychological and demographical risk factors of CPSP have been identified, a good understanding of the genetic risk factors and its putative role in CPSP is still lacking to date. The aim of this thesis was to the study the genetic risk factors of CPSP and to identify the functional effects of genetic variation on nociception and chronic pain in both clinical and preclinical studies.

A systematic review on the genetic risk factors of CPSP revealed that SNPs associated with the dopaminergic neurotransmission might be involved in CPSP. To further identify the involvement of genetic variations within the dopaminergic neurotransmission in the development of CPSP, the current literature regarding clinical and preclinical is summarized in Chapter 2. Three genes (COMT, GCH1, $D R D 2$ ) within the dopaminergic neurotransmission have been studied extensively in relation to CPSP, pain sensitivity and analgesic requirement. Although the direction of the effect (inhibitory or excitatory) is unclear due to conflicting results, ample evidence suggests a modulatory role for dopamine in the pain transmission. Due to its modulatory role, the dopaminergic neurotransmission system is an excellent pharmacological target in the treatment of (chronic) pain. Interestingly, pharmacological modulation of the dopaminergic neurotransmission system can aid both prevention (via D1 receptors) and treatment (via $\mathrm{D} 2$ receptors) of chronic pain.

Delving deeper into the genetics of CPSP, the first genome-wide association study (GWAS) on CPSP in two independent cohorts is reported in Chapter 3. A casecontrol GWAS study in both a discovery (a well-studied and previously characterised cohort of hysterectomy patients, $\mathrm{n}=330$ ) and replication (cohort 
consisting of patients undergoing abdominal surgeries or knee replacements, $\mathrm{n}=203$ ) cohort comparing patients with and without CPSP did not reach genomewide significance. However, the meta-analysis did reveal a potential risk locus for CPSP (IQGAP1 and CRTC3, $p=2.26 \times 10^{-6}$ ). The genes within this locus (IQGAP1 and $C R T C 3$ ), both have been associated with the immune system and neurological processes. This study provides initial evidence on genome-wide risk factor of CPSP, and gives suggestions for future research.

Chapter 4 describes the functional effects of single nucleotide polymorphisms (SNPs), a type of genetic variation, on gene expression and potential causal effects on CPSP. Meta-analysis of the different cohorts in the analysis indicated the first genome-wide significant locus (rs17882261) associated with CPSP. Transcriptome-wide mendelian randomization (TWMR) analysis identified two genes (SNAP29 and VSP8) to be potentially causally associated with CPSP in multiple tissues. Both genes are associated with immune system and neuronal morphology. This shows that the TWMR approach allows to identify both tissuespecific and global potential causal genes associated with CPSP. The identified loci and genes are in need of further functional follow-up studies to identify underlying biological mechanisms and confirm the potential causal relationship.

Establishing the intersection and/or overlap of genetic networks between various chronic pain syndromes may help define common mechanisms in chronic pain and provide starting points for functional and intervention studies. Polygenic risk scores (PRS) allow testing for genetic correlation (i.e. overlap) between different phenotypes. The genetic overlap between different chronic peripheral pain syndromes and CPSP is described in Chapter 5. Using polygenic risk scores, we identified a genetic overlap between sciatic pain, chronic widespread pain, rheumatoid arthritis and CPSP. Based on the gene ontology analysis the genetic overlap was suggested to involve neuronal signalling, specifically sodium channel functioning, and inflammatory response. In conclusion, this study is the first to 
report genetic overlap between regulatory processes implicated in CPSP and chronic peripheral pain syndromes. The genes involved in the genetic overlap are related to the regulation of neurological signalling and inflammatory responses. Enhanced understanding of mechanisms underlying chronification of pain will aid the development of new preventative therapeutic strategies for CPSP.

To further examine the impact and role of genetic variations related to dopaminergic neurotransmission in CPSP, we modelled a clinical phenotype of decreased dopamine D2 receptor expression in zebrafish in Chapter 6 and the effects of a pharmacological intervention targeting dopamine receptor 2 was tested. The experiments showed that a decrease in drd2a receptor expression is associated with increased locomotion in response to a thermal nociceptive stimulus, indicative of an increased pain response. To verify the anti-nociceptive role of drd2a, a pharmacological intervention using agonist Quinpirole was tested. Agonism of the drd2a showed dose-dependent anti-nociceptive properties during a heat stimulus. The established model allows for further screening and testing of genetic variation and treatment involved in nociception and pain. 


\section{Samenvatting}

Chronische Post Operatieve Pijn (CPOP) blijft een groot klinisch probleem en treft gemiddeld $20 \%$ van de patiënten die een operatie ondergaan. CPOP heeft een grote impact op de levenskwaliteit van zowel de getroffen patiënten en hun naasten. Het leid tot een toename in zorgverbruik en de daarbij horende kosten. Alhoewel klinische, psychologische en demografische risicofactoren van CPOP bekend zijn, is er nog een gebrek aan kennis over genetische risicofactoren en hun mogelijke rol in CPOP. Het doel van deze thesis was om de genetische risicofactoren te onderzoeken die betrokken zijn bij CPOP en mogelijke functionele effecten te ontdekken van de genetische variatie op nociceptie en chronische pijn in zowel klinische als preklinische studies.

Een samenvatting van de huidige literatuur aangaande klinisch en preklinisch onderzoek in relatie tot genetische variatie in de dopaminerge neurotransmissie wordt gegeven in Hoofdstuk 2. Drie genen (COMT, GCH1, DRD2) binnen de dopaminerge neurotransmissie zijn uitgebreid bestudeerd in relatie met CPOP, pijngevoeligheid en pijnstilling. Het precieze effect (inhiberend of exciterend) van genetische variatie binnen deze genen is momenteel nog niet volkomen duidelijk vanwege tegenstrijdige resultaten. Echter, er is voldoende bewijs om te stellen dat dopamine een modulerende werking op pijn heeft. Vanwege de modulerende werking is de dopaminerge neurotransmissie een uitstekend farmacologisch doelwit in de behandeling van (chronische) pijn. Interessant is dat de dopaminerge neurotransmissie kan helpen bij zowel de preventieve behandeling (via de D1 receptoren) alsook in (chronische) pijnbestrijding (via de D2 receptoren).

Diepgaander onderzoek naar de genetica van CPOP leidde tot de eerste genoomwijde associatie studie (GWAS) naar CPOP in twee onafhankelijke cohorten, gerapporteerd in Hoofdstuk 3. Een case-control studie in een primair cohort (een uitgebreid bestudeerd en gepubliceerd cohort van hysterectomie patiënten, 
$\mathrm{n}=330$ ) en replicatie cohort (een cohort van patiënten die buik of knie operaties zijn ondergaan, $n=203$ ) waarbij patiënten met en zonder CPOP worden vergeleken. Deze studie leidde niet tot een genoom-wijd significante locus die geassocieerd wordt met CPOP. Echter, een meta-analyse wees wel een potentiële risico locus aan voor CPSP (IQGAP1 en CRTC3, $\left.\mathrm{p}=2.26 \times 10^{-6}\right)$. De genen in deze locus (IQGAP1 en CRTC3) zijn beiden geassocieerd met het functioneren van het immuun systeem en neurologische processen. Deze studie zorgde voor het eerste bewijs van genoom-wijde genetische risicofactoren in CPOP en verzorgde aanknopingspunten voor verder onderzoek.

Hoofdstuk 4 beschrijft de functionele effecten van single nucleotide polymorfismes (SNPs), een vorm van genetische variatie, op gen expressie en potentiële causale effecten in CPOP. Meta-analyse van de beschikbare cohorten leidde tot de eerste genoom-wijd significante associatie (rs17882261) met CPOP. De transcriptoom-wijde mendeliaanse randomisatie (TWMR) analyse identificeerde twee genen (SNAP29 en VSP8) die mogelijk causaal geassocieerd zijn met CPOP in meerdere weefsels. Beide genen zijn geassocieerd met het functioneren van het immuun systeem en neuronale morfologie. Dit toont aan dat de TWMR methode zowel weefsel specifieke als globaal potentieel causale gene kan identificeren en associëren met CPOP. De geïdentificeerde loci en genen moeten verder onderzocht worden door middel van functionele studies om de onderliggende biologische mechanismen op te ontdekken en het causale verband te bevestigen.

Het vaststellen van een snijpunt of overlap tussen genetische netwerken van verschillende chronische pijnsyndromen kan helpen bij het identificeren van gemeenschappelijke mechanismen en zorgt voor aanknopingspunten voor functionele en interventionele studies. Polygene risico scores maken het mogelijk om de genetische correlatie (m.a.w. overlap) tussen verschillende fenotypes te testen. De genetische overlap tussen verschillende chronische perifere 
pijnsyndromen en CPOP is beschreven in Hoofdstuk 5. Gebruikmakende van polygene risico scores hebben we een genetische overlap tussen ischias, fibromyalgie pijn, en reumatoïde artritis en CPOP vastgesteld. De gen ontologie analyse suggereert betrokkenheid van neurologische processen, specifiek de betrokkenheid van natrium kanalen, en inflammatoire reacties. In conclusie, deze studie heeft genetische overlap aangetoond tussen regulerende processen betrokken bij CPOP en chronische perifere pijnsyndromen. De genen betrokken bij de genetische overlap zijn betrokken bij de regulatie van neurologische signalen en de inflammatoire reacties. Betere kennis van de onderliggende mechanismes van chronificatie van pijn zal bijdragen aan het ontwikkelen van nieuwe preventieve behandelingen voor CPOP.

Om de impact en rol van genetische variaties in de dopaminerge neurotransmissie in relatie tot CPOP verder te onderzoeken, hebben we een klinisch fenotype van verlaagde dopamine D2 receptor expressie gemodelleerd in zebravissen in Hoofdstuk 6 en de effectiviteit van een farmacologische behandeling gericht op de dopamine receptor 2 getest. De experimenten tonen aan dat een afname in de $\mathrm{drd} 2 \mathrm{a}$ expressie geassocieerd word met een toename in beweging als reactie op een nociceptieve hitte stimulus als maat voor een toegenomen pijn reacte. Om de antinociceptieve werking van $\operatorname{drd} 2$ a te verifiëren, hebbe we een farmacologische behandeling toegepast middels de drd2a agonist Quinpirole. Activatie van de drd2a receptor leidde tot een daling in beweging als reactie op de nociceptieve hitte stimulus en bevestigde daarmee de eerdere resultaten. Het opgezette model is geschikt voor het verdere screenen en testen van genetische variaties en farmacologische behandelingen die betrokken zijn bij nociceptie en pijn. 


\section{Valorisation}

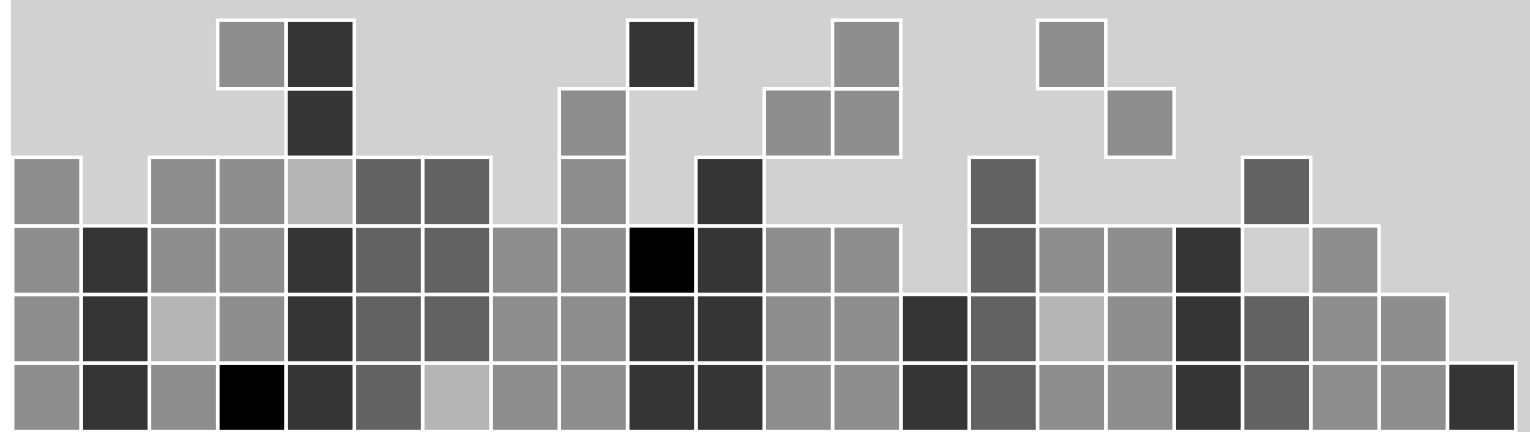


$200 \mid$ A p p endix 
Academic research should aim to reach further than solely contributing to scientific knowledge and be beneficial to society as much as possible. For this reason, the current chapter will focus on the societal perspective and valorisation of the research on genetic risk factors in prediction and treatment of Chronic PostSurgical Pain (CPSP) as presented in this dissertation. Valorisation is defined as follows: Valorisation is the process of creating value from knowledge by making knowledge suitable and available for societal and/or economic application and by transforming it into products, services, processes and new business. This definition will be used to address the valorisation of the research in this dissertation specified to the following topics:

- Impact of research: What is the social and economic impact of the results of the research as described in this dissertation?

- Audience of research: Which stakeholders could benefit from the results of the experiments relevant outside of the academic community?

- Product of research: What value (as defined earlier) can be created from the research in this dissertation?

\section{Impact of research}

Annually, an estimated 313 million surgeries take place around the globe [1]. Of all patients undergoing surgery, 5-85\% develops chronic postsurgical pain (CPSP), varying with the type of surgery and with an average incidence of $18 \%$ [2]. CPSP negatively affects the quality of life (QoL) of the patients as well as their relatives. Furthermore, patients with CPSP report higher incidences of sleep disturbances, depressive symptoms and comorbid disorders [3]. CPSP and its comorbid disorders (depression, stress, anxiety) have a large impact on the daily functioning of the patients affected. CPSP patients are less able to participate in private activities and at work, the degree of which is correlated with the pain intensity [3]. Due to the chronic pain and its comorbidities, some patients enter a vicious cycle 
wherein the different problems including pain further worsen their quality of life [3]. The QoL can be measured by the use of questionnaires and these have shown QoL to be significantly decreased in patients affected by CPSP [3]. The majority of CPSP patients are prescribed multiple medications against the pain and the comorbidities (including opioids and NSAIDs) and on average visit a medical professional 12 times per year [3]. The economic costs associated with the decreased daily functioning and QoL has been estimated to be $\$ 41.463$,- per year per patient in the United States of America alone, leading to a huge loss for the world economy [3]. Combining the incidence of CPSP, volume of surgery and estimated cost make clear that CPSP is a major problem with immense societal impact. CPSP has a tremendous impact on the economic status of the patients and their families.

Next to the group of surgical patients who develop CPSP each year, there is also a substantial group of patients exposed to the same surgeries, but who do not develop CPSP. It is important to study these patients as well. Prediction of which patients have a higher risk of developing CPSP is important, as it provides the opportunity to employ preventive strategies (e.g. alternative surgical approach, additional counselling) or to personalize the medication regime before, during and after surgery. Research has shown that for a cohort of hysterectomy patients, a combination of demographic and clinical factors explains $78 \%$ of the variance in the incidence of CPSP [4]. Nevertheless this implies still 22\% of the incidence remains unexplained. Here, genetics might contribute to the solution. Part of the unexplained variance could be related to genetic variations and differential distributions of these variations between the patients with and without CPSP. Data from this dissertation shows that combining genetic data related to multiple surgeries can lead to the identification of genetic risk factors of CPSP and finally may lead to personalized treatment of the patient undergoing surgery. An example of successful personalized medicine has been reported in genetic mutations within 
the cytochrome p450 enzyme, which alter the metabolism of opioid medication, thereby leading to a higher or lower dosage requirement for a similar effect [5].

To further increase understanding of genetic factors involved in CPSP, an increase in sample size is needed. Increasing the sample sizes of genetic studies is expected to lead to the identification of more genetic risk factors of CPSP in general as well as specific genetic risk factors related to specific surgeries. Interestingly, this dissertation has shown that the genetic profile underlying CPSP is not unique, as there is a genetic overlap with multiple chronic peripheral pain syndromes. This suggests that inclusion of other pain syndromes might be very beneficial in the development of new prevention and treatment strategies for chronic pain syndromes. Finally, studying the genetics of CPSP will help to develop personalized medicine and this should increase the responder rate to treatments, thereby lifting a burden from society by decreasing the associated costs and increasing QoL of many patients.

\section{Audience of the research}

The main beneficiaries of the research on genetic risk factors of CPSP are the 313 million patients who undergo surgery every year and their families. Studying the genetic factors of CPSP will lead to new developments in individual characterization and possible prediction and prevention of CPSP, but can also lead to personalized treatment after establishment of CPSP. Unravelling the individual genetic risk for each CPSP patient is an initial and important step towards personalized medicine. This will lead to an increase in QoL for the patients and their families. Moreover, research in this dissertation shows that there is genetic overlap across chronic peripheral pain syndromes (e.g. chronic widespread pain, sciatic pain) and CPSP, indicating a shared biological mechanism. Therefore, strategies working for one chronic pain disorder might proof beneficial for patients suffering other pain disorders as well. This will be of interest to clinicians treating all kinds of chronic pain patients, and researchers on other chronic pain 
disorders. More knowledge on how chronic pain develops will aid the development of novel treatment and prevention strategies, which will ultimately aid the clinician in his or her daily practice. CPSP is an ideal chronic pain disorder to study the chronification of pain, as it involves a clear defined time-point zero.

Finally, Major stakeholders in this research are the health insurance companies and the local and national governments. CPSP has a tremendous effect on the society and the associated costs are very high as explained earlier. Better prediction, prevention and treatment of CPSP will be reflected in a reduction in the associated costs and have major impact for society.

\section{Product of the research}

The primary product culminating from the research as described in this dissertation is the deeper understanding of the genetic factors and molecular processes involved in the development of CPSP. Earlier studies have shown that it is possible to integrate genetic risk factors into clinical prediction models [4]. Integrating genome-wide identified risk factors will further optimize the clinical prediction models currently available. Moreover, the identified risk factors could lead to new pharmacological targets for CPSP and other chronic pain disorders. The pharmacological targets of interest need to be tested and verified in preclinical studies before clinical implementation.

The second important product from this research is the establishment of a genetic and pharmacological screening model. Studies performed in zebrafish have shown the possibility of modelling clinical phenotypes and testing the effects on morphology, development and nociception [6]. This provides a novel method to functionally asses the effects of genetic mutation on organisms. Of all the associations between SNPs and phenotypes, roughly 3\% has been functionally assessed [7]. Research in this dissertation showed that Dopamine D2 receptor might be a viable candidate in modulating pain and prevention of chronification 
of pain but more research is necessary [8]. This screening model can aid in this development.

Preclinical studies in zebrafish has several advantages for animal studies; they provide a fast screening of the targets due to a high replication rate; the genome is fully sequenced and easily manipulated; the associated costs for maintenance are low; and they have less ethical restrictions compared to rodents. Ultimately, research in zebrafish will decrease the numbers of rodents necessary by prioritizing the most likely candidates first.

Next to the pharmacological treatment strategies, non-pharmacological intervention could also aid in the prevention of CPSP. Improving physical health (e.g. Better in Better out concept) and/or mental health pre-surgery, focussed on individual risk factors of CPSP, can minimize the risk of developing CPSP.

Finally, through extensive research, the gap between prediction and treatment of CPSP might decrease in the future. Extensive prediction models including genetic information will provide clear indications of the postsurgical recovery trajectory while simultaneously providing options on prevention and treatment of CPSP. The research presented in this dissertation is a first contribution to study genome wide genetic associations in CPSP. The approach presented, combined with further analysis, will be necessary to ensure implementation into the clinical practice to aid a vulnerable population of chronic pain patients. 


\section{References}

1. Weiser TG, Haynes AB, Molina G, Lipsitz SR, Esquivel MM, Uribe-Leitz T, Fu R, Azad T, Chao TE, Berry WR: Estimate of the global volume of surgery in 2012: an assessment supporting improved health outcomes. The Lancet 2015, 385:S11.

2. Schug SA, Lavand'homme P, Barke A, Korwisi B, Rief W, Treede R-D, Pain TITftCoC: The IASP classification of chronic pain for ICD-11: chronic postsurgical or posttraumatic pain. PAIN 2019, 160(1):45-52.

3. Parsons B, Schaefer C, Mann R, Sadosky A, Daniel S, Nalamachu S, Stacey BR, Nieshoff EC, Tuchman M, Anschel A: Economic and humanistic burden of post-trauma and postsurgical neuropathic pain among adults in the United States. Journal of pain research 2013, 6:459.

4. Hoofwijk DMN, van Reij RRI, Rutten BPF, Kenis G, Theunissen M, Joosten EA, Buhre WF, van den Hoogen NJ: Genetic polymorphisms and prediction of chronic post-surgical pain after hysterectomy-a subgroup analysis of a multicenter cohort study. Acta Anaesthesiol Scand 2019, 63(8):1063-1073.

5. Holmquist GL: Opioid Metabolism and Effects of Cytochrome P450. Pain Medicine 2009, 10(suppl_1):S20-S29.

6. Eijkenboom I, Sopacua M, Otten ABC, Gerrits MM, Hoeijmakers JGJ, Waxman SG, Lombardi R, Lauria G, Merkies ISJ, Smeets HJM et al: Expression of pathogenic SCN9A mutations in the zebrafish: A model to study small fiber neuropathy. Experimental Neurology 2018, 311:257-264.

7. Gallagher MD, Chen-Plotkin AS: The Post-GWAS Era: From Association to Function. The American Journal of Human Genetics 2018, 102(5):717-730.

8. van Reij RRI, Joosten EAJ, van den Hoogen NJ: Dopaminergic neurotransmission and genetic variation in chronification of post-surgical pain. British Journal of Anaesthesia 2019, 123(6):853-864. 
Curriculum Vitae

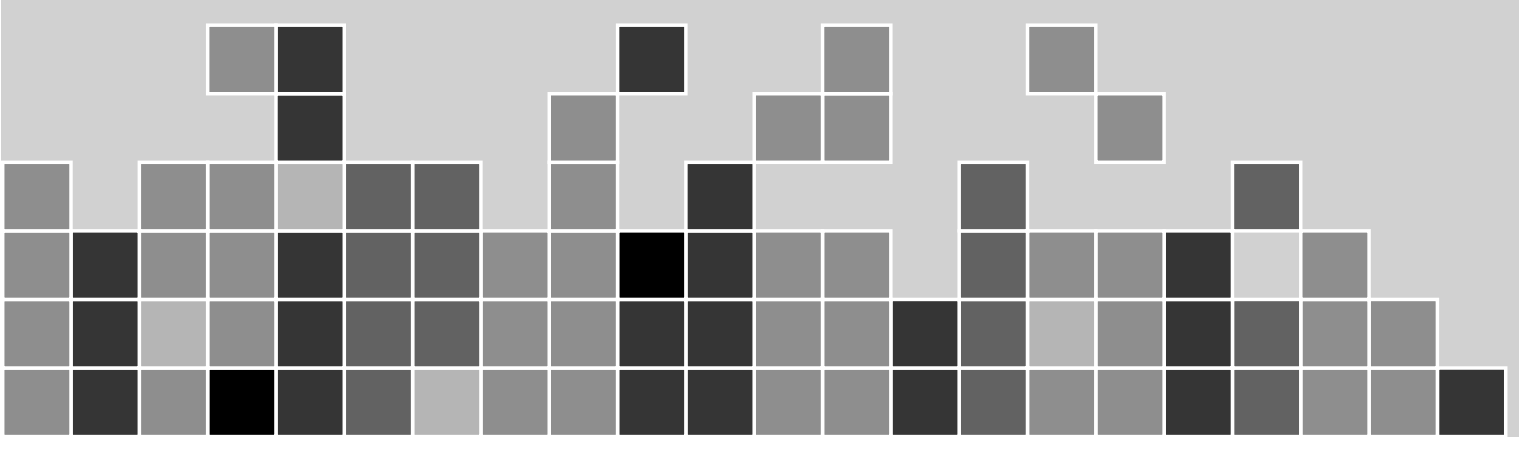


208 |A p p en dix 
Roel van Reij was born March 17th 1993, in Maastricht. He attended the secondary school at Porta Mosana in Maastricht, where he obtained his Lyceum degree and International Baccalaureate in English in 2011.

The same year he started his Bachelor Studies on Biomedical Sciences, specialization Molecular Life Sciences, at Maastricht University. During his bachelor internship, he studied the detection of HPV infection using fluorescent in situ hybridization amplification techniques under supervision of Dr. Monique Ummelen and Dr. Anton Hopman. He obtained his Bachelor degree in 2014, and enrolled in the Research Master in Cognitive and Clinical Neuroscience, specialization Fundamental Neuroscience.

During his Master's, he joined the lab of Prof. Dr. Bert Joosten at Maastricht University, Department of Anaesthesiology and Pain Management. Here, he started a dual clinical and preclinical research internship to study the genetic risk factors and predictors of chronic postsurgical pain where he was supervised by Dr. Nynke van den Hoogen and Dr. Daisy Hoofwijk.

After graduating in 2016, Roel continued his research on the genetics of chronic postsurgical pain in Maastricht supervised by Prof. Dr. Bert Joosten (promotor) and Dr. Nynke van den Hoogen (co-promotor). During his PhD, Roel has collaborated with Dr. Alfredo Ramirez and colleagues at University of Bonn, Germany where he was trained on the analysis of GWAS data. Furthermore, he collaborated with Prof. Dr. Luda Diatchenko at McGill University, Montreal, Canada, where he spent three months to analyse functional aspects of genetic variation in relation to CPSP and infer possible causality. The results of his studies are presented in this thesis.

After his thesis defence, Roel will continue his scientific career as a postdoctoral researcher at the Department of Anaesthesiology and Pain Management and at the school for Mental Health and Neuroscience at Maastricht University. 
Roel van Reij is geboren op 17 maart 1993 te Maastricht. De middelbare school heeft hij afgelegd aan het Porta Mosana College waar hij zijn Lyceum diploma en International Baccalaureaat Engels behaalde in 2011.

Hetzelfde jaar startte hij met de Bachelor Studie Biomedische Wetenschappen, specialisatie Moleculaire Levenswetenschappen, aan de Universiteit van Maastricht. Gedurende zijn bachelorstage heeft hij de detectie van HPV-infecties bestudeerd, gebruikmakende van fluorescente in situ hybridisatie amplificatie methodes onder begeleiding van dr. Monique Ummelen en dr. Anton Hopman. Hij heeft zijn bachelordiploma verkregen in 2014, waarna hij verder gegaan is met de Research Master Cognitive and Clinical Neuroscience, specialisatie Fundamental Neuroscience.

De masterstage heeft hij uitgevoerd in het lab van prof. dr. Bert Joosten aan de Universiteit van Maastricht, afdeling Anesthesiologie en Pijnbestrijding. Bij dit gecombineerde klinische en preklinische onderzoek lag de focus op genetische risicofactoren en voorspellers van chronische postoperatieve pijn onder begeleiding van dr. Nynke van den Hoogen en dr. Daisy Hoofwijk.

Na zijn afstuderen in 2016 heeft Roel het onderzoek naar de genetica van postoperatieve pijn verder gezet in Maastricht onder begeleiding van prof. dr. Bert Joosten (promotor) en dr. Nynke van den Hoogen (co-promotor). Gedurende zijn promotie traject heeft Roel samengewerkt met dr. Alfredo Ramirez en collega's aan de Universiteit van Bonn in Duitsland waar hij korte tijd heeft doorgebracht om de analyse van GWAS data te leren. Daarnaast werkt hij samen met prof. dr. Luda Diatchenko aan McGill University in Montréal, Canada, waar hij drie maanden heeft doorgebracht om de functionele aspecten van genetische variatie in chronische postoperatieve pijn in kaart te brengen en aanwijzingen voor causale verbanden te vinden. De resultaten van zijn studies staan uitgebreid beschreven in dit proefschrift.

$\mathrm{Na}$ de verdediging van zijn proefschrift zal Roel zijn carrière binnen de wetenschap voortzetten als postdoctorale onderzoeker aan de afdeling Anesthesiologie en Pijnbestrijding en de School for Mental Health and Neuroscience van de Universiteit van Maastricht. 


\section{List of Publication}

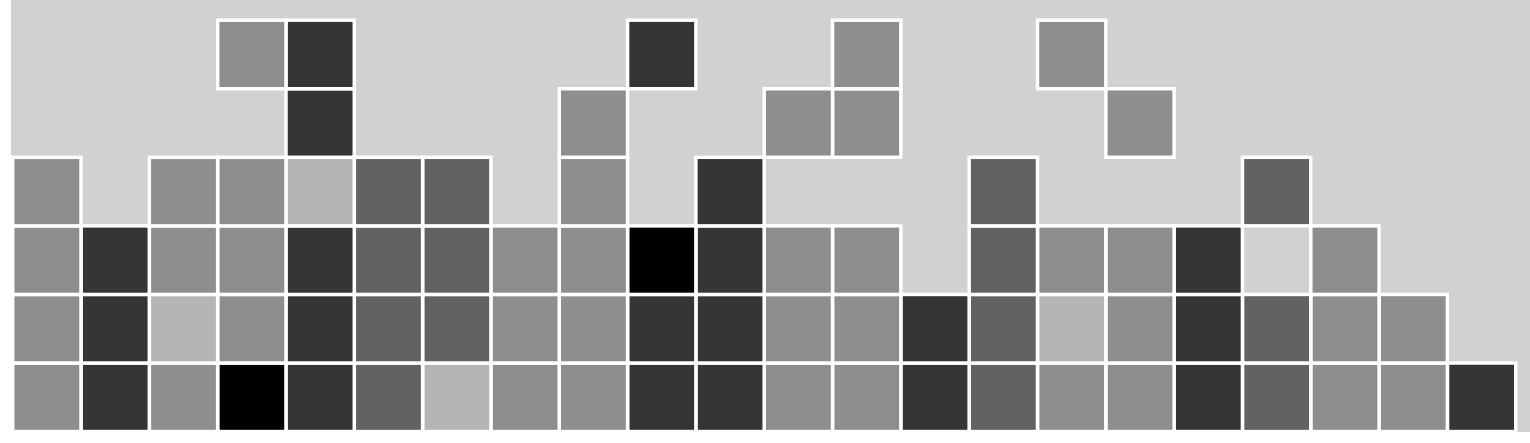


212|A p pendix 


\section{Peer reviewed publications}

\section{Published}

2020 van Reij RRI, Voncken J-W, Joosten EAJ, van den Hoogen NJ. Polygenic risk scores indicates genetic overlap between peripheral pain syndromes and Chronic Postsurgical Pain. Neurogenetics; 2020:1-11.

2020 van Reij RRI, Hoofwijk DMN, Rutten BPF, et al. The association between genome-wide polymorphisms and chronic postoperative pain: a prospective observational study. Anaesthesia 2020; 75 Suppl 1: e111-e20.

2019 van Reij RRI, Joosten EAJ, van den Hoogen NJ. Dopaminergic neurotransmission and genetic variation in chronification of post-surgical pain. British Journal of Anaesthesia 2019; 123(6): 853-64.

2019 Hoofwijk DMN, van Reij RRI, Rutten BPF, et al. Genetic polymorphisms and prediction of chronic post-surgical pain after hysterectomy-a subgroup analysis of a multicenter cohort study. Acta Anaesthesiol Scand 2019; 63(8): 1063-73.

2018 van den Hoogen NJ, van Reij RRI, Patijn J, Tibboel D, Joosten EAJ. Adult spinal opioid receptor mu 1 expression after incision is altered by early life repetitive tactile and noxious procedures in rats. Dev Neurobiol 2018; 78(4): 417-26.

2016 Hoofwijk DMN, van Reij RRI, Rutten BP, Kenis G, Buhre WF, Joosten EA. Genetic polymorphisms and their association with the prevalence and severity of chronic postsurgical pain: a systematic review. British Journal of Anaesthesia 2016; 117(6): 708-19. 
Under review or in preparation

2020 van Reij RRI, Salmans MMA, Eijkenboom I, van den Hoogen NJ, Joosten EAJ, Vanoevelen JM. Dopamine-neurotransmission and nociception in zebrafish: an anti-nociceptive role of Dopamine Receptor drd2a. Under review Pain Feb 2020, major revisions

2020 van Reij RRI, Khoury S, Parisien M, van den Hoogen NJ, Allegri M, de Gregori M, Belfer I, Chelly J, Rakel B, Aasvang E, Kehlet H, Buhre WF, Joosten EAJ, Diatchenko L. Meta-analysis and Transcriptome-wide Mendelian Randomization Identifies Potential Risk Loci in the Development of Chronic Post-Surgical Pain. In preparation

\section{Other publications}

2018 Van Reij RRI, Joosten EA, van den Hoogen NJ. Genetica en perioperative medicine Deel 4: Genome-wide associatie studies. Nederlands Tijdschrift voor Anesthesiologie 2018; 31: 88-93

2017 Van Reij RRI, Meuwissen KPV, Joosten EAJ. Anatomie en Fysiologie van Pijn. Nascholingsartikel A\&I: 9(4) 2017

2017 Van Reij RRI, Eijkenboom I, Vanoevelen J, Hoofwijk DMN, Joosten EAJ, van den Hoogen NJ. Genetica en perioperative medicine; Deel 3: Genetische screening, nociceptie en pijn in zebravissen. Nederlands Tijdschrif voor Anesthesiologie 2017; 30 : 146-148

2017 Van Reij RRI, Hoofwijk DMN, van den Hoogen NJ, Joosten EA. Genetica en perioperative medicine; Deel 2: Systematische Review naar de relatie tussen Genetica en Chronische Post-Surgical Pain. Nederlands Tijdschrift van Anesthesiologie 2017; 30: 74-78

2016 van Reij RRI, Joosten EA, Hoofwijk DMN, van den Hoogen NJ. Genetica en perioperative medicine; Deel 1: introductie in de genetica en genetisch onderzoek. Nederlands Tijdschrift voor Anesthesiologie 2016; 29(3): 8992. 


\section{Abstract publications}

2019 European Pain School, Sienna, Italy

Oral Presentation: Genome-wide association analysis identifies potential risk loci for chronic postsurgical pain

2019 Topics in Translational Neuroscience, Maastricht, The Netherlands

Invited Lecture: Pain and comorbidities : Genetics of Chronic PostSurgical Pain

2019 Genetics retreat -NVHG graduate meeting, Kerkade, The Netherlands.

Oral Presentation: Genome-wide association analysis identifies potential risk locus for chronic postsurgical pain

2019 Nederlandse vereniging van Anesthesiologie wetenschapsdag, Utrecht, The Netherlands

Oral Presentation: Genome-wide association analysis identifies potential risk locus for chronic postsurgical pain

2019 Science Café department of Anesthesiology Radboud UMC, Nijmegen, The Netherlands.

Oral presentation: Genome-wide association analysis identifies potential risk loci for chronic postsurgical pain

2018 IASP world congress on pain, Boston, Massachusetts, USA

Poster presentation: Genome-wide association analysis identifies potential risk loci for chronic postsurgical pain after hysterectomy 
2018 MHeNS research day, Maastricht, The Netherlands.

Oral Presentation: Genome-wide association analysis identifies potential risk loci for chronic postsurgical pain after hysterectomy Awarded first prize in the category PhD students

2017 Nederlandse vereniging van Anesthesiologie wetenschapsdag, Amsterdam, The Netherlands.

Oral Presentation: Genetic polymorphisms within the gene encoding Catechol-O-methyltransferase (COMT) are associated with prevalence of Chronic Post-Surgical Pain after Hysterectomy

2017 MHeNS research day, Maastricht, The Netherlands.

Poster presentation: Genetic screening in zebrafish as a first step towards understanding mechanisms underlying chronic pain and other neurological disorders

2016 Nederlandse vereniging van Anesthesiologie wetenschapsdag, Rotterdam, The Netherlands.

Oral presentation: Genetic polymorphisms and their association with the prevalence and severity of chronic postsurgical pain

2016 Dutch Neuroscience meeting, Lunteren, The Netherlands

Poster presentation: Genetic polymorphisms and their association with the prevalence and severity of chronic postsurgical pain - A systematic review

2016 MHeNS research day, Maastricht, The Netherlands

Poster presentation: The expression of OPRM1 and GLuR1 in the spinal cord after surgery and the nociceptive behavior 


\section{Dankwoord}

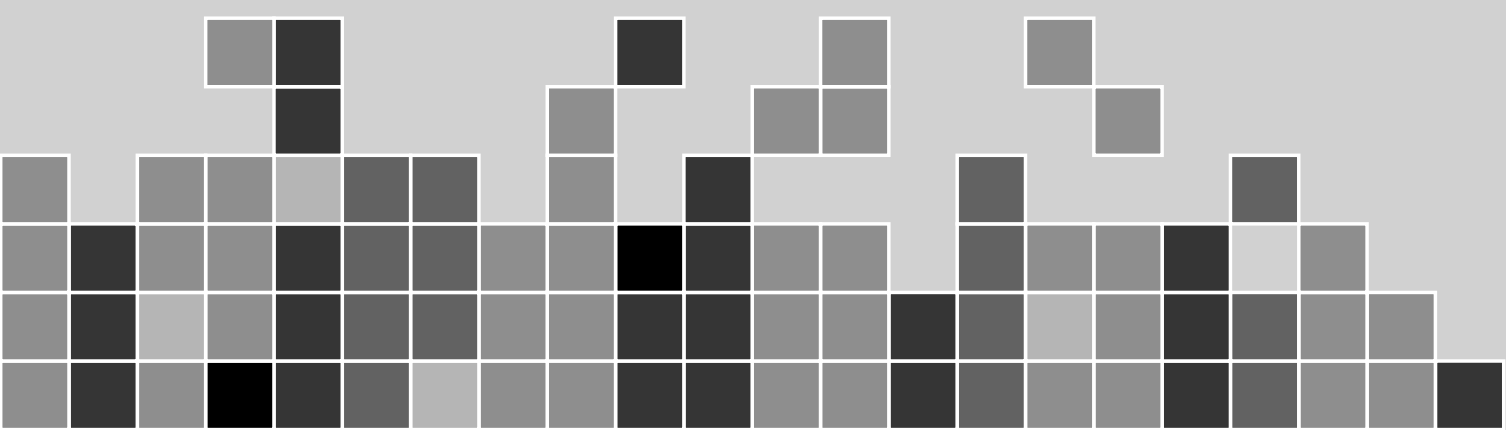


218 A p pen dix 
Een promotietraject vraagt zowel fysiek als mentaal uithoudingsvermogen van een promovendus maar ook van zijn naasten. Tien jaar geleden toen ik voor het eerst de universiteit binnenstapte had ik nooit gedacht aan een promoveren. Het zijn tien turbulente jaren geweest met vele hoogte- en enkele dieptepunten waarbij ik gelukkig altijd heb kunnen vertrouwen op de mensen om mij heen, in zowel de privé- als de werksfeer. Wat begon als een ambitieus en abstract idee tijdens mijn masterstage is uitgegroeid tot een fantastisch project dat de basis legt voor nog jaren aan vervolgonderzoek. Dit idee had meer nodig dan mijn handen om uit te groeien tot het proefschrift dat nu voor u ligt. Daarom neem ik nu het podium om alle mensen te bedanken die bijgedragen hebben in welke mate dan ook. Mocht ik je onverhoopt zijn vergeten te benoemen, bedankt voor je bijdrage!

Ten eerste wil ik mijn promotieteam, prof. dr. Bert Joosten en dr. Nynke van den Hoogen, bedanken voor hun steun bij het "vullen" van het proefschrift en bij de vorming van mij als zelfstandig onderzoeker.

Beste prof. Joosten, beste Bert, we hebben van meet af aan een duidelijke klik gehad waardoor we al snel een vertrouwensband hadden. Je pusht me om beter te worden en zonder jouw kritische noten zou het proefschrift nooit geworden zijn wat het nu is. Tijdens overleggen "kalle ver plat" en we vergeten nog wel eens terug naar ABN te gaan als Nynke of iemand anders aanschoof bij het overleg. In de afgelopen 3,5 jaar zijn we het maar over één ding nooit eens geworden: Ajax of PSV blijft een heikel punt. Gelukkig heeft dit ons onderzoek nooit in de weg gestaan en hoop ik nog lang met je samen te werken.

Beste dr. Van den Hoogen, beste Nynke, we go way back. Dat is ook wat we vertellen als mensen vragen hoe lang we elkaar nu al kennen. We hebben elkaar leren kennen tijdens de bachelor bij Helix (studievereniging Biomedische wetenschappen) en ook toen al stond je altijd klaar met advies voor iedereen. Jouw 
advies aan mij om voor mezelf en mijn interesses te kiezen tijdens een van de zware periodes uit mijn leven hebben aan de basis gestaan van het hele promotietraject. Ook professioneel kunnen we heel goed samenwerken en zorgen we er samen voor dat er mooie projecten van de grond komen. Nog steeds waardeer ik je adviezen en ondersteuning en ik wens je al het goeds toe.

During my PhD training I was lucky enough to do a foreign research training twice. My first steps in the genetic analysis and data science were done at the University Clinic of Bonn under supervision of dr. Alfredo Ramirez. Together with dr. Markus Leber, dr. Leonie Weinhold, dr. Michael Knapp and prof. dr. Matthias Schmid you have taught me the principles of genetic research and guided me through my first genome-wide association study. Thank you for welcoming and teaching me and most of all being patient with me and answering my multitude of questions.

My second research visit was to the Human Pain Genetics lab of McGill university led by prof. dr. Diatchenko. Dear prof. Diatchenko, dear Luda, thank you for welcoming me into your lab and into your team. I learned a lot during my visit, adapted my scientific perspective accordingly and fell in love with the beautiful city of Montreal. You have a wonderful and dedicated team who accomplish great things. Thank you Francesca, Gillian, Audrey, Niko, Adam, Ryan, Xiang, Katerina, Kelly, Marc and Samar for accepting me in your group, guiding me and for joining this silly dutchman with his lunch ordeals (2 sandwiches a day). Marc and Samar you were my go to people at the lab and I learned so much from you. The level of expertise the both of you have enabled me to become a better researcher and I cherish our work together. A special word of thanks for Katerina ZorinaLichtenwalter and Kelly Cool, both of you have made sure I would see more of Montreal than a regular tourist. Dear Katerina, from the moment I arrived you have made sure I was up to speed of all the lectures and events happening on campus, showed me the best place for an afterwork drink and convinced me that 
going climbing was a good idea. Dear Kelly, each Monday you requested an update on the places in Montreal I had visited, made sure I would go to the Festival of Light and you have drilled me that I have to come back to Montreal in summer because in summer the city would be even better you said. No worries, I will come back to Montreal when there is no snow (apparently I had something to do with the early snow storm). I hope to see you all again in the future.

Daarnaast zijn er twee mensen die letterlijk achter mij staan tijdens de verdediging, mijn paranymfen Dean en Daan. We hebben elkaar leren kennen tijdens de studie en hadden al snel een klik. Ieder van ons heeft via zijn eigen weg een mooi onderzoeksproject zich eigen gemaakt en ik ben super trots op jullie en op wat wij bereikt hebben. Dean, altijd vrolijk en in "vuur un teske koffie". Daan, altijd behulpzaam en gezellig. Zonder jullie was het organiseren van mijn grote dag niet gelukt en zeker niet zo leuk geweest. Tijdens de stapavonden gedurende studie zijn er al enkele oneliners ontstaan (“one with the jacket on") en ik hoop dat we nog vele mooie momenten mogen meemaken.

Onderzoek doe je samen en de afgelopen jaren heb ik met heel veel leuke en verschillende mensen mogen werken in zowel klinische als preklinische projecten. Ten eerste het Pijn-team bij mij op kantoor: Glenn, je staat altijd klaar voor een gesprek of het nu over onderzoek of flat earth gaat, je kunt er altijd iets over kwijt. Rose, altijd vrolijk en betrokken, je staat voor mensen klaar of het nu tijdens een experiment is of met koffie. Perla, de enige met wie ik dialect kan praten op kantoor en dat hoeft niet altijd over werk te gaan. Daarnaast bestaat ons team nog uit Lonne, Martijn en Thomas verdeeld over de hele gang. Aan allen, hartelijk dank voor de koffie, de gesprekken en de ondersteuning waar nodig.

Naast het preklinisch team heb ik ook nog intensief samen gewerkt met verschillende clinici. Daisy, samen zijn we het genetica- en CPSP-project gestart en zonder jouw invloed was het niet op deze manier van de grond gekomen. Vergaderen deden we met goede koffie en onze kennis over het onderzoek was 
complementair zodat we perfect konden samenwerken. Ik hoop dit in de toekomst vaker te doen. Daarnaast ben ik in verschillende projecten betrokken geweest bij onderzoek samen met prof. Buhre, prof. Van Kleef, prof. Van Zundert, Nelleke, Mischa, Sander, Dianne, Maurice, Anne, Brigitte, Andrea, Philma, Carine, Veerle en Jose, hartelijk dank voor de fijne samenwerking.

Verder wil ik alle collegae binnen MHeNS bedanken, zoals gezegd onderzoek doe je samen en jullie maken het zeker aangenamer. Wouter, je was mijn partner-incrime wat betreft de tosti's, bedankt ook voor de curry! Christian, druk bezig met het oog te onderzoeken maar daarnaast ook spindoctor op het gebied van kebab. Chris, "Lunch?" Manon en Alix, jullie hadden altijd tijd voor een koffie als het mij te veel werd en even afstand nodig had, zelfs tijdens de Coronacrisis. Iedereen bedankt voor de adviezen, aanwezigheid bij presentaties en momentjes bij het koffiezetapparaat: Clara, Katherine, Roman, Jeroen, Margot, Ralph, Ellis, Sylvana, An, Jana, Fred, Artemis, Magda, Janou, Renzo, Philippos, Caterina, Marina, Shenghua, Nikita, Tanya, Jackson, Govert, Michiel, Mario, Pilar, Jos, Daniel, Ehsan, Gunter, Lars, Roy, Laurence, Tim, Christian, Sarah, Ali, Rachelle, Marjan, Helen, Denise, Barbie, Wiel, Marie-Thérèse, Nicole, Ankie, Tom, David, Bart en iedereen ik die onverhoopt nog vergeet te noemen.

Ik heb het geluk gehad om tijdens mijn PhD ook betrokken te raken bij de zebravisgroep. Jo, toen Bert en ik bij jou op kantoor binnenstapten met ons projectidee was je direct enthousiast en hebben we samen een heel mooi interessant project opgezet. Ivo, direct een klik dankzij onze gedeelde passie voor Star Wars, was er. Me alles geleerd wat jij wist over de vissen, heb je. Het niet zonder jou gekund, had ik! Janine en Ellen, jullie hebben de afgelopen jaren altijd klaar gestaan om te helpen en vragen te beantwoorden met betrekking tot de vissen. Jullie kunde en toewijding maakt het makkelijk om deel te worden van een team en om onderzoek te doen. 
Tijdens mijn PhD-periode heb ik enkele studenten mogen begeleidden tijdens hun stages en zij hebben mooie bijdrage geleverd aan dit proefschrift. Maud, jouw bijdrage aan de farmacologie tijdens het zebravisexperiment is van onschatbare waarde geweest. Antonio, you have accepted a challenging internship project and so far have excelled. At the start of your internship I was still in Canada and it did not stop you. You have an amazing future ahead of you.

Naast de mensen op het werk wil ik ook alle mensen buiten het werk bedanken en dan met name mijn vrienden en mijn familie. Dit wil ich geire in t dialect doen zoe es zich dat huurt.

Es ierste wil ich de vrun van de Koninklijke Oude Harmonie van Eijsden oftewel de Blôw bedanken. Ten ierste Bob, er is gein probleem wat ver neet hebbe kinnen oplossen mit Fifa en unne pot beer. Veul geknoeterd en veul gelachen doer dik en dun. Het miest verassende van de aofgelaope jaore is dat se mich aon 't sporten hebs gekreige en ich bliek ' $t$ aog nog leuk te vinden. Dennis, Daisy en Davey, saome zien ver menig pretpark in Europa aofgegange en dao bie genog verteld en gelachen. Daoneive staot ger altied klaor mit raod en gezelligheid. Mun vrun van Blow hebben er altied vuur gezurg dat ich un oetlaotklep haw, d'r unne pot beer of sterker veirdig stond en ich mit beide beentjes op de grond bleef stoen. Lars, Hanke, Simone, Guyon, Joep, Celine, Jim, Elke, Bo, Harm, Mark, Dayenne, Tom, Tessa, Raoul, Bjorn, Martine en Philippe dankjewel vuur de aw kloete vuur, nao en tiedens de repetities en in de café.

Ich wil aog ming femilie bedanke, ger beet altied geïnteresseerd geweis en heb regelmaotig ming verhaole beloesterd uuver ming onderzeuk. Alle neifkes, nichekes, nonkes en tantes dankjewel. Opa en oma van Reij, ger beet mit van ming groetste supporters. Ger beet altied geïnteresseerd in wat ich doon en ich kaom altied geire bie uch langs um te kalle onder t genot van un gleiske wien. Ger geneet van t leive en moedigt mich aon um dat zieker aog te blieve doen. Opa en oma van den Boorn, al van jongs af aon heb ger os gepusht um mer vuural good te 
liere, zieker umdat oma dat vreuger zelf neet heit kinne doen. Oma, uche breef dee ger sjreef vuur ming middelbare sjaol diploma hink nog altied op en is ming inspiratie um doer te blieve goen. Ich been noe klaor mit liere oma, mer nog neet klaor op de uni. Es klein jungske heb ich 't geluk gehad um un derde "opa en oma” te hebben, ming oppas awwers Jean \& Jessy. Jean \& Jessy, ondanks dat unne babysit al efkes niemie nuudig is, kaom ich nog altied geire bie uch, zieker es Jessy vlaoi heit gebakken. Ger heb mich un paor kier gevraog of ger bie de verdediging mocht zien, en ich wil uch hiebie nogmaols op t hart drukken dat ger van harte welkom beet. Ger huurt vuur mich er bie.

Fred \& Sylvia en Philippe, es awwers en broor van Nadine beet aog gier nauw betrokken geweis bie ming traject op de uni. Onder $t$ genot van un wijntje loesterde ger nao ming onderzeuk en huurde ger mich oet uuver wie t noe precies zaot. Zoe es ger gemirk heb zurgde de wien ervuur dat ich bleef kalle. Dat is nooit un probleem geweis gelukkig en steunt ger mich in keuzes.

Un speciaol plekske in ming dankwoerd is er vuur mam. Mam, weurd kinne neet umsjrieve wie 't veult um dadelijk te verdedigen op “de Berg”. Lange tied waors dich synoniem vuur mich mit de universiteit, en waor de Berg de plaots oe se wirkdes en ich af en tow gewoen binnenwandelde. 10 jaor naodat ig zelf op de uni begonnen been staon ig dalijk bie dich op de Berg zonder dich, mer blief de uni vuur mich nog altied verbonden mit dich. De hebs mich un stamp onder die vot geigeve es $\mathrm{t}$ mos mer mich vuural aog aofgeremd es ig teveul tiegeliek wow. Ver geun der unne sjoene doag van maoke, unne Grimbergen op drinke en noets mie vergeite! Mam, tot eng van dies daog...

G wil aog mun broor, pap \& Eveline en de hun bedanke. Ingo en Funske, gier kint dit neet leize mer toch wil ich uch numme want wandele mit uch is de biste meneer um de kop leig te maoke en ger beet altied doer 't dolle zoe blij es ich binne koam. Henk, mit dich kin ich altied uuver onderzeuk kalle want ver kalle de zelfde taol op dat gebied. Soms geit $t$ hèl tiege hèl mer wat wils se es se alletwie 
geliek hebs. Es awwer broor lits se nog altied op mich, zieker es ich te fanatiek vuur Ajax juich mer stimuleers se mich aog um t biste eroet te hoele. Eveline, de bis de definitie van un powervrouw. De menier oe op stich projecten op paks en ien 't leive steis, is un inspiratie en ich maok geire gebruuk van ding ervaring en advies. De brings kleur mit dich mit en un bitje hoegnuudige chaos. Pap, Peter, 't is gelukt. Dinge steun waor oneindig de aofgelaope paor jaor, hebs mich altied gevraog wie 't ging en vuural gepusht um doer te goen. Toen ich besloet vuur un paor maond nao Canada te goen waors se de ierste dee dinger ging oetzeuke vuur mich ondanks dat se 't toch un bitje lestig vons. Ver lieke qua karakter veul op elkaar en 't doorzettingsvermogen heit mich geholpen um de PhD op dis meneer in elkaar te kinne zitte. Pap, Eveline, Henk, Ingo en Funske, dankjewel!

Leeve Nadine, de aofgelaope jaore tiedens de promotie bis dich ming steun en toeverlaat geweis. 't Promotietraject vergt veul en dich hebs er altied vuur gezurg dat ich t positieve er van ien zaog, neet teveul aon michzelf twiefelde en mich eekere kier oetgehuurd uuver wie 't noe precies zaot mit ming onderzeuk. De aofgelaope jaore bis zelf druk bezig geweis mit ding eigen studie rechten mer de bis ondertussen ongetwiefeld de miest biologisch onderlagde jurist gewoere! ' $t$ lestigste vons se de boetelandse reizen die ich gemak heb vuur 't onderzeuk mer praktisch es se bis hebs se van de nood een deugd gemak en mich achternao gereis vuur vekansie es dat meugelijk woar. Nadine, 't is vuur mich un groete geruststelling geweis um te weite dat stig er altied vuur mich bis. Ich haw 't neet zonder dich gewild of gekind. 